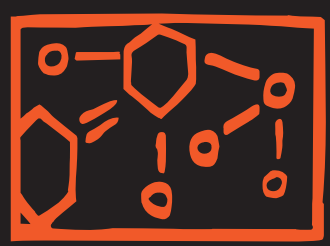

La comprensión de contenidos científicos en estudiantes universitarios
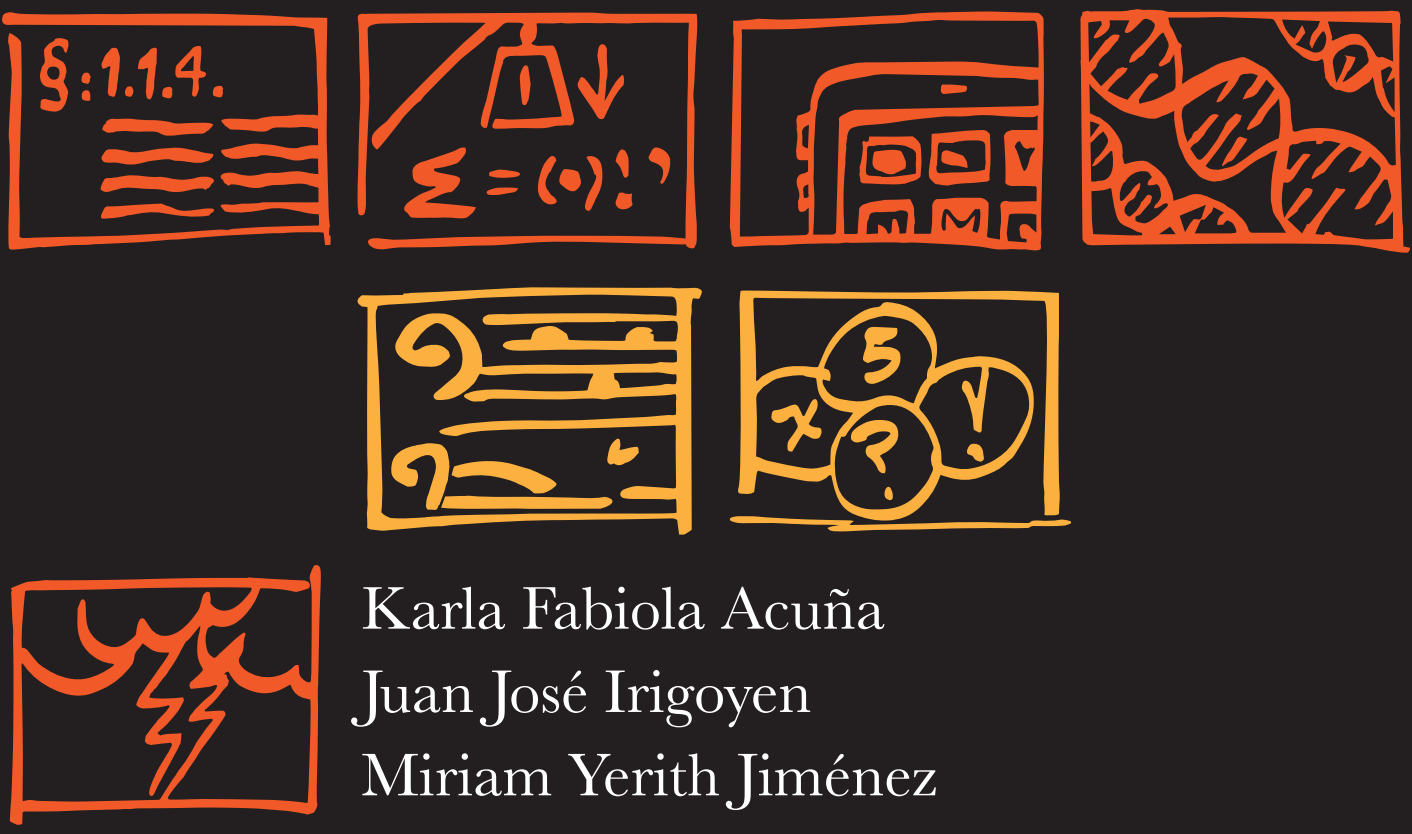

Karla Fabiola Acuña

Juan José Irigoyen

Miriam Yerith Jiménez

\title{
Qartuppi.
}



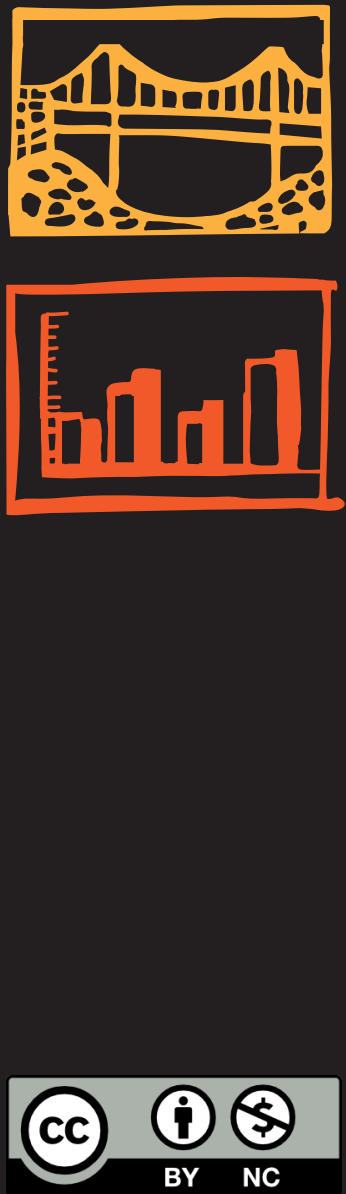

Esta obra está bajo una Licencia Creative Commons Atribución-NoComercial 4.0 Internacional.

https://creativecommons.org/licenses/by-nc/4.0/deed.es 


\section{La comprensión de contenidos científicos en estudiantes universitarios}

Karla Fabiola Acuña

Juan José Irigoyen

Miriam Yerith Jiménez 
La comprensión de contenidos científicos en estudiantes universitarios

lera. edición, diciembre 2013

ISBN 978-607-96359-0-9

DOI 10.29410/QTP.13.01

C 2013. Qartuppi, S. de R.L. de G.V.

Calle Real 63, Col. Villa Satélite

Hermosillo, Sonora 83200 México

http://www.qartuppi.com

Diseño editorial y de portada:

León Felipe Irigoyen Morales

Comité Gientífico y de Revisión Técnica:

Dra. María Oliva Márquez Sánchez. Universidad Autónoma de Madrid.

Dr. Abel Leyva Castellanos. Universidad Autónoma de Sinaloa.

Dra. Guadalupe Mares Cardenas. Universidad Nacional Autónoma de México.

Dra. María Antonia Padilla Vargas. Universidad de Guadalajara.

Mtro. Luis Alberto Quiroga Baquero. Universidad Católica de Colombia. 


\section{Índice}

Problemática de la Educación en México

Consideraciones sobre algunas reformas educativas en México, propuestas curriculares por competencias

Definición de competencia como disposición

Aproximación a la enseñanza-aprendizaje de contenidos científicos

Aproximación al estudio del comportamiento científico

Elementos que componen el Modelo de la Práctica Científica Individual

Aproximaciones al estudio de la enseñanza-aprendizaje de contenidos científicos: Implicaciones psico-pedagógicas

Propuesta para el análisis del proceso enseñanza-aprendizaje: 
Análisis de los modos lingüísticos en la comprensión de contenidos científicos

Definición de comprensión

Análisis de la interacción estudiante-objetos referentes

Capítulo 4

Aproximación metodológica al análisis de la comprensión de contenidos científicos

Estudio 1

Estudio 2

Estudio 3

Implicaciones para la planeación de interacciones didácticas de contenidos científicos 


\section{Prólogo}

Para un universitario es crítico ser capaz de dominar el lenguaje técnico de su disciplina, ello implica que pueda ejercitar, por lo menos, los modos lingüísticos de hablar, leer y escribir, empleando con fluidez tal, el lenguaje. Y hasta ahora se ha asumido que los estudiantes de nivel medio y superior, por el solo hecho de haber logrado llegar a tales niveles, son capaces de leer comprensivamente, pero varios estudios han demostrado que comúnmente dichas poblaciones son incapaces de hacer contacto con materiales técnicos. A pesar de tal situación, el entrenamiento en habilidades lecto-escritoras es más un efecto colateral que un objetivo central en los planes curriculares universitarios. Por ello, es fundamental analizar cómo pueden los estudiantes universitarios ser capaces de comprender contenidos científicos para que ello permita diseñar herramientas didácticas efectivas que permitan el ejercicio de habilidades lecto-escritoras en estos niveles académicos.

Y justamente ese es el objetivo del presente libro, estudiar la comprensión de contenidos científicos en estudiantes universitarios analizando la dimensión psicopedagógica del ámbito educativo, es decir, la relacionada con el proceso de enseñanza-aprendizaje de contenidos científicos, particularmente la vinculada con las interacciones del estudiante con los referentes mediados por el profesor. Una de las grandes virtudes del libro es que no sólo se queda en el análisis, sino que además presenta una propuesta en la que se señalan cuáles serían las condiciones idóneas para la adquisición de desempeños efectivos y variados en ámbitos disciplinares específicos. Ello garantiza que su publicación, dados sus contenidos, enriquecerá enormemente el área y cubrirá un vacío en el desarrollo científico. Y seguramente, por su calidad, rigor metodológico y propuestas, este libro rápidamente se convertirá en una referencia obligada para los que trabajan en el tema de la educación y afines.

En el Capítulo 1 se hace una exhaustiva y clarificadora descripción de la problemática actual de la Educación en México analizando el impacto de algunas reformas educativas, como la propuesta de los planes curriculares por competencias, analizando sus resultados y concluyendo que desafortunadamente el panorama no es nada alentador, dado que la implementación de tales estrategias no ha logrado modificar el sistema educativo en su conjunto, en breve no existen evidencias de que lo que se ha hecho a la fecha haya logrado 
incidir en la calidad del aprendizaje de los estudiantes. Los autores señalan que ello puede deberse a que "no es posible hablar de calidad si no se recuperan indicadores de desempeño efectivo a nivel de gestión, y del proceso de enseñanza- aprendizaje, que permitan contrastar el grado de correspondencia entre lo planeado como criterio normativo y las prácticas educativas cotidianas".

Por otra parte, en el Capítulo 2 se examina la enseñanza-aprendizaje de contenidos científicos centrándose en el análisis de la práctica científica desde una dimensión psicopedagógica, proponiendo para ello el uso, como herramienta heurística, del Modelo de la Práctica Científica Individual (MPCI). Algo sumamente interesante y valioso de este capítulo es la propuesta de analizar el proceso de enseñanza-aprendizaje a partir de las interacciones didácticas como el segmento analítico para las interacciones educativas (episodios instruccionales), noción que definen "como el intercambio recíproco entre sujetos (docente y estudiante) y objetos o situaciones referentes (materiales de estudio) en condiciones definidas por el ámbito de desempeño (disciplina o profesión)". Esta manera de analizar el fenómeno, y de intervenir en éste para resolver los problemas de enseñanza-aprendizaje, no sólo en el nivel medio y superior, sino en cualquiera, cuenta con todos los elementos críticos de este fenómeno, lo que podría garantizar su éxito.

Por otro lado, en el Capítulo 3, se analizan los efectos de exponer a los estudiantes a diferentes modos lingüísticos en la comprensión de contenidos científicos, concretamente en lo relativo a las interacciones de los alumnos con los objetos referentes, en este caso, con materiales de divulgación científica. Destaca la manera en que los autores conceptualizan a la comprensión como "la interacción entre el estudiante y los objetos referentes (materiales de estudio, por ejemplo, texto, video, conferencia, gráfico, material multimedia) en condiciones definidas por el área de conocimiento, los requerimientos a cumplir en la interacción (explicitados por los saberes conceptuales, instrumentales y de medida de dicha área de conocimiento) y las condiciones situacionalmente necesarias para que la interacción entre éstos pueda ocurrir”. Propuesta que tiene la gran ventaja de desmitificar a la comprensión dejando de concebirla "como un evento oculto al margen de aquello que se comprende y de las condiciones que posibilitan o interfieren en su ocurrencia", y por lo tanto, como un fenómeno no susceptible de análisis. Aquí los autores proponen estudiar el proceso formativo 
del estudiante a partir de su exposición al discurso didáctico del profesor, el cual lo pone en contacto con saberes conceptuales y/o procedimentales que requieren el ejercicio de distintas modalidades lingüísticas (observar, escuchar, leer, señalar, hablar y escribir).

En el Capítulo 4 se hace una propuesta metodológica para el análisis de la comprensión de contenidos científicos. El gran valor de ésta es que permite, de una manera objetiva y medible, analizar la comprensión de materiales científicos de estudiantes universitarios exponiéndolos a diferentes tipos de contenidos (objetos referentes), modalidades lingüísticas (escribir y hablar) identificando el nivel funcional en el que se desempeñan (intrasituacional, extrasituacional o transituacional), con el objeto de contestar tres preguntas: ¿cuál es el efecto de la explicitación del criterio de ajuste en la comprensión de estudiantes universitarios ante un material de estudio (objeto referente) con contenidos científicos? ¿cuál es el efecto de presentar variaciones en la secuencia de las modalidades lingüísticas (escribir-hablar, hablarescribir) en la comprensión de materiales (objetos referentes) con contenidos científicos? y ¿cuál es el efecto de presentar dos modalidades del objeto referente (texto o audio) en el nivel funcional de comprensión de estudiantes universitarios? Los resultados mostraron que: a) la explicitación del criterio tiene un efecto facilitador sobre la comprensión de contenidos científicos, b) las tareas que implicaban a los estudiantes menor grado de desligamiento fueron en las que éstos presentaron mayor porcentaje de aciertos, c) cuando los alumnos se exponían a la lectura de los materiales científicos su desempeño era mejor que cuando los escuchaban, y por otra parte, d) cuando la ejecución implicaba hablar el desempeño era mucho mejor que cuando el criterio de logro requería escribir, y finalmente, e) un dato sumamente interesante fue el hallazgo de que el desempeño de los participantes pareció depender más del modo lingüístico, del tipo de tarea y su nivel funcional implicado, que del contenido particular de los materiales científicos empleados.

En el Capítulo 5 se hace un análisis de cuáles podrían ser las implicaciones de los hallazgos de los diferentes estudios realizados para la planeación de interacciones didácticas de contenidos científicos. Para ello proponen "analizar concretamente las relaciones que se establecen entre: docente-estudiante-objetos referentes, docente-objetos referentes, estudiante-objetos referentes, y estudiante-objetos referentes-docente, con lo que se recupera el sentido psicopedagógico del proceso de enseñanza-aprendizaje”. 
Además de lo ya señalado, hay dos aspectos sumamente valiosos en el presente libro, la propuesta que los autores hacen respecto de cómo debe ser concebida la evaluación de desempeños académicos, y algo adicional, que es fundamental, dado el momento de transición que se está viviendo, la posibilidad de aplicar los hallazgos relativos a los modos lingüísticos en los procesos de enseñanza-aprendizaje mediante las Tecnologías de la Información y la Comunicación (TICs).

En relación al primer aspecto, en la presente obra se enfatiza que es indispensable que al estudiante se le expliciten los criterios de logro que deberá cubrir al realizar cada una de las actividades que se le indican, lo que implica que de la estrategia empleada en la enseñanza necesariamente deberá derivarse la modalidad de evaluación. Ello incluso debe ir más allá, implica que el proceso de enseñanza-aprendizaje y el de la evaluación no pueden y no deben involucrar momentos separados. Son y deben ser uno solo. Se debe evaluar conforme a lo que se enseña.

Finalmente, a pesar de que cada vez es más común el empleo de materiales multimedia como herramientas didácticas en los procesos de enseñanza-aprendizaje, sus efectos han sido poco explorados, por lo que el análisis sistemático de los efectos del empleo de diferentes materiales científicos en distintos modos lingüísticos realizado en el presente libro es de gran valor dado que aporta datos confiables que podrían permitir el uso eficiente de las Tecnologías de la Información y la Comunicación (TICs) en el proceso educativo gracias a la presentación de los materiales a los que se expone a los estudiantes en el modo lingüístico pertinente. Es decir, para que la inclusión de las nuevas tecnologías probabilicen o auspicien cumplir con los objetivos del proceso de enseñanza-aprendizaje, se deberán "plantear de forma clara los objetivos instruccionales, el perfil competencial requerido en cierto momento curricular, el nivel competencial que se requiere establecer, el tipo de material u objeto referente a presentar y los criterios de evaluación que serán requeridos". He ahí el gran reto que para la educación plantea esta valiosa obra. •

María Antonia Padilla Vargas Guadalajara, Jalisco, México. Octubre, 2013. 
Capítulo 1

Problemática de la Educación en México

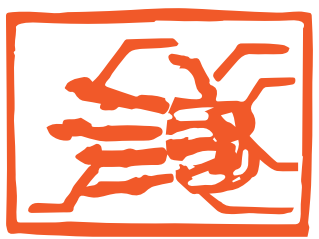


(Página en blanco) 
La calidad de la educación de un país, y en particular la relacionada con la formación científica y tecnológica, es fundamental en cualquier intento por superar los desafíos que implican la competitividad global en el siglo XXI. La formación en estos ámbitos, incide en que un país pueda revertir el desempleo, la exclusión social y abatir aquellos elementos que generan índices de desarrollo muy bajos en comparación con el resto de la población, como sucede por ejemplo, con las comunidades indígenas. Según datos del Programa de Naciones Unidas para el Desarrollo (PNUD, 2009), en México el 38\% padece pobreza alimentaria; $46 \%$ no ha concluido la primaria y la mitad de los hogares de este grupo, gastan $30 \%$ de sus ingresos en salud.

Se reconoce, por ejemplo, que el conocimiento científico incrementa los niveles de bienestar de la población (el efecto se observa en mayor salud y mejoramiento general en los estándares de vida de los miembros de una sociedad), además el conocimiento sobre educación, salud, ecología, economía son elementos indispensables en la solución de problemas sociales, y para el desarrollo de los procesos productivos. Diversos estudios muestran que las sociedades alfabetizadas científicamente son más fuertes económicamente, ya que una ciudadanía mejor informada puede ser innovadora y más crítica de los productos y servicios de la ciencia (Domínguez, 2012).

Sin embargo, a pesar de que se reconocen los beneficios que se derivan de la ciencia y la tecnología, en México no se han logrado avances relevantes en este sentido, a pesar de esfuerzos significativos hay importantes rezagos en comparación con los niveles de desarrollo de otros países (Domínguez, 2012; Fuentes y Sánchez, 1989).

Las evaluaciones internacionales de la Organización para la Cooperación y el Desarrollo Económico (OCDE), han encontrado que los mexicanos que cursan niveles de enseñanza básica, presentan niveles muy bajos en competencias de lectura, matemáticas y ciencias (OCDE, 2001, 2003, 2006, 2009, 2011). Estos repertorios son fundamentales para los niveles educativos subsiguientes y por lo tanto, para la formación de estudiantes en ámbitos disciplinares particulares. Estos indicadores educativos internacionales permiten ilustrar la 
condición que guarda la educación en nuestro país en comparación con los logros alcanzados en relación con otros sistemas educativos, y niveles alcanzados dentro del propio sistema educativo mexicano, tanto en el área de ciencias como en lectura, matemáticas y expresión escrita.

El panorama general de los repertorios de estudiantes mexicanos tanto en estudios internacionales y nacionales nos indica que uno de los principales problemas que enfrenta la educación en México, es el nivel de deserción y rezago en los diferentes niveles de formación. El Instituto Nacional para la Evaluación de la Educación (INEE, 2009) al seguir la trayectoria escolar de generaciones nacidas entre 1988-2002, mostró que del 98\% de alumnos que ingresan a primaria ${ }^{1}$, sólo el 13\% terminaron estudios de licenciatura. A más de una década, estos resultados no se han modificado significativamente.

Por este motivo, desde las últimas décadas del siglo XX, la preocupación por la calidad de la educación escolar ha aumentado de manera significativa en México, lo cual se ha traducido en diferentes estrategias de actuación, tanto a nivel de gestión, curricular, como a nivel de proceso de enseñanza-aprendizaje.

Al respecto, Martínez (2010) señala que el sistema de educación en México a pesar de que ha realizado grandes esfuerzos para mejorar su calidad en los últimos años no ha logrado todavía éxitos tangibles. El autor explica que el trabajo que se ha venido realizando toma en consideración particularmente dos vías. En la primera, se pone el término calidad educativa como el eje de las políticas en el sistema, y en la segunda, la instrumentación de diversos sistemas de evaluación.

La evaluación se ha impulsado de manera sobresaliente -como un mecanismo para mejorar los problemas persistentes en el sistema educativo-, aunque se considera que en México el esfuerzo se ha dirigido hacia la Educación Básica - preescolar, primaria y secundaria- (Calderón, 2009; 2011) y en menor medida a los demás niveles de formación.

$1 \quad$ Cifras proporcionadas por el INEE en México indican que alrededor de 33 millones de personas mayores de 15 años muestran diferentes grados de rezago (es decir, que no ha alcanzado el nivel educativo que se considera básico), desde analfabetismo hasta deserción escolar, durante los años de la educación básica. 
Desafortunadamente, los resultados de las evaluaciones no han logrado incidir en el sistema educativo, aún cuando las estrategias de evaluación son amplias y diversas (INEE, 2009). Por ejemplo, se presentan datos sobre escuelas, matrícula, gasto educativo, evaluaciones del rendimiento escolar, evaluaciones de los conocimientos o del desempeño profesional de los docentes, diagnósticos o evaluaciones de impacto de programas educativos. En tres décadas, el sistema educativo mexicano pasó de tener información parcial de algunos aspectos del sistema, a una generación amplia de datos que año con año se obtienen y de manera cada vez más frecuente, se difunden. A pesar de ello, no existen evidencias de que los ejercicios de evaluación que se están llevando a cabo mejoran la calidad educativa (Fernández y Midaglia, 2005; Martínez, 2010). Para autores como Orozco, Olaya y Villate (2009), la calidad de la educación, más que un propósito y/o una estrategia ha venido a constituir un discurso, convirtiéndose en retórica que la sitúa como un fin en sí misma. Así, la calidad no puede ser asumida únicamente como aquella relacionada con la eficiencia del sistema educativo, como un asunto de estándar de mínimos. Ésta debiera concebirse como una práctica evaluativa coherente respecto a los aspectos normativos, de gestión, psicopedagógicos y su concreción en prácticas cotidianas definidas de manera clara y precisa. Se considera que lograr la calidad de las instituciones de educación, implica intervenir pertinentemente en las diferentes dimensiones del proceso educativo, en donde sólo la planeación y evaluación sistemática de los criterios normativos y su implementación en las prácticas instruccionales cotidianas, incidirán en la calidad de la educación.

En otro momento se han expuesto (Acuña, Irigoyen y Jiménez, 2011) algunas normativas de calidad tanto internacionales (como por ejemplo, el Programa de Educación para Todos del PNUD ${ }^{2}$ ) como nacionales (el Programa Sectorial de Educación -México2007-2012) y los niveles de mínima correspondencia entre el decir y el hacer en el proceso educativo que se han venido implementando en las aulas mexicanas. Ahí se discuten $2 \quad$ El PNUD, creado en 1965, pertenece al sistema de Naciones Unidas y su función es contribuir a la mejora de la calidad de vida de las naciones. El PNUD promueve el cambio y conecta los conocimientos, la experiencia y los recursos necesarios para ayudar a los pueblos a forjar una vida mejor (PNUD, 2009). 
algunas reflexiones en función de resultados obtenidos en investigaciones recientes, y la poca concordancia que existe entre los aspectos normativos y los desempeños académicos. En la discusión se retoma a la evaluación como recurso de reflexión y análisis de centros, de actores y de procesos, señalándose que si esto no ocurre se continuarán planteando ideales en nuestras políticas educativas que si bien en algunos casos se corresponden con la dinámica social o con requerimientos de corte internacional, no logran incidir en la calidad del aprendizaje de los estudiantes.

En este sentido, se considera que se requiere caracterizar y evaluar (con indicadores claros) las condiciones existentes en las diferentes instituciones educativas (sistemas y subsistemas) en México, a la que se enfrentan directores, administradores, profesores y alumnos todos los días en sus centros de trabajo, para que de esta manera se formulen normativas de calidad congruentes y coherentes con las necesidades del escenario educativo mexicano.

De tal manera, que dada la complejidad de los problemas del ámbito educativo, el abordaje del mismo debiera darse de manera complementaria por las distintas disciplinas científicas (la biología, la psicología, la sociología, entre otras); cada una de ellas aportando a partir de sus dimensiones analíticas formas de segmentar y analizar el fenómeno bajo estudio, no perdiendo de vista el nivel analítico del que se parte (definición de objeto), que le dan sentido a la instrumentación o al abordaje de una problemática particular dentro de cada área de conocimiento específica. La pertinencia para el abordaje de un problema lo "otorga" el fenómeno bajo estudio, a partir de las preguntas que requieren ser contestadas y la manera en cómo podría abordarse cierta problemática desde su dimensión analítica.

Así, lograr la calidad educativa de las instituciones de educación, implica reconocer e intervenir pertinentemente a las diferentes dimensiones que confluyen en el proceso educativo, en donde sólo la planeación y relación pertinente de los criterios normativos institucionales, el currículo académico, los programas de materia, los objetivos instruccionales, entre otros, determinarán si el desempeño de los estudiantes formados se corresponde coherentemente con los criterios curriculares y los requerimientos que su entorno social establece (ver Figura 1). 
En este sentido, se sugiere que la evaluación debiera de ser el nodo y/o el punto de enlace para diagnosticar y retroalimentar el funcionamiento en cada uno de estos aspectos y/o dimensiones analíticas que confluyen en el ámbito educativo. En otro espacio, se ha señalado (Acuña et al. 2011) que no existe una cultura de la evaluación sistemática en el sistema educativo mexicano, de lo que ocurre en las aulas, de los materiales, de los contenidos, de lo que los docentes hacen, de las modalidades de las interacciones didácticas

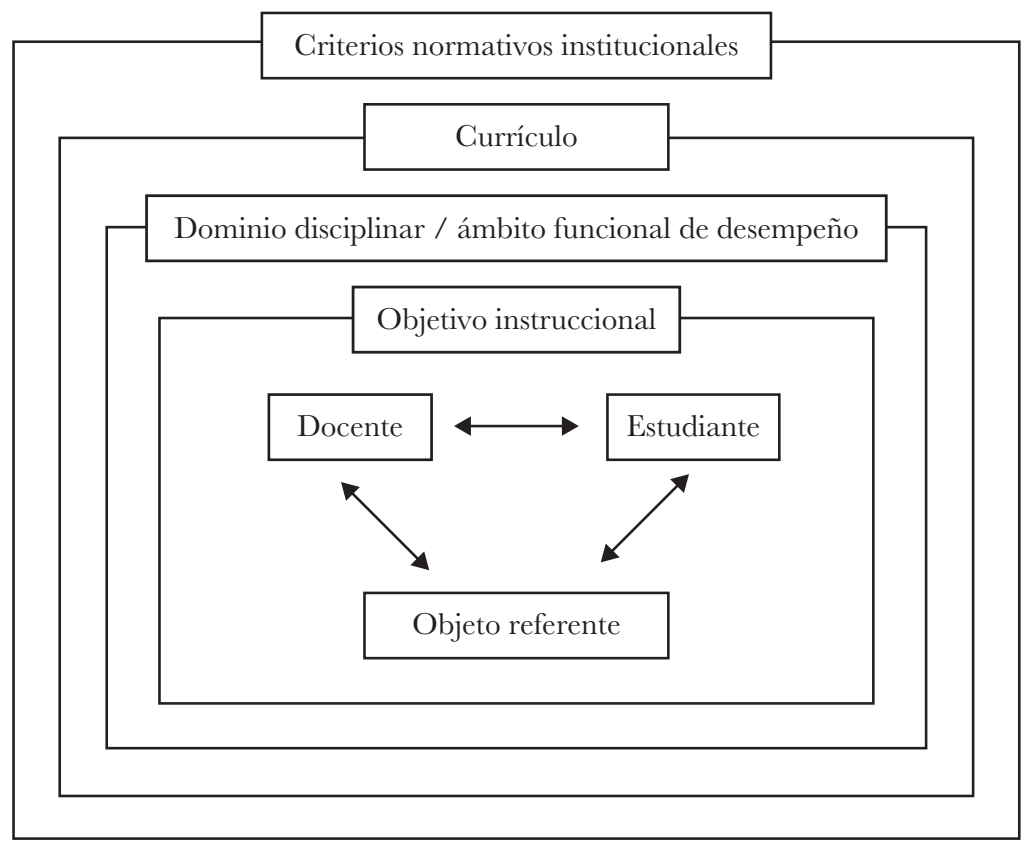

Figura 1. Representa los elementos que conforman los niveles de análisis del proceso de enseñanza-aprendizaje (recuperado de Irigoyen 2006, p. 125) y ajustada por los autores. 
implementadas y por lo tanto, del aprendizaje de los desempeños requeridos. Solamente una evaluación que recupere estos aspectos, podrá retroalimentar al sistema educativo en su conjunto.

De esta manera el concepto de calidad no debiera presentarse separado al de evaluación. El concepto de calidad usado en el ámbito educativo "calidad educativa" es una categoría que debiera permitir conocer si se están cumpliendo los objetivos planteados. Por ello, es necesario la construcción de indicadores que permitan desarrollar formas pertinentes de evaluación para la modificación del sistema educativo en su conjunto3.

Se requiere una clara definición conceptual de "calidad educativa" y la construcción de referentes empíricos en cada uno de los niveles analíticos que confluyen en el ámbito educativo. De esta manera, no es posible hablar de calidad si no se recuperan indicadores de desempeño efectivo a nivel de gestión, administración y del proceso de enseñanzaaprendizaje, que permitan contrastar el grado de correspondencia entre lo planeado como criterio normativo y las prácticas educativas cotidianas. Para ello, los criterios administrativos, de gestión e instruccionales deberán ser congruentes con la concepción de lo que se pretende formar tanto a nivel de conocimiento técnico, como actitudinal y social.

Es importante enfatizar que estos indicadores no se imponen unos sobre otros, sino por el contrario, más bien se complementan para lograr caracterizar y evaluar la calidad de las instituciones de educación superior; en donde indicadores de tipo político-administrativo posibilitan evaluar y plantear mejoras a las instituciones para el cumplimiento de sus objetivos, y de igual manera, los indicadores de tipo pedagógico-didáctico posibilitan retroalimentar el proceso educativo, y de esta manera, cumplir mejor y con mayor pertinencia con los objetivos institucionales, y de nivel de formación.

Lamentablemente, la evaluación de instituciones y programas educativos se ha centrado, con demasiada frecuencia, en la sola evaluación aislada de los factores o insumos del

3 Martínez (2010) describe de manera muy atinada seis experiencias en la construcción de indicadores y metodologías para evaluar centros educativos. 
proceso de enseñanza-aprendizaje: instalaciones, planes de estudio, profesorado, alumnado; dando respuestas a problemas aislados, y ha prestado poca atención a la integración de los resultados de la evaluación. En palabras de Reyes (1997) “ [...] si bien los recursos son indispensables para lograr la eficacia educativa, por lo general no explican la mejora de las cosas. Más recursos no se convierten automáticamente en mejora [...] En la calidad de los productos y en la eficacia del proceso también intervienen -y de manera muy importanteotros factores, tales como la naturaleza y características del proceso educativo mismo (el trabajo real que ejecutan estudiantes y maestros) y diversos elementos complejos del entorno social, material y cultural del programa y de la institución" (p. 18).

El presente manuscrito se centra en la dimensión psicopedagógica del ámbito educativo, es decir, aquella relacionada con el proceso de enseñanza-aprendizaje de contenidos científicos, particularmente la vinculada con las interacciones del estudiante con los referentes mediados por el profesor. En este sentido, se presenta una propuesta que permite recuperar el sentido psicopedagógico del proceso de enseñanza-aprendizaje, y por lo tanto, analizar cuáles son las condiciones idóneas para la formación de desempeños efectivos y variados en ámbitos disciplinares específicos. 


\section{Consideraciones sobre algunas reformas educativas en México, propuestas curriculares por competencias}

En México, con la finalidad de mejorar la calidad del sistema educativo y de responder a los desafios sociales de los últimos tiempos, un importante movimiento de reformas ha tenido lugar: en 2004 en Educación Preescolar, en 2008 en Educación Básica, en 2004 en Educación Media Superior (Secretaría de Educación Pública -SEP-, 2006; Subsecretaría de Educación Media Superior -SEMS-, 2008) $)^{4}$. Estas reformas e implementación de nuevos currículos en algunos casos, han adoptado el enfoque por competencias (como paradigma de formación centrado en el estudiante), partiendo del supuesto de una transformación en cuanto al quehacer educativo en torno a la enseñanza, el aprendizaje y la evaluación. Diversos autores han señalado, por ejemplo, que la modificación de las formas de evaluación constituye el punto de partida para una transformación en profundidad de la práctica educativa y para una verdadera reforma curricular (Barrón, 2005; Coll, Barbera y Onrubia, 2000).

En esta búsqueda por mejorar los indicadores de calidad de la educación, el tema del enfoque por competencias ha estado cada vez más presente en las discusiones sobre los distintos niveles del sector educativo (prácticamente en todos los países europeos y en muchos latinoamericanos), a tal grado que se le considera como una propuesta para el cambio de las instituciones escolares en la sociedad del conocimiento, así como medio para lograr una formación integral, con equidad y para toda la vida (Coll, 2007; Zabala y Arnau, 2007).

Díaz-Barriga y Rigo (2000) señalan que la Educación Basada en Competencias $(\mathrm{EBC})$ surge del interés por establecer una vinculación entre la escuela y la vida, entre lo que el alumno aprende en las aulas y sus actividades fuera de ella. Intenta relacionar estrechamente la teoría y la práctica, como una vinculación entre el saber decir y el saber

$4 \quad$ La fase de capacitación de la Reforma Integral de la Educación Media Superior (RIEMS) inicia en 2008, aún cuando la reforma curricular de los bachilleratos tecnológicos comenzó propiamente en 2004. De hecho la reforma ya se anunciaba en el Programa Nacional de Educación 2000-2006. 
hacer. Al respecto Coll (2007) comenta: "El concepto competencia y los enfoques basados en competencias tienen elementos interesantes que constituyen un avance en la manera de plantearse, afrontar y buscar soluciones a algunos de los problemas y de las dificultades más acuciantes con los que se enfrenta la educación escolar en la actualidad” (p. 34).

Los aspectos más importantes que este autor sugiere para abordar la "complejidad" de la educación escolar son: la funcionalidad del aprendizaje, la integración de los distintos tipos de conocimientos y la importancia del contexto, los cuales se describen a continuación.

$\mathrm{El}$ primer aspecto es la funcionalidad de los aprendizajes, el cual se presenta como uno de los rasgos distintivos de las nuevas tendencias educativas, en donde el aprendizaje que se desea promover tenga sentido tanto en términos de los repertorios de los estudiantes, así como de los requerimientos disciplinares y sociales en el momento de formación.

La importancia de la funcionalidad del aprendizaje como uno de los rasgos distintivos del aprendizaje "significativo" ha sido subrayada en numerosas ocasiones por las teorías constructivistas del aprendizaje escolar (Ausubel, 2002). Asimismo, otra de las propuestas educativas vigentes derivada de estas teorías es la enseñanza situada (para una revisión exhaustiva de la propuesta ver F. Díaz-Barriga, 2006).

El segundo aspecto es la necesaria integración de distintos tipos de conocimientos (conceptuales y factuales, procedimentales y actitudinales; Coll, 2007). De esta manera, se propone que la formación en el ámbito científico deberá considerar las distintas modalidades del saber decir y del hacer (como modalidades lingüísticas: observar, escuchar, leer, señalar, hablar y escribir, ver Camacho, Irigoyen, Gómez, Jiménez y Acuña, 2007; Fuentes y Ribes, 2001; Pérez-Almonacid y Quiroga, 2010).

Una de las discusiones al respecto enfatiza que se ha preferenciado una orientación hacia las habilidades técnico-instrumentales, y no así hacia una propuesta de formación general y sólida (F. Díaz-Barriga, 2006), en donde se enfatice la generación de desempeños involucrando las diferentes modalidades lingüísticas. Adicionalmente, autores como Irigoyen, Jiménez y Acuña (2007); Padilla (2006) señalan que: "Es importante que los contenidos 
científicos sean enseñados de manera conjunta con las formas de comportamiento que llevaron a la obtención de dichos productos ya que conceptos y procedimientos resultan inseparables, y a menudo las distinciones demasiado rígidas al respecto pueden servirle al profesor para ordenar su actividad docente, pero no son realistas con respecto a la enseñanza y los criterios de evaluación del aprendizaje en términos del hacer, del decir, del decir sobre el hacer, del hacer respecto al decir y del decir acerca del decir" (Irigoyen et al. 2007, p. 39). Así, cuando hablamos del desempeño ante contenidos científicos (concepto de competencia) se implican necesariamente aspectos conceptuales e instrumentales, aún cuando en algunos momentos de la formación se enfaticen más cierto tipo de saberes (declarativo o actuativo); es decir, el decir y el hacer no son dos cosas separadas sino más bien modalidades del saber.

$\mathrm{El}$ tercer aspecto es la importancia del contexto. Al respecto es necesario enfatizar que las competencias no pueden desligarse de los contextos de la práctica en los que se adquieren y se aplican. Por ello se plantea la necesidad de enseñar a los alumnos a poder aplicar (transferir) lo aprendido en una situación concreta a otras situaciones distintas.

Zabala y Arnau (2007) mencionan que para identificar los mecanismos que intervienen en un desempeño competente, es necesario partir de la necesidad de una situación única y compleja en un contexto determinado "situación única, ya que, por muy parecidas que sean las circunstancias, éstas nunca serán iguales; y compleja, ya que en la mayoría de las ocasiones el número de variables que en ella participan y sus relaciones serán múltiples” (p. 40). En otro espacio, se ha documentado (Irigoyen, Acuña y Jiménez, 2010) que el comportamiento competente implica continuar desempeñándose efectivamente estableciendo una equivalencia funcional entre situaciones diferentes a las entrenadas originalmente, e incluso de ser capaz de identificar y proponer ejemplares en los que dicha relación funcional se mantenga.

Según la Real Academia Española (RAE), el término de competencia tiene varios significados: a) como oposición o rivalidad entre dos o más personas que aspiran a obtener la misma cosa; b) como situación de empresas que rivalizan en un mercado ofreciendo 
o demandando un mismo producto o servicio; c) como incumbencia y d) como pericia, aptitud, idoneidad para hacer algo o intervenir en un asunto determinado. La definición de competencia de la que se parte en este documento corresponde a esta última acepción: ser experto o tener conocimiento suficiente acerca de algo. Podemos decir entonces, que el concepto de competencia refiere a la disposición para actuar efectivamente ante condiciones variantes.

Las definiciones del concepto de competencia - en el ámbito educativo-básicamente se han utilizado en dos sentidos: como capacidad o como disposición a actuar en determinadas condiciones. A continuación se describe brevemente cuáles son las implicaciones de estas acepciones y la pertinencia que guardan estos planteamientos para el establecimiento y evaluación de la formación de desempeños competentes en un área de conocimiento.

De acuerdo con el proyecto DeSeCo (Definition and Selection Competences: Theorical and Conceptual Foundations) de la Organización para la Cooperación y Desarrollo Económico (OCDE, 2002), una competencia es: "la capacidad para responder a las exigencias individuales o sociales o para realizar una actividad o una tarea [...] Cada competencia reposa sobre una combinación de habilidades prácticas y cognitivas interrelacionadas, conocimientos, motivación, valores, actitudes, emociones y otros elementos sociales y de comportamiento que pueden ser movilizados conjuntamente para actuar de manera eficaz" (p. 8).

Perrenoud (2004) propone una definición del concepto de competencia en este mismo sentido: como la capacidad de movilizar varios recursos cognitivos para hacer frente a un tipo de situaciones, insistiendo en cuatro aspectos: 1) las competencias no son en sí mismas conocimientos, habilidades o actitudes, aunque movilizan e integran tales recursos, 2) esta movilización sólo resulta pertinente en situación, y cada situación es única, 3) pasa por operaciones mentales complejas, sostenidas por esquemas de pensamientos, los cuales permiten determinar y realizar un acción relativamente adaptada a la situación, 4) las competencias profesionales se crean, en formación, pero también a merced de la búsqueda cotidiana del practicante, de una situación de trabajo a otra. 
En estas definiciones ser competente se interpreta como equivalente a ser capaz. Ser capaz significa tener cabida, y los usos en esta dirección se han utilizado como equivalentes a facultades o capacidades contenidas en el individuo que lo hacen poder llevar a cabo la solución en una situación problema (la mayoría de las veces sólo referida a aspectos conceptuales y no de instrumentación). Por su parte, Ribes (2006) ha discutido la lógica del uso del concepto de competencia y sus implicaciones para la formación y práctica profesional. El autor destaca que: "Ser competente implica tener la atribución para tratar acerca de algo o resolver algo, ser experto o tener conocimiento acerca de algo" (p. 20). En ese sentido, ser competente no es simplemente aplicar un conjunto de conocimientos a una situación, es poder organizar la actividad para ajustarse efectivamente a las características de la situación (pero porque se ha hecho con anterioridad), es decir, un desempeño que es efectivo en condiciones variantes ${ }^{5}$.

De esta manera, el concepto de competencia se aplica cuando, además de que es estipulado un requerimiento de logro, se especifica la manera o maneras de obtenerlo. Una competencia, desde este punto de vista, consiste en desempeños que satisfacen criterios diferenciados, criterios que incluyen el logro a cumplir y la(s) manera(s) de hacerlo. Por ello, la competencia es un concepto que vincula por una parte los criterios de ajuste que se imponen en los diferentes momentos curriculares y el desempeño que deberá exhibirse para el cumplimiento de estos criterios, sea este conceptual, metodológico, instrumental y/o actitudinal.

Así, es posible caracterizar desempeños competentes en los estudiantes en formación en el ámbito científico a partir del ajuste efectivo del comportamiento del estudiante a los criterios de logro como condiciones variantes en: tipo de tarea, modalidad lingǘstica y nivel funcional (Irigoyen et al. 2007; Mateos y Flores, 2008; Morales, Cruz, León, Arroyo y Carpio, 2010). Para lo cual, se propone que en los diferentes niveles de enseñanza, el alumno sea expuesto a actividades y tareas variadas y funcionalmente "significativas" que

$\overline{5}$ El desempeño efectivo y variado se refiere cuando el comportamiento cumple con éxito los requerimientos solicitados en diferentes momentos y situaciones problema. 
les permitan la adquisición de los repertorios efectivos requeridos para el ámbito disiciplinar específico. En este tenor, Ruiz (2009) menciona lo siguiente: "generar un profesional que llene las expectativas que de él se tienen y resuelva problemas en un medio laboral real que demanda conocer e interactuar de un modo coherente, no se conseguirá simplemente tras exponer al aspirante profesional a constantes disertaciones por parte de uno o más docentes, o a la lectura y disertación de tratados" (p. 292).

Bajo el enfoque por competencias, lo que se plantea es un aprendizaje que se puede transferir a diferentes situaciones inéditas. Autores como Zabala y Arnau (2007) han insistido en que hasta este momento se ha auspiciado un aprendizaje reproductivo y descontextualizado, así como una enseñanza expositiva, en donde los desempeños de los estudiantes no pueden dar respuesta satisfactoria a situaciones reales, dado que estas situaciones nunca se promovieron en condiciones de formación, citando en extenso: "Optar por una educación en competencias representa la búsqueda de estrategias de enseñanza que sitúen su objeto de estudio en la forma de dar respuesta satisfactoria a situaciones reales, y por lo tanto complejas. Dado que estas situaciones reales nunca serán aquellas con las que se ha de encontrar el alumno en la realidad, podríamos aceptar, en cualquier caso, que las aplicaciones concretas de las competencias, las del futuro, no pueden enseñarse, pero sí pueden enseñarse los esquemas de actuación de las competencias y su selección y práctica en distintos contextos generalizables" (p. 42).

Los autores señalan que una dificultad en la enseñanza bajo este enfoque está dada por la forma de auspiciarlas, ya que estas estrategias implicarían actividades muy alejadas de la tradición escolar. Esta práctica se ha sustentado en la transmisión verbal y en la reproducción más o menos literal de lo aprendido en exámenes convencionales -típicamente de reproducción de la información-, lo cual no permite de ninguna manera diferenciar los desempeños de los estudiantes ni instrumentar criterios de evaluación variantes que permita establecer contacto con las características diferenciales de cada uno de ellos; aspectos fundamentales para el aprendizaje de las competencias (Zabala y Arnau, 2007). 
Sin duda que la propuesta de la formación bajo un enfoque por competencias, intenta plantear de una manera distinta la concepción e implementación de la enseñanza, el aprendizaje y la evaluación, enfatizando de forma clara los desempeños efectivos ante condiciones variantes, tanto en los docentes como en los estudiantes, y por lo tanto, las condiciones necesarias para la ocurrencia de dichos de desempeños.

Ribes (2011) por su parte, ha señalado la pertinencia de la planeación de competencias, pero siempre y cuando el significado de un término como el de competencia, se vincule lógicamente con las categorías de una teoría científica acerca del comportamiento, que permita tener un sentido unívoco - como concepto técnico-y su ubicación -como categoría abstracta- dentro de una teoría del desarrollo psicológico y como dimensión psicológica en la educación. 


\section{Definición de Competencia como disposición}

El término competencia se vuelve un concepto técnico de enlace o de interfase entre una teoría general de proceso (Ribes y López, 1985), el lenguaje técnico de la descripción del desarrollo psicológico de un individuo y la relación con el proceso de enseñanza-aprendizaje. Este concepto es definido como: "Las competencias conductuales son clases interactivas definidas en términos de las propiedades morfológicas de los eventos de estímulo y de respuesta. En este sentido, una misma competencia, entendida como disponibilidad interactiva respecto a morfologías de conducta y eventos, puede tener funcionalidad en diferentes niveles de organización cualitativa de la conducta" (Ribes y López, 1985, p. 65). La evolución psicológica se da entonces, como proceso, en la transición de los niveles funcionales más "simples" a los más "complejos".

El desarrollo competencial, que en esencia define al proceso psicológico, es sustancialmente diferencial y desigual en la exhibición de competencias a diferentes niveles funcionales, intra y entre sujetos. Bajo este supuesto, el desarrollo de competencias no es un proceso lineal, sino variable, dependiendo de cada situación de aprendizaje y de las habilidades y competencias requeridas para el cumplimiento del criterio en una situación específica, lo que hace necesario analizar el nivel funcional de contacto del sujeto con objetos, eventos o situaciones específicas en los distintos momentos de formación.

Por lo tanto, la investigación del aprendizaje escolar debiera dirigirse a determinar aquellas condiciones necesarias y suficientes bajo las cuales el desempeño del individuo en interacción con el profesor y los objetos referentes satisface "nuevos" criterios. Por ello, el análisis de competencias (como desempeño efectivo y variado) no puede ser evaluado en un sólo momento o en una sola modalidad, ya que el concepto de competencia esta referido a colecciones de hechos en condiciones variantes, por lo tanto, no puede ser analizada como evento único, ya que lo que se observa es el cumplimiento en casos o situaciones concretas de los criterios que las definen. El análisis de competencias (como colección de ocurrencias) 
sólo es posible con evaluaciones que permitan monitorear los cambios en el comportamiento de los estudiantes ante criterios morfológicos o funcionales variantes, por ejemplo, que impliquen distintos niveles de complejidad (nivel funcional), tipos de tarea y modalidades lingüísticas.

Además, el concepto de competencia como concepto técnico, debe incluir bajo la perspectiva del presente manuscrito, dos aspectos: 1) la especificación del desempeño y, 2) la explicitación de los criterios que dicho desempeño debe satisfacer. En otras palabras, se aprende a ser competente en la medida en que se aprenden desempeños y criterios de ejercicio de los diferentes saberes (conceptuales, procedimentales y de medida).

Este concepto implica necesariamente un desempeño efectivo -como tendenciaante condiciones variantes (Ribes, 2006). En palabras del autor "Ser competente implica tener la atribución para tratar acerca de algo o resolver algo, ser experto o tener conocimiento acerca de algo. Ser competente, por consiguiente, se refiere a que se puede hacer algo porque ya se ha hecho por que se tiene conocimiento de lo que se tiene que hacer" (p. 20). Así, lo que finalmente se observa no es la competencia sino los desempeños del estudiante como ajustes efectivos, es decir, como la disposición a ajustarse a criterios cambiantes de forma efectiva.

Por ello, como lo señalan Martín y Coll (2003) las competencias como las capacidades de ajuste efectivo, no son directamente evaluables. Hay que elegir las situaciones adecuadas para trabajarlas, definir la secuencia y el grado propio de los distintos niveles y cursos, para poder establecer indicadores precisos de logro, y acertar en las tareas que finalmente se le pide al alumno que realice, para de esta manera caracterizar los desempeños competentes de los estudiantes.

Así, la evaluación de competencias -académicas- para no confundirla con el mero ejercicio repetitivo no debiera soslayar lo siguiente: a) las características específicas del problema; b) las características de la situación problema; c) características específicas del desempeño, y d) la complejidad del desempeño requerido; considerando el ámbito funcional de desempeño y el objetivo instruccional específico. 
Tomando en consideración esta lógica, Ribes (2008) señala que las reformas educativas se han planteado de manera errónea desde tres perspectivas diferentes: por una parte, unas han propuesto métodos de enseñanza que fomenten la libertad y libre expresión de las capacidades de los educandos, con base únicamente en concepciones intuitivas acerca de la naturaleza cognoscente del ser humano, y sobre todo de cuáles son las condiciones idóneas para el aprendizaje; por otra parte, se ha supuesto que el mejoramiento de la educación pasa por la incorporación creciente de tecnologías audiovisuales y computacionales, que facilitan y aumentan el flujo de información que recibe y puede buscar el educando, y por último, el abordaje más frecuente consiste en la actualización y estructuración expositiva de los contenidos de enseñanza, y la actualización y capacitación de las destrezas didácticas de los profesores.

A continuación en las siguientes líneas se describen estas tres perspectivas. En 2004 entró en vigor una Reforma Curricular en los bachilleratos tecnológicos que si bien se anunciaba desde el Programa Nacional de Educación 2000-2006, se concretó en ese año. Con la puesta en marcha de la Reforma Integral de la Educación Media Superior (RIEMS), los docentes de este ciclo enfrentan nuevos desafios entre los que sobresalen: instrumentar un marco curricular común con base en desempeños terminales según ciertas competencias genéricas, disciplinares y profesionales establecidas de antemano y asumir ellos mismos el compromiso de cumplir con un perfil que les exige, entre otras cosas: "enseñar a aprender", "dominar y estructurar los saberes para facilitar experiencias de aprendizaje significativo", y "planificar los procesos de enseñanza atendiendo al enfoque por competencias en contextos disciplinares, curriculares y sociales amplios" (SEP, s/f). En la RIEMS sobresalen dos ejes discursivos que privilegian, por un lado, prácticas educativas basadas en competencias y, por el otro, un enfoque pedagógico constructivista, sin que necesariamente los profesores tengan claro el concepto mismo de competencia, y lo que implica en el trabajo cotidiano de aula un enfoque constructivista (López y Tinajero, 2009). 
Con respecto a las concepciones de aprendizaje de docentes, Sánchez (2005) llevó a cabo un estudio con el objetivo de conocer las concepciones de aprendizaje de docentes universitarios y profesionales no docentes a fin de compararlas. Su muestra fueron profesores con conocimiento sobre el aprendizaje, profesores legos en el aprendizaje y profesionales no docentes legos en el aprendizaje. Los resultados evidencian elementos compartidos en las concepciones de los profesores y legos. Además de la presencia de elementos incoherentes en algunas concepciones de los docentes con formación en aprendizaje. La autora concluye que estos resultados parecieran reafirmar que las concepciones de los docentes, aunque tengan contacto con contenidos científicos, muchas veces son reconstrucciones que realizan de sus prácticas cotidianas.

En relación con la perspectiva del mejoramiento de la educación dado el desarrollo y promoción de Tecnologías de la Información y Comunicación (TICs), se presupone que la incorporación de las tecnologías en las aulas permite (por si misma) mejorar el aprendizaje de los alumnos. No obstante, se han analizado los usos reales de las TICs, y su impacto en la práctica educativa, en donde la diferencia entre los diversos usos no radica en las características de los recursos tecnológicos utilizados, sino en la incidencia que los usos de estas herramientas tienen sobre las interacciones didácticas, y por lo tanto, en el aprendizaje de los alumnos. Los resultados encontrados en el estudio de Coll, Mauri y Onrubia (2008) fueron interacciones áulicas en donde los usos de las TICs mostraron un efecto limitado en la transformación y mejora de las prácticas educativas, no modificando sustancialmente las formas de implementación, organización y evaluación desarrolladas a lo largo de las actividades de enseñanza.

En este sentido, se ha expuesto en otros espacios (Irigoyen, Jiménez y Acuña, 2003) que la inserción de las nuevas tecnologías en la educación no ha generado una concepción diferente del proceso de enseñanza-aprendizaje. Sino que se ha recuperado como "regla" general que la instrucción en grupo y la enseñanza asistida por los medios audiovisuales son suficientes para el aprendizaje individual. Por el contrario, la inclusión de las nuevas 
tecnologías sólo se han visto reflejadas como un nuevo modo de presentar la información, reiteración de información en aula, contacto unidireccional, poco variante, en el cual las nuevas tecnologías únicamente han suplantado a la vieja pizarra, pero con la misma función.

En relación a las estrategias de enseñanza y la actualización y capacitación de las destrezas didácticas de los profesores se considera que requieren ser replanteadas para propiciar el desarrollo de las habilidades y competencias pertinentes en los diferentes niveles de formación. En estudios llevados a cabo por Guevara (2008) se plantea que los procedimientos y las estrategias de enseñanza no están adaptados de manera óptima para la promoción y facilitación del aprendizaje (los estudios fueron llevados a cabo en educación básica).

Irigoyen, Jiménez y Acuña (2004) realizaron un estudio para analizar el desempeño docente a nivel universitario, para lo cual evaluaron las categorías de planeación, evaluación de repertorios de entrada, ilustración y retroalimentación. Los resultados muestran a un docente cuya práctica es con mayor frecuencia discursiva, con pocas variaciones en el uso de materiales didácticos, así como en la modalidad de enseñanza y en criterios de evaluación.

En cuanto a los cursos de actualización de profesores en relación con contenidos científicos y su enseñanza, autores como Alvarado (2007) y Alvarado y Flores (2010) enfatizan que estudios llevados a cabo con profesores muestran que los cursos de actualización no modifican sus concepciones acerca de la enseñanza, el aprendizaje y la evaluación; los cambios se restringen al discurso (aprendizaje de nuevos nominativos), no reflejándose en una manera diferente de decir-hacer en la práctica en el aula. Por ejemplo, en un estudio llevado a cabo por López, Rodríguez y Bonilla (2004) se analizan las concepciones sobre el aprendizaje de la ciencia, y su relación con la práctica de los profesores de bachillerato del área de ciencias naturales, así como su posibilidad de transformación a partir de los Cursos Nacionales de Actualización-CNA-(ofrecidos por la SEP). Los resultados mostraron que independientemente de haber cursado o no los CNA, la mayoría de los profesores centran su práctica docente en los contenidos programáticos presentados en los libros de texto, por lo que el origen del 
conocimiento está en los contenidos de aprendizaje expuestos por ellos o en los encontrados en los libros, y no en el fenómeno científico mismo, dando como resultado la enseñanza de verdades absolutas y fortaleciendo así, una visión dogmática y ahistórica de los diferentes contenidos científicos. En todos los profesores se presentaron diferentes formas de evaluación del aprendizaje, sin embargo, todas ellas enfatizan desempeños que involucran memorización y reproducción de la información. Finalmente, como una de las conclusiones se presenta que los cambios parecen restringirse al discurso, no reflejándose en la práctica en el aula.

En este mismo tenor, Fernández-Nistal, Pérez, Peña y Mercado (2011) llevaron a cabo un estudio para caracterizar las concepciones sobre enseñanza de los profesores de contenidos científicos de secundaria y su actuación en el aula. Los participantes manifestaron por ejemplo, que la evaluación forma parte de los procesos de enseñanza y aprendizaje, mencionando la necesidad de valorar el proceso que el alumno realiza, pero al mismo tiempo, se enfocaron a la evaluación de los resultados del aprendizaje. En relación al análisis entre las concepciones de enseñanza que presentaron los profesores en la entrevista y las concepciones obtenidas en el comportamiento observado, los resultados indican incoherencias entre ambos aspectos. Las implicaciones educativas de estos resultados se sitúan en el diseño de cursos de formación y actualización docentes dirigidos a un cambio - sustancial-que mejore las prácticas educativas que, en definitiva, son las que impactan en el aprendizaje de los estudiantes.

Dentro de los documentos oficiales (UNESCO, 2007 -Educación para todos en 2015-) se insiste en ofrecer una educación integral, con el propósito de equilibrar la formación en valores ciudadanos, el desarrollo de competencias y la adquisición de conocimientos, a través de actividades regulares del aula, la práctica docente y el ambiente institucional. En estos documentos se enfatiza ampliar las oportunidades educativas, el propósito es una mayor igualdad de oportunidades educativas, de género, entre regiones y grupos sociales como indígenas, inmigrantes y emigrantes, así como personas con necesidades educativas especiales. Las preguntas al respecto serían ¿pero realmente se esta ofreciendo una educación integral?, ¿las prácticas educativas están respondiendo a las necesidades del Siglo XXI? 
Es relevante considerar que la planeación de espacios educativos, deberá considerar que la enseñanza es grupal pero el aprendizaje es individual, y que por lo tanto, los haceres en las interacciones didácticas deberán partir de la consideración de individuos en el proceso educativo que responden diferencialmente en tiempo y modo a los referentes que se están pretendiendo establecer. En otro momento se han expresado (Acuña, Jiménez e Irigoyen, 2010) una serie de consideraciones sobre la planeación de espacios educativos para la formación de estudiantes competentes. Se discute que una propuesta de revisión curricular no sólo implica la modificación de aspectos normativos y de gestión en el ámbito institucional, sino cambios sustanciales en las maneras en cómo se conciben y se implementan las interacciones didácticas (estrategias docentes, criterios de evaluación y modalidades de objetos referentes utilizados).

Por una parte las evaluaciones realizadas a nivel internacional y regional muestran información relevante sobre la habilitación competencial de los estudiantes de los países desarrollados y en desarrollo. Cada vez son más numerosos los gobiernos que están llevando a cabo evaluaciones nacionales del aprendizaje. El 81\% de los países desarrollados, el 50\% de los países en desarrollo y el 17\% de los países en transición (periodo del 2000-2006). Pero también se necesita recuperar indicadores en lo específico, de cómo se están disponiendo las condiciones de interacción didáctica en el aula, así como cuáles son los repertorios de los estudiantes cuando ingresan y egresan a los diferentes niveles de formación. Se requiere asimismo el perfil del personal docente y su seguimiento -en términos de indicadores concretos- a partir de programas de formación.

De esta manera, enfrentar el rezago, ampliar la cobertura de los servicios educativos, elevar la calidad de la formación, mejorar su pertinencia, introducir cambios y anticipar necesidades y soluciones a los problemas previsibles, son algunos de los desafíos que requiere enfrentar la educación en México. Sin embargo, no es suficiente con situar el debate sobre la calidad en el centro de las políticas educativas y proyectar la necesidad de abordarla, sin 
tomar en cuenta que no existen acuerdos respecto al significado del término y cuáles serían las estrategias que deberían seguirse para alcanzar determinados estándares de calidad.

Si se pretende lograr una educación de calidad, se deberá reflexionar sobre la caracterización del papel de los actores involucrados en el proceso educativo (administradores, gestores, profesores y alumnos), al formular las políticas educativas. Se requiere en este sentido, clarificar cuáles son los objetivos de la educación y cuáles serían los mecanismos para el cumplimiento de estos, así como también el reconocimiento de la individuación del estudiante, en donde éste, va interactuando con los objetos referentes y/o materiales de estudio en formas y ritmos distintos. Para ello, tanto los criterios administrativos, de gestión e instruccionales deberán ser congruentes con la concepción de lo que se pretende formar tanto a nivel de conocimiento técnico, actitudinal y social.

La función de las instituciones educativas desde el punto de vista planteado en este manuscrito, más que ser la transmisora de conocimiento, deberá ser auspiciadora y generadora de individuos competentes en los distintos niveles de formación. En el caso de la Educación Superior, su objetivo es procurar la formación de profesionales, investigadores o docentes de las distintas áreas del saber, como mediadores expertos tanto para la generación de conocimiento, como en la resolución de problemas sociales en sus distintos campos. El reto entonces para la Educación Superior, es el establecimiento coherente de las competencias disciplinares en las distintas áreas de conocimiento.

Así, las instituciones de educación superior enfrentan el reto de generar individuos con los repertorios suficientes que les permitan desempeñarse de manera eficiente en relación a las situaciones problema que su área de conocimiento les plantee, así como la posibilidad de transferir sus desempeños a las diferentes problemáticas y dar respuesta a las nuevas demandas sociales y del sector laboral. El presente manuscrito intenta reflexionar y hacer aportaciones en cuanto al proceso de enseñanza-aprendizaje desde una aproximación competencial. Permitiendo así, dar cuenta de los distintos momentos del desarrollo de competencias del estudiante al enfrentarse con los referentes disciplinares. • 
Capítulo 2

Aproximación a la enseñanza-aprendizaje de contenidos científicos

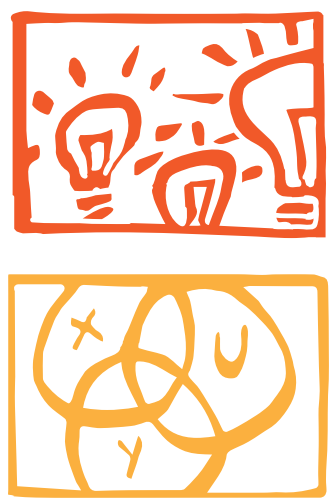


(Página en blanco) 
Los cambios tan acelerados que se viven en el ámbito mundial, en sus diferentes órdenes: económico, político, científico-tecnológico y sociocultural, plantean a las Instituciones de Educación Superior la revisión de su quehacer en forma integral. En este entorno de acelerados cambios, dichas instituciones se han visto forzadas a repensar sus fundamentos, a definir de nuevo sus misiones y medios, y a reorganizar sus funciones, para mantener el papel protagónico en el desarrollo de la ciencia y la tecnología, y la formación de profesionales de alto nivel.

Uno de los principales desafíos de la sociedad del conocimiento para la enseñanza y el aprendizaje universitario, es formar individuos acordes a su tiempo, capaces de reflexionar acerca de la pertinencia de un problema con respecto a su disciplina de estudio, así como la de generar soluciones alternativas a los mismos, es decir, formar individuos competentes. Sin embargo, uno de los retos a vencer en la formación universitaria es la provisionalidad de los saberes, como rasgo que caracteriza la nueva dinámica social, incluso cuando se habla de la formación en disciplinas especializadas, como lo es la formación en los ámbitos científicos.

Por ello, los procesos de formación de los noveles estudiantes de las distintas disciplinas científicas (y tecnológicas) deberán modificarse tanto en concepción como en instrumentación, si se desea que se superen los desafios de la competitividad global en el siglo XXI. Rocha y Landa (2012) en este tenor comentan lo siguiente: "vivimos una época en que la educación sigue siendo el reto a vencer, en especial para las instituciones de educación superior" (p. 17).

En este sentido, López (2001) señala que: "El mundo contemporáneo exige versatilidad en la formación profesional. La acumulación de saberes sin que medien procesos comprensivos relacionados con la vida cotidiana de cada profesión, pone en riesgo la eficacia de la enseñanza universitaria, sobre todo ahora cuando lo que se ha dado en llamar sociedad del conocimiento ha puesto en primer orden la exigencia de apertura de las instituciones de educación superior; por un lado, en los modos como los actores escolares se han de relacionar para discernir los saberes constituidos, y por el otro, el uso de los aprendizajes durante los procesos de formación universitaria” (p. 171). 
De esta manera se plantea la necesidad de formar profesionales competentes para la exigencia del mundo contemporáneo, por ejemplo, la capacidad para trabajar ante situaciones de cambio, de trabajo en equipo e interacciones mediadas por diversas tecnologías que también están en constante variación, además la necesidad de habilidades y competencias de innovación y de generación de conocimiento. Una sociedad que no sea capaz de producir su propio conocimiento estará condenada a la dependencia, tanto científica como tecnológica, y por consecuencia, económica.

En la llamada sociedad del conocimiento, la educación superior es un agente clave en los procesos de modernización de todos los países del mundo. Como fue señalado en la Conferencia Regional de la UNESCO en 1996: "la educación general, y la superior en particular, deben ser instrumentos esenciales de valor estratégico para enfrentar exitosamente los desafíos del mundo moderno y para formar ciudadanos capaces de construir una sociedad más justa y abierta" (p. 11).

Amaya (2006) menciona que el desarrollo económico contemporáneo demanda principalmente: conocimiento científico, información, avances tanto en la tecnología dura (maquinaria, instrumentos y procedimientos técnicos para la producción) como en tecnología blanda (organización y administración de la producción y del trabajo), así como exigencias de incremento de la competitividad en los mercados de bienes y servicios.

De esta manera, lograr derivar conocimiento científico para un país, requiere de especialistas que analicen las variables y procesos que se involucran en la formación de nuevos científicos, para de esta manera habilitar a los individuos en la generación de nuevo conocimiento. Por ello, el presente manuscrito centra su discusión en el análisis de la práctica científica a partir de una dimensión psicopedagógica, es decir, como ocurre (o debiera ocurrir) la formación de noveles estudiantes en relación a contenidos científicos, como práctica científica individual. El análisis que se ilustra es a nivel universitario, porque se considera éste un espacio fundamental para la formación de noveles científicos; pero sin duda, buena parte de la discusión y propuestas pueden ser aplicadas a otros niveles de formación. 
La práctica científica como actividad profesionalizada, es un fenómeno que se inicia en el siglo XX. Su profesionalización se vió acompañada por la institucionalización de su enseñanza en el nivel universitario. A partir de ello, la universidad se convirtió en el espacio por excelencia para formar a los nuevos científicos y tecnólogos (Ribes, 2009).

De esta manera las Instituciones de Educación Superior tienen como encargo especial, el auspicio, generación y aplicación del conocimiento, sin embargo, una de las principales problemáticas de los últimos años en el ámbito educativo (no sólo a nivel universitario) es la formación de estudiantes en contenidos científicos. Al respecto, Benito (2009) señala: “en los últimos años se ha instalado con especial énfasis el interés por indagar los motivos de la creciente crisis de la educación científica, manifestada en las dificultades de aprendizaje de los alumnos, quienes parecen aprender menos ciencia de la que se les enseña, a la vez que presentan menor interés por lo que aprenden. A ello se suma la sensación de frustración por parte de los docentes acerca del éxito de sus esfuerzos por la enseñanza de las ciencias” (p. 28). Así, en los últimos años se ha producido un notable incremento de las críticas a los fines, métodos y formas que han adoptado la enseñanza y el aprendizaje escolar en general, y el de los contenidos científicos en particular. Benito (2009) enfatiza que gran parte de las críticas coinciden en señalar:

a) Que después de tantos años de escolarización los estudiantes no obtienen ni el conocimiento ni las estrategias necesarias para el manejo de información de contenidos científicos. Por ejemplo, Mares, Hickman, Cabrera, Caballero y Sánchez (2009) e Irigoyen et al. (2009) realizaron dos estudios con el propósito de hacer una caracterización de estudiantes de primer ingreso a la carrera de Psicología de dos universidades públicas de México. En estos estudios los autores evaluaron las condiciones económicas, sociales y académicas; a partir de la aplicación de una evaluación conformada por 7 secciones: 1) datos sociodemográficos, 2) trayectoria escolar, 3) nivel de conocimiento del ámbito disciplinario, 4) dominio de programas de cómputo, 5) cultura general, 6) aptitud para la ciencia y 7) comprensión de lectura 
en el idioma inglés. Los resultados del desempeño de los estudiantes coinciden en ambas instituciones, en términos de porcentajes muy similares en cuanto a una capacidad deficiente en la prueba de aptitud para la ciencia, y en competencia lectora específicamente en lo que concierne a la lectura de gráficos, la argumentación con base en la información de un texto y la comunicación de ideas complejas.

b) Otra crítica a la enseñanza-aprendizaje de contenidos científicos es, que gran parte del tiempo de enseñanza se ocupa en la transmisión de conocimientos y destrezas que en poco tiempo quedarán obsoletas. Autores como Galicia, Sánchez, Pavón y Mares (2005) y Varela (2002), señalan que los programas instruccionales en niveles básico y medio, se han centrado en la enseñanza de contenidos, dejando a un lado la enseñanza de procesos de abstracción o desarrollo de habilidades de razonamiento; repertorios fundamentales particularmente para la enseñanza-aprendizaje de las ciencias.

c) La siguiente nota, es que una parte importante del proyecto educativo se ocupa en potenciar una cultura científica idealizada y alejada sustancialmente de lo que ocurre realmente en el quehacer científico. En este sentido, autores como Irigoyen et al. (2007), Morales, Pacheco, Canales, et al. (2010) y Silva y Morales (2008) discurren sobre las maneras tradicionales de concebir la enseñanza de la ciencia-como la mera reiteración de información- - y enfatizan que ésta debiera de implicar el ajuste gradual del comportamiento del futuro practicante de ciencia a los criterios disciplinares específicos, en coordinación con un experto en la disciplina. De esta manera, el estudiante va aprendiendo las prácticas científicas, en los espacios científicos y ajustándose a los criterios científicos, es decir, aprende ciencia practicándola como formas de decir y hacer (señalar, leer, hablar, escribir).

d) Un aspecto adicional es, que no existe ninguna garantía que el conocimiento enseñado en las aulas, proporcione habilidades y competencias que cualifiquen a los estudiantes para la inserción en el sistema profesional y/o productivo. 
En relación a este aspecto se puntualiza, que uno de los problemas con el manejo de lenguajes formales (repertorios necesarios para el uso o manejo de lenguajes científicos), es que la enseñanza de éstos se ha centrado en el contenido de las materias o áreas y no en las formas de decir y hacer como desarrollo de las habilidades y competencias científicas. Galicia et al. (2005) plantean la necesidad de proponer que en los diferentes niveles de formación particularmente en los primeros grados de educación básica, se implementen estrategias instruccionales que puedan funcionar como antecedentes importantes para alcanzar un dominio de los lenguajes científicos y formales.

Este es uno de los aspectos más relevantes que se sustenta en el presente manuscrito a manera de propuesta, que las prácticas científicas se aprenden como cualquiera de las demás prácticas (p.e. prácticas filosóficas, de sentido común), como un saber (es) que tiene sentido dentro de contextos particulares. Toda vez que las nuevas necesidades educativas apuntan hacia la formación de individuos que se ajusten a circunstancias y problemas cambiantes, es necesario caracterizar las condiciones situacionales y disposicionales que permiten auspiciar el intercambio efectivo y pertinente del estudiante con los contenidos científicos.

A continuación se describen cuales son las prácticas conductuales implicadas en el quehacer científico, según el Modelo de la Práctica Científica Individual-MPCI- (propuesto por Ribes, 1993; Ribes, Moreno y Padilla, 1996; Padilla, 2006), y de esta manera proponer cuales serían las formas más pertinentes para el auspicio de desempeños competentes dentro de un ámbito o dominio disciplinar. 


\section{Aproximación al estudio del comportamiento científico}

$\mathrm{Al}$ aproximarse al estudio del comportamiento científico, se encuentra que la actividad científica ha sido mitificada (Padilla, Buenrostro y Loera, 2009), por lo menos en dos sentidos, los cuales se describen en las siguientes líneas.

Por una parte, se ha mantenido a lo largo de la historia que el conocimiento científico es el único verdadero y que las demás formas de conocimiento (p.e. filosófico, religioso, mitológico, de sentido común), son más que maneras distorsionadas del saber acerca del mundo y de nosotros mismos.

En el devenir de la historia, el ser humano ha buscado describir y explicar los fenómenos de la naturaleza y la relación que guarda con ellos. De ahí que la Ciencia, la Filosofía, el Arte y la Mitología, se hayan constituido como sistemas de conocimiento que han intentado explicar dichos fenómenos. Estas formas de conocimiento (filosófico, científico) deberán entenderse como una construcción social mediada lingüísticamente. La Ciencia como sistema de conocimiento constituye al igual que la Filosofia, una manera de responder y describir la "realidad". Consiste fundamentalmente en una organización de experiencias reguladas convencionalmente, y que han sido verificadas con el mayor número de hechos que representan una relación más parsimoniosa, congruente y coherente de su objeto de estudio; esto es, conservando una semántica y una sintáctica que permitan una clara descripción de pertinencia con su objeto de estudio.

En un principio, el conocimiento del mundo se articulaba en una sola matriz compleja que aglutinaba información e interpretaciones respecto a todos los fenómenos de la naturaleza y la sociedad. La filosofia y la ciencia griegas constituyen el mejor ejemplo de estas visiones integradas del universo. Con el transcurso del tiempo por distintas condiciones sociales (es decir, por la progresiva organización social y de las relaciones de producción), se llegaron a diferenciar los sistemas de generación del conocimiento y de su aplicación social. Así, se originaron tres grandes núcleos de conocimiento: la Ciencia (y su vinculación 


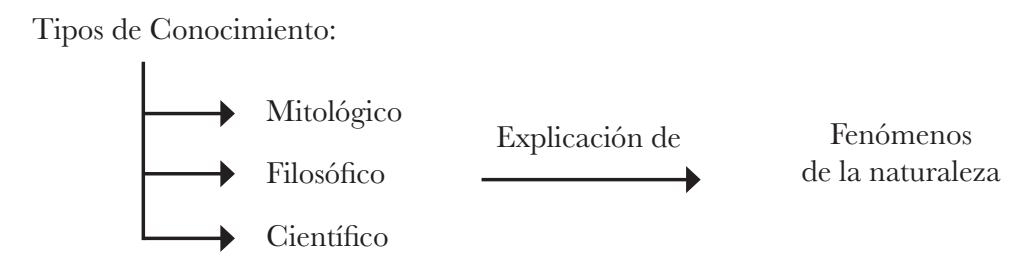

Figura 2. Presenta los diferentes tipos de conocimiento (recuperada de Tamayo, 2005, p. 14) y modificada por los autores.

eventual con la tecnología), la Mitología (vinculada a la religión) y la Filosofía (como un saber argumentativo y comprensivo), como se muestra en la Figura 2.

Pero, ¿qué relación guarda la Ciencia con otros modos de conocimiento? Para Johannes (1978), la respuesta se relaciona con la cultura. Citando al autor, éste nos plantea lo siguiente: "Todas estas formas de conocimiento están entrelazadas por un vínculo común, que reside en su objeto [...] Todas ellas quieren en el fondo dar una interpretación de la realidad, forjar una concepción del universo. Lo que las diferencia es el origen de esta concepción” (p. 8). Así entonces, estas formas de conocimiento se constituyeron a partir de la interpretación dada a los fenómenos estudiados, diferenciándose por los criterios de validación social de cada uno de ellos.

Se considera que la diferenciación de la Ciencia con otros modos de conocimiento, no es una cuestión de juicios de valor, sino un requerimiento formal. Esta ha de hacerse en los términos de la función social que desempeñan las distintas prácticas de conocimiento, mismas que son ordenadas de acuerdo con criterios objetivos (la pertinencia semántica y sintáctica de los conceptos utilizados), donde la objetividad viene dada por una convención, como acuerdos acerca de qué propiedades del objeto de conocimiento son contrastadas con los criterios de objetividad y validación en ciencia.

En el caso de las prácticas que se dan en el ámbito científico, autores como Carpio, Pacheco, Canales y Flores (2005), López (1994) y Padilla (2006) enfatizan que éstas son similares a las que ocurren con otras prácticas culturales, en donde la práctica científica es generada, ejercitada, aprendida y auspiciada por individuos concretos en circunstancias 
definidas por criterios de organización y valoración específicos. Por lo cual, dicha práctica no puede analizarse al margen del momento sociohistórico en el que se da, ya que los criterios de valoración y por lo tanto, de validación del conocimiento son distintos para cada época.

Por ejemplo, en la historia se observa como ciertas formas de conocimiento científico se han desarrollado de un modo más prolífero que en otros, en el período renacentista se facilitaba el desarrollo de disciplinas como la Biología y Medicina, contrario al período de la Edad Media (en la que cabe destacar la fuerte influencia de las concepciones metafísicas), siendo esta época un período de poca o casi nula actividad científica. Por lo tanto, en cualquier intento por analizar la práctica científica, se requiere considerar que el conocimiento científico está permeado por los criterios de validación del momento en que es (o fue) planteado. Un ejemplo de ello lo constituye Galileo Galilei al ser obligado a retractarse de su Teoría Heliocéntrica (Siglo XVII).

Padilla et al. (2009) en este mismo tenor comentan: "quienes desean incursionar en la actividad científica como profesión se sorprenden al escuchar que la ciencia es subjetiva en cuanto a que se trata de una actividad humana de naturaleza social. Pero que también es objetiva porque la obtención del conocimiento ocurre según un conjunto de criterios con los que es posible trascender lo aparente e inmediato de lo observado" (p. 6). En este sentido, las instituciones sociales y académicas (p.e. gremiales científicas) han creado los criterios de validación de cada uno de los modos de conocimiento actualmente conocidos, es decir, la actividad científica es creada y compartida convencionalmente mediante una serie de prácticas significativas.

Por su parte, Kantor (1990) destaca la influencia que la cultura ejerce sobre las teorías y la práctica científica a través del tiempo, señalando que la concepción del hombre acerca de los objetos, ha cambiado conforme la sociedad lo hace, de manera que si se retrocede en el tiempo, por ejemplo a la antigua Grecia, la época medieval, la edad media, o el renacimiento mismo, y se comparan con los conocimientos de la era contemporánea, es posible estimar cómo gran cantidad de teorías han sido modificadas o destituidas a través 
de la historia a partir de nuevas maneras de referir, relacionar e integrar los productos del conocimiento científico. Así, es necesario enfatizar, que la valoración e interpretación de los hechos, así como la percepción y descripción de los diferentes objetos de conocimiento, no pueden analizarse al margen de su momento sociohistórico, por ello, en ciencia el criterio de objetividad no tiene un sentido absoluto, más bien siempre constituye un proceso continuo de objetivización, y no un dato fijo y definitivo (Schaff, 1974).

Kantor (1980) enfatiza que la ciencia progresa fundamentalmente de dos formas: 1) mediante el descubrimiento de eventos desconocidos (a través de la investigación); y 2) mediante la revaloración de los eventos en base a criterios mejorados ${ }^{1}$. Esto deja a un lado la idea de que la ciencia sólo implica productos, como conocimiento científico (p.e. informes de nuevas patentes, artículos de divulgación científica, entre otros).

Esto es fundamental para concebir a la ciencia no solamente como producto, como algo estático y lineal, sino también como las prácticas de los investigadores cuando están haciendo ciencia y cómo estas prácticas son afectadas por aspectos económicos y sociales de todo tipo. Por ejemplo, el tipo de financiamiento y aspectos de socialización del saber científico, por mencionar algunos. Esto es esencial cuando hablamos de la enseñanzaaprendizaje de contenidos científicos, en donde deberán recuperarse tanto los resultados de la ciencia pero también sus procesos, y cómo estos se ven afectados por aspectos políticos, económicos y de organización de los miembros de un grupo de referencia que trabajan en algún proyecto de investigación.

Así, la actividad científica está relacionada con las demás actividades humanas, sólo que su tarea se diferencia por sus objetivos, la manera de proceder para cumplirlos y sus formas de validación convencional: observación sistemática, manipulación, comprobación y verificación de eventos así como sus relaciones.

$1 \quad$ Por ejemplo, la revolución de Copérnico consistió en el replanteamiento de los hechos conocidos a través de nuevas formas. La Revolución de Copérnico es el nombre con el que suele conocerse a la revolución científica que se produce en Europa Occidental, representada en la astronomía por el paso del tradicional sistema geocéntrico de Ptolemeo, al innovador sistema heliocéntrico de Copérnico. 
El segundo aspecto importante que se ha mitificado alrededor de la práctica científica (y que también ha impactado la forma de su enseñanza) es que se ha creído que las personas que se dedican a las cuestiones científicas tienen una serie de facultades o características especiales, por ejemplo, la de poseer una gran "inteligencia" o en muchos casos se llega hasta el absurdo de pensar en características físicas (p.e. barba, canas), tipificado así, físicamente al científico.

Se ha creído que el científico posee una serie de facultades específicas (p.e. capacidad intelectual de orden superior) que lo hacen un individuo especial. Autores como Carrillo (1983) disipan cualquier duda en este sentido, al mencionar como algunas versiones vigentes llegan al grado de caricaturizar al individuo que se dedica a las cuestiones científicas [...] "La personalidad física como sujeto de la acción científica no se atribuye aquí llanamente a ese espectro introvertido, venerable y barbado que se considera el científico, sencillamente porque no existe. En la actualidad es tal la multiplicidad de tareas relacionadas con la actividad científica que rara vez se podría hallar un ejemplo de científico puro. En efecto la academia, la administración, la diplomacia, la política, la colegiabilidad, la representación, la asesoría y la burocracia constituyen hoy escenarios que reclaman demasiadas horas hombre de ciencia" (p. 31).

López (1994) por su parte, expone que la Ciencia como parte de la cultura, implica una práctica compartida, y que la membresía a una cultura es lograda a través de un complejo aprendizaje de sus prácticas, la cual es adquirida mediante el contacto con "otros significativos". En otras palabras, una persona se convierte en físico/químico/biólogo/ matemático en la medida en que su hacer y decir se corresponde en términos de pertinencia con lo que hacen y dicen los físicos, químicos, biologos y matemáticos.

De esta manera, la Ciencia enfatizada en su dimensión social, se aprende en la medida que se comparten tareas y actividades con otros, contando con la supervisión de expertos. En palabras de Padilla et al. (2009) "El aprendizaje de la ciencia ocurre de la misma manera que el aprendizaje del lenguaje ordinario, ya que constituye un proceso por medio 
del cual la conducta de los individuos se asemeja progresivamente a la de otros miembros de la comunidad o de la sociedad" (p. 16).

La formación de noveles científicos deberá sustentarse en dos aspectos complementarios: a) en primer término, por la acumulación histórica elaborada por un grupo social particular (es decir, los productos); b) en segundo término, por el conjunto de las instituciones que regulan las relaciones recíprocas de los grupos sociales (esto es, los procesos). De esta manera, la Ciencia debe ser entendida como el resultado de las prácticas de los individuos que se dedican a las tareas científicas, y como un proceso continuo de contrastación y verificación de los enunciados formulados (p.e. teorías), es decir, como proceso y como resultado.

Sin embargo, en el estudio de la Ciencia se han realzado mucho más sus productos que sus procesos, dejando a un lado las actividades y el contexto que da origen a dichos productos (Padilla, 2006), de ahí que en muchas ocasiones se les caracterice como un cuerpo acabado de conocimientos acumulados. Esto, por supuesto, ha traído una serie de implicaciones para la enseñanza de la Ciencia, tema medular en este manuscrito, ya que ésta se enseña solamente como un producto (p.e. teorías, leyes e hipótesis) en donde el estudiante típicamente es expuesto a un discurso meramente oral, y no a estrategias relacionadas con el modelado del proceso de obtención de esos productos o las maneras en cómo obtener dicha evidencia. Al respecto Morales, Pacheco, Canales et al. (2010) comentan: "uno de los principales problemas o limitaciones de la enseñanza de la ciencia es que se centra en los productos de la ciencia, y la formación de los futuros científicos queda reducida a hacer uso de los productos de la ciencia, desconociéndose la manera en la que se produce ciencia, así como en una dificultad (o incapacidad) de los nuevos científicos para generar criterios y conocimiento nuevo" (p. 96).

En otros manuscritos se ha discutido (Irigoyen et al. 2007) que en la formación de noveles científicos, más que generar la acumulación de conocimientos o sustituir unos conceptos por otros, debería promover las prácticas pertinentes acordes a los diferentes juegos de lenguaje (identificación de hechos, elaboración de preguntas pertinentes, entre 
otros). En donde las prácticas de los profesores y aprendices sean reguladas por criterios disciplinares y que se signifiquen en función de las dimensiones del objeto de conocimiento bajo criterios de contrastación y verificación.

Una propuesta que permite entender tanto a los procesos como a los productos en el análisis de la práctica científica, es la planteada por Carrillo (1983), la cual da cobijo a los aspectos fundamentales en el análisis de la construcción y validación del conocimiento científico:

a) Factores internos: Están constituidos por una serie de replanteamientos formales acerca de la relación entre ciencia y el valor social "de verdad". Estos factores ponen especial atención en los aspectos que corresponden a las operaciones formales de la práctica científica (lógicas y de modelización matemática).

b) Factores externos: Están constituidos por el papel que desempeña la ciencia como institución convencional y, como ésta, es determinada por dichas instancias sociales (p.e. políticas, económicas, etc.).

Estos factores explicitan la consideración de los aspectos de producción del conocimiento, de validación, así como su socialización, tanto de los productos como de los procesos. En el intento de sistematizar y categorizar los elementos que conforman la estructura científica, en muchos casos se recuperan como definitorios elementos formales (p.e. productos) que resultan a veces insuficientes para una definición que dé cobertura al fenómeno científico como un todo.

Padilla (2006), llevó a cabo una revisión de cada uno de los niveles de análisis bajo los cuales se ha estudiado la Ciencia: 1) Análisis formales o lógicos (sustentándose en autores como Carnap, 1965; Nagel, 1968); 2) Análisis de los criterios lógicos previos a la investigación (Lakatos, 1983; Popper, 1975) y 3) Análisis de las circunstancias sociohistóricas (Bernal, 1975; Kuhn, 1977). Dentro de este último apartado se encuentran los estudios de la Ciencia que enfatizan por ejemplo: a) la historia y el desarrollo de las ideas, b) las circunstancias sociológicas y económicas de su origen y desarrollo y, c) las prácticas etnológicas de ejercicio y organización. 
La aproximación de la que parte el presente manuscrito consiste en un acercamiento al comportamiento científico desde una perspectiva de la práctica individual -Modelo de la Práctica Científica Individual-, la cual analiza el quehacer científico como variación individual del método bajo condicionantes lógicos, culturales y sociales (Ribes, 1993; Ribes et al. 1996; Padilla, 2006). Las implicaciones de este modelo para la enseñanza de la ciencia, radican en la posibilidad de analizar las condiciones idóneas en las que se aupicia la formación de noveles científicos.

Este enfoque analiza la práctica científica como un nivel de análisis complementario a los de la lógica, la historia, la sociología, entre otros. En donde el análisis de la Ciencia supone que la práctica es individual en la medida en que es una práctica idiosincrásica regulada por la comunidad científica a la que pertenece el estudiante o profesional, pero a la que cada individuo le impone una forma particular de decir-hacer.

El supuesto general de la propuesta es que un estudiante novel se convierte o se puede llegar a convertir en un practicante de la Ciencia en la medida en que aprende el conjunto de prácticas como decires (habilidades y competencias conceptuales) y haceres (habilidades y competencias operacionales y de medida), las cuales no consisten en la mera reiteración por parte del estudiante de las formas del saber, sino en la identificación de las máximas que regulan las condiciones sobre las cuales se aprende, la formulación de relaciones y el establecimiento de equivalencias funcionales entre el saber científico y su posible vinculación con un concepto o fenómeno científico. Así, el saber del estudiante puede ser analizado como: un decir, un hacer, un decir del hacer, un hacer del decir, un hacer del hacer o un decir del decir en un área de conocimiento particular.

Tradicionalmente el proceso de investigación científica se identificaba como un proceso enmarcado por una serie de pasos -fijos- que el investigador debía seguir para obtener el conocimiento científico. Autores como Diéguez (2005); Feyerabend (1975); Kuhn (1977); Lakatos (1983) han considerado a la Ciencia como proceso dinámico, que no admite la concepción de un método rígido o estático, puesto que sus teorías están en constante 
construcción (adhesión de nuevos conocimientos, rectificación-validación de teorías), cuyo desarrollo ha implicado con el paso del tiempo una diversidad de métodos "como modos particulares de hacer ciencia". Por su parte, Ribes et al. (1996) consideran que así como existen gran cantidad de individuos que practican la ciencia, de igual manera es posible encontrar infinidad de modos o métodos individuales efectivos de obtener conocimiento. Luego entonces, no sería factible la idea de un "método científico" como guía general que explicite al practicante de ciencia qué es lo que deber hacer, puesto que tornaría la práctica como un trabajo "mecanizado". Como se sabe, nada más lejos que esto.

Bajo estos supuestos es posible analizar y por lo tanto, formular una propuesta para la enseñanza de la práctica científica, a partir de la identificación de los elementos fundamentales que interactúan en la modulación del desempeño del profesional o investigador y los criterios convencionales a los que responde. El modelo fue propuesto inicialmente por Ribes (1993) y posteriormente modificado por Ribes et al. (1996). Ver Figura 3.

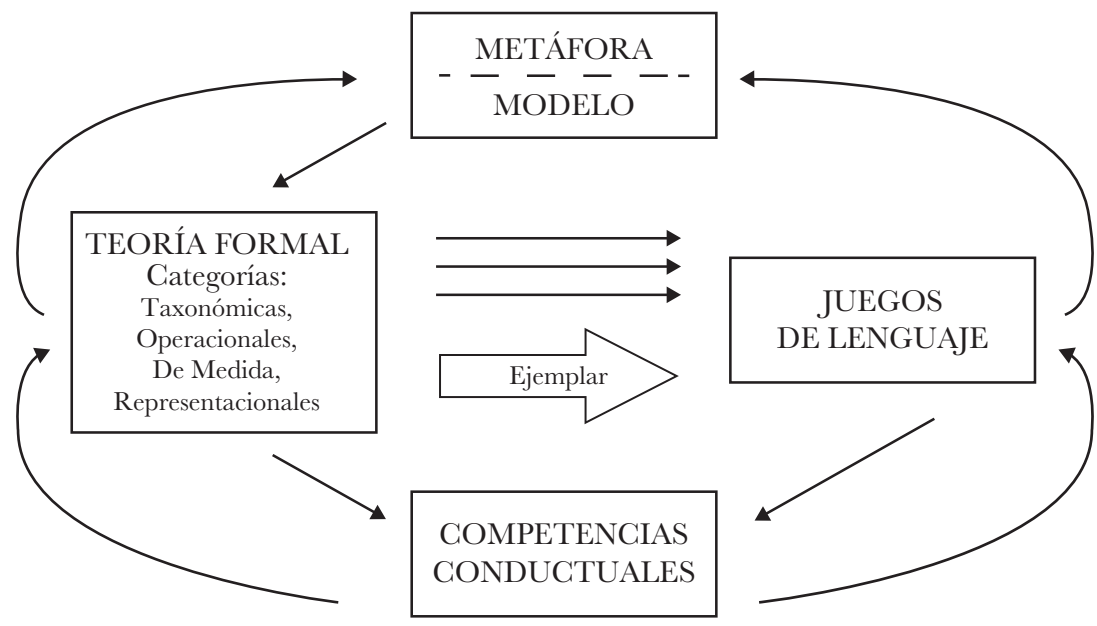

Figura 3. Presenta el Modelo de la Práctica Científica Individual (tomada de Padilla, 2006, p. 58). 


\section{Elementos que componen el Modelo de la Práctica Gientífica Individual}

El modelo de la práctica científica individual considera los siguientes aspectos fundamentales en interrelación: la metáfora-raíz, la teoría, los juegos del lenguaje, el ejemplar y las competencias conductuales. Estos serán descritos en las siguientes líneas.

a) La metáfora-raíz y el modelo. Consisten en los supuestos y creencias que amparan la actividad científica en cualquier nivel. Estas creencias, como maneras de pensar de un individuo, probabilizan un determinado comportamiento, y modulan la forma en que el científico entra en contacto con la teoría y sus categorías, así como la manera en que realiza una actividad en el contexto de la práctica científica (o juegos de lenguaje).

De esta manera, el objeto de estudio de una disciplina científica, tiene sus fundamentos en aspectos ontológicos y epistemológicos particulares ${ }^{2}$. La forma en que se caracteriza ontológicamente el objeto de una disciplina determina la manera en que se aborda el problema, la forma de conocer, el proceder metodológico y por lo tanto, los criterios instrumentales pertinentes. Ribes (2004) señala al respecto lo siguiente: "La formulación de un objeto de conocimiento específico reviste dos dimensiones de compromiso conceptual. El primer compromiso, que determina en gran medida la forma que asume el segundo, tiene que ver con la definición del objeto que se pretende conocer. El segundo compromiso se vincula con la selección de las propiedades - analizables- del objeto de estudio definido, a fin de estipular los criterios de conocimiento válidos y pertinentes" (p. 19).

Por su misma naturaleza, las creencias y los supuestos que sustentan la actividad científica no son necesariamente identificables para el propio científico, independientemente de su nivel de expertes (Padilla, 2006). Tener la posibilidad de analizar las creencias que sustentan la práctica científica, se considera relevante en la medida que éstas modulan de manera relevante la forma en que el científico entra en contacto con las categorías de una

2 Los aspectos ontológicos están relacionados con la definición del objeto de estudio que se pretende conocer y los epistemológicos con los criterios de validación de ese conocimiento. 
teoría y, por lo tanto, afectan la forma en que se practica dicha teoría en el contexto de los aspectos empíricos (Acuña et al. 2009).

Estas metáforas consisten en los supuestos y creencias que amparan la actividad científica (o profesional) en cualquier nivel. A continuación se describen tres ejemplos vinculados con la práctica docente que ilustran cómo las creencias tanto en relación a la ciencia como al aprendizaje, tienen un efecto modulador en la enseñanza de las ciencias.

Fernández-Nistal y Peña (2008) realizaron un estudio con profesores de primaria, con el propósito de analizar las concepciones sobre la forma del planeta Tierra y el sistema de referencia geométrico determinado por la gravedad. Los investigadores a partir de los patrones de respuesta de los profesores identificaron cuatro concepciones: a) el planeta Tierra tiene una forma indefinida; b) la Tierra es una esfera en cuyo interior viven las personas; c) la Tierra es esférica y las personas viven en su superficie según un sistema de referencia absoluto y d) concepción científica. Los resultados mostraron que sólo la mitad de los profesores presentó una concepción científica (encontrándose coincidencias con resultados de estudios realizados con niños). Las implicaciones educativas que señalan los resultados de este estudio apuntan al diseño y planificación de programas de formación de calidad y equidad, para que los maestros logren una alfabetización científica.

Asimismo, Soto (2009) llevó a cabo un estudio de caso para analizar las creencias religiosas como elemento relevante en las posturas que asumen los docentes con respecto a la teoría de la evolución biológica y su didáctica, así como formular propuestas educativas para la formación docente. A partir del análisis de las entrevistas se concluyó que las creencias religiosas tienen un fuerte arraigo en los participantes, y que éstas determinan las posturas que asumen los profesores con respecto a la teoría de la evolución biológica y, a su vez, cómo guían las prácticas educativas de los docentes.

Autores como Fernández-Nistal et al. (2011) realizan un análisis amplio acerca de las visiones "deformadas" de la ciencia transmitidas por la enseñanza, señalando que incluso a nivel universitario, apenas se presenta la ocasión a los estudiantes de familiarizarse con las 
estrategias características del trabajo científico. Como consecuencia de esto, las concepciones de los estudiantes, e incluso de los mismos profesores, acerca de la naturaleza de la ciencia no difieren de las visiones ingenuas adquiridas social o popularmente.

Las implicaciones educativas de estos estudios, apuntan hacia la necesidad de diseñar y planificar programas de formación de calidad y equidad para maestros en el área de la enseñanza de las ciencias. Las instituciones educativas deberán tomar las medidas más adecuadas para que todos los maestros de ciencia logren una alfabetización en esta área, que les permita ser profesionales de la educación informados, críticos y responsables, capaces de mediar los saberes científicos que enseñan en los diferentes niveles de formación.

b) La teoría es el universo de eventos o elementos con los que trabaja el científico (y de cómo estos elementos se relacionan entre sí), sea explícita o implícitamente. La función que cumple la teoría es delimitar los elementos, las herramientas y los criterios de interacción pertinentes con los fenómenos de estudio. Por ello, todos los sucesos estudiados por un científico son hechos teóricos, ya que el científico abstrae analíticamente las propiedades de los eventos que son de interés, para crear hechos que sólo son observables y tienen sentido desde una teoría particular.

Para Ribes et al. (2006) la teoría científica delimita los elementos, las herramientas y los criterios de interacción con el objeto de estudio, es decir, la observación e investigación científica consisten en un proceso guiado por la teoría. Para los autores, la teoría y la práctica tienen una relación inseparable, ya que la teoría constituye un sistema categorial para seleccionar, relacionar y presentar hechos de la "realidad" bajo estudio. La práctica (que para los autores está determinada en sus modalidades decir-hacer como el ejemplar y los juegos de lenguaje), es el conjunto de actividades que tienen que ver con la formulación y planteamiento de "problemas" pertinentes a una teoría y el diseño de procedimientos y acciones que lleven a su manejo eficiente.

Padilla (2008) realizó un estudio para probar si el tipo de competencias que se ejercita es determinado por la teoría a la que se es expuesto. En el estudio participaron 
cuatro grupos de estudiantes preuniversitarios realizando actividades características del quehacer científico. Cada grupo se expuso a los postulados teóricos y metodológicos de una teoría psicológica distinta, y posteriormente realizaron un experimento completo. Los datos mostraron que cada grupo ejercitó competencias diferentes, aparentemente determinadas por las características de la teoría a la que fueron expuestos, lo cual permitió evaluar la dominancia de cierto tipo de categorías en el ejercicio y la aplicación de juegos de lenguaje diferenciados.

La Ciencia -en general- tiene el mismo conjunto de acontecimientos del continuo espacio-tiempo como dominio. Sin embargo, cada disciplina científica segmenta dicho continuo para motivos analíticos, es decir, la segmentación es una convención arbitraria para fines de estudio. Al respecto, Carrillo (1983) señala que: "Para una disciplina particular el límite de su dominio deberá estar expresado en su definición. El límite es el criterio mediante el cual se pueden diferenciar los elementos que pertenecen al dominio. Dicho límite se redefine sucesivamente conforme los alcances instrumentales de una disciplina son mayores y más precisos. No es que la medición otorgue existencia al fenómeno: éste ya se encontraba ahí. Es simplemente que pasa a ser un fenómeno conocido: se define dentro del sistema" (p. 124).

c) Los juegos de lenguaje, constituyen los criterios necesarios para llevar a cabo las actividades relacionadas con el comportamiento científico, como prácticas con sentido. Estos juegos de lenguaje no constituyen en sí mismos actividades y, por consiguiente, no pueden identificarse con actividades específicas de la práctica científica. Más bien un mismo conjunto de actividades puede ubicarse en uno u otro juego de lenguaje dependiendo de las prácticas comprendidas en el proceso científico, es decir, es posible examinar las prácticas en relación a la satisfacción de distintos propósitos o criterios como juegos de lenguaje (identificación de hechos, planteamiento de preguntas pertinentes, elaborar sistemas de registro a partir de la observación, diseño de instrumentos para generar evidencias, cuantificación y análisis de resultados). 
Para López (1994) la ciencia, el mito, la religión y las prácticas normativas se adquieren y reproducen lingüísticamente. El lenguaje como relaciones lingüísticas arbitrarias posibilita desligarse de las propiedades físico-químicas (forma, tamaño, color, duración) de los eventos presentes en la situación, así como hacer contacto con objetos o eventos no presentes a través de sus representaciones convencionales. De esta manera, el lenguaje como práctica compartida, media y normaliza el contacto de diferentes sujetos a las dimensiones de los objetos o a los objetos mismos.

El lenguaje permite referir, regular y transformar la realidad. En el caso de los procesos educativos, y específicamente, el de la enseñanza-aprendizaje de contenidos científicos, las interacciones no necesariamente se llevan a cabo ante los objetos "naturales", sino ante sus representaciones convencionales como juegos de lenguaje.

Así, en el contexto de la formación científica universitaria, lo que se enseña son los juegos de lenguaje ${ }^{3}$ como prácticas reguladas por criterios disciplinares en lo conceptual, metodológico, instrumental y de medida; el estudiante por su parte, establece contacto con estos juegos de lenguaje a través de las diferentes modalidades del decir y el hacer (observar, escuchar, leer, señalar, hablar y escribir).

Ribes (1993) propone que las prácticas presentes en toda actividad científica se constituyen en los siguientes juegos de lenguaje, a saber:

a) El juego de la identificación de los "hechos", en el cual se especifican abstracciones empíricas que delimitan los fenómenos y sus componentes, y se determina el ámbito empírico en que pueden ocurrir dichos "hechos";

b) El juego de las preguntas pertinentes, en el cual se relacionan unos hechos con otros, se especifican cuantitativa y cualitativamente sus propiedades, y se proponen categorías que hacen "pertinentes" a los "hechos" en distinto grado;

3 La noción de juego de lenguaje propuesta por Wittgenstein (1988), plantea que el lenguaje tiene sentido para aquellos que comparten ciertas convenciones sociales, lo cual implica que el lenguaje es una forma de vida, una forma de entrar en contacto con la "realidad". 
c) El juego de la aparatología, en el cual se diseñan las condiciones en que se producen y se registran los "hechos", y como los registros se transforman en datos; d) El juego de la observación, en el cual se determinan los criterios para la identificación y selección de hechos del universo empírico para considerarlos evidencia;

e) El juego de la representación, en el cual se establece la relación hecho-problema y en que medida ese "hecho" es significativo y porqué;

f) El juego de la inferencia y las conclusiones, en el cual se reformulan los problemas con base en la evidencia obtenida de la observación de hechos.

Esto se vuelve fundamental no sólo para el análisis de la práctica científica sino para la enseñanza de ésta. La manera en cómo deberán enseñarse las prácticas que constituyen los juegos del lenguaje, es disponiendo las circunstancias que faciliten el ejercicio de éstas, a partir del modelamiento (ejemplificación e ilustración), moldeamiento, retroalimentación y evaluación de los desempeños pertinentes al dominio disciplinar y tecnológico (Carpio e Irigoyen, 2005; Irigoyen et al. 2007). Por lo que el docente de una disciplina científica se convierte en un auspiciador de desempeños variados y pertinentes al dominio que enseña.

d) El ejemplar. El ejemplar consiste en el conjunto de prácticas que tienen que ver con la formulación y planteamiento de "problemas" pertinentes a una teoría y el diseño de procedimientos y acciones que lleven a su formulación. En otras palabras, el ejemplar está relacionado con las maneras en cómo se implementan estudios de investigación para la observación y registro de datos, y las maneras que posibilitan el establecimiento de evidencia empírica en un ámbito disciplinar particular.

e) Los procesos y competencias conductuales consisten en las formas de organización funcional de las habilidades sobre criterios de efectividad específicos. Una competencia conductual puede identificarse a partir de las habilidades involucradas y el criterio de logro especificado, el cual puede estar determinado por las propiedades físico-químicas o convencionales de los objetos, eventos o circunstancias con las que interactúa, y por las demandas sociales (en este 
caso determinadas por la disciplina y el colectivo disciplinar) que definen la funcionalidad de una determinada forma de decir-hacer como ajuste a una situación.

Recapitulando, el MPCI supone que la Ciencia, como una práctica social, es un proceso variado y flexible. Por ello, cada disciplina (y aún dentro de un mismo dominio) se expresan formas diferenciadas o estilos de decir-hacer, en función de los criterios disciplinares. Lo que aprende entonces el estudiante en formación de un ámbito disciplinar es a observar, escuchar, leer, señalar, hablar y escribir con respecto a una serie de eventos y/o situaciones construidas a partir de un sistema de referencia (la física, la química, la biología, la psicología, la sociología) como juegos de lenguaje.

En la Tabla 1 se describen los juegos de lenguaje de la práctica científica, las competencias vinculadas a ésta, la modalidad lingüística que podría estar involucrada idealmente y las situaciones en las que estos desempeños deberían auspiciarse.

Esto tiene implicaciones para la pedagogía de la Ciencia, en donde para poder enseñarla, sería necesario identificar los criterios de logro o ajuste a los cuales deberá adecuarse el estudiante en formación pero al mismo tiempo cuales son las estrategias instruccionales que facilitan cierto tipo de competencias. Padilla (2006) propone al respecto lo siguiente: "El diseño de una metodología de la enseñanza de la ciencia como actividad práctica podría hacer más eficiente el proceso de enseñanza-aprendizaje de las destrezas y competencias científicas. Se supone que dicho objetivo sería más fácil de alcanzar si se identifican, de la forma más detallada posible, los criterios de ejecución a exigir a un aprendiz científico” (p. 200).

El docente a partir de los objetos referentes (teorías, modelos, procedimientos, criterios de medida) media y auspicia los desempeños en relación con las diferentes modalidades del "decir" y "hacer" (hablar, escribir, observar, escuchar y leer) que el ámbito funcional de desempeño prescribe. Así, enseñar se traduce en modelar, ilustrar, ejemplificar, moldear, retroalimentar y evaluar los diferentes desempeños efectivos en cada uno de los juegos antes mencionados, los cuales no deben confundirse con la repetición o reiteración de éstos, sino como prácticas efectivas, variadas y novedosas (Carpio e Irigoyen, 2005). 


\begin{tabular}{|c|c|c|c|}
\hline $\begin{array}{l}\text { Juegos de lenguaje de } \\
\text { la práctica científica }\end{array}$ & Competencias & $\begin{array}{l}\text { Modalidad } \\
\text { lingüística } \\
\text { involucrada }\end{array}$ & Situaciones \\
\hline $\begin{array}{l}\text { Identificación } \\
\text { de los hechos }\end{array}$ & \multirow{7}{*}{$\begin{array}{c}\text { Planeación de estudios } \\
\text { Implementación } \\
\text { de estudios } \\
\text { Análisis de datos } \\
\text { Elaboración de reportes } \\
\text { experimentales } \\
\text { Exposición de reportes } \\
\text { experimentales } \\
\text { Lectura de materiales } \\
\text { técnicos } \\
\text { Entrenamiento de otros } \\
\text { (docencia) } \\
\text { Publicación de artículos, y } \\
\text { divulgación }\end{array}$} & \multirow{4}{*}{$\begin{array}{l}\text { Observar-señalar } \\
\text { Observar-escribir } \\
\text { Observar-hablar } \\
\text { Escuchar-señalar } \\
\text { Escuchar-hablar }\end{array}$} & \multirow{7}{*}{$\begin{array}{l}\text { Aula, taller, } \\
\text { laboratorio }\end{array}$} \\
\hline Preguntas pertinentes & & & \\
\hline Aparatología & & & \\
\hline Observación & & & \\
\hline & & Leer-señalar & \\
\hline Representación & & Leer-escribir & \\
\hline $\begin{array}{c}\text { Inferencias } \\
\text { y conclusiones }\end{array}$ & & Leer-hablar & \\
\hline
\end{tabular}

Tabla 1. Representa los juegos de lenguaje involucrados en la práctica científica, así como el tipo de competencias vinculadas (tomado de Padilla, 2006). A manera de propuesta se sugieren las modalidades lingüísticas que podrían estar involucradas y las situaciones en las que podrian tener lugar dichos juegos de lenguaje. 
En relación a las formas en que se puede enseñar-aprender un juego de lenguaje (aspectos conceptuales, instrumentales y de medida de una disciplina o profesión), Ribes y Sánchez (1994) plantean cuatro formas:

a) prescripción o dogma (como un saber por aceptación que se fundamenta en que las cosas sólo pueden ser lo que su nombre indica),

b) entrenamiento directo (como un saber directo y funcional que adquiere significado en función de lo que se hace en el contexto en donde se enseña),

c) referencia (como un saber referido mediante la demostración y/o el discurso, y que se fundamenta en el hecho de que las cosas son lo que otros dicen de ellas), y

d) fe (como creencia de que las cosas son en función de lo que se haga con ellas, sin conocer las circunstancias de la eficacia del comportamiento).

El aprendizaje de los saberes de un área de conocimiento se establece interactuando con los objetos, eventos o situaciones referentes (o debiera establecerse), tanto en el decir como en el hacer. Se considera que es necesario enfatizar las implicaciones que tiene una u otra forma de enseñanza-aprendizaje. Por ejemplo, si se piensa en la enseñanza de contenidos científicos por referencia, por ejemplo, probablemente se tendría a un estudiante que solamente puede repetir conceptos relevantes de una teoría pero sin significación funcional, como un intercambio meramente retórico altamente discursivo y referido a situaciones, autores y contenidos en una modalidad puramente anecdótica. En otras palabras, el concepto de Ciencia sólo tiene sentido con respecto a la referencia con la que se aprendió y es aplicable a condiciones situacionales explicitadas por la misma referencia.

Es de hacer notar, que las interacciones de los estudiantes se establecen fundamentalmente en un área de conocimiento como aquellas que involucran dimensiones no aparentes, en donde los referentes de los cuales se habla o se hace, se significan en función de las teorías, modelos, procedimientos y técnicas, por lo tanto, se considera no debieran de enseñarse nada más como una serie de nominativos sin un referente conceptual y procedimental coherente. 
Es importante enfatizar que las modalidades de mediación del profesor con respecto a los materiales científicos, resultan sumamente relevantes, ya que existe evidencia experimental que demuestra que el tipo de interacciones que los profesores promueven en los alumnos, tienen efectos en el desempeño de éstos; ya que en muchos casos los estudiantes terminan comportándose como lectores que sólo reproducen el grafo, escuchas y repetidores de información descuidándose las actividades experimentales y analíticas que permiten a los alumnos tener una relación más cercana con los objetos de conocimiento (Irigoyen et al. 2004; Mares, Guevara, Rueda, Rivas y Rocha, 2004).

En este sentido, un individuo se comporta como científico cuando realiza las mismas prácticas (como juegos de lenguaje: identificar o considerar hechos, formular preguntas pertinentes, observar y seleccionar hechos, representar relaciones observadas y formular inferencias), que son consideradas como científicas por el grupo de referencia de esa disciplina particular en la que está inmerso el practicante (Padilla, 2006). La única forma de diferenciar entre un individuo que hace ciencia y el que no la hace, es analizando los criterios a los cuales se ajusta el desempeño de ese individuo.

Por ello, no es posible soslayar la relevancia del modelo teórico seleccionado por el profesor de ciencia (enseñanza por dogma, entrenamiento directo, por referencia, etc.), ya que tiene implicaciones para las formas de proceder en el aula. En la siguiente sección se ilustra detenidamente esta implicación. 


\section{Aproximaciones al estudio dela enseñanza-aprendizaje de contenidos científicos. Implicaciones psico-pedagógicas.}

Como respuesta a la problemática dentro del ámbito de la enseñanza de la ciencia, en las últimas dos décadas se han venido trabajando una serie de líneas de investigación, particularmente desde la psicología cognitiva y constructivista, a partir de las cuales se ha llevado a cabo investigación educativa en la enseñanza de las ciencias relacionada con:

- El análisis de las prácticas docentes y lo que se ha denominado el conocimiento pedagógico de los profesores (Shulman, 1986),

- el de las representaciones sobre la naturaleza de la ciencia (Flores, 2004; Flores, Gallegos y Reyes, 2007),

- el del uso de la historia de la enseñanza (Campanario, 2003; Campanario y Moya, 1999),

- el de las concepciones de ciencia de los profesores, así como su formación (Alvarado y Flores, 2001; Alvarado y Flores, 2010) y,

- el de los procesos cognoscitivos básicos como el cambio conceptual y representacional (Pozo y Flores, 2007).

Estos estudios tienen sus fundamentos en diferentes presupuestos teóricos, y por lo tanto, han derivado como resultado diferentes aproximaciones metodológicas que buscan dar solución a ésta problemática. De hecho todas estas posiciones difieren, fundamentalmente, en la concepción que sus propuestas han formulado alrededor del proceso de construcción del conocimiento, y en qué consiste el proceso de aprendizaje.

Por más de tres décadas se ha tratado de conocer el problema y construir un marco de referencia educativo que permita establecer propuestas para derivar estrategias didácticas que incidan en que el alumno aprenda ciencia (Gallegos y Flores, 2008). Sin embargo, aun no se ha evidenciado desde estas aproximaciones las variables que hacen posible una formación 
en el ámbito científico pertinente al momento curricular y social. En este sentido, Alvarado y Flores (2001) enfatizan que la investigación en el área de la enseñanza de la ciencia en México, no ha logrado un estado que le permita influir en la práctica docente y mucho menos en el desarrollo de políticas educativas tendientes a mejorarla.

Por su parte, Flores (2000) señala la importancia de la investigación en el área de la enseñanza de las ciencias. El autor presenta una reseña general de las líneas de investigación que se desarrollan a nivel internacional y la problemática que de manera particular se presenta en México. Haciendo énfasis en la importancia de la investigación desde la perspectiva constructivista y la forma en que la ausencia de desarrollo de esta línea de trabajo en México repercute de manera negativa en la formación de los estudiantes y profesores de ciencias. Asimismo, hace notar las raíces epistemológicas del constructivismo como aspecto subyacente a las perspectivas psicológicas de este enfoque. Entre los principales temas que discute se encuentran las ideas previas, el cambio conceptual y las implicaciones heurísticas de la historia de la ciencia.

Pozo y Rodrigo (2001) y Pozo (2003) describen a la luz de estos supuestos, que en una época la enseñanza de la ciencia consideró que el aprendizaje de ciencias era determinado fundamentalmente por las concepciones que los estudiantes adquieren al margen de la instrucción, y que la tarea de la enseñanza era encontrar los modos para que esas concepciones cambiaran.

Como lo refieren Gallegos y Flores (2003, 2008), gran parte de la investigación se dirigió a indagar las características de las concepciones incorrectas y a evaluar procedimientos que lograran erradicarlas de los estudiantes. Estas investigaciones mostraron que los estudiantes, aún los universitarios, respondían ante problemas científicos con nociones similares a las intuitivas y qué, independientemente de su escolaridad, resultaban ser antagónicas a las nociones científicas. Así, estos trabajos pusieron de manifiesto que los profesores de ciencias mantenían una "creencia" sobre los conocimientos de sus estudiantes acerca de una fenomenología que difería de las "creencias" de sus estudiantes sobre el mismo fenómeno, lo cual 
implicaba que el proceso de aprendizaje no se alcanzaba tal y como ellos, lo habían creído.

Adicionalmente, los autores enfatizan que los estudios generalmente reportan que las concepciones incorrectas son resistentes a los diferentes métodos utilizados durante la enseñanza. De hecho, hoy en día la mayoría de los investigadores del área aceptan que las concepciones incorrectas conforman teorías implícitas que desempeñan una función cotidianamente antes y después de la instrucción. Por lo cual, han enfocado el problema del aprendizaje con la transformación de las ideas previas de los estudiantes.

Algunas teorías parten del supuesto de que los estudiantes tienen estructuras de conocimiento estables, en forma de modelos mentales (Gilbert y Boutler, 1998) o bien, que tienen una teoría marco que les permite comprender el mundo (Vosniadou, 2003). Otros autores conciben el conocimiento de los estudiantes como "recursos cognitivos" (Hammer, 2004), o bien como categorías ontológicas donde las concepciones de los alumnos requieren pasar de una a otra (Chi, 1992).

De acuerdo con estos planteamientos, las propuestas teóricas e instruccionales actuales, más que dirigirse al análisis del contenido de las concepciones o su corrección respecto de los conceptos científicos, se dirigen a: 1) estudiar las diferentes formas de construir representaciones explícitas o modelos de las situaciones y contextos a partir de la información proporcionada por las teorías implícitas y 2) indagar cómo es que las representaciones organizan múltiples estructuras más consistentes y coherentes en los estudiantes de ciencias (Alvarado y Flores, 2001; López, Flores y Gallegos, 2000; Postigo y López-Manjón, 2012). Esto señala que dependiendo de cómo se conciba el proceso de conocimiento del estudiante, tiene un impacto fundamental en la manera en cómo se aborde la enseñanza de la ciencia.

Se considera que las aportaciones desde estas perspectivas han sido dominantes en el estudio de la enseñanza de la ciencia. Sin embargo, en la mayoría de los casos adolecen de la derivación de aspectos instrumentales que posibiliten la generación de desempeños inteligentes (como decires y haceres) durante el proceso de enseñanza-aprendizaje, y el análisis de las condiciones que auspician la transferencia de desempeños posteriores al 
momento de enseñanza. Las propuestas derivadas de los resultados de investigaciones no han logrado incidir en la mejora de los indicadores de desempeño de los profesores y de los estudiantes en condiciones de enseñanza de la ciencia (Alvarado y Flores, 2001), así como tampoco una formación docente que propicie la aplicación de nuevas estrategias, o más efectivas para que los estudiantes entren en contacto con los referentes de la disciplina que aprenden, en donde estos referentes tienen un sentido funcional como un decir-hacer coherente.

Desde el punto de vista del presente manuscrito, una desventaja de algunas de estas propuestas teóricas en el abordaje de la enseñanza de la ciencia es que ha prevalecido la estrategia de enseñanza verbal de contenidos, como el principal recurso didáctico, y no las formas en donde ese saber tiene significado como práctica con sentido (en lo conceptual, instrumental o actitudinal). Otro aspecto importante, es que se ha recuperado para análisis solamente la variable "conocimiento previo" o "lo que el alumno ya sabe acerca de la ciencia" -p.e. representaciones de la ciencia- y no todas y cada una las variables que confluyen en el aprendizaje de la ciencia (p.e. estrategia instruccional del profesor, modalidad del objeto referente presentado en el episodio de interacción didáctica).

Se considera que sustentar el análisis del proceso de enseñanza-aprendizaje de contenidos científicos bajo la lógica del MPCI, lleva de la mano a una serie de implicaciones importantes. La primera de ellas se vincula con los alcances teóricos posibilitados por sus fundamentos ontológicos y epistemológicos de la propuesta de la que se parte, los cuales en muchas ocasiones no son explícitos (o identificables) para el científico o profesional.

La forma en que se caracteriza ontológicamente el objeto de una disciplina permea la manera en que se aborda el problema del método de conocimiento, y por lo tanto, la aplicación -en términos de solución de problemas- del mismo. Como ejemplo pensemos en dos planteamientos ontológicos distintos en cuanto a la enseñanza y el aprendizaje de la ciencia. Un profesor que concibe que el aprendizaje se da entre una entidad -mente- y el medio que le rodea, en donde las relaciones con el medio se dan a través de esa mente como 
constructo de representación. Este modelo ontológico que sustentaría la práctica de este profesor, concibe al estudiante como un receptor de las ideas y del conocimiento del profesor, el aprendizaje entonces es evaluado en términos del grado de adecuación de lo dicho por el estudiante con respecto a lo que dijo el profesor.

Si se continúa con el ejemplo, pensemos en un segundo profesor que define el aprendizaje como los cambios funcionales en el decir-hacer del estudiante a partir de las formas de interacción mediadas por el profesor en cuanto al decir-hacer en relación a cierta área de conocimiento. Así, el aprendizaje es evaluado en términos no solamente del decir sino del hacer. Es posible entonces pedirle que escriba reproduciendo un texto o que formule nuevas relaciones, también es posible requerirle que genere un modelo representativo para ejemplificarlo a sus compañeros, es decir, el decir y el hacer aquí se expresan como dos modalidades del saber.

De esta manera, cada uno de estos profesores planteará hechos de distinta naturaleza, así como los métodos, criterios de evidencia y de explicación de lo que ocurre en el aula, y los criterios de evaluación implementados serán muy diferentes.

Bajo la lógica del MPCI cada metáfora-raíz determinará el tipo de eventos a analizar en el ámbito educativo y por lo tanto, las maneras en cómo se implementará el proceso de enseñanza-aprendizaje así como, los criterios de evaluación explicitados. Recuperando el ejemplo de los dos tipos de profesores anteriormente ilustrados, se tendrían como hechos para el primero, la formación de esquemas o representaciones mentales del individuo, en donde las relaciones hipotéticas estarían correlacionadas con las operaciones que puede realizar un sujeto, las cuales son atribuidas a su desarrollo cognoscitivo - mental-, los datos se relacionarían con la ocurrencia/no ocurrencia de cierto tipo de interacciones de tipo discursivo para poder caracterizar el nivel de aprendizaje en el que se encuentra el individuo. En el caso del segundo ejemplo, es posible analizar los desempeños del estudiante ante ciertos objetos referentes como formas de decir-hacer, y el cambio tanto morfológico como funcional de dichos desempeños en los distintos momentos de formación. 
El trabajo expuesto por Hernández (2004) permite ilustrar lo señalado anteriormente. $\mathrm{El}$ autor presenta un análisis exhaustivo de los principales paradigmas que confluyen en la psicología de la educación, y como cada paradigma plantea un discurso teórico-práctico, así como epistémico-metodológico, enfatizando cuáles son los alcances y limitaciones de cada una de ellos en su aproximación al contexto educativo.

Hernández (2004) identifica como principales paradigmas en la educación: conductismo, humanismo, cognoscitivismo, constructivismo psicogenético y el constructivismo sociocultural. A manera de ejemplo en la Tabla 2 se ilustran tres perspectivas teóricas representativas en referencia a los procesos educativos, tanto de sus actores como de sus procesos.

Cada uno de estos paradigmas plantea sus propios supuestos teóricos, fundamentos epistemológicos, criterios metodológicos y aplicaciones sobre fenómenos educativos. Un comentario con respecto a las aproximaciones cognoscitiva y sociocultural al análisis de los procesos educativos, es que se fundamentan en una falsa dicotomía entre conocimiento y desempeño, presuponiendo que cuando se aprende "algo", esto se realiza mediante un acto de conocimiento, el cual tiene lugar como un proceso interno de representación de lo que se aprende.

Con base en esto, se continúa manteniendo el supuesto de que el intercambio se da en un sentido unidireccional - del individuo que enseña al individuo que aprende o, del individuo que aprende con relación a los materiales de estudio-, y por lo tanto, se sigue sustentando la creencia de factores únicos que actúan como entidades causales del proceso de enseñanza-aprendizaje (Irigoyen et al. 2007). 


\begin{tabular}{|c|c|c|c|}
\hline Actores & Cognoscitiva & Sociocultural & Conductual \\
\hline Alumno & $\begin{array}{l}\text { Sujeto que construye } \\
\text { su andamiaje concep- } \\
\text { tual, asimilado a su } \\
\text { estructura cognoscitiva } \\
\text { para generar aprendi- } \\
\text { zaje estratégico. }\end{array}$ & $\begin{array}{l}\text { Agente (protagonis- } \\
\text { ta) que efectúa una } \\
\text { reconstrucción de } \\
\text { saberes que le per- } \\
\text { mitan socializarse. }\end{array}$ & $\begin{array}{l}\text { Participante que establece contacto } \\
\text { interactivo con los objetos referen- } \\
\text { tes mediados por el discurso del } \\
\text { docente, un texto o un material } \\
\text { multimedia (a través de los dife- } \\
\text { rentes modos lingüísticos: señalar/ } \\
\text { gesticular-observar, hablar-escuchar, } \\
\text { escribir-leer). }\end{array}$ \\
\hline Docente & $\begin{array}{l}\text { Sujeto organizador } \\
\text { de la información que } \\
\text { funge como promotor } \\
\text { de habilidades de pen- } \\
\text { samiento y estrategias } \\
\text { para un aprendizaje } \\
\text { significativo. }\end{array}$ & $\begin{array}{l}\text { Agente cultural de } \\
\text { mediación entre el } \\
\text { saber y los procesos } \\
\text { de apropiación del } \\
\text { alumno. }\end{array}$ & $\begin{array}{l}\text { Participante que media la interac- } \\
\text { ción entre los juegos de lengua- } \\
\text { je-aprendiz; modelando, ilustrando, } \\
\text { ejemplificando, realimentando y } \\
\text { evaluando los desempeños a partir } \\
\text { de modalidades de respuesta, niveles } \\
\text { funcionales y tipos de tareas. }\end{array}$ \\
\hline \multicolumn{4}{|l|}{ Procesos } \\
\hline Aprendizaje & $\begin{array}{l}\text { Inducción de compe- } \\
\text { tencias y/o pericias } \\
\text { para lograr un conoci- } \\
\text { miento significativo y } \\
\text { estratégico. }\end{array}$ & $\begin{array}{l}\text { Transmisión de } \\
\text { saberes culturales } \\
\text { mediante interac- } \\
\text { ción en la zona de } \\
\text { desarrollo próximo. }\end{array}$ & $\begin{array}{l}\text { Proceso que consiste en el ajuste } \\
\text { funcional del decir y hacer, en } \\
\text { relación con las prácticas las cuales } \\
\text { varían dependiendo de criterios } \\
\text { (¿qué?), situaciones (¿dónde?) y des- } \\
\text { empeños (¿cómo?, ¿para qué?). } \\
\end{array}$ \\
\hline Enseñanza & $\begin{array}{l}\text { Proceso de estructura- } \\
\text { ción de conocimiento } \\
\text { que permite la cons- } \\
\text { trucción significativa } \\
\text { de representaciones y } \\
\text { significados. }\end{array}$ & $\begin{array}{l}\text { Proceso constructi- } \\
\text { vo de la apropiación } \\
\text { de representaciones } \\
\text { convencionalmente } \\
\text { relevantes. }\end{array}$ & $\begin{array}{l}\text { Establecimiento de repertorios vin- } \\
\text { culados a los juegos de lenguaje de } \\
\text { cierto ámbito disciplinar, resultando } \\
\text { así ajustes de comportamiento efec- } \\
\text { tivo ante condiciones y demandas } \\
\text { específicas. }\end{array}$ \\
\hline
\end{tabular}

Tabla 2. Presenta la descripción de actores y procesos de la enseñanza-aprendizaje desde diferentes aproximaciones conceptuales. 


\section{Propuesta para el análisis del proceso enseñanza-aprendizaje: Interacciones didácticas}

Una aproximación analítica al estudio de las interacciones en el proceso de enseñanzaaprendizaje es la sustentada por Carpio e Irigoyen (2005); Irigoyen (2006); Irigoyen y Jiménez (2004); Irigoyen et al. (2007) que sugiere la noción de interacción didáctica como el segmento analítico para las interacciones educativas (episodios instruccionales), noción que se define como el intercambio recíproco entre sujetos (docente y estudiante) y objetos o situaciones referentes (materiales de estudio) en condiciones definidas por el ámbito de desempeño (disciplina o profesión). En la Figura 4 se presenta dicho segmento analítico.

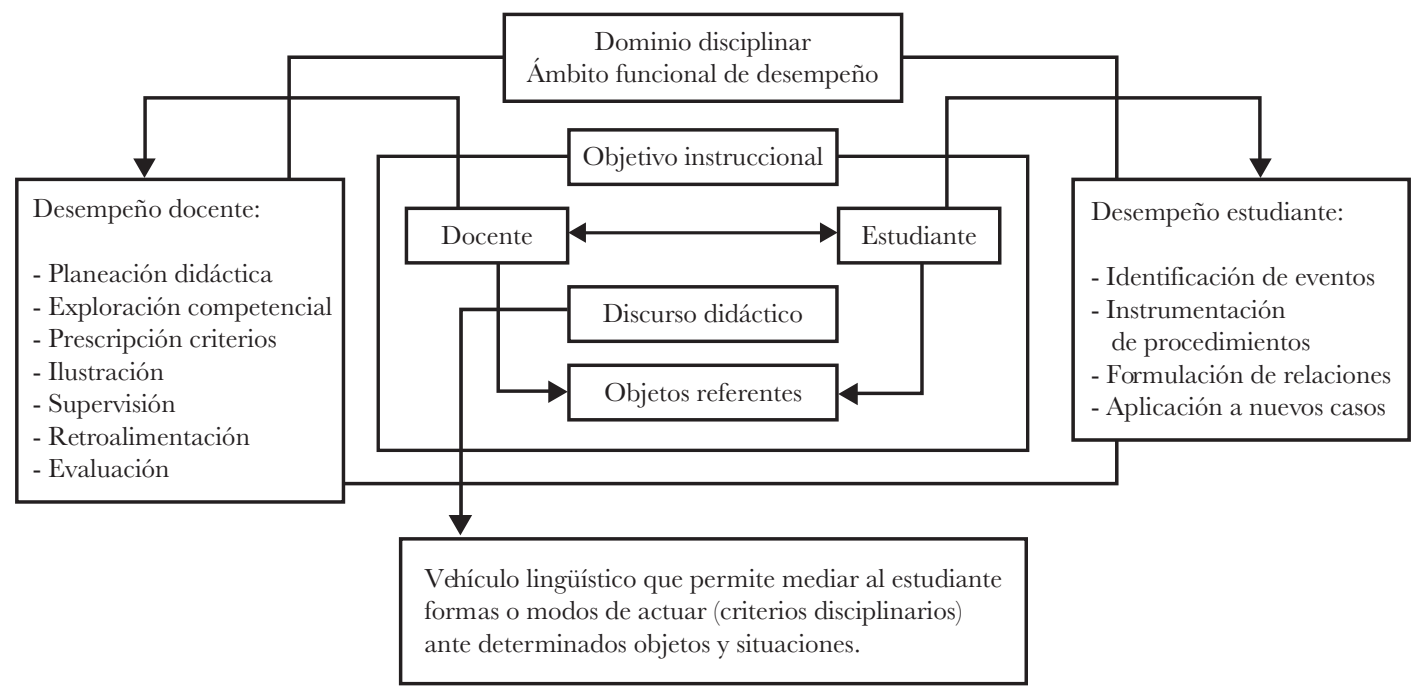

Figura 4. Representa los factores que configuran una interacción didáctica (tomado de Irigoyen, Acuña y fiménez, 2011, p. 85). 
El concepto de interacción didáctica enfatiza de igual manera a los factores participantes en la interacción, es decir, todos los factores son sincrónicamente necesarios en la configuración del episodio de interacción. La pertinencia de tomar como agente determinante a uno de los factores (docente, aprendiz, contexto, materiales) se ha cuestionado por autores como Carretero (2000) en el contexto de la enseñanza-aprendizaje de las ciencias, así como la discusión respecto a la participación del pensamiento formal como requisito para comprender el lenguaje científico.

Así mismo, no es posible hablar de una relación entre sujetos como algo independiente de los contenidos de conocimiento, ya que éstos cobran sentido como práctica social (como un hacer en contexto). Al respecto Moreno (1990) comenta: "el conocer y los conocimientos de la Educación suponen no se dan en el vacío; son actos, procesos o resultados de individuos concretos. Parece por tanto que la interacción mutua entre individuo-medio resulta ser la mejor forma de representar lo que el conocimiento y el conocer significan" (pp. 21 y 23).

La noción de interacción didáctica como unidad analítica del proceso de enseñanzaaprendizaje se deriva de una lógica de campo psicológico (Ribes y López, 1985), la cual proporciona una descripción de la relación contingencial entre factores históricos (tendencias, disposiciones del organismo) y situacionales que probabilizan el contacto funcional entre el organismo y aspectos específicos del medio. Bajo esta lógica, todos los factores son sincrónicamente necesarios en la configuración de un episodio de interacción. Describe categorías con distintas funciones lógicas (de proceso, disposicionales y posibilitadoras) e identifica los fenómenos psicológicos como sistemas de relaciones molares entre organismos individuales y objetos de estímulo y/o organismos individuales en el marco de un medio de contacto (físico, ecológico y/o convencional) (Ribes, 2011).

En la propuesta que se sustenta en el presente manuscrito (Ribes y López, 1985) se plantean cinco tipos cualitativos de procesos generales psicológicos, progresivamente inclusivos del comportamiento de los organismos, permitiendo caracterizar competencialmente las formas cualitativamente diferentes de cómo el estudiante establece contacto con el discurso 
didáctico y los objetos referentes. El término competencia se vuelve un concepto técnico de enlace o de interfase entre la teoría general de proceso y el lenguaje técnico propio de la descripción del desarrollo y de la relación enseñanza-aprendizaje (Ribes, 2008; 2011).

Las derivaciones más importantes de la propuesta de interacción didáctica (Irigoyen et al. 2007) son:

1) La posibilidad de analizar el tipo de discurso didáctico que deberá promoverse en función de las competencias a establecer (las cuales explicitan qué y cómo deberán de conducirse las interacciones didácticas). A diferencia del proceso de enseñanzaaprendizaje "tradicional", las situaciones de enseñanza y mediación no se limitan a la modalidad expositiva sino que se implementan estrategias instruccionales (ilustración, ejemplificación, moldeamiento) pertinentes a los diferentes juegos de lenguaje. 2) La posibilidad de analizar el desempeño del estudiante (observar, escuchar, leer, señalar, hablar y escribir) como el responder efectivamente ante los diferentes criterios, permitiendo especificar niveles de complejidad diferenciados (diferencial, efectivo, pertinente, congruente y coherente) en conjunción con diferentes criterios de tarea (identificar, relacionar, formular, elaborar). Su ejecución pertinente dependerá de su repertorio en términos de habilidades y competencias del ámbito funcional de desempeño y de la posibilidad de identificar las condiciones pertinentes a la tarea. 3) La posibilidad de analizar las modalidades de los materiales de estudio (objetos referentes), en sus diversas formas de presentación: videos, conferencias, materiales multimedia y textos, y su pertinencia para el entrenamiento de los diferentes juegos de lenguaje. Los materiales en las propuestas tradicionales tienen la función didáctica per se, por el contrario, en el modelo de interacción didáctica un material asume la función de didáctico sólo en la medida en que posibilita un contacto efectivo del estudiante con el referente.

4) La posibilidad de evaluar la interacción mediada entre el desempeño del profesor - discurso didáctico- y del alumno, así como los objetos referentes pertinentes al 
cumplimiento del objetivo instruccional, para de esta manera caracterizar las condiciones de evaluación idónea para la identificación de desempeños (en aula, laboratorio, campo).

Es importante señalar que la concepción que tienen los profesores sobre la ciencia -como se señaló anteriormente- tiene implicaciones sobre lo que enseñan y las estrategias utilizadas en las interacciones didácticas cotidianas (Fernández-Nistal y Peña, 2008; Sánchez, 2005; Soto, 2009). En otros manuscritos se ha enfatizado que el docente para llevar a cabo una mediación pertinente requiere de una formación en un sentido disciplinar, esto es, una formación especializada que atienda al conjunto de prácticas (conceptuales, procedimentales y de medida) específicas de un área o disciplina; y en un sentido pedagógico-didáctico, una formación en los aspectos científicos y técnicos que requiere el propio ejercicio de la docencia, como mediación de saberes (Acuña et al. 2009; Irigoyen et al. 2004; 2007; Morán, 2004).

De esta manera, el profesor podrá auspiciar comportamiento competente e inteligente en sus estudiantes, en la medida en que éste pueda exhibir dicho tipo de comportamiento. Sólo un profesor que es competente podrá explicitar y mediar los desempeños pertinentes para el cumplimiento de los criterios disciplinares según sea el caso.

La modalidad que se asuma por los docentes como forma de mediar a los estudiantes (discurso didáctico) es relevante, ya que se requieren formas de decir y hacer pertinentes a los desempeños disciplinares que se enseñan, para que de esta manera, el alumno pueda generar los repertorios necesarios y suficientes como un desempeño efectivo y con posibilidades de transferencia. Sólo se generarán estudiantes capaces de comportarse de manera inteligente (efectiva, variada y novedosa), si se auspician situaciones en donde se enseñe no sólo el qué, sino también el cómo, moldeando (a través de la ejemplificación e ilustración), y/o modelando al estudiante la identificación de los componentes de las situaciones problema a las que es enfrentado y permitiendo que el estudiante pueda establecer relaciones de 
equivalencia funcional entre situaciones conceptuales e instrumentales morfológicamente diferentes (como identificación de componentes de una máxima o regla de dichas situaciones problema).

Varela y Ribes (2002) señalan al respecto lo siguiente: "el comportamiento inteligente se enseña, primordialmente, a través del discurso didáctico. El principio fundamental en el que se basa el discurso didáctico es que sólo aquel que domina una competencia puede enseñarla. Aún cuando se enseña primordialmente con base en la demostración y el ejemplo, se requiere de máximas, instrucciones y descripciones que expliciten los criterios bajos los cuales dichos ejemplos y demostraciones son efectivos, las diversas maneras en que otros ejemplos y ejercicios de una competencia pueden también serlo" (p. 202).

El discurso didáctico no consiste únicamente en una interacción expositiva (de morfología verbal) sobre lo qué se debe hacer y no hacer, y en cómo llevarlo a cabo, sino que consiste en la demostración, ejemplificación y ejercicio del desempeño que se pretende enseñar. Por ello, el profesor necesariamente deberá ser un experto en lo que enseña, además de tener conocimientos pedagógicos y didácticos que le permitan auspiciar este tipo de condiciones.

Con respecto a la forma de mediar al estudiante la interacción con los objetos referentes (discurso didáctico), Varela (2002) enfatiza los siguientes aspectos: a) solicitar a los estudiantes que identifiquen y describan los elementos y condiciones que son parte de la situación problema o son funcionales para su solución; b) auspiciar que el alumno refiera su propio comportamiento ante otros. En este caso específico, se solicita al alumno que describa lo que hace mediante los elementos y las condiciones presentes para poder satisfacer el criterio de logro que demanda la situación ${ }^{4}$. El ejercicio variado de las habilidades anteriores, facilita que el alumno gradualmente sea capaz de identificar los componentes funcionales que son comunes a las circunstancias (en términos de instancias, modalidades, relaciones

$4 \quad$ Varela y Quintana (1995) propone analizar el comportamiento inteligente a partir de la variación de cuatro elementos: dimensión, relación, instancia y modalidad. 
y dimensiones) presentadas durante el ejercicio variado; c) preguntar al estudiante la descripción de los elementos funcionales o implícitos, solicitándole que identifique las semejanzas y diferencias. Por lo tanto, la formulación de principios y/o máximas consiste en la elaboración de una descripción general que englobe las descripciones particulares que comparten una misma propiedad, es en sí una competencia transituacional que facilita el manejo lógico de situaciones presentes y futuras. Este aspecto es posible mediante la retroalimentación que los alumnos pueden ir realizando a la par del profesor, enfatizando los pasos con los que se logró satisfacer los criterios de logro o ajuste de las diferentes situaciones problema.

Por tanto, el aprendizaje de los contenidos científicos se establece interactuando y ejercitando los diferentes juegos de lenguaje en las diferentes modalidades con los objetos, eventos o situaciones referentes, tanto en el decir como en el hacer. En este sentido, las interacciones de los estudiantes se establecen fundamentalmente como interacciones que involucran dimensiones no aparentes (interacciones mediadas lingüísticamente), en donde los referentes de los cuales se habla o se hace, se significan en función de las teorías, modelos, procedimientos y técnicas.

Esto es lo que finalmente se pretende al formar individuos en ámbitos científicos, individuos que se continúen desempeñando efectivamente estableciendo una equivalencia funcional aún entre arreglos diferentes a los entrenados originalmente, e incluso de ser capaz de identificar y proponer ejemplares en los que dicha relación funcional se mantenga aplicación de la regla- (Ribes, 2000; Tena, Hickman, Moreno, Cepeda y Larios, 2001), es decir, individuos que se comporten extrasituacionalmente.

Por lo tanto, para que el estudiante se desempeñe competentemente deberá identificar la relación funcional que comparten diferentes situaciones, ya sea en instancias o relaciones, en donde abstrae o formula el principio que le permitirá desempeñarse de manera efectiva ante estas situaciones o criterios posteriormente. En otras palabras, el estudiante deberá identificar el nivel de correspondencia que comparten dos o más situaciones que son morfológicamente diferentes, pero que funcionalmente son reguladas de manera equivalente, 
siendo capaz describir su ejecución efectiva y las circunstancias en las que ésta ocurre, lo que ha sido llamado saber cómo - ejecución efectiva- y saber por qué - descripción del principio o máxima- (Moreno, Cepeda, Tena, Hickman y Plancarte, 2005; Rodríguez, 2000).

Una implicación de lo anterior para el ámbito educativo, consistiría en la posibilidad que tiene un estudiante de establecer contacto relacional con los criterios de ajuste y por lo tanto, poder resolver problemas que no guardan necesariamente semejanza morfológica sino funcional. Zabala y Arnau (2007) plantean con respecto a las situaciones a las que un estudiante en formación (y posteriormente en su ejercicio profesional) se enfrentará, que éstas son únicas y complejas, ya que, por muy parecidas que sean las circunstancias, éstas nunca serán iguales; y complejas, toda vez que el número de variables involucradas puede variar frecuentemente.

Ryle (2005) señala en su análisis en torno a la inteligencia y al pensamiento, que las ejecuciones relacionadas al "saber qué" y "saber por qué", se desarrollan después de que el sujeto domina una tarea (ejecución exitosa), y sólo cuando las ejecuciones exitosas y las descripciones son suficientemente variadas. Así, puede hablarse de comportamiento competente e inteligente por extensión, cuando el individuo se muestra capaz de describir su ejecución efectiva ante condiciones variadas y las diferentes circunstancias en las que ésta ocurre y se significa, es decir, podrá exhibir desempeños efectivos ante circunstancias variantes independientemente de que ellas guarden o no en común propiedades aparentes en una situación determinada.

Autores como Rodríguez, Vera, García y Guitrón (2012) presentan una serie de estudios que han venido realizando algunos investigadores mexicanos con el propósito de proponer metodologías que le permitan al estudiante desligarse de la situación presente y/o concreta. El propósito es que "el estudiante pueda convertirse en una mediador de su propio conocimiento y hablar sobre el objeto de estudio de tal manera que su respuesta lingǘstica varia funcionalmente con la respuesta congruente de él mismo o de otro estudiante como mediado" (p. 215). 
- En el primer estudio (Bain, 2004, citado en Rodríguez et al. 2012) se señalan los efectos en el desempeño del estudiante en función de las metodologías de enseñanza, así como los modos lingüísticos involucrados, es decir, cómo se promueve desempeños de distinto nivel de complejidad, pero sobre todo como lograr que el estudiante sea "el director de su proyecto de aprendizaje".

- En el segundo estudio (Guitrón, Rodríguez, Vera y Soltero, 2005, citado en Rodríguez et al. 2012), se implementaron las siguientes actividades: 1) Los estudiantes leyeron sobre el tema en cinco textos diferentes, se les pidió que escribieran un texto con argumentos propios respecto a un tema de química; b) después se les pidió que elaboraran un mapa conceptual como estrategia didáctica para establecer explícitamente relaciones entre conceptos del dominio de la química; c) posteriormente, se revisaron problemas de tarea en equipo, como estrategia didáctica se les proporcionó el resultado y una estrategia de solución para que, de forma comparativa con ésta y con los resultados de los otros integrantes del equipo, enriquecieran sus argumentos; d) análisis de artículos científicos con el objetivo de promover el establecimiento de relaciones en reacciones químicas novedosas a partir de reacciones típicas abordadas en clase; e) llevar a cabo prácticas de laboratorio ya diseñadas por el profesor, en donde se les permitió a los alumnos plantear una pregunta de investigación; f) llevar a cabo una evaluación con reactivos opción múltiple, y por último, g) a partir de una visita industrial se les pidió a los estudiantes que trajeran a clase información sobre los productos que se elaboran en dicha industria y los procedimientos de síntesis química que se aplican. Los resultados son comparados con otros dos grupos que solamente utilizaron la clase magistral y la resolución de problemas. El desempeño de todos los grupos fue evaluado mediante tres exámenes parciales y un examen departamental. El grupo experimental es el que muestra calificaciones mayores a 60 o mayores a diferencia de los otros dos grupos. 
La evaluación de desempeños competentes por lo tanto, estaría dirigida a la constatación del desempeño efectivo ante condiciones variantes en función de las diversas prácticas del área de conocimiento como juegos de lenguaje (conceptuales, instrumentales y de medida), y los objetivos instruccionales propuestos.

En otros escritos (Irigoyen y Jiménez, 2004; Irigoyen et al. 2007; Jiménez, Irigoyen y Acuña, 2011) se han propuesto formas de evaluación como parte de las estrategias instruccionales que permitan caracterizar cómo entra en contacto el estudiante con el decir y el hacer de su disciplina de estudio, permitiendo de esta manera monitorear sus ejecuciones en diferentes niveles de complejidad (diferencial, efectivo, pertinente, congruente y coherente), modalidades linguísticas (señalar, hablar, escribir) y tipo de tarea (identificar, definir, instrumentar, relacionar y formular). El nivel funcional refiere a la complejidad del criterio de tarea y los recursos conductuales necesarios para su solución efectiva. La modalidad consiste en las maneras lingüísticas en que el desempeño o la actividad del aprendiz tiene lugar (señalar, hablar, escribir). El criterio de tarea involucra la dimensión de ocurrencia del desempeño del aprendiz, definido a partir de criterios observacionales (nominar, describir, instrumentar, relacionar y/o argumentar).

En este sentido, se sugiere que evaluar el aprendizaje de una disciplina o profesión no sólo debiera consistir en la reproducción precisa de contenidos verbales o escritos expresados por el docente o en los objetos referentes, sino en la identificación del desempeño del alumno con relación a las diferentes modalidades del "decir" y el "hacer" (escribir, hablar) que el ámbito disciplinar prescribe, esto es, en cada uno de los diferentes juegos de lenguaje.

Bajo esta lógica se propone un modelo de evaluación de las interacciones didácticas (Jiménez et al. 2011) el cual es representado en la Figura 5, en el cual se indican los elementos mínimos necesarios a considerar en el diseño de situaciones de evaluación.

El modelo explicita que los criterios para evaluar el aprendizaje de contenidos científicos y por lo tanto, su comprensión (ajuste lector) tendrán que ser congruentes con por lo menos los siguientes aspectos: a) los juegos de lenguaje que correspondan al dominio 
disciplinar; b) la modalidad lingüística del desempeño, c) la forma en que tuvo lugar el aprendizaje (declarativo o actuativo); d) la naturaleza de los objetos referentes (fisicos o sustitutos); e) el tipo de arreglo contingencial (cerrado, abierto) y f) los criterios de tarea y su nivel funcional (criterio de logro). La comprensión entonces es entendida como la interacción y ajuste del estudiante frente a los objetos referentes, considerando como aspectos fundamentales la modalidad lingüística implicada, el tipo de tarea y su nivel funcional. •

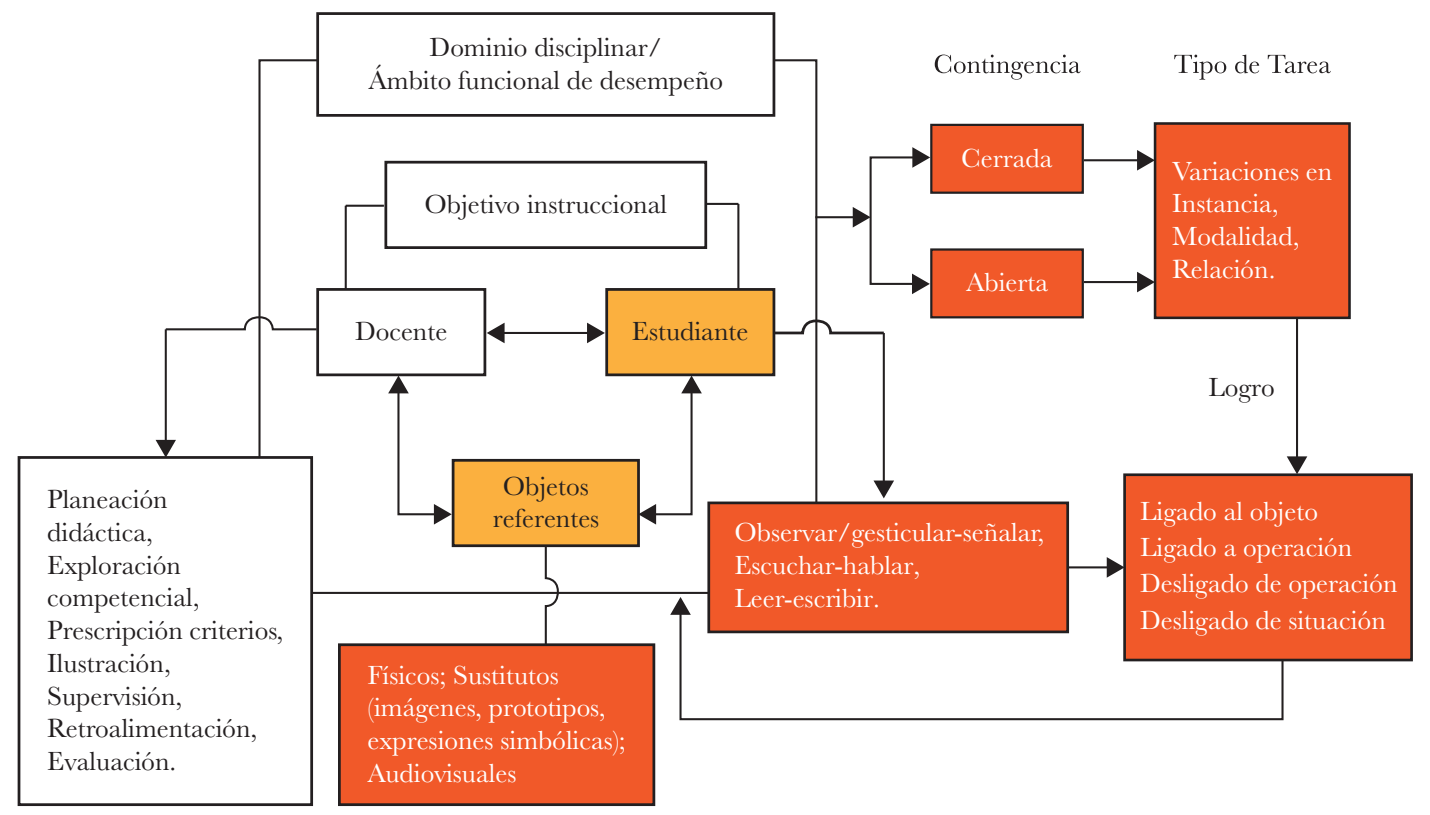

Figura 5. Representa los elementos mínimos necesarios para el diseño de una situación de evaluación. 
(Página en blanco) 


\section{Capítulo 3}

Análisis de los modos lingüísticos

en la comprensión de contenidos científicos
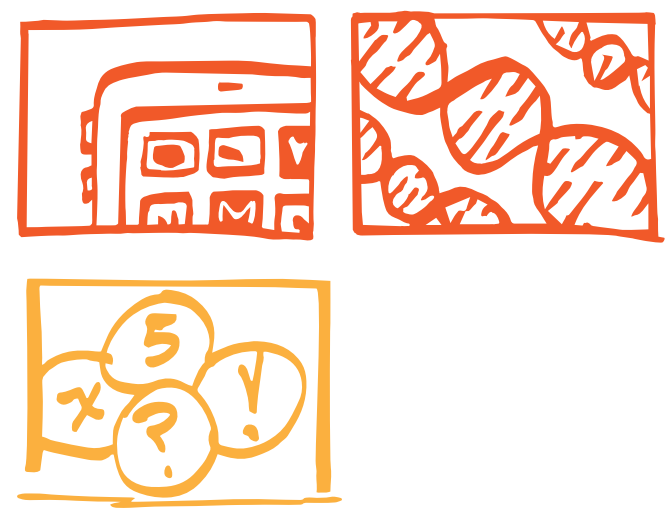
(Página en blanco) 


\section{Definición de comprensión}

Uno de los propósitos de la educación escolarizada es que el alumno pueda establecer contacto con aquello que se dice o se hace en el aula (comprender). El estudiante a partir de la mediación del profesor con respecto a objetos, acciones y/o textos, va estableciendo un decir y un hacer con sentidos funcionales específicos a la disciplina o área de conocimiento que está aprendiendo.

El estudiante entonces, a partir de los criterios explicitados por el profesor o en los mismos materiales de estudio, deberá ajustar su desempeño ya sea señalando, escribiendo y/o hablando según corresponda al criterio solicitado, a la modalidad del discurso didáctico y/o de los objetos referentes. Así pues, la comprensión es identificada a partir de la pertinencia de lo que se dice o se hace en función de los requerimientos instruccionales en un episodio de interacción didáctica.

El concepto de comprensión tiene como constante su uso en situaciones en las que se presenta una adecuación y/o ajuste del desempeño de un individuo a algo que le es requerido en una situación particular. En el caso del contexto escolar este concepto es referido a cuando el estudiante es capaz de desempeñarse cumpliendo requerimientos impuestos por el docente y en los mismos materiales de estudio (objetos referentes -que pueden ser una imagen, un video, una conferencia y/o un texto-) a los cuales se enfrenta cotidianamente.

Las propuestas tradicionales en el estudio de la comprensión(De Vega, 1984; Johnston, 1989; León, 1996; Sánchez, 1974) han supuesto que cuando un estudiante comprende es porque ocurren cambios en el interior de su organismo, sea a nivel cognoscitivo (como algún tipo de representación mental) o neuronal, otorgándole un papel fundamental al estudiante y a su posibilidad "comprensiva". Desde estas perspectivas, no se puede concebir a la comprensión sin la existencia de una estructura o proceso como la memoria. La memoria viene a constituirse como una estructura o proceso bifuncional que, por una parte, sería la responsable de almacenar el cambio logrado como aprendizaje en alguna ubicación del 
sistema nervioso central preferentemente y, por otra, sería la reguladora que selecciona, activa y recupera lo comprendido para su uso o ejercicio en ocasiones posteriores (Johnston, 1989).

Autores con una gran trayectoria en la investigación en el área de la comprensión lectora señalan por ejemplo lo siguiente: "la teoría del esquema y de los modelos mentales, están permitiendo explicar de manera coherente cómo se representa y comprende el conocimiento en la mente del sujeto, cómo se almacena, así como de los procesos y estrategias que entran en juego" (León, 1991, p. 6). Éste autor ha señalado que cuando leemos un texto llevamos a cabo una tarea cognitiva enormemente compleja que implica diferentes procesos que actúan coordinadamente sobre la información escrita. Kleiman por ejemplo (1982, citado en León, 1991) sugiere que desde la lectura de un texto impreso hasta su comprensión final se necesita:

a) un conocimiento general del mundo y de las acciones humanas;

b) un conjunto de procesos perceptivos y cognitivos entre los que se incluyen procesamientos de discriminación perceptual, la intervención de la memoria a corto plazo, una codificación en orden serial, la localización y dirección de la atención, y un procesamiento inferencial;

c) proceso de comprensión del lenguaje entre los que se incluyen la recuperación e integración del significado de la palabra, el análisis sintáctico de frases, la determinación de referencias anafóricas y diversos análisis de la estructura del discurso.

Todo esto conlleva la idea de que la lectura y particularmente, que la comprensión, implica un proceso complejo o de orden superior, a través del cual, el lector construye activamente una representación del significado poniendo en relación las ideas contenidas en el texto a partir de sus conocimientos. Este modelo mental -o también denominado modelo de la situación- según De Vega, Díaz y León (1999), está constituido por representaciones dinámicas - que van cambiando a medida que se avanza en la lectura del texto- de lo singular o lo concreto, a lo que no se puede visualizar en un contexto espacio-temporal específico. 
Pero ¿cómo es que un lector logra construir de manera exitosa una representación del texto? León (2002) encuentra que existen diversas estrategias de lectura que se desarrollan para lograr la interpretación en un texto; para el autor entender el proceso seguido por novatos y expertos permite entender el proceso de representación del texto que lleva a cabo todo lector y la importancia del dominio de una disciplina en el proceso de construcción de nuevos conocimientos (ver Tabla 3).

Un aspecto que resalta la Tabla 3 y con el cual se coincide, es la importancia que tiene el conocimiento previo del dominio específico para la comprensión de un texto. Gallegos y Flores (2008) comentan que un texto también puede ser mejor comprendido en función de la presencia de indicadores y señalización dentro del mismo. La relación entre estos dos factores favorece su comprensión debido a que el dominio del conocimiento específico permite al estudiante reproducir el texto y usarlo de manera constructiva, porque hace posible la representación de la base del texto para incluirla dentro de su modelo de representación. Dado que el nivel de comprensión del texto depende del nivel de conocimientos sobre un dominio específico, entre mayor sea éste, se requerirá en menor grado de la cohesión del texto y de redundancia de ideas (León, 2002).

\begin{tabular}{|l|l|l|}
\hline $\begin{array}{l}\text { Componentes de las estrate- } \\
\text { gias de lectores expertos }\end{array}$ & $\begin{array}{l}\text { Componentes de las } \\
\text { estrategias de lectores } \\
\text { novatos }\end{array}$ & $\begin{array}{l}\text { Características que debe } \\
\text { cumplir el texto para atender a } \\
\text { las dos estrategias }\end{array}$ \\
\hline $\begin{array}{l}\text { Genera o activa conocimientos } \\
\text { que el sujeto posee (uso de co- } \\
\text { nocimiento previo del alumno). }\end{array}$ & $\begin{array}{l}\text { No relaciona la infor- } \\
\text { mación del texto con la que } \\
\text { posee. }\end{array}$ & $\begin{array}{l}\text { Establecer explícitamente como } \\
\text { referentes los conocimientos } \\
\text { previos de los alumnos y el con- } \\
\text { texto cotidiano y en un lenguaje } \\
\text { accesible. Repetir la información } \\
\text { desde distintos contextos. }\end{array}$ \\
\hline
\end{tabular}




\begin{tabular}{|c|c|c|}
\hline $\begin{array}{l}\text { Establece relaciones entre la } \\
\text { nueva información y la que } \\
\text { posee el lector e infiere infor- } \\
\text { mación ausente en el texto. }\end{array}$ & $\begin{array}{l}\text { Reproduce textualmente la } \\
\text { información ya que carece } \\
\text { de formas de organización. }\end{array}$ & $\begin{array}{l}\text { Establecer formas de organización } \\
\text { entre los conceptos de manera ex- } \\
\text { plícita de tal forma que el alumno } \\
\text { construya criterios de organización } \\
\text { y se percate de la forma lógica en } \\
\text { la que se relaciona el contenido. }\end{array}$ \\
\hline $\begin{array}{l}\text { Identifica las principales } \\
\text { relaciones lógicas del pasaje, } \\
\text { conecta las diferentes proposi- } \\
\text { ciones del texto dentro de una } \\
\text { secuencia coherente. }\end{array}$ & $\begin{array}{l}\text { Representa la información } \\
\text { de manera fragmentada y } \\
\text { lineal. }\end{array}$ & $\begin{array}{l}\text { El texto debe favorecer las rela- } \\
\text { ciones lógicas entre conceptos y } \\
\text { señalar su relación con el modelo } \\
\text { de referencia. }\end{array}$ \\
\hline $\begin{array}{l}\text { Construye modelos mentales } \\
\text { que permiten organizar la } \\
\text { información del texto de forma } \\
\text { coherente y organizada, cuali- } \\
\text { tativa y personalizada. }\end{array}$ & $\begin{array}{l}\text { El pasaje es una lista } \\
\text { de sucesos para ser } \\
\text { memorizados. Carece de } \\
\text { un plan estratégico de } \\
\text { procesamiento de textos. }\end{array}$ & $\begin{array}{l}\text { Utilizar el modelo del que parte } \\
\text { la conexión entre conceptos a } \\
\text { partir de diversas estrategias que } \\
\text { permitan que el estudiante cons- } \\
\text { truya en variedad de situaciones } \\
\text { y contextos las relaciones lógicas } \\
\text { y de integración jerárquica de la } \\
\text { información. }\end{array}$ \\
\hline $\begin{array}{l}\text { Comprende el texto sin } \\
\text { necesidad de recordar toda la } \\
\text { información específica. }\end{array}$ & $\begin{array}{l}\text { Recuerda algo del texto lo } \\
\text { que implica un desconoci- } \\
\text { miento en la organización } \\
\text { jerárquica del contenido. }\end{array}$ & $\begin{array}{l}\text { El texto deberá presentar elemen- } \\
\text { tos de integración y organización } \\
\text { de la información de tal forma que } \\
\text { la conclusión lleve a la organiza- } \\
\text { ción general y a la identificación } \\
\text { del modelo. }\end{array}$ \\
\hline $\begin{array}{l}\text { Conoce la forma de organi- } \\
\text { zación de los textos lo que } \\
\text { permite buscar y utilizar la } \\
\text { estructura como marco organi- } \\
\text { zacional de donde se codifica y } \\
\text { recupera la información. }\end{array}$ & $\begin{array}{l}\text { Concibe el texto como una } \\
\text { lista de elementos aisla- } \\
\text { dos de toda organización } \\
\text { lógica. }\end{array}$ & $\begin{array}{l}\text { El texto debe presentar una estruc- } \\
\text { tura lógica explícita de tal forma } \\
\text { que el estudiante pueda construir } \\
\text { una estrategia de recuperación, } \\
\text { integración y construcción de la } \\
\text { información. }\end{array}$ \\
\hline
\end{tabular}

Tabla 3. Comparación entre dos estrategias de lectura presentadas por León (2002) y las características que el texto debe tener para atender a dos tipos de lectores (recuperada de Gallegos y Flores, 2008, pp. 124 y 125). 
Algunos de estos aspectos han llevado necesariamente a suponer que comprender es una actividad especial, que tiene lugar adicionalmente a los comportamientos que se aprenden (a lo que se dice o se hace), y en algunos casos concebida como un evento que antecede a la acción "comprensiva". Toda vez que el comprender no se "observa" directamente, se asume una actividad paralela, que causa, determina o facilita que ocurra un cambio en el comportamiento del estudiante y sus resultados (lo que se comprende). Ribes (2004) sustenta que “[...] los términos o expresiones mentales son siempre empleados en relación a circunstancias explícitas y a la conducta de un hablante y/o escucha [...] Las expresiones y términos mentales más bien poseen propiedades episódicas o disposicionales. Tienen que ver con descripciones episódicas de logros o maneras en lo que se hace tiene lugar, o con explicaciones de colecciones de ocurrencias en la forma de propensiones o tendencias que predicen o señalan las condiciones en que determinados actos pueden o no ocurrir" (p. 9).

En relación al concepto de comprensión el mismo autor señala: "Cuando comprendemos una fórmula matemática o comprendemos la fórmula que subyace a una serie numérica, no podemos señalar algo que corresponde directa o unívocamente al hecho de comprender y que podamos atender. Comprender no es un evento, sino el resultado de una serie de eventos acompañantes que tienen lugar durante el fenómeno [...]Es a ese conjunto de acompañamientos y al hecho de comprender (logro) a lo que llamamos comprender" (p. 13).

De tal manera que los términos mentales siempre son utilizados en relación a circunstancias explícitas y a la conducta de un hablante, lector y/o escritor. A continuación se describen tres ejemplos:

a) Si se le pide a un estudiante que nos señale oralmente tres aspectos importantes mencionados por el profesor de biología acerca de las características de los seres vivos y el estudiante puede hacerlo, se dice que comprendió la instrucción;

b) Si se le requiere que formule tres preguntas relevantes y lo hace a partir de la lectura de un reporte de investigación de física, se dice que comprendió lo solicitado y, 
c) Si se le solicita que redacte un ensayo en donde realice una contrastación de propuestas teóricas en Psicología y su abordaje metodológico, a partir de lo revisado y leído en clase, y lo hace, también comprendió el criterio.

Por lo cual, la expresión y/o el término de comprensión tiene que ver más con la descripción episódica del logro o logros del estudiante con respecto a un criterio, así como las maneras en que lo que se hace tiene lugar como tendencia que predice un desempeño y las circunstancias en que puede o no ocurrir, como probabilidad (no como evento aislado). Más bien, el concepto de comprensión en los diferentes contextos de uso, se aplica cuando se satisface un requerimiento, el cual puede ser mediado por alguien (p.e. profesor) o implícito en la misma interacción que se establece con el material de estudio que se observa, escucha o lea, según sea el caso.

De esta manera, el concepto de comprensión refiere a una categoría de tipo episódica, en donde es necesario identificar el requerimiento explicitado en la tarea a realizar y las formas (como desempeño) en que podría resolverse dicha tarea. La pertinencia del decir o hacer está determinada por la situación específica en la que se interactúa, o en la que se comprende, en este caso referida a un criterio de ajuste en un área de conocimiento particular (p.e. la biología, la química, la psicología).

Carpio, Pacheco, Flores y Canales (2000) han sugerido que los actos o procesos cognoscitivos son formas de comportamiento a los que no cabe adjetivar como internos, privados u ocultos. Demostrando lógicamente que más bien este término refiere a una categoría de $\operatorname{logro}{ }^{1}$, la cual describe el ajuste o correspondencia del comportamiento del sujeto respecto a un requerimiento social y/o educativo (Canales, Morales, Arroyo, Pichardo y Pacheco, 2005; Irigoyen et al. 2004, Irigoyen et al. 2007; Zarzosa y Luna, 2007). Bajo este supuesto, no es algo que el individuo "tenga", sino algo que el individuo hace (observar, escuchar, leer, señalar, hablar y escribir) en relación con la modalidad del material de estudio.

1 Una categoría de logro, como la palabra misma lo subraya, es aquella en la que los términos indican, sugieren o tienen que ver con resultados, productos o consecuencias. 
Así una persona no "posee comprensión" sino que se ajusta ante determinados criterios de tareas (identificar, describir, relacionar, formular, elaborar) cumpliéndolos de manera efectiva, a esto se le llama comprensión.

Plantear el análisis de la comprensión como el ajuste efectivo ante un criterio de logro explicitado a partir de un texto, un video o un material multimedia, puede ser susceptible de verificación experimental y en este sentido, aportar elementos importantes a los profesores (y administradores de la educación) sobre qué modalidad del objeto referente sería pertinente utilizar según el tipo de saber (declarativo o procedimental) y que criterios debieran explicitarse a partir del material (tipo de instrucciones, tipo de retroalimentación, etc.). Esta reflexión se desarrollará en forma detallada en las siguientes líneas, como parte fundamental de la propuesta de este manuscrito.

Ahora bien, con la inserción de las nuevas tecnologías es cada vez más frecuente incorporar a las secuencias didácticas de los profesores, objetos referentes variados (video, texto, audio, imágenes, gráficos), sin que en muchas ocasiones se atienda a las modalidades lingüísticas involucradas y a los criterios que se solicitan a los estudiantes en términos del tipo de tarea y su nivel de complejidad, dando por supuesto que la mera presentación o sumación de estas variaciones produce un aprendizaje más efectivo. Por ejemplo, un video puede tener la misma función que un texto, si lo que se le pide al alumno es que sólo señale aspectos contextuales o situacionales a partir de éste, pues no es el material por si mismo lo que determina su "didacticidad" o el nivel de contacto del alumno, sino el criterio de logro o ajuste que permite evaluar la manera y nivel de contacto funcional del estudiante.

Por ello, en otro espacio se ha propuesto analizar la comprensión como interacción entre el estudiante y los objetos referentes (materiales de estudio, por ejemplo, texto, video, conferencia, gráfico, material multimedia) en condiciones definidas por el área de conocimiento, los requerimientos a cumplir en la interacción (explicitados por los saberes conceptuales, instrumentales y de medida de dicha área de conocimiento) y las condiciones situacionalmente necesarias para que la interacción entre éstos pueda ocurrir (Acuña, Irigoyen 
y Jiménez, 2010; Irigoyen et al. 2004). Se considera que continuar hablando de comprensión como un evento oculto al margen de aquello que se comprende y de las condiciones que posibilitan o interfieren en su ocurrencia, implica realizar inferencias de aquello que ocurre en el individuo mientras "se comprende".

La propuesta que se presenta en este manuscrito, se sustenta en una teoría de desarrollo funcional del comportamiento (como se describió en el capítulo anterior) para el análisis de los procesos educativos. Las ventajas de sustentar la propuesta bajo esta lógica (Ibáñez y Ribes, 2001) son:

a) La posibilidad de identificar aquellos factores que en forma indispensable actúan para determinar la naturaleza de las modulaciones de comportamiento (comprensión) que se circunscriben a determinados ámbitos,

b) concebir la complejidad de los fenómenos educativos (en su dimensión psicológica) como producto de la interdependencia sincrónica de los factores involucrados,

c) contar con categorías analíticas para ubicar en su correcta dimensión lógica, los conceptos dentro de la teoría, evitando caer en errores categoriales (Ryle, 2005) o pudiendo plantear preguntas de investigación no factibles de resolver empíricamente, y d) analizar el desarrollo de desempeños o competencias a lo largo de distintos niveles de aptitud funcional sistematizando así, la investigación de estos ajustes y guiando la elección de los métodos específicos requeridos para abordarlos.

En relación al primer inciso, se sugiere que partir de una concepción de campo (como relaciones interdependientes de condicionalidad) para el estudio de la comprensión, permite analizar todos y cada uno de los elementos determinantes de la misma, tomando en consideración las condiciones necesarias y suficientes al analizar los elementos de la interacción. Es importante señalar que la manera en cómo se conceptualice el fenómeno de estudio, constituye la base para identificar las variables que influyen en la naturaleza del mismo. 
Continuar buscando las causas del comportamiento en términos de variables internas imposibilita el análisis objetivo de todos los cofactores involucrados en el fenómeno de comprensión. Plantear la explicación de la comprensión sólo desde variables únicas o de relación unicausal, arroja poca información sobre cómo el profesor puede lograr que sus estudiantes comprendan. La lógica de campo constituye una alternativa para la representación pertinente de los fenómenos psicológicos concebidos como segmentos interconductuales. Esta lógica se caracteriza por una interdependencia entre factores en tiempo sincrónico, por la consideración de unidades analíticas molares, y por la representación conceptual de factores históricos y contextuales (Kantor, 1990).

La distinción realizada por Kantor (1990) entre funciones de estímulo y respuesta y los factores disposicionales, tanto históricos como situacionales, constituye una aportación fundamental para distinguir los conceptos que pueden entrar en enunciados legales de aquellos que sólo pueden formar parte de enunciados descriptivos de "estados" o de enunciados predictivos relacionados con tendencias, propensiones y condiciones semejantes. Esta distinción de categorías evita caer en errores conceptuales, y analizar en su justa dimensión el fenómeno de estudio, en este caso el fenómeno de comprensión.

Resumiendo, en esta lógica se intenta describir y explicar la comprensión (ajuste lector) en términos de factores interdependientes: estudiante, objetos referentes, tipo de criterio explicitado en la interacción, que confluyen en un tiempo y espacio definido curricularmente.

Ribes y López (1985) a partir de los postulados propuestos por J. R. Kantor (19241926) acerca del campo interconductual, elaboraron la propuesta de Teoría de la Conducta. La propuesta consiste en una taxonomía de funciones, basadas en relaciones de campo. Dicha taxonomía contempla categorías con distintas funciones lógicas (de proceso, disposicionales y posibilitadoras), e identifica los fenómenos psicológicos como sistemas de relaciones molares entre organismos individuales y objetos de estímulo y/o organismos individuales, en donde dichas relaciones son posibilitadas por un medio de contacto físico, ecológico y/o convencional (Ribes, 2010). 
El campo interconductual o psicológico (como sistema de contingencias ${ }^{2}$ ) se configura a partir de dos procesos: mediación y desligamiento funcional. En palabras de Ribes y López (1985), la mediación se define como "el proceso por el cual diversos eventos entran en contacto recíproco directo y/o indirecto” (p. 52). La mediación funcional consiste en el proceso mediante el cual, alguno de los elementos de la interacción se constituye en un factor crítico para la estructuración del campo de contingencias.

De esta manera las interacciones psicológicas, como sistemas de relaciones en las que participa un individuo (en este caso el estudiante), y otros elementos de su entorno (para el caso señalado objetos referentes, criterio de ajuste, etc.) se pueden diferenciar en términos de su nivel de desligamiento, lo cual permite llevar a cabo un análisis paramétrico de dichas interacciones.

En la Teoría de la Conducta, se plantean cinco niveles funcionales de contacto, cualitativamente diferenciados progresivamente, en términos de inclusividad (competencial) para describir las interacciones psicológicas. Ribes y López (1985) señalan que: "El proceso de evolución psicológica consiste en la transición de las formas de función estímulo-respuesta menos complejas a las más complejas, dadas las posibilidades reactivas y ambientales de los individuos" (p. 64). Para entender esta evolución psicológica, la categoría analítica de desligamiento es fundamental, el cual consiste en "la posibilidad del organismo de responder en forma ampliada y relativamente autónoma respecto a los eventos concretos y de los parámetros espaciales y temporales que las definen situacionalmente" (p. 58).

La noción de desligamiento como una manera de caracterizar la forma en cómo se estructuran las relaciones funcionales (espacio-temporalmente), permite también el análisis paramétrico de los distintos niveles aptitudinales de las funciones psicológicas. Los distintos tipos de desligamiento funcional se pueden caracterizar como procesos de actualización de los elementos y/o relaciones de dependencia que comprende una interacción.

2 La noción de contingencia viene a sustituir el concepto tradicional de "causalidad" empleado en la explicación de la ocurrencia de los eventos psicológicos. A diferencia de ésta, una relación de contingencia describe una relación probabilística de condicionalidad entre los eventos y factores que conforman un campo. 
De acuerdo al tipo de desligamiento, los cinco niveles de organización funcional del comportamiento puede englobarse en tres niveles (Varela y Quintana, 1995):

- Nivel intrasituacional. Implican interacciones en las que el individuo se ajusta respondiendo a las propiedades espacio-temporales de los eventos, produciendo cambios en los objetos o eligiendo relaciones más adecuadas entre los eventos para producir cambios dentro de una situación. Por ejemplo, cuando un estudiante a partir de la lectura puede seleccionar entre una serie de opciones de respuesta, aquella que se corresponde con una definición o enunciado.

- Nivel extrasituacional. Implican interacciones en las que el individuo se ajusta alterando las relaciones entre objetos e individuos de la situación presente con base en relaciones de una situación distinta. Por ejemplo, a partir de lo leído en un texto poder identificar eventos o relaciones relevantes, y a partir de ello redactar de forma congruente una serie de enunciados.

- Nivel transituacional. Implican interacciones en las que el individuo se ajusta respondiendo convencionalmente a eventos también convencionales, comparándolos, subordinándolos o reformulándolos. Por ejemplo, cuando a un estudiante se le pide que formule un resumen o una serie de conclusiones en función de lo leído en un texto.

Partiendo de esta lógica, Arroyo, Canales, Morales, Silva y Carpio (2005) propusieron un programa de investigación para el análisis funcional de la comprensión como ajuste lector, considerando variables vinculadas al estudiante, al texto, al criterio de ajuste y a los elementos que pueden facilitar o interferir en el ajuste lector en la interacción -variables disposicionales-. Una de las derivaciones del programa a decir de los autores, es que el ajuste lector ha de evaluarse atendiendo a por lo menos tres aspectos esenciales: a) el criterio a satisfacer, aquello que se le demanda al lector, y que puede establecerse en cinco diferentes niveles de complejidad dada la taxonomía de funciones conductuales; b) la historia de contactos con el referente, ya sea en términos del nivel funcional en el que se pretende establecer el 
contacto, o de las habilidades y competencias desarrolladas en la historia del lector; y c) la interacción entre el criterio y la historia del lector, pues se ha demostrado que la mera imposición del criterio no basta para que el individuo sea capaz de cumplirlo, dado que si en su historia no se han desarrollado las habilidades necesarias para ello, simplemente no será capaz de realizarlo.

Ahora bien, en el caso del análisis del fenómeno de comprensión de contenidos científicos, los desempeños como modalidades lingüísticas - escribir y hablar- podrían estructurarse no sólo como interacciones intrasituacionales sino como comportamiento extrasituacional o transituacional, si se pretende que los estudiantes universitarios puedan responder a situaciones diferentes en las que se enseñó cierto desempeño, pero sobre todo, situaciones problema que no guardan correspondencia necesaria con la ejemplificación o ilustración presentada por parte del profesor a lo largo de su formación.

En este sentido, el estudio de las condiciones que posibilitan que el estudiante se ajuste a criterios variantes, es esencial para poder caracterizar las circunstancias que probabilizan este ajuste efectivo o no, y el nivel funcional del contacto con los materiales, los cuales pueden estar en función de un objeto o evento, operación o procedimiento, situación problema (como se presenta en el modelo de evaluación, de la Figura 5, p.79). Cada vez más se enfatiza por parte de planeadores de la educación, la formación de estudiantes competentes, dadas las nuevas condiciones de manejo de información así como, de la provisionalidad de la misma. Por consiguiente, se plantea la necesidad de recuperar como criterio de evaluación: la modalidad lingüística del desempeño, la naturaleza de los objetos referentes, el tipo de arreglo contingencial de la situación problema al que es enfrentado el estudiante (abierto o cerrado), los criterios de tarea y su nivel funcional.

La modalidad del discurso didáctico es fundamental en los primeros momentos de formación, para que el estudiante pueda adecuarse efectivamente a los criterios impuestos por el profesor o en los materiales de estudio, y posteriormente a su ejercicio profesional. Toda vez que estas modalidades le implican una morfología de respuesta diferente, si el 
discurso es solamente oral y no lo acompaña la ilustración o la ejemplificación el estudiante solamente se comportará como un escucha, pero si el profesor ilustra, por ejemplo, a partir de un video, puede solicitarle al estudiante que redacte un párrafo o hable de lo que observó y escuchó en clase. De esta manera, el requerimiento explicitado al estudiante se va estructurando morfológica y funcionalmente con el desempeño del profesor.

Por ello, no podemos soslayar las habilidades y competencias que requiere un profesor para la planeación e instrumentación de las interacciones didácticas. En muchas ocasiones los profesores transmiten conocimientos en forma expositiva, sin actualizar el saber y en algunos casos improvisando las estrategias instruccionales. Como lo enfatiza López (2007) "la práctica docente se realiza fundamentalmente con base en la transmisión de saberes, en donde la memorización de datos se sobrepone a los procesos comprensivos" (p. 118). Así, la mediación llevada a cabo por los profesores con respecto a los objetos referentes que sólo consiste en la mera repetición o reiteración de información, auspiciará en los estudiantes desempeños situacionales, carentes de significación y por lo tanto, poco transferibles a situaciones problema relevantes al ámbito disciplinar o social.

A partir de los componentes de la interacción didáctica citados anteriormente objetivo instruccional, discurso didáctico, estudiante, objetos referentes--, Ibáñez (2007) planteó estilos de interacción del profesor, quedando conformados de la siguiente manera:

1. Estilo sin presencia de objetivo instruccional, sin discurso didáctico, sin objeto referente $(\Theta \mathrm{I}, \mathrm{ÐÐ}, \Theta \mathrm{\Theta R})$. En esta modalidad de interacción, no es posible encontrar propiamente una interacción didáctica.

2. Estilo con presencia de objetivo instruccional, sin discurso didáctico, sin objeto referente (OI, Đ円, $\mathrm{OR})$. En esta modalidad de interacción el docente explicita lo que deben hacer los alumnos, dejándolos que ellos busquen la información (DD) y los objetos referentes.

3. Estilo con presencia de objetivo instruccional, sin discurso didáctico, con objeto referente (OI, ĐĐ, OR). En esta modalidad de interacción el docente explicita a 
los alumnos lo que deben hacer o decir frente a un objeto referente, modelando o moldeando las maneras sobre cómo decirlo o hacerlo.

4. Estilo sin presencia de objetivo instruccional, sin discurso didáctico, con objeto referente $(\Theta I, \mathrm{D円}, \mathrm{OR})$. En esta modalidad de interacción didáctica el profesor presenta a los estudiantes el objeto referente pero no explicita a los alumnos los criterios del qué y el cómo con respecto a ese objeto referente.

5. Estilo sin presencia de objetivo instruccional, con discurso didáctico, sin objeto

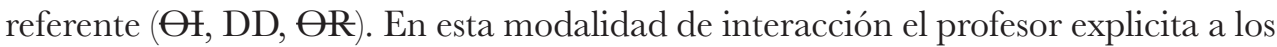
alumnos el qué y el cómo del hacer y del decir, pero la ausencia del objeto referente impide el contacto de los alumnos, como práctica.

6. Estilo sin presencia de objetivo instruccional, con discurso didáctico, con objeto referente $(\Theta I, \mathrm{DD}, \mathrm{OR})$. En esta modalidad de interacción didáctica el profesor explicita las maneras del decir y hacer a sus alumnos en relación a los objetos referentes, pero dejando implícito qué se espera como criterio de logro.

7. Estilo con presencia de objetivo instruccional, con discurso didáctico, con objeto referente (OI, DD, OR). En esta modalidad de interacción el profesor explicita a los alumnos qué se espera de ellos y les dice cómo hacerlo, mediando el contacto con el objeto referente, lo cual posibilita que los estudiantes pongan en práctica lo dicho y hecho por el profesor.

Es muy importante mencionar que el discurso didáctico no consiste únicamente en exposiciones verbales sobre lo que se debe hacer y no hacer y en cómo hacerlo, sino que consiste en una exposición aunada a la práctica como demostración, ejemplificación y ejercicio del desempeño a ser aprendido (Varela y Ribes, 2002). Tradicionalmente el discurso del profesor se ha interpretado (erróneamente) como la exposición oral, y que es efectivo por sí mismo al margen del tipo de saber que se este enseñando (conceptual, instrumental o actitudinal). De forma alternativa el concepto de discurso didáctico es aplicable y hace referencia solamente a las interacciones efectivas del profesor para auspiciar los desempeños planeados. 
El docente en este sentido, deberá cumplir la función de auspiciar interacciones efectivas entre el alumno y los referentes de la disciplina que lleven a la confrontación entre alternativas explicativas, vinculando el conocimiento científico y el cotidiano. Resulta necesario enfatizar que la concepción que el docente tiene acerca de cómo aprenden sus alumnos es decisiva en la metodología de enseñanza que vaya a desarrollar, así como los indicadores que tomará del desempeño del alumno (Rodríguez-Moneo y Carretero, 2000; Sánchez, 2005).

Esto se vincula necesariamente con los momentos de formación del estudiante, y cómo éste va exponiéndose al discurso didáctico del profesor en relación a distintos saberes. El estudiante entonces establece contacto con saberes conceptuales y/o procedimentales que requieren de el comportamiento en distintas modalidades lingüísticas (observar, escuchar, leer, señalar, hablar y escribir). Este comportamiento ha sido analizado como modos lingüísticos por Gómez (2005). Estos modos lingǘsticos han sido divididos para motivos de análisis en: a) modos reactivos (observar, escuchar y leer); y b) activos (señalar/gesticular, hablar y escribir). Los primeros se han sugerido para el aprendizaje de conocimiento declarativo, es decir, saberes referidos a hechos o acontecimientos. Los activos se han propuesto para el aprendizaje de conocimiento actuativo, es decir, conocimiento que se identifica como y a partir de un desempeño específico, ya sea motriz, lingüístico, o con varias morfologías de comportamiento (Ribes, 2008).

En el análisis de la adquisición de los modos lingüísticos se considera en primer lugar, que cada modo tiene propiedades funcionales específicas y, por consiguiente, las variables que tienen que ver con la adquisición de los modos reactivos pueden ser condición necesaria para la adquisición de los modos productivos. En segundo lugar, que en los episodios lingüísticos los modos pueden ocurrir intercalados y su aparición inicial no depende de su carácter reactivo o productivo.

Los modos lingüísticos se actualizan como interacciones con diferentes niveles funcionales. La posibilidad de interactuar en los diferentes niveles dependerá de las 
posibilidades reactivas del individuo y del arreglo de las contingencias a las cuales es expuesto. Fundamentado en el marco general de la propuesta de Ribes y López (1985), Mares y Rueda (1993) afirman que las características reactivas del organismo y su historia de interacción facilitan o dificultan el cambio lingüístico (por ejemplo, de hablar a escribir, de escribir a hablar o de señalar a hablar), mientras que el arreglo de las contingencias define la dirección de ese cambio.

Así, las distintas situaciones de aprendizaje explicitan cierto tipo de desempeños lingüísticos (en el caso del aprendizaje de contenidos científicos) que idealmente se corresponden funcionalmente con esas situaciones. La naturaleza de estos desempeños depende del tipo de objeto referente (visual, auditivo) con el que se está interactuando y del criterio de ajuste requerido -explícito o implícito- .

El contar con una propuesta de desarrollo funcional, posibilita la caracterización de los desempeños efectivos no solamente en términos cuantitativos sino como formas cualitativas de organización funcional. Si se piensa en un ejemplo, la conducta de escribir puede tener lugar como copiado o transcripción, pero también como formulación o reformulación con base en una situación o condición distinta a la de la elaboración de la tarea.

De tal manera que el estudio de la comprensión y las condiciones que probabilizan su ocurrencia, necesariamente se relaciona con el estudio experimental de las interacciones lingüísticas -escribir y hablar- (como desarrollo morfológico y también funcional). La comprensión siempre se identifica a partir de actos, lingüísticos y no lingüísticos -aunque se insiste que en el caso del aprendizaje de contenidos científicos son siempre lingüísticos-, que resultan en un desempeño que cumple con un criterio en una situación determinada. 


\section{Análisis de las interacciones estudiante-objetos referentes}

$\mathrm{Al}$ analizar la comprensión como interacción (bajo la lógica del modelo de interacción didáctica), es posible identificar cuatro grupos de factores que condicionan su ocurrencia:

\section{1) Factores relacionados con el estudiante}

Dentro de estos factores se pueden encontrar dos tipos de repertorios: a) aquellos relacionados con los repertorios lingüísticos básicos que se refieren a las habilidades y competencias en el uso del lenguaje (como hablante o escritor), así como la posibilidad de establecer contacto con los productos lingüísticos de los demás (como observador, escucha y lector). Dichas competencias se denominan básicas por suponerse como condición necesaria para que el estudiante pueda entrar en contacto e interactuar con los diferentes materiales de estudio; y b) los repertorios lingüísticos referidos a la disciplina de conocimiento -lenguaje formal/técnico-, consisten en las referencias lingüísticas con las que cuenta el estudiante universitario del ámbito funcional de desempeño que está aprendiendo y que modulan su ejecución actual (historia de referencialidad ${ }^{3}$ ). Por ejemplo, el estudiante aprende un vocabulario específico referido a conceptos, categorías, modelos, teorías, que le permiten la identificación y delimitación de hechos de la disciplina que aprende, así como la contrastación, interpretación y análisis de hechos.

\section{2) Factores relacionados con los objetos referentes}

El objeto referente consiste en los eventos o situaciones ante las cuales el estudiante debe desempeñarse según los criterios disciplinares, los cuales pueden presentarse en forma física o sustituta, como discurso, texto, grabación, video, conferencia, fotografía, gráfico. En el

3 En esta propuesta se utiliza el concepto de historia de referencialidad como los contactos sustitutivos precedentes de tipo referencial y no referencial, mientras que la historia de contactos no sustitutivos queda definida como historia situacional efectiva (para una revisión de este concepto ver Arroyo, 2002). 
aprendizaje de contenidos científicos se convierten en eventos o situaciones lingüísticas (p.e. átomo para el lenguaje de la química, electrón para la física, fotosíntesis para la biología, segmento interconductual para la psicología).

En las diferentes modalidades de presentación de los objetos referentes y/o materiales de estudio sobresalen como dimensiones relevantes:

a) La longitud -texto, audio-, sintaxis, presentación del material (expositiva, narrativa y explicativa), si contiene gráficos e imágenes (para la modalidad textual), y b) la duración, ilustraciones contenidas, si son estáticas o en movimiento (para la modalidad multimedia).

Por ejemplo, en el caso del material textual, Fuentes y Ribes (2001) y Fuentes (2007) han caracterizado los textos en tres modalidades con respecto al efecto que produce el escritor en el lector (actuativa, constativa y definicional) y el tipo de competencias que el lector debe exhibir en función del texto, descritas en la Tabla 4.

\begin{tabular}{|c|l|l|}
\hline Texto & \multicolumn{1}{|c|}{ Conformación } & \multicolumn{1}{c|}{ Cectura Comprensiva } \\
\hline Modalidad & \multicolumn{1}{|c|}{ Compencias } \\
\hline Actuativa & $\begin{array}{l}\text { Requiere que al leerse se haga algo con } \\
\text { él o respecto a él. El objeto de estímulo es } \\
\text { situacional. }\end{array}$ & $\begin{array}{l}\text { Ejecutivas: identificar y realizar las } \\
\text { acciones requeridas a llevar a cabo. }\end{array}$ \\
\hline Constativa & $\begin{array}{l}\text { Describe, narra o menciona en lo general } \\
\text { objetos o eventos. El objeto de estímulo es } \\
\text { extrasituacional. }\end{array}$ & $\begin{array}{l}\text { Imaginativas: reconocer el episodio } \\
\text { mencionado, narrado o descrito com- } \\
\text { portándose "como si" estuviera en la } \\
\text { situación. }\end{array}$ \\
\hline $\begin{array}{c}\text { Definicio- } \\
\text { nal }\end{array}$ & $\begin{array}{l}\text { Establece relaciones intralingǘsticas. El } \\
\text { objeto de estímulo es transituacional. }\end{array}$ & $\begin{array}{l}\text { Teóricas: identificar y responder a las } \\
\text { relaciones intralingǘsticas establecidas. }\end{array}$ \\
\hline
\end{tabular}

Tabla 4. Competencias que requiere el lector para ajustarse de manera efectiva a la modalidad del texto (Tomado de Fuentes, 2007, p. 288). 
Otra clasificación es la presentada por Garza (2006, citado en Cepeda y López, 2010), dicha propuesta enfatiza que los textos pueden clasificarse en cinco tipos atendiendo a su estructura: argumentativo, explicativo, descriptivo, narrativo y expositivo. Cada uno de ellos compuestos por distintos elementos (p.e. tesis, argumentos, cuerpo, conclusión, opinión personal de los autores, premisas, objetivo, entre otros).

Por su parte, Cepeda y López (2010) señalan con respecto al texto, que sus características presuponen una manera determinada de lectura, pero sobre todo, que es la intención del lector la que determina la forma y el grado de la exigencia lectora. Los autores mencionan diferentes tipos de lectura, por ejemplo, algunas son:

- Selectiva. Guiada con propósito ordenador o para extraer una vaga idea global.

- Exploratoria. Identificada por saltos para encontrar una información determinada.

- Informativa. Búsqueda rápida de una información puntual.

En cuanto a la clasificación de materiales Ogalde y González (2008), realizaron una clasificación de materiales de estudio según la forma en que se entra en contacto con ellos, el cual se ilustra en la Tabla 5. En dicha tabla se agregó la modalidad lingüística por los autores del presente manuscrito, con el propósito de describir cuáles son las variaciones en las modalidades lingüísticas auspiciadas por la modalidad de presentación de estos materiales, y cómo a pesar de que las presentaciones multimedia pudieran ser sensorialmente más estimulantes, las modalidades lingüísticas involucradas y las competencias que pudieran generarse en interacción con éstas, no necesariamente implican un desempeño efectivo y variado. 


\begin{tabular}{|l|l|l|}
\hline \multicolumn{1}{|c|}{ Modalidad de presentación } & \multicolumn{1}{|c|}{ Ejemplos } & $\begin{array}{c}\text { Modalidad lingüística } \\
\text { involucrada }\end{array}$ \\
\hline Texto palabra escrita & Libros, folletos, apuntes, hipertexto & Observar-Leer \\
\hline Imagen visual fija & Fotografías, dibujos y pinturas & Observar-Leer \\
\hline Imagen visual en movimiento & Animaciones, videos, películas & Observar-Leer \\
\hline Imagen sonora & $\begin{array}{l}\text { Audiodigital, audiolibro, programas } \\
\text { de radio }\end{array}$ & Observar-Escuchar \\
\hline Texto con imagen visual fija & Mapas, diagrama & Observar-Leer \\
\hline Texto con imagen sonora & Canciones, diálogos de muestra & Observar-Escuchar \\
\hline $\begin{array}{l}\text { Imagen visual fija con imagen } \\
\text { sonora }\end{array}$ & $\begin{array}{l}\text { Diapositivas con narración grabada, } \\
\text { imágenes con explicación auditiva }\end{array}$ & Observar-Escuchar \\
\hline $\begin{array}{l}\text { Imagen visual en movimiento } \\
\text { con imagen sonora }\end{array}$ & $\begin{array}{l}\text { Videos, películas, programas de } \\
\text { televisión, animaciones con sonido }\end{array}$ & Observar-Escuchar \\
\hline
\end{tabular}

Tabla 5. Clasificación de los materiales de estudio según la forma en que se entra en contacto con ellos (tomado de Ogalde y González, 2008, pp. 93 y 94) y modificada por los autores.

\section{3) Condiciones necesarias para la interacción (históricas y situacionales)}

Las condiciones necesarias para la interacción (bajo la lógica del modelo de campo) pueden ser de dos tipos: históricas y situacionales. Estas son condiciones que pueden facilitar o interferir la interacción funcional del estudiante con los objetos referentes. Entre los factores que pudieran afectar la interacción del estudiante con respecto a los objetos referentes son: a) aquellos que dependen de estados del organismo como sueño, hambre, fatiga, salud, enfermedad; b) los que dependen de la situación como la iluminación de lugar, ruido, temperatura, y c) los que dependen de la historia situacionalmente efectiva del estudiante. 


\section{4) Criterios de ajuste}

El criterio de ajuste consiste en el requerimiento conductual a satisfacer en una situación el cual puede ser implícito o explícito. Dicho criterio puede analizarse en función de:

a) el tipo de tarea (identificar, enunciar, describir, instrumentar, diagramar, relacionar y argumentar),

b) el nivel de complejidad (interacciones intrasituacionales, extrasituacionales y transituacionales) y

c) la modalidad lingüistica implicada (señalar, hablar, escribir).

El tipo de tarea involucra la dimensión de ocurrencia del desempeño del estudiante, definido a partir de criterios observacionales, que puede ser analizado en función de las instancias empleadas (gráfico, número, icono) o las relaciones requeridas (reflexividad, simetría, transitividad, inclusión, exclusión).

El nivel de complejidad del desempeño se identifica a partir del criterio funcional estipulado en la situación de interacción, que puede ir desde responder en términos situacionales en donde se involucran interacciones directas con los eventos o sus propiedades (interacciones intrasituacionales), hasta interacciones sustitutivas en donde la posibilidad del individuo le permite desligarse de las relaciones espacio-temporales produciendo alteraciones impuestas por los eventos dentro de la situación (interacciones extra y transituacionales).

En relación a la modalidad lingüística esta refiere a la forma en que ocurre la respuesta en su dimensión lingüística. Las circunstancias en que ocurre el aprendizaje como saber y conocer demandan la participación diferencial de modos lingüísticos. Los modos lingüísticos han sido agrupados (Camacho y Gómez, 2007; Fuentes y Ribes, 2001; Varela, 2004) en reactivos: observar, escuchar, leer (texteo); y activos: gesticular/señalar, hablar, leer (lectura comprensiva) y escribir. Así, el saber declarativo demanda de manera prominente la participación de los modos lingüísticos reactivos, y en el caso del saber, cuya circunstancia de ocurrencia es actuativa, predominan los modos lingüísticos activos (Ribes, 2010). 
Autores como Camacho (2006); Camacho y Gómez (2007); Camacho et al. (2007), han realizado una serie de estudios para analizar los modos lingüísticos (reactivos -observar, escuchar, leer- y activos -señalar, hablar, escribir-) sobre la transferencia a un modo distinto en niños de primaria. Los autores discuten los resultados en función de las variaciones de los modos lingüísticos, las cuales presentan modulaciones de comportamiento diferenciales ante su adquisición y posibilidad de transferencia explicitados en la Tabla 6.

\section{Modos lingüísticos}

\begin{tabular}{|l|l|l|l|l|l|}
\hline Activos & Reactivos & $\begin{array}{l}\text { Facilidad de } \\
\text { adquisición }\end{array}$ & $\begin{array}{l}\text { Situación por la } \\
\text { cual se da su nivel } \\
\text { de adquisición }\end{array}$ & $\begin{array}{l}\text { Grado de } \\
\text { desliga- } \\
\text { miento }\end{array}$ & Características \\
\hline $\begin{array}{l}\text { Gesticular } \\
\text { /Señalar }\end{array}$ & Observar & Alta & $\begin{array}{l}\text { Es parte del } \\
\text { repertorio natural } \\
\text { del sujeto, tiene } \\
\text { respuestas con } \\
\text { características mor- } \\
\text { fológicas específicas, } \\
\text { es menos arbitrario. }\end{array}$ & Bajo & $\begin{array}{l}\text { Por estar circunscritos } \\
\text { a un sistema reactivo } \\
\text { motriz (sensorial), que } \\
\text { tiene lugar en tiempo } \\
\text { y espacio restringidos y } \\
\text { singulares. }\end{array}$ \\
\hline Hablar & Escuchar & Media & $\begin{array}{l}\text { Tiene respuestas } \\
\text { con características } \\
\text { convencionales } \\
\text { que ocurren ante } \\
\text { estímulos auditi- } \\
\text { vos momentáneos } \\
\text { con morfología y } \\
\text { discriminabilidad } \\
\text { específicas. }\end{array}$ & Medio & $\begin{array}{l}\text { Por ser sistemas } \\
\text { reactivos convencio- } \\
\text { nales arbitrarios y sus } \\
\text { respuestas ocurren } \\
\text { ante estímulos auditi- } \\
\text { vos momentáneos con } \\
\text { morfología y discrimi- } \\
\text { nabilidad específicas. } \\
\text { La arbitrariedad de la } \\
\text { morfología de respues- } \\
\text { ta es lo que facilita su } \\
\text { desligabilidad. }\end{array}$ \\
\hline
\end{tabular}




\begin{tabular}{|l|l|l|l|l|}
\hline Escribir & Leer & Baja & $\begin{array}{l}\text { La conducta es } \\
\text { estrictamente } \\
\text { simbólica y se } \\
\text { reacciona ante es- } \\
\text { tímulos convencio- } \\
\text { nales. Tiene mayor } \\
\text { dificultad para } \\
\text { ejercitarse mediante } \\
\text { respuestas arbitra- } \\
\text { rias, con morfología } \\
\text { específica que se } \\
\text { emiten ante objetos } \\
\text { de estímulo lingǘs- } \\
\text { ticos. }\end{array}$ & $\begin{array}{l}\text { Alto } \\
\text { sistemas reactivos ante } \\
\text { objetos de estímulo lin- } \\
\text { güísticos y como pro- } \\
\text { ductores de esa misma } \\
\text { clase de estímulos, con } \\
\text { morfología específica } \\
\text { y discriminabilidad di- } \\
\text { recta. Tienen sistemas } \\
\text { reactivos constituidos } \\
\text { por objetos de estímulo } \\
\text { lingǘsticos, con per- } \\
\text { manencia no limitada } \\
\text { en tiempo y espacio } \\
\text { en el que ocurre la } \\
\text { respuesta. }\end{array}$ \\
\hline
\end{tabular}

Tabla 6. Condiciones de adquisición y grado de desligamiento de los modos lingüísticos (tomado de Camacho y Gómez, 2007, pp. 113 y 116).

La emisión de comportamiento efectivo ante situaciones novedosas, dependerá del tipo de entrenamiento y del nivel de desligamiento de la respuesta en la situación en la que se aprendió. El grado de desligamiento de la respuesta parece depender de la naturaleza del modo lingüístico y de su evolución en la ontogenia (Camacho, 2006), por lo que cada modo lingǘstico tiene un nivel distinto de desligabilidad que depende de su funcionalidad situacional.

Por su parte, Mares et al. (2006), llevaron a cabo un estudio con el propósito de analizar si las características referidas al uso de imágenes, a las demandas de actividades y a la estructura de los textos utilizados en la enseñanza de la biología promueven la comprensión lectora y la transferencia de lo aprendido. Para ello, utilizaron las siguientes categorías:

1) coherencia del texto (a través del propósito de la lección y el tipo de vinculación de los enunciados y párrafos), 
2) solicitud de alguna actividad con relación a las imágenes no decorativas en el texto principal y en los ejercicios (a través de la mención de la imagen en el texto, la indicación al lector a que observe la imagen, o si se solicita que se haga algún ejercicio con la imagen),

3) preguntas o instrucciones incluidas en textos y ejercicios (a través de la formulación de preguntas relativas a conceptos, solicitudes que implican que el niño relacione, que organice, etc.), y

4) correspondencia con el sistema conceptual de la biología (a través de los errores en la definición y/o ejemplos de conceptos abordados en la lección, relaciones o explicaciones no pertinentes, entre otros). Los resultados señalaron que en las lecciones dedicadas a la enseñanza de la biología la mayoría de los profesores no especifican el objetivo instruccional de la lección; en más del 90\% de las ilustraciones no se solicita realizar actividades con ellas, siendo pocas las solicitudes de observación y descripción de eventos en este reporte, así como la ausencia de correspondencia con el sistema conceptual de la disciplina que se enseña.

Derivado del estudio anterior, Mares et al. (2009), realizaron un estudio para evaluar las competencias lingüísticas de biología, en niños de segundo grado de primaria, y la comparación de la ejecución en tres modalidades de textos, uno elaborado por la SEP -y su estrategia de enseñanza- y dos modificados por los autores de la investigación. Las estrategias analizadas fueron: a) estrategia oficial (en donde se solicitaba leer sobre la temática de interés, platicar en clase sobre la lectura, dibujar algunos de los aspectos revisados, entre otras actividades); b) texto modificado e integración de la competencia (en donde se auspiciaron actividades de integración por medio de actividades de redacción sobre lo leído y expuesto en clase, guiando a los alumnos a la búsqueda intencional de elementos relevantes del texto); c) texto modificado y promoción de deducciones (en donde se presentaron ilustraciones de la temática de interés, y se plantearon preguntas que permiten a los niños 
la reelaboración de la definición de los conceptos, para que con base en esto, elaborarán las respuestas a las preguntas). Los resultados indicaron que sólo en el grupo de promoción de deducciones se encontraron diferencias significativas entre las dos evaluaciones; los avances en las competencias por concepto se analizan en términos de sus posibles relaciones con los textos y las estrategias empleadas en cada grupo.

A partir de los resultados del estudio los autores propusieron una serie de lineamientos para el diseño de los libros de texto, los cuales quedaron organizados en cuatro aspectos:

- Estructura del texto (se propone indicar de manera explícita el propósito de la lección, establecer vínculos con lo visto en lecciones anteriores y organizar los párrafos con base en el propósito especificado y no a través de un tema).

- Imágenes (se propone establecer una vinculación explícita entre el texto y la imagen, y solicitar que los niños realicen actividades con ellas (completar, describir, comparar, dibujar), para lograr el contacto con el contenido del texto).

- Preguntas, instrucciones y ejercicios (se propone introducir preguntas y/o ejercicios después de cada párrafo en donde se presenten conceptos, que permitan ejercitar, integrar, aplicar, inferir y elaborar las expresiones lingüísticas propias del lenguaje científico que están aprendiendo).

- Contenidos (se propone un análisis de éstos por especialistas de la ciencia que se enseña, del desarrollo, de la enseñanza y del aprendizaje).

Otro estudio que también incluye, entre otros aspectos, el examen de las imágenes, es el realizado por Varela (2008). El autor analizó las secciones correspondientes a la enseñanza de la geografía incluidas en los libros de ciencias naturales y geografía. Los resultados indicaron que: a) al tener los mismos contenidos en los libros de geografía y los de ciencias naturales, los maestros se ocupan sólo de uno de ellos, sin que se presente la oportunidad de interactuar con los contenidos de dos formas distintas; b) en general no se hace referencia explícita a las ilustraciones, ni tampoco se identifica el lugar específico donde se tomaron las 
fotografias; c) aunque se practica la elaboración de mapas y gráficas, su frecuencia es tan baja que resulta difícil esperar un aprendizaje significativo; d) las secciones prácticas tienen un predominio de preguntas cuyas respuestas requieren sólo la repetición de los conocimientos expuestos en la lección; y e) las actividades incluidas en las secciones relativas a la evaluación del aprendizaje se convierten en guías de estudio para los exámenes que, generalmente, sólo incluyen la evaluación periódica de contenidos memorizados.

Por su parte, Bazán y Mares (2002) y Mares, Rivas y Bazán (2002) aportan evidencia con respecto al tipo de entrenamiento con base en niveles funcionales diferenciados e indican que el nivel funcional en el cual se instruye a elaborar lingüísticamente una relación, afecta el grado de transferencia de la expresión relacional hacia otros eventos susceptibles de ser elaborados de la misma manera. En particular, Mares et al. (2002), encontraron que los niveles funcionales en los cuales se aprende y ejercita una competencia lingüística promueve diferencias considerables a favor del grupo más complejo, lo cual sugiere que el nivel funcional en que se entrene o ejercite una competencia funge como un factor disposicional de la ejecución futura.

Un dato adicional, es que en los trabajos en los cuales se ha encontrado que los niveles que implican un contacto con eventos no aparentes por parte de los estudiantes, éstos aumentan la probabilidad de transferencia, caracterizándose por incluir, además de las expresiones lingǘsticas relacionales, el contacto con los eventos ante los cuales la expresión relacional cobra sentido -imágenes- (Pineda, Aguirre, Gómez y Mares, 2008). Por ejemplo, Mares, Guevara y Rueda (1996) llevaron a cabo un estudio con el propósito de explorar si la inclusión de sustitutos de acontecimientos relacionales (imágenes) y preguntas acerca de las relaciones en los textos, facilitan la adquisición de competencias lingüísticas de elaborar relaciones condicionales, causales y funcionales, aprendidas a través de la lectura, y su transferencia hacia otro tema, incorporando algunas variaciones en los textos de entrenamiento. Las variaciones consistieron en incluir en cada texto: 1) un dibujo para cada relación elaborada en el texto, 2) un dibujo igual que el anterior, en el cual faltaba la parte que 
representaba la relación leída, y 3) preguntas escritas sobre las relaciones entre eventos. Con este entrenamiento se logró que los niños transfirieran las competencias de elaborar relaciones.

Pineda et al. (2008) basándose en el estudio anteriormente citado, evaluaron el efecto que las imágenes por sí mismas puede tener en la transferencia de lo aprendido y el efecto que las preguntas acerca de las relaciones pueden tener sobre la transferencia, así como cuál de estas variables son más relevantes para auspiciarla. Los resultados apuntan a considerar que ninguna de las dos tareas implementadas en ambos tipos de entrenamiento tuvo más peso en el aprendizaje y su transferencia. Los datos reportados señalan la conveniencia de combinar durante la lectura, con niños de primaria estas variables: a) textos con una estructura que facilite el contacto lingǘstico con el referente -imagen--, b) el uso de imágenes representativas que medien el contacto con el referente, c) la realización de conductas adicionales a sólo observar las imágenes -p.e. describir las imágenes-, y d) las preguntas de inferencia que promuevan una mejora en la comprensión de la lectura y la transferencia de lo aprendido.

En las siguientes líneas se presentan de forma sintetizada los planteamientos generales derivados de los estudios llevados a cabo por Mares y colaboradores. Se considera que ésta lógica puede ser aplicable a estudiantes universitarios, y como punto de partida de la metodología presentada en este trabajo (Mares, 2008):

1) La relación que el estudiante establece con los textos y con su contenido es vista como una relación histórica, construida a lo largo de su vida, especialmente a través de sus contactos directos con los objetos y eventos a los cuales el texto hace referencia. 2) El leer y el escribir (así como también el hablar) pueden ser ordenados en términos de niveles cualitativos de desligamiento, con base en la taxonomía funcional del comportamiento propuesta por Ribes y López (1985). Dependiendo del nivel en el que se establece la competencia, las competencias de lectura y escritura pueden ejercitarse en el modo hablado y transferirse al modo escrito, o facilitar su aprendizaje. La influencia también se da en el otro sentido, del modo escrito al hablado.

3) Existen diferencias importantes entre los campos conductuales involucrados en el 
dominio de la lengua hablada y los implicados en el dominio de la lengua escrita. La relación escucha-hablante y la relación lector-escritor conllevan distancias temporales y espaciales distintas con respecto a la ubicación de los participantes. En el segundo caso, el lector y el escritor interactúan con alguien no presente ubicado en un contexto distinto, situación que obliga al desarrollo de competencias que les permitan ajustarse al lector y escritor ausentes, situados en otros contextos. El cambio de la relación escuchar-hablar a leer-escribir implica un cambio del medio a través del cual se establece el contacto con los participantes y la relación referida. El producto del habla es evanescente mientras el que resulta del producto escrito es permanente. El estudiante puede interactuar con el producto generado por su conducta y modificarlo, reflexionar sobre él, analizarlo. Esto abre posibilidades de desarrollo funcional, al permitir o fortalecer otras maneras de interacción con los textos.

4) Cuando un estudiante se inicia en el aprendizaje de contenidos científicos, se requiere que aprenda: a) competencias que posibiliten observar las secuencias, las transformaciones y las relaciones de dependencia de los objetos, organismos y eventos de la naturaleza; b) competencias lingüísticas de nombramiento de los objetos, organismos y eventos estudiados por la ciencia, elaborar lingüísticamente las secuencias, transformaciones y relaciones de dependencia entre ellos, así como realizar inferencias basadas en aspectos de los sistemas lingüísticos, y c) competencias operativas y de procedimiento, con diferentes grados de elaboración, que posibiliten la observación y la manipulación de los objetos de estudio.

5) Las competencias lingüísticas relacionales (competencias declarativas) que están integradas como competencias observacionales y operativas, ligadas al mismo grupo de objetos y eventos, se transfieren hacia grupos de objetos que se relacionan de la misma manera. La configuración de estas competencias necesita suceder de manera desligada de las circunstancias situacionales concretas. 
6) Las competencias lingüísticas relacionales que no están integradas con competencias observacionales $\mathrm{u}$ operativas ligadas al mismo grupo de objetos y eventos, difícilmente se transfieren. Permanecen en la esfera del discurso.

7) Algunas de las condiciones que favorecen la integración funcional de diferentes competencias observacionales, operativas y lingüísticas ligadas con un mismo grupo de objetos o eventos son:

- El contacto con la expresión lingüística relacional y con los eventos o sus sustitutos, de manera cercana en tiempo. Este contacto cuasi-simultáneo debe entenderse como un ir de la interacción con los objetos que se relacionan o transforman a la interacción con la expresión lingüística relacional, de tal manera que los eventos pertinentes se elaboren como relación (Mares et al. 1996; 2002).

- El planteamiento de preguntas que vayan más allá de lo explícitamente contenido en las elaboraciones lingüísticas evita que la interacción con el niño se circunscriba estrictamente a lo lingüístico, y a su vez promueve que el niño interactúe con las expresiones en su carácter de construidas sobre la trama de lo observado y de sus relaciones. Este tipo de preguntas promueve el contacto indirecto con el referido y, por lo mismo, la integración funcional de los sistemas reactivos observacionales, operativos y lingüísticos.

8) Algunas de las condiciones que favorecen el desligamiento de las competencias observacionales, operativas y lingüísticas de las circunstancias no pertinentes a las competencias estudiadas son:

- La introducción de una demora de 24 horas entre el contacto con los objetos y sus relaciones, y el contacto con las expresiones lingüísticas relacionales.

- El planteamiento de preguntas sobre relaciones entre los objetos presentes y progresivamente sobre las relaciones entre objetos no presentes y entre acontecimientos pasados y futuros.

- La variación sistemática de las propiedades aparentes de los objetos, organismos y circunstancias involucradas en los eventos, relaciones y transformaciones. 
En relación a estudios llevados a cabo con estudiantes universitarios, muestran resultados similares a los mencionados anteriormente con niños, es decir, las meras descripciones lingüísticas no parecen promover ajustes de mayor nivel de desligamiento. Arroyo (2002) evaluó los efectos de entrenar distintos tipos de contactos previos con el referente de un texto en una prueba de comprensión lectora. Se conformaron cinco grupos experimentales, correspondientes a los cinco niveles funcionales (propuestos por Ribes y López, 1985), encontrándose que el porcentaje de respuestas correctas, en la prueba de comprensión, fue incrementándose ligeramente conforme acrecentaba el nivel de complejidad del entrenamiento, lo cual parece semejante a lo encontrado por Mares et al. $(1996,2006)$. No obstante, las diferencias entre los grupos fueron pocas e incluso el grupo de mayor complejidad (sustitutivo no referencial) obtuvo resultados ligeramente inferiores a los del grupo adyacente, el sustitutivo referencial.

Arroyo y Mares (2009) con el objetivo de evaluar los efectos de las relaciones entre objetos y sus elaboraciones lingüísticas sobre el ajuste lector de estudiantes universitarios entrenaron cinco tipos de contacto, es decir, construyeron experimentalmente cinco tipos de relaciones entre los objetos y sus elaboraciones lingüísticas (grupos experimentales), relaciones que iban de lo más simple a lo más complejo (en términos de niveles de desligamiento), mientras que en un sexto grupo no tuvo ningún tipo de entrenamiento (grupo control). Los resultados demostraron que conforme se incrementa la complejidad funcional de las relaciones objeto-expresión lingüística aumentan el porcentaje promedio de aciertos, específicamente en los niveles más complejos.

Los siguientes estudios analizan si la explicitación del criterio, las variaciones en el tipo de tarea y su nivel funcional, y la modalidad lingüística implicada genera desempeños diferenciales en la comprensión de objetos referentes y/o materiales de estudio con contenido científico en estudiantes universitarios de ciencias sociales y ciencias de la salud. El marco de referencia en el cual se sustenta el presente trabajo es la Teoría de Campo Interconductual (Kantor y Smith, 1975), la Teoría de la Conducta - que permite una clasificación de niveles 
funcionales del comportamiento psicológico- (Ribes y López, 1985), y de los cuales se derivan el Modelo de la Práctica Científica Individual (Ribes et al. 1996; Padilla, 2006), así como el Modelo de Interacción Didáctica (Carpio e Irigoyen, 2005; Irigoyen, 2006; Irigoyen y Jiménez, 2004; Irigoyen et al. 2007), estos modelos han permitido una heurística al análisis de la dimensión psicológica en los procesos educativos y particularmente, aquellos vinculados a la enseñanza-aprendizaje de contenidos científicos.

En el caso específico de la propuesta que se presenta en este manuscrito, dos consideraciones son importantes:

a) El concepto de comprensión es entendido como una categoría episódica, el cual permite analizar la interacción del estudiante en relación con los objetos referentes (sean estos textos, videos, fotografías, conferencias), así como los elementos que posibilitan satisfacer o no los criterios o requerimientos en una situación (p.e. historia de referencialidad) $y$,

b) la posibilidad de analizar las interacciones del estudiante con los objetos referentes -como ajuste efectivo-, en distintos niveles funcionales. De tal manera que los desempeños del estudiante (p.e. leer, hablar y escribir) pueden configurarse funcionalmente en diferentes niveles.

Así, comprender (desde una perspectiva interconductual) significa que el desempeño del estudiante se ajuste efectivamente a criterios específicos en un ámbito funcional de desempeño. Los requerimientos conductuales que el estudiante "debe" satisfacer en una situación específica, pueden ser analizados a partir del tipo de tarea y su nivel funcional, así como la modalidad lingüística implicada. De esta manera, el episodio al que denominamos "comprensión" involucra necesariamente el desempeño efectivo del estudiante, el objeto referente, así como el criterio de ajuste que demanda la situación problema, y el objetivo instruccional; elementos todos que configuran una función, es decir, una relación de afectación recíproca (Kantor, 1980). • 
(Página en blanco) 


\section{Capítulo 4}

Aproximación metodológica al análisis de la comprensión de contenidos científicos
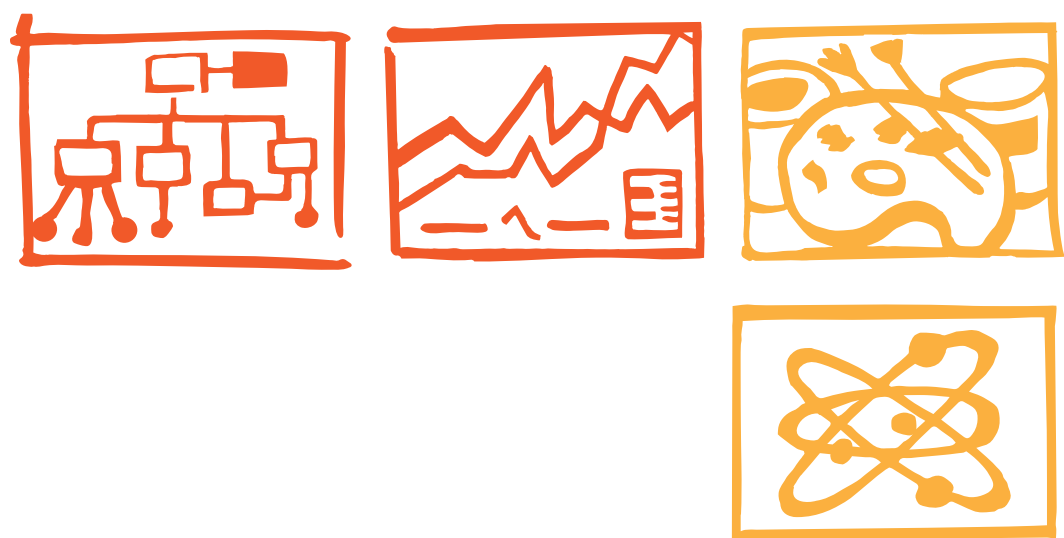
(Página en blanco) 
El planteamiento de una metodología adecuada garantiza que las relaciones que se establecen y los resultados o nuevos conocimientos obtenidos tengan el máximo grado de confiabilidad. Martínez y Moreno (2002) señalan que “...en el proceso de medición la correspondencia entre la representación formal-numérica y los fenómenos empíricos ha de considerarse mediada por las propiedades abstraídas por el investigador de dicho fenómeno, de acuerdo con algún modelo teórico y con la ayuda de su instrumental metodológico” (p. 90).

Autores como Carrillo (1983) enfatizan que una teoría científica, al igual que un modelo filosófico, representa solamente arreglos convencionales, es decir, sistemas de categorías que segmentan artificialmente sus dominios de conocimiento y describen en formas distintas una misma realidad. Pero la Ciencia no ofrece sus categorías como entidades dadas a priori ni en forma definitiva. El sistema (en lo conceptual, procedimental y métrico) se va ampliando y modificando conforme se desarrollan sus instrumentos de conocimiento, conforme puede ir ampliando sus relaciones categoriales, generando criterios instrumentales y derivando los parámetros para el análisis cuantitativo o cualitativo de los fenómenos.

Domínguez (2007) en este mismo tenor comenta: “...queda claro que construir un objeto -de estudio- implica una complejidad creciente de relaciones en las que se develan una serie de indicadores, variables, datos, hechos (o como se les quiera nombrar, dependiendo de la lógica utilizada), no consideradas en un inicio" (p. 48).

En este sentido, se considera que los modelos juegan un papel fundamental en la explicación teórica de los hechos. Bunge (1985) plantea el origen de los modelos y el rol que desempeñan en el proceso de construcción científica "para apresar la realidad se empieza por apartar información. Se agregan, luego, elementos imaginarios (o más bien hipótesis) pero con una intención realista. Se construye así un objeto modelo esquemático y que puede dar frutos, deberá integrarse en una teoría susceptible de ser confrontada con los hechos" (p. 15). En otras palabras, la metodología no es más que la aplicación de los criterios lógicos de la teoría y del análisis de los fenómenos empíricos previamente delimitados. 
El modelo de interacciones didácticas (descrito detalladamente en la Figura 4, p. 68) ha permitido integrar bajo una misma lógica conceptual y metodológica, las interacciones entre los actores y los medios que confluyen en el escenario educativo, posibilitando identificar y analizar algunas de las variables críticas asociadas al aprendizaje y la enseñanza de una disciplina científica (Irigoyen et al. 2007; 2011) a saber:

a) Las estrategias instruccionales del profesor con relación a los objetos referentes y/o materiales de estudio y sus maneras de mediarlos,

b) el desempeño del estudiante con relación a los objetos referentes y/o materiales de estudio, así como las diferentes maneras de entrar en contacto con estos,

c) las características del objeto referente.

Bajo esta perspectiva, la definición de las interacciones en el ámbito educativo, se establece en términos de una configuración de elementos integrados e interdependientes. Esta concepción general implica un sistema descriptivo y explicativo para el análisis de las interacciones del ámbito educativo, como es el caso de la denominada "comprensión". Así, su análisis implica la delimitación de las circunstancias de ocurrencia y los criterios para su identificación. A decir de Moreno (1998), las características de la evaluación deben guardar una correspondencia con la concepción que se tenga del evento a estudiar. La comprensión por lo tanto, es evaluada en la presente obra a partir de los elementos que constituyen un episodio de interacción: estudiante, objeto referente, criterio de ajuste, área de conocimiento que se enseña-aprende.

Es importante señalar que las formas de interacción del profesor (como discurso didáctico) y la modalidad de los objetos referentes o materiales que utiliza en clase, pueden ser ausipiciadores o no, o tener un efecto facilitador o no, sobre la adquisición de desempeños competentes de distintos niveles funcionales (que pueden ir desde interacciones que dependen de la situación concreta hasta interacciones abstraídas, y que transcienden cualquier referencia a eventos y/o situaciones concretas). En este sentido, estarían implicadas formas 
diferenciales de ajuste efectivo del estudiante (comprensión) en función de las modalidades del discurso didáctico y del objeto referente. Es necesario tener presente que en el caso del aprendizaje de contenidos científicos se requiere que el estudiante sea capaz de mediar lingüísticamente (sea escribiendo o hablando) los hechos, operaciones y los criterios de medida pertinentes al ámbito funcional de desempeño que se enseña-aprende.

El estudiante mientras se va adecuando a los criterios disciplinares científicos, aprende una serie de conceptos técnicos propios de la disciplina, así como formas de instrumentación particular que le posibilitan transitar y mediar el contacto con los eventos (de lo concreto a lo abstracto y de lo abstracto a lo concreto) como aprendizaje de los juegos de lenguaje de una disciplina. Como se comentó en el Capítulo 2, el estudio de Padilla (2006) probó que el tipo de competencias (como desempeños con tendencia a la efectividad) que se ejercitan están determinadas por la teoría. Los resultados mostraron que cada uno de los estudiantes exhibieron competencias diferentes en función de las características de la teoría a la que habían sido expuestos previamente.

Si bien el estudio de Padilla no tenía el propósito de analizar explícitamente la comprensión de contenidos científicos, si se desea enfatizar que los estudiantes en dicho estudio fueron expuestos a la lectura de textos científicos y videofilmaciones, los cuales fueron evaluados con una serie de tareas tales como: contestar un cuestionario, re-escribir con sus propias palabras el material leído (paráfrasis), elaborar un diseño experimental, realizar un experimento, escribir un reporte experimental y presentar de forma oral el reporte experimental. Los resultados obtenidos señalaron una correlación entre la dominancia categorial de la teoría con el tipo de competencias mostradas por los estudiantes.

Por su parte, Morales et al. (2013) llevaron a cabo un estudio con el propósito de evaluar los efectos de variar el tipo de criterio de ajuste y el tipo de morfología de la respuesta en tareas de ajuste lector. Los estudiantes universitarios que participaron en el estudio fueron asignados a uno de cuatro grupos que se distinguían por la constancia-variabilidad del criterio y la constancia-variabilidad de la morfología de la respuesta para satisfacer el criterio. En los 
resultados se encontró que, en general, el entrenamiento variable de criterios y morfologías tuvo mayores efectos positivos sobre el desempeño en ajuste lector, en contraste con los grupos expuestos a un solo criterio o a una sola morfología. Los resultados permiten sugerir que la exposición a la variabilidad de criterios y a la variabilidad de formas de satisfacerlos (morfología de la respuesta) afecta diferencialmente, auspiciando un desempeño lector pertinente.

A partir de los resultados de los estudios de Morales, Cruz, León et al. (2010) y Morales et al. (2013) se plantean cuando menos dos implicaciones: 1) que el texto tiene una estructura y sentido formal, mientras que psico-pedagógicamente, tiene tantos sentidos como criterios sean impuestos en la situación de lectura, y 2) que el contenido teórico se puede tornar homogéneo funcionalmente hablando, si el criterio de ajuste no cambia, a tal punto que un estudiante puede leer muchos textos de diferentes perspectivas teóricas, pero si siempre cumple el mismo tipo de criterio será de poco valor funcional.

Los autores reportan que si a los estudiantes de licenciatura se les impone el mismo tipo de criterio - por ejemplo, uno que demande solamente repetir lo leído- la habilidad que se desarrollará tendrá que ver con la repetición literal de los textos, sin importar que lean textos diferentes; en ese sentido, el criterio al ser del mismo tipo funcional, parece tornar homogéneos los materiales. Por el contrario, si se imponen criterios de diferente complejidad funcional a los estudiantes, se incrementan las probabilidades de exhibir desempeños pertinentes en tareas de ajuste lector aunque sea el mismo texto.

De ahí que resulte relevante el estudio de la comprensión a partir de cofactores que integran un campo, toda vez que permite analizar variables como la explicitación del criterio a cumplir, el tipo de tarea (como criterio morfológico), el criterio de ajuste o logro (como criterio funcional). En el estudio de la comprensión se han enfatizado las formas particulares de la actividad del estudiante independientemente del ámbito funcional de desempeño, del criterio de logro o ajuste y del tipo de tarea, lo que ha dado como resultado la valoración de capacidades o actividades con valor universal. 
Se considera que el análisis de la comprensión bajo la propuesta del presente manuscrito, permite analizar lo que el estudiante dice y/o hace con respecto a los diferentes juegos de lenguaje (p.e. identificación de hechos, formulación de preguntas, representación de las relaciones observadas, formulación de inferencias o conclusiones) que se enseñan dentro de un ámbito funcional de desempeño, tomando en cuenta, la modalidad del discurso didáctico, la modalidad del objeto referente, el criterio de ajuste y las condiciones que probabilizan que la ocurrencia del desempeño como ajuste efectivo (aquí entrarían en juego los denominados repertorios linguísticos básicos y repertorios linguísticos de ámbito).

De esta manera, la comprensión esta dada en términos de las posibilidades lingüísticas del estudiante con relación a la demostración del profesor o a partir de la interacción con un texto, ya sea señalando, hablando y/o escribiendo, es decir, la comprensión es entendida como ajuste efectivo a criterios diferenciales que tienen lugar como un decir-hacer lingǘstico de manera pertinente respecto también de un decir-hacer lingüístico de ese ámbito funcional de desempeño.

Por lo que, el análisis de la modalidad lingüística implicada, la naturaleza de los objetos referentes, el tipo de tarea y su nivel funcional implica poder identificar las condiciones que favorecen formas de mediación efectiva o que constituyen un papel fundamental para la habilitación competencial del estudiante con respecto a la disciplina que aprende.

$\mathrm{Al}$ contar con una clasificación funcional de niveles jerarquizados (Ribes y López, 1985), la comprensión como ajuste efectivo a los distintos criterios puede estructurarse en diferentes niveles de complejidad, posibilitando así, el análisis de aspectos tanto cuantitativos como cualitativos de la interacción del estudiante con respecto a los objetos referentes y/o materiales de estudio en los distintos momentos de formación.

Así, el estudio experimental de las condiciones necesarias para la evaluación de la comprensión requiere considerar cuando menos las siguientes variables:

- En relación al estudiante es necesario considerar los repertorios lingüísticos básicos, repertorios lingüísticos de dominio (historia de referencialidad). Los denominados 
repertorios básicos refieren a las habilidades y competencias en el uso del lenguaje (como hablante o escritor), así como la posibilidad de establecer contacto con los productos lingüísticos de los demás (como observador, escucha y lector). En el caso de los repertorios lingüísticos de ámbito, en el caso universitario (lenguaje formal/ técnico), constituyen el ámbito funcional de desempeño en donde el comportamiento de los individuos se significa.

- En relación a los objetos referentes es necesario considerar que estos pueden presentarse en forma física o sustituta, como discurso, texto, grabación, video, fotografía, material multimedia. Por ejemplo, en el caso de que el material sea multimedia: la duración, ilustraciones contenidas, si son estáticas o en movimiento; si el material sea escrito: la longitud del texto, sintaxis, presentación del material - expositiva, narrativa y explicativa- ${ }^{-}$, características del material -si contiene gráficos, imágenes, etc- ${ }^{-}$.

- Con relación a los factores disposicionales es necesario considerar que son elementos o factores que probabilizan el contacto funcional del estudiante con los objetos referentes, los cuales pueden ser históricos o situacionales. En el caso de los históricos: la historia de referencialidad como historia situacionalmente efectiva del estudiante que le posibilitará interactuar en cierto nivel funcional de contacto. En el caso de los situacionales, que dependen del individuo: sueño, hambre, fatiga, salud, enfermedad; en el caso de los situacionales que se identifican en la situación: iluminación, ruido, temperatura.

- Con relación al criterio de ajuste o requerimiento a satisfacer en una situación puede analizarse en función de: a) el tipo de tarea (identificar, enunciar, describir, instrumentar, diagramar, relacionar y argumentar), b) el nivel funcional (interacciones intrasituacionales, extrasituacionales y transituacionales) y c) la modalidad lingüística implicada (señalar, hablar, escribir). 
Bajo estos supuestos, se ha evidenciado la importancia de analizar en la interacción del estudiante con respecto a los objetos referentes, variables como: el tipo de tarea (Irigoyen, Acuña y Jiménez, 2006; Mateos y Flores, 2008), el modo lingüístico (Irigoyen, Jiménez y Acuña, 2006; Mejía y Camacho, 2007; Quiroga, 2010), el nivel funcional de la tarea (Irigoyen et al. 2004), variación en el tipo de criterio y morfología de la respuesta (Mateos y Flores, 2008; Morales, Cruz, León et al. 2010), habilidades escritoras y su enseñanza (Pacheco, 2010) en el aprendizaje de contenidos científicos.

Analizar la interacción estudiante-objetos referentes tomando en cuenta la modalidad lingǘstica implicada (escribir, hablar), la tarea y su nivel funcional, se considera que posibilita una caracterización de cómo el estudiante va configurando lo que se denomina "aprender" ciertos contenidos científicos. Por lo cual, indagar sobre algunas de las variables relevantes a esta relación, permite clarificar las maneras en cómo adquiere el estudiante universitario una serie de habilidades y competencias correspondientes al área de conocimiento en la cual se está formando, que le permitirá exhibir repertorio pertinente a las demandas impuestas por el currículo académico, y posteriormente a su ejercicio profesional de manera eficiente y variada.

Los antecedentes empíricos sobre los que se sustenta el presente manuscrito se describen brevemente en las siguientes líneas. Esto con el propósito de mostrar la consistencia en la evidencia empírica sobre el tipo de variables relevantes al análisis de la interacción del estudiante con los objetos referentes, y al mismo tiempo, formular categorías analíticas y su derivación paramétrica, de mayor pertinencia. Los estudios fueron llevados a cabo con estudiantes universitarios, el primero con el propósito de evaluar si los modos lingüísticos (leer-señalar, leer-escribir) determinaban ajustes diferenciales en el aprendizaje de un área de conocimiento, y el segundo, para caracterizar el desempeño del estudiante a partir de la modalidad lingüística escribir (representación de un concepto, así como la justificación del mismo) en el contexto de la enseñanza-aprendizaje de una disciplina científica. 
El primer estudio se llevó a cabo con 40 estudiantes universitarios del segundo semestre de la carrera de Psicología. Para tal propósito, se elaboraron una serie de pruebas que contenían resúmenes de artículos de investigación científica en el ámbito de la psicología (de 2-5 textos) y entre 10-15 reactivos cada una, las cuales fueron estructuradas en función de tipos de tarea variantes; dichas tareas se incluyeron en dos modos lingüísticos: leer-señalar y leer-escribir. De tal manera que cada modo lingüístico quedó conformado por cuatro tareas. Los resultados indicaron que los participantes exhiben repertorio diferenciado en lo que respecta a las variaciones de los diferentes tipos de tarea, no así en relación al modo lingǘstico involucrado, tal vez por el tipo de referentes involucrados en las tareas (evento, segmento, diagrama-concepto), en el estudio se concluyó que el modo lingüístico no puede analizarse al margen del juego de lenguaje (conceptual, instrumental o actitudinal) (Irigoyen et al. 2006).

Por ello, complementariamente y con el propósito de analizar como el estudiante formula una serie de oraciones o un párrafo, y de esta manera caracterizar los aspectos de referencia tanto textuales como funcionales de la conducta de escribir, se llevó a cabo un estudio con universitarios para evaluar el desempeño del estudiante a partir de la modalidad lingüística señalar-escribir, (representación de un concepto, así como la justificación del mismo), en el contexto del aprendizaje de una disciplina científica (Irigoyen, Acuña y Jiménez, 2011).

En el estudio participaron 40 noveles estudiantes que cursaban los primeros semestres de la carrera de Psicología. La evaluación estuvo conformada por una serie de textos breves y 8 reactivos de formulación que consistieron en la elaboración del gráfico y su justificación, 4 de ellos referidos a textos que presentan las instancias solamente, esto es, se presentan sólo los eventos con los cuales se podría elaborar el gráfico, y 4 referidos a textos que presentaban no solamente las instancias sino las relaciones que le daban un sentido de coherencia en lo disciplinar, es decir, en las cuales se mostraban los eventos y el contexto de su ocurrencia. Los resultados señalaron que los estudiantes utilizaron en la justificación conceptos técnicos sólo 
como nominativos, establecieron relaciones entre instancias, pero difícilmente establecieron relaciones de relaciones, siendo el uso de conectivos escaso y con una función de introducir en la oración una relación de dependencia causal, enfatizando relaciones unicausales en las justificaciones y no causalidad múltiple como se requiere en las versiones más actualizadas en ciencia (Irigoyen et al. 2011).

Lo anterior supone que el estudiante puede utilizar el lenguaje de la disciplina que aprende (uso de nominativos), pero sin el significado y su uso pertinente en contexto, esto dificulta la expresión correcta de los enunciados para describir un concepto, una relación, un proceso, en este caso, la posibilidad de elaborar una justificación pertinente que permita describir coherentemente semántica y sintácticamente aquello que se hace (o se dice), es decir, sólo sabiendo el qué y el cómo, un estudiante podría describir aquello que se hizo en un área de conocimiento.

Autores como Arroyo y Mares (2009); Fuentes (2007); Morales, Cruz, León et al. (2010) y Morales et al. (2013), han sugerido enfáticamente que el estudio de la comprensión requiere fundamentalmente de la exposición variada a situaciones (p.e. variaciones en los criterios de ajuste) que permitan caracterizar qué, cómo y bajo que condiciones un estudiante comprende $-\mathrm{y}$ en que nivel funcional- los objetos referentes y/o materiales de estudio. Los estudios anteriormente citados han permitido una aproximación al estudio de variables relevantes a la interacción estudiante-objetos referentes, y por lo tanto, de las formas en cómo éste estudiante establece contacto con los materiales.

Por su parte, Pacheco (2010) y Varela $(2010 ; 2013)$ han cuestionado si efectivamente se enseña a escribir a los universitarios, proponiendo estrategias didácticas para el aprendizaje de habilidades como las escritoras (en el ámbito de la Psicología), y cómo estas, sólo pueden aprenderse mediante el ejercicio supervisado, el modelamiento, la evaluación-corrección y el discurso didáctico que explicita los criterios pedagógicos y disciplinares que debe cumplir el estudiante. 
Este acercamiento al análisis de la comprensión a partir de distintos modos lingüísticos, y en el caso particular del modo lingüístico escribir presentado anteriormente, permitió la elaboración de categorías relevantes, así como su delimitación paramétrica. Asimismo, tener un punto de referencia para el diseño de situaciones de evaluación que permitan establecer desempeños diferenciales en términos de los distintos tipos de tarea y su nivel funcional.

Por lo tanto, con la finalidad de analizar la comprensión de estudiantes universitarios a partir del tipo de tarea, su nivel funcional y la modalidad lingüística implicada (escribir y hablar) con relación a materiales de estudio (objetos referentes) con contenidos científicos, se plantearon tres preguntas:

- ¿Cuál es el efecto de la explicitación del criterio de ajuste en la comprensión de estudiantes universitarios ante un material de estudio (objeto referente) con contenidos científicos?

- ¿Cuál es el efecto de presentar variaciones en la secuencia de las modalidades linguísticas (escribir-hablar, hablar-escribir) en la comprensión de materiales (objetos referentes) con contenidos científicos?

- ¿Cuál es el efecto de presentar dos modalidades del objeto referente (texto o audio) en el nivel funcional de comprensión de estudiantes universitarios?

Para responder a las preguntas planteadas se llevaron a cabo 3 estudios con estudiantes universitarios de las áreas de ciencias sociales y de ciencias de la salud, con el propósito de analizar la comprensión en función de la modalidad lingüística implicada (escribir-hablar, hablar-escribir) ante variaciones en la explicitación del criterio de ajuste, la modalidad del objeto referente (texto o audio) y el tipo de tarea y su nivel funcional en estudiantes universitarios.

La muestra quedó conformada por 48 estudiantes universitarios de una población de 200 estudiantes, 32 que cursaban los primeros semestres del área de ciencias sociales y 
16 del área de ciencias de la salud de una universidad pública del norte del país, quienes no presentaban experiencia previa con la tarea experimental. La selección de la muestra se llevó a cabo en términos del promedio obtenido en el semestre inmediato anterior al inicio del estudio, los promedios de los estudiantes se dividieron en triatiles tomando solamente los estudiantes del triatil medio ( 60 y $75 \%$ ), toda vez que era importante que los estudiantes exhibieran habilidades suficientes de lecto-escritura para poder presentar sensibilidad ante los criterios paramétricos de los estudios, ya que en algunas ocasiones con poblaciones con puntajes extremos esto no es posible.

Los materiales que se utilizaron en la situación de evaluación fueron seleccionados de una serie de artículos de divulgación científica de la Revista Ciencia, la cual pertenece a la Revista de la Academia Mexicana de Ciencias, esto con el objetivo de que el contenido temático de las evaluaciones se vinculara a ciencia y tecnología. Los artículos seleccionados para el diseño de los instrumentos para evaluar la comprensión fueron cuatro:

- Material A: Cambio climático y sequías en México ${ }^{1}$.

- Material B: La disminución en el nivel trófico de las capturas pesqueras en México².

- Material C: Las micotoxinas contaminantes naturales de los alimentos 3 .

- Material D: Efectos del Cambio Climático en la Salud

$\overline{1}$ Magaña, V.y Neri, C. (2012). Cambio climático y sequías en México. Ciencia, Revista de la Academia Mexicana de Ciencias, 63 (4), 26-35.

2 Reyes, H., Calderón, L., Oropeza, O., Díaz, J., Pérez, H., Del Monte Luna, P., lluch, S. y López-Lemus, L. (2009). La disminución en el nivel trófico de las capturas pesqueras en México. Ciencia, Revista de la Academia Mexicana de Ciencias, julio-septiembre, 1-9. Versión electrónica disponible en: http://wrercerevistaciencia.amc.edu.mx/ online/634_NivelTropico.pdf

3 Méndez, A. y Moreno, E. (2009). Las micotoxinas: contaminantes naturales de los alimentos. Ciencia, Revista de la Academia Mexicana de Ciencias, julio-septiembre, 1-7. Versión electrónica disponible en: http://werere. revistaciencia.amc.edu.mx/online/619-Albores\%20Micotoxinas.pdf

4 De Celis, R., Hernández, G., Bravo, A. y Feria, A. (2012). Efectos del Cambio Climático en la Salud. Ciencia, Revista de la Academia Mexicana de Ciencias, 63 (4), 8-17. 
Estos materiales se sometieron a un panel de expertos para un proceso de selección y validación de los tipos de tarea y su nivel funcional por tres profesores con experiencia en investigación educativa. Era importante su opinión en relación a la pertinencia de la extensión y terminología de los textos seleccionados, así como del tipo de preguntas para evaluar el nivel funcional que se pretendía, y las categorías de análisis para evaluar el desempeño de los participantes.

A partir de los artículos originales, se diseñaron distintas situaciones de evaluación con variaciones en el tipo de tarea y su nivel funcional, así como en la modalidad lingüística implicada (escribir y hablar). Se elaboraron dos versiones: una en texto y otra en audio (lo cual implicó una adaptación y ajuste de los materiales originales), esto con el propósito de poder evaluar a los estudiantes ante dos condiciones diferentes de la modalidad del objeto referente - texto y audio- ${ }^{-}$. La selección de los materiales atendió a la posibilidad de evaluar diferentes tipos de tarea y modalidades lingüísticas en la comprensión de contenidos científicos en estudiantes universitarios, en otras palabras, para poder caracterizar la forma en como los estudiantes median lingüísticamente su contacto -en la modalidad lingǘstica hablar y escribir- ante materiales relacionados con contenidos de ciencia y tecnología.

Cada situación de evaluación quedó conformada por un texto y/o un audio, y una serie de preguntas vinculadas a cada material (20 reactivos), un resumen y una conclusión. Los requerimientos que se prescribían como tipos de tarea, fueron: 1) seleccionar de entre una serie de opciones de respuesta el descriptor ${ }^{5}$ pertinente al enunciado (10 reactivos en formato de opción múltiple), este tipo de tarea se ubicó funcionalmente como interacciones intrasituacionales; 2) formular congruentemente de forma escrita y oral una o varias oraciones $^{6}$ en función de lo leído o escuchado en el material ( 5 reactivos en formato de

$5 \quad$ En el presente trabajo, el descriptor está relacionado con un concepto y/o referente teórico y su descripción (p.e. red trófica).

$6 \quad$ En el presente trabajo, la oración está referida a un conjunto de palabras que expresa un sentido gramatical completo, en este caso, vinculado con la explicación de un evento o una relación entre eventos (p.e. la sequía meteorológica es un fenómeno natural y recurrente, y su severidad debe medirse en términos de anomalías de precipitación). 
respuesta abierta para la modalidad escribir y 5 para la modalidad hablar), este tipo de tarea se situó funcionalmente como interacciones extrasituacionales. Finalmente (3), se solicitó la formulación de un resumen y una conclusión con el propósito de caracterizar si el estudiante podía elaborar con sus propias palabras una referencia escrita acerca de los aspectos relevantes discutidos en el material, así como las implicaciones propuestas, esta tarea se ubicó funcionalmente como interacciones transituacionales.

Los reactivos estaban dirigidos a evaluar tres tipos de interacciones de acuerdo a los distintos niveles de desligamiento posibles (Varela y Quintana, 1995), a saber:

1. Interacciones intrasituacionales: el estudiante responde a tres tipos de relaciones funcionales. En la primera el estudiante responde a las condiciones estimulantes del entorno (objetos, eventos, actividad de otros individuos) sin alterar la situación. Un ejemplo en el caso de la escritura de este tipo de interacciones son el copiado o la transcripción de letras a partir de un modelo. En la segunda se incluyen relaciones en las que el individuo con su actividad cambia las relaciones entre eventos ya sea introduciendo o eliminando objetos o eventos en una situación específica. Estas interacciones quedan ejemplificadas en el caso de la escritura cuando el estudiante completa nombres incompletos. En la tercera se incluyen relaciones funcionales que implican que el estudiante responda adecuándose a condiciones cambiantes del entorno, para producir efectos en la situación. Un ejemplo de este tipo de interacciones es cuando el estudiante selecciona de entre una serie de opciones la respuesta pertinente, que varia en términos de la respuesta correcta.

2. Interacciones extrasituacionales: el estudiante altera a través de respuestas lingüísticas las condiciones (relaciones entre objetos e individuos) de una situación con base en las características de una situación distinta. Estas interacciones se ejemplifican cuando un estudiante puede elaborar un reporte escrito o una presentación en forma oral en función de una temática particular. 
3. Interacciones transituacionales: el estudiante interactúa lingüísticamente con y en términos de los productos del comportamiento lingǘstico de otros individuos o de el mismo, pudiéndose desligar de las propiedades concretas de cualquier situación particular, por ejemplo, elaborar un ensayo en el cual compara dos propuestas teóricas sin necesariamente referirse a un concepto o un evento en concreto.

Para evaluar estos niveles de interacción del estudiante con el material de prueba, el instrumento de evaluación quedó conformado como se muestra en la Tabla 7.

\begin{tabular}{|l|l|l|l|}
\hline & $\begin{array}{l}\text { Interacciones intr- } \\
\text { asituacionales }\end{array}$ & $\begin{array}{l}\text { Interacciones } \\
\text { extrasituacionales }\end{array}$ & $\begin{array}{l}\text { Interacciones } \\
\text { transituacionales }\end{array}$ \\
\hline Tipo de tarea & $\begin{array}{l}\text { Seleccionar de entre } \\
\text { una serie de opcio- } \\
\text { nes de respuesta el } \\
\text { descriptor pertinen- } \\
\text { te al enunciado }\end{array}$ & $\begin{array}{l}\text { Elaborar congruente- } \\
\text { mente de forma escrita } \\
\text { y oral una o varias } \\
\text { oraciones en función de } \\
\text { lo leído o escuchado en } \\
\text { el material }\end{array}$ & $\begin{array}{l}\text { Formular coherentemen- } \\
\text { te de forma escrita un re- } \\
\text { sumen y una conclusión } \\
\text { en función de lo leído o } \\
\text { escuchado en el material }\end{array}$ \\
\hline $\begin{array}{l}\text { Modalidad lingüística } \\
\text { implicada }\end{array}$ & - & Escribir & Hablar \\
\hline $\begin{array}{l}\text { Competencia } \\
\text { involucrada }\end{array}$ & Identificación & Elaboración & Escribir \\
\hline
\end{tabular}

Tabla 7. Muestra los tipos de tarea, su nivel funcional y la modalidad lingüística implicada, recuperados para la elaboración de los instrumentos de evaluación.

La evaluación fue aplicada en un cubículo exento de ruidos. Para su aplicación se utilizaron cinco computadoras con audífonos (tanto para el caso de la modalidad textual -documento en versión PDF- y auditiva -versión PowerPoint con audio-), así como una grabadora para recabar los datos de la modalidad lingüística hablar. La duración de la sesión 
la estableció el desempeño del participante (aproximadamente 45 min.). Los desempeños tanto de la modalidad lingüística escribir como la de hablar fueron transcritos a una base de datos Excel para su análisis. Algunas de las sesiones fueron filmadas al azar, esto con el propósito de tener evidencia observacional de algunas formas de interacción no contenidas en los análisis de los estudios, y que se consideran importantes retomarlas en algunos momentos del escrito.

Las instrucciones se presentaban de forma oral por el investigador a los participantes, como se presentan en las siguientes líneas: "A continuación se te presentará un texto (o un audio) sobre un contenido temático que se vincula a la ciencia y a la tecnología, tu tarea consiste en leer un texto (o escuchar un audio) sobre el Cambio climático y sequías en México/La disminución en el nivel trófico de las capturas pesqueras en México... (la instrucción variaba, según el material), y contestar una serie de preguntas posteriores a que leas (o escuches) el material. Una vez iniciada la sesión de lectura (o audio) no podrás regresar al texto o al audio, contesta todas las preguntas que te sea posible".

Una diferencia entre el Estudio 1 y los Estudios 2 y 3 es que en estos últimos se introdujo la variable de explicitación del criterio, el cual se presentaba en la pantalla del monitor al inicio de la situación de evaluación, a partir de tres preguntas rectoras, el cual implicaba un nivel funcional extrasituacional. Una vez que los participantes iniciaban la lectura o el audio, no se les proporcionó instrucción alguna, ni se les retroalimentó. Cuando los participantes terminaban de leer o escuchar el material, se les presentaba la prueba en hojas impresas, las cuales ya tenían la secuencia prescrita para cada participante según el grupo al que había sido asignado previamente - primero escribir y luego hablar para unos casos, o primero hablar y posteriormente escribir para los otros-. $\mathrm{Al}$ finalizar la sesión, se agradecía la participación de los estudiantes.

Se empleó un diseño cuasiexperimental balanceado de materiales equivalentes con varios grupos de comparación (Campbell y Stanley, 1982; Kerlinger y Lee, 2002). Los participantes fueron asignados aleatoriamente a cuatro grupos en función de la secuencia en 


\begin{tabular}{|c|c|c|c|c|c|c|c|}
\hline & \multicolumn{4}{|c|}{ FASE I } & & & \\
\hline & $\begin{array}{l}\text { Grupos } \\
(\mathrm{N}=4)\end{array}$ & \multicolumn{2}{|c|}{$\begin{array}{l}\text { Modalidad del objeto } \\
\text { referente }\end{array}$} & $\begin{array}{l}\text { Secuencia de } \\
\text { la modalidad } \\
\text { lingüística }\end{array}$ & & & \\
\hline \multirow{5}{*}{$\begin{array}{c}\text { Estudio } 1 . \\
\text { Estudiantes } \\
\text { del área } \\
\text { de ciencias } \\
\text { sociales }\end{array}$} & \multicolumn{4}{|c|}{ SIN CRITERIO DE AJUSTE EXPLÍCITO } & & & \\
\hline & G1 & \multirow{2}{*}{$\begin{array}{c}\text { Material A. } \\
\text { Textual }\end{array}$} & Es & $\mathrm{Ha}$ & & & \\
\hline & G2 & & $\mathrm{Ha}$ & Es & & & \\
\hline & G3 & \multirow{2}{*}{$\begin{array}{c}\text { Material A. } \\
\text { Auditiva }\end{array}$} & Es & $\mathrm{Ha}$ & & & \\
\hline & G4 & & $\mathrm{Ha}$ & Es & & & \\
\hline & & & \multicolumn{2}{|c|}{ FASE I } & \multicolumn{3}{|c|}{ FASE II } \\
\hline & & \multicolumn{2}{|c|}{$\begin{array}{l}\text { Modalidad del objeto } \\
\text { referente }\end{array}$} & $\begin{array}{c}\text { Secuencia de } \\
\text { la modalidad } \\
\text { lingüística }\end{array}$ & $\begin{array}{l}\text { Modalidad } \\
\text { del objeto } \\
\text { referente }\end{array}$ & \multicolumn{2}{|c|}{$\begin{array}{c}\text { Secuencia de } \\
\text { la modalidad } \\
\text { lingüística }\end{array}$} \\
\hline \multirow{5}{*}{$\begin{array}{c}\text { Estudio } 2 . \\
\text { Estudiantes } \\
\text { del área } \\
\text { de ciencias } \\
\text { sociales }\end{array}$} & \multicolumn{7}{|c|}{ CON GRITERIO DE AJUSTE EXPLÍGITO } \\
\hline & G1 & \multirow{2}{*}{$\begin{array}{c}\text { Material A. } \\
\text { Textual }\end{array}$} & Es & $\mathrm{Ha}$ & \multirow{2}{*}{$\begin{array}{c}\text { Material B. } \\
\text { Auditiva }\end{array}$} & $\mathrm{Ha}$ & Es \\
\hline & G2 & & $\mathrm{Ha}$ & Es & & Es & $\mathrm{Ha}$ \\
\hline & G3 & \multirow{2}{*}{$\begin{array}{c}\text { Material A. } \\
\text { Auditiva }\end{array}$} & Es & $\mathrm{Ha}$ & \multirow{2}{*}{$\begin{array}{c}\text { Material B. } \\
\text { Textual }\end{array}$} & $\mathrm{Ha}$ & Es \\
\hline & G4 & & $\mathrm{Ha}$ & Es & & Es & $\mathrm{Ha}$ \\
\hline \multirow{5}{*}{$\begin{array}{c}\text { Estudio } 3 . \\
\text { Estudiantes } \\
\text { del área de } \\
\text { ciencias de } \\
\text { la salud }\end{array}$} & \multicolumn{7}{|c|}{ CON CRITERIO DE AJUSTE EXPLÍGITO } \\
\hline & G1 & \multirow{2}{*}{$\begin{array}{l}\text { Material A. } \\
\text { Textual }\end{array}$} & Es & $\mathrm{Ha}$ & \multirow{2}{*}{$\begin{array}{l}\text { Material B. } \\
\text { Auditiva }\end{array}$} & $\mathrm{Ha}$ & Es \\
\hline & G2 & & $\mathrm{Ha}$ & Es & & Es & $\mathrm{Ha}$ \\
\hline & G3 & \multirow{2}{*}{$\begin{array}{c}\text { Material A. } \\
\text { Auditiva }\end{array}$} & Es & $\mathrm{Ha}$ & \multirow{2}{*}{$\begin{array}{c}\text { Material B. } \\
\text { Textual }\end{array}$} & $\mathrm{Ha}$ & Es \\
\hline & G4 & & $\mathrm{Ha}$ & Es & & Es & $\mathrm{Ha}$ \\
\hline
\end{tabular}

Tabla 8. Muestra la asignación y la secuencia a la que fueron expuestos los participantes en los tres estudios (G: Grupo, Es: Escribir, Ha: Hablar, SML: Secuencia en la Modalidad Lingüística). 
la modalidad lingüística y la modalidad del objeto referente (ver Tabla 8). Los estudiantes se exponían a dos modalidades del objeto referente: textual y auditiva, y a dos secuencias diferentes considerando la modalidad lingǘstica, una diferente para cada grupo. De esta manera, el diseño quedó conformado por cuatro grupos: Grupo 1 (G1): escribir-hablar bajo una modalidad del objeto referente textual; Grupo 2 (G2): hablar-escribir bajo una modalidad textual; Grupo 3 (G3): escribir-hablar bajo una modalidad auditiva; Grupo 4 (G4): hablar-escribir también bajo una modalidad auditiva. Cada grupo quedó conformado por cuatro participantes. El criterio de cambio de una modalidad a otra fue determinado por la ejecución de los participantes.

Este diseño se fundamenta en la equivalencia de las muestras de materiales a las que se aplicaron las variables experimentales: explicitación del criterio, tipos de tarea y su nivel funcional, así como la modalidad lingüística implicada. La elección del diseño obedece al propósito de los estudios.

En relación al análisis de los resultados, las respuestas de los participantes tanto de los productos físicos (audios) como de los escritos fueron analizados por tres observadores independientes hasta obtener $100 \%$ de acuerdo. Para el análisis de los resultados se elaboraron una serie de categorías tanto morfológicas o formales como funcionales para analizar la modalidad de escribir y hablar, las cuales se presentan en la Tabla 9.

\begin{tabular}{|l|l|l|}
\hline $\begin{array}{l}\text { Categorías morfológicas o } \\
\text { formales }\end{array}$ & Definición operacional & Ejemplos \\
\hline $\begin{array}{l}\text { 1. Conceptos técnicos } \\
\text { utilizados }\end{array}$ & $\begin{array}{l}\text { Hace mención de } \\
\text { términos técnicos } \\
\text { vinculados con el } \\
\text { material. }\end{array}$ & $\begin{array}{l}\text { Anomalías } \\
\text { Cambio climático } \\
\text { Oscilaciones decadales/multidecadales } \\
\text { Forzantes o cambios forzantes } \\
\text { Circulaciones atmosféricas }\end{array}$ \\
\hline
\end{tabular}




\begin{tabular}{|c|c|c|}
\hline $\begin{array}{l}\text { 2. Conectivos empleados en } \\
\text { la referencia oral o escrita }\end{array}$ & $\begin{array}{l}\text { Utiliza conectivos en la } \\
\text { estructura de las ora- } \\
\text { ciones formuladas. }\end{array}$ & $\begin{array}{l}\text { Aditivos: } \\
\text { y/e, que, además } \\
\text { Causales: } \\
\text { Porque, pues, ya que, dado que, por lo } \\
\text { que, por lo tanto } \\
\text { Aclaratorios o de secuencia: } \\
\text { Es decir, en otras palabras, mejor } \\
\text { dicho, precisamente... } \\
\end{array}$ \\
\hline 3. Extensión de la referencia & $\begin{array}{l}\text { Número de palabras que } \\
\text { utiliza para elaborar la } \\
\text { referencia del contenido. }\end{array}$ & $\begin{array}{l}\text { "La variabilidad natural del clima está } \\
\text { relacionada con la comprensión de } \\
\text { los forzantes clave y cómo funcionan } \\
\text { e interactúan los procesos físicos del } \\
\text { clima. Por ejemplo, una anomalía de } \\
\text { la temperatura del mar, como la que } \\
\text { ocurre durante el evento denominado } \\
\text { "El niño", afecta las lluvias en México } \\
\text { y en muchas otras partes del mundo, al } \\
\text { alterar las circulaciones atmosféricas y } \\
\text { con ello los patrones de lluvias". }\end{array}$ \\
\hline \multicolumn{3}{|l|}{ Categorías Funcionales } \\
\hline $\begin{array}{l}\text { 1. Conceptos técnicos } \\
\text { utilizados de manera } \\
\text { pertinente }\end{array}$ & $\begin{array}{l}\text { Utiliza los términos } \\
\text { técnicos para describir un } \\
\text { evento/suceso o alguna } \\
\text { relación entre eventos. }\end{array}$ & $\begin{array}{l}\text { Al explicar las variaciones recientes } \\
\text { del clima o proyectar los potenciales } \\
\text { impactos en el mismo sobre un } \\
\text { determinado sector económico o } \\
\text { región se requerirá que los climatólogos } \\
\text { analicen la importancia de cada uno de } \\
\text { estos forzantes climáticos. }\end{array}$ \\
\hline $\begin{array}{l}\text { 2. Formula relaciones entre } \\
\text { eventos/fenómenos como } \\
\text { causalidad única }\end{array}$ & $\begin{array}{l}\text { Establece relaciones } \\
\text { únicas con un evento } \\
\text { o fenómeno de forma } \\
\text { unicausal. }\end{array}$ & $\begin{array}{l}\text { La sequía se produce por las anomalías } \\
\text { en los cambios de temperatura (p.e. en } \\
\text { la parte norte de México, Coahuila). }\end{array}$ \\
\hline $\begin{array}{l}\text { 3. Formula relaciones entre } \\
\text { eventos/fenómenos como } \\
\text { relaciones multicausales }\end{array}$ & $\begin{array}{l}\text { Establece relaciones } \\
\text { entre varios eventos/ } \\
\text { fenómenos como } \\
\text { relaciones múltiples. }\end{array}$ & $\begin{array}{l}\text { Las sequías se producen al alterar } \\
\text { las circulaciones atmosféricas y los } \\
\text { patrones de lluvia, con gases de } \\
\text { invernadero, (forzantes internos). }\end{array}$ \\
\hline
\end{tabular}

Tabla 9. Presenta el tipo de categorías utilizadas para analizar las modalidades lingüísticas de escribir y hablar, así como sus relaciones paramétricas. 


\section{Estudio 1}

El objetivo del primer estudio fue evaluar si las variaciones en el tipo de tarea y la modalidad lingüística involucrada determina ajustes diferenciales en la comprensión de un material (texto o audio) con contenido científico en estudiantes universitarios del área de Ciencias Sociales.

Los participantes de este estudio fueron 16 estudiantes universitarios que cursaban los primeros semestres del área de Ciencias Sociales de una universidad pública del norte del país. La selección de la muestra se llevó a cabo en términos del promedio obtenido en el semestre inmediato anterior al inicio del estudio, el promedio de los estudiantes (de una población de 140 estudiantes) se dividió en triatiles tomando solamente los estudiantes del triatil medio (60 y $75 \%)$.

Se diseñó una situación de evaluación a partir de un artículo con un contenido temático sobre ciencia y tecnología con una extensión de 3096 palabras (Material A, mencionado en la descripción general de los estudios). De esta manera, el instrumento de evaluación consistió de un texto o un audio y una prueba cuyas preguntas implicaban variaciones en el tipo de tarea y su nivel funcional, así como la modalidad lingüística implicada - escribir y hablar-. Los requerimientos que se prescribían como tipos de tarea, fueron: 1) seleccionar de entre una serie de opciones de respuesta el descriptor pertinente al enunciado (10 reactivos en formato de opción múltiple), este tipo de tarea se ubicó funcionalmente como interacciones intrasituacionales; 2) formular congruentemente de forma escrita y oral una o varias oraciones en función de lo leído o escuchado en el material ( 5 reactivos en formato de respuesta abierta para la modalidad lingüística escribir y 5 para la modalidad hablar), este tipo de tarea se situó funcionalmente como interacciones extrasituacionales. Finalmente, se solicitó la elaboración de un resumen y una conclusión (en modalidad escrita) con el propósito de caracterizar si el estudiante podía formular con sus propias palabras los aspectos relevantes discutidos en el material, así como algunas de las implicaciones propuestas, este tipo de tarea se ubicó como interacciones transituacionales. 
En el instrumento de evaluación se presentaba el objeto referente o material de estudio en dos modalidades: textual -en formato PDF- y auditiva - en presentación de PowerPoint-. Para ambas condiciones de evaluación se mantuvieron equivalentes tanto el tipo de tarea y su nivel funcional, así como la modalidad linguística involucrada. De esta manera, la situación de prueba permitió evaluar interacciones intrasituacionales, extrasituacionales y transituacionales.

La prueba se presentaba de forma impresa en hojas de papel bond tamaño carta y se proporcionaron lápices con goma. El orden en que se mostraban las preguntas variaba en función del grupo al que fue asignado previamente el estudiante, es decir, en los Grupos 1 y 3 la secuencia de la modalidad linguística fue escribir para posteriormente hablar y en los Grupos 2 y 4 fue primero hablar seguida por la de escribir. Para obtener una medida inicial del desempeño del participante con respecto al material, previó a la presentación de las secuencias, se exponía a los participantes a una serie de preguntas vinculadas con una tarea de identificación, esto con el propósito de caracterizar los desempeños ante una tarea que implicaba un criterio mínimo necesario para poder posteriormente, elaborar la referencia de forma congruente y coherente al escribir y al hablar.

La evaluación se llevó a cabo en cubículos exentos de ruidos. Para su aplicación se utilizaron cinco computadoras con audífonos (que permitieran la presentación del material tanto en la modalidad textual como en la auditiva), así como una grabadora para recabar los datos de la modalidad lingüística hablar. La duración de la sesión la estableció el desempeño del estudiante (aproximadamente 45 min.). Los desempeños tanto de la modalidad lingüística escribir como la de hablar fueron transcritos a una base de datos de Excel diseñada para su análisis.

Se empleó un diseño cuasiexperimental balanceado de materiales de evaluación equivalentes con cuatro grupos de comparación (Campbell y Stanley, 1982; Kerlinger y Lee, 2002). Los participantes fueron asignados aleatoriamente a los grupos en función de si el material de estudio se presentaba en modalidad textual o auditiva. El estudio constó 
solamente de una fase en donde los participantes se exponían a dos modalidades del objeto referente o material de estudio y dos secuencias diferentes considerando las modalidades lingüísticas involucradas, una diferente para cada grupo, cada grupo quedó conformado por 4 estudiantes (ver Tabla 10).

\begin{tabular}{|c|c|c|c|}
\hline ESTUDIO 1 & \multicolumn{3}{|c|}{ FASE 1 } \\
\hline $\mathrm{N}=16$ & \multicolumn{2}{|c|}{ SIN CRITERIO EXPLÍCITO } \\
\hline \multirow{2}{*}{$\begin{array}{c}\text { Grupos } \\
(\mathrm{N}=4)\end{array}$} & \multirow{2}{*}{$\begin{array}{c}\text { Modalidad del } \\
\text { objeto referente }\end{array}$} & \multicolumn{2}{|c|}{$\begin{array}{c}\text { Secuencia de la modalidad } \\
\text { lingǘstica }\end{array}$} \\
\hline G1 & \multirow{2}{*}{ Material A. Textual } & $\mathrm{Es}$ & $\mathrm{Ha}$ \\
\cline { 3 - 4 } & & $\mathrm{Ha}$ & $\mathrm{Es}$ \\
\hline G2 & \multirow{2}{*}{ Material A. Auditiva } & $\mathrm{Es}$ & $\mathrm{Ha}$ \\
\cline { 3 - 4 } & & $\mathrm{Ha}$ & $\mathrm{Es}$ \\
\hline G4 & & & \\
\hline
\end{tabular}

Tabla 10. Muestra la asignación y la secuencia a la que fueron expuestos los participantes del Estudio 1. G: Grupo, Es: Escribir, Ha: Hablar.

Las instrucciones se presentaban de forma oral por el investigador a los participantes, como se describen en el siguiente parrafo: "A continuación se presentará un texto (o un audio) sobre un contenido temático que se vincula a la ciencia y a la tecnología, tu tarea consiste en leer un texto (o escuchar un audio para el caso de la modalidad auditiva) sobre el Cambio Climático y Sequías en México, y contestar una serie de preguntas posteriores a que leas (o escuches) el material. Una vez iniciada la sesión de lectura (o audio) no podrás regresar al texto (o al audio), contesta todas las preguntas que te sea posible". Cuando los participantes terminaban de leer o escuchar el material, se les proporcionó las hojas impresas con la prueba para resolver. Al finalizar la sesión, se agradecía la participación de los estudiantes. 
El desempeño de los participantes fue analizado en términos de interacciones intrasituacionales (a partir de la correspondencia del desempeño del participante ante el tipo de tarea), extrasituacionales (a partir de la congruencia formulada por los participantes para el caso de las modalidades lingüísticas de escribir y hablar) y transituacionales (a partir de la coherencia presentada en la elaboración de un resumen y una conclusión a partir de lo leído o escuchado). Adicionalmente, se llevó a cabo un análisis del desempeño de los participantes (en la modalidad lingüística escribir) del resumen y la conclusión, a partir de dos tipos de categorías que se denominaron: morfológicas o formales y funcionales (como se muestra en la Tabla 9, p. 131-132). El desempeño en las categorías morfológicas fue analizado en términos de: a) el número de conceptos técnicos utilizados para elaborar la referencia escrita, b) el número de conectivos usados para elaborar la referencia, c) el número de palabras que utiliza para elaborar la referencia; para el caso de las categorías funcionales: a) la ocurrencia del número de conceptos técnicos utilizados de forma pertinente, b) el número de relaciones que establece entre eventos de forma unicausal, y c) el número de relaciones entre eventos como relaciones multicausales.

En la Figura 6 se muestra el desempeño por participante en las interacciones intrasituacionales. $\mathrm{Al}$ analizar el desempeño grupalmente se encontró que el Grupo 2 es el que presentó mayor porcentaje de aciertos con 70\%, seguido por los Grupos 1 y 4 con 58\%, y finalmente el Grupo 3 con $53 \%$, si se promedian los grupos que leyeron encontramos que estos obtuvieron 58\% de aciertos y los que escucharon 55\%. En cuanto al desempeño individual las ejecuciones se muestran diferenciales (en términos de aciertos) para cada participante aunque consistentes en el rango del 60 y $70 \%$ de aciertos promedio.

Los participantes del Grupo 2 presentaron los siguientes porcentajes (P6, 80\%, P5 y P8, 70\%, P7, 60\%), seguidos por los participantes del Grupo 4 (P13, P15 y P16, 60\%, P14 $50 \%$ ), luego por los del Grupo 1 (P1, 70\%, P2, P3 y P4, 60\%) y finalmente, para el caso del Grupo 3 el porcentaje de aciertos fue consistentemente más bajo para todos los participantes (P11, 60\%, P9, P10 y P12, 50\%). 
G1. Interacciones Intrasituacionales MOR: Textual

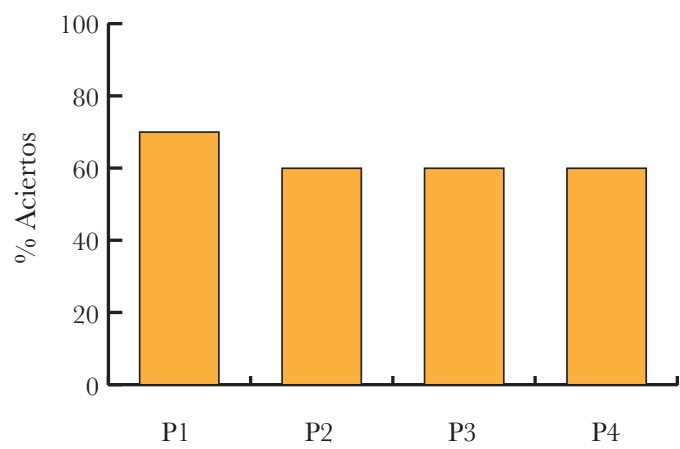

G3. Interacciones Intrasituacionales MOR: Auditiva

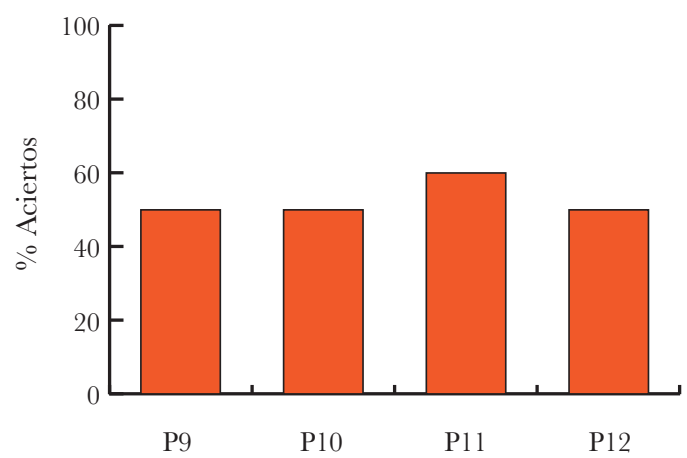

G2. Interacciones Intrasituacionales MOR: Textual

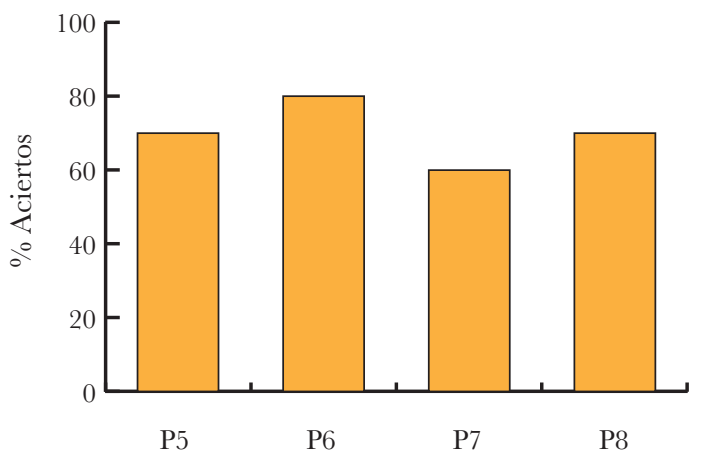

G4. Interacciones Intrasituacionales MOR: Auditiva

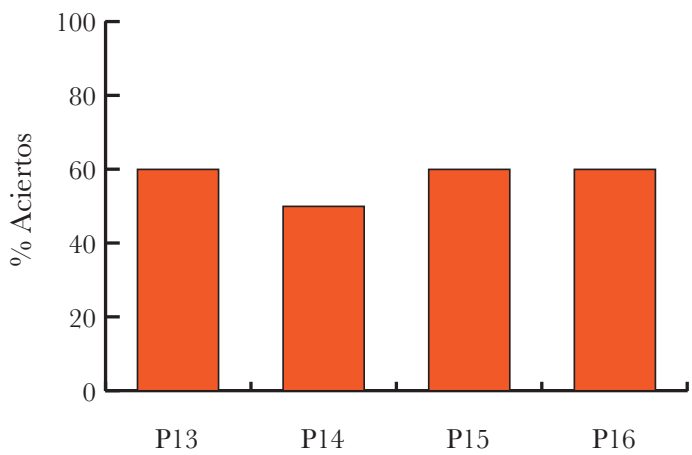

Figura 6. Presenta el porcentaje de aciertos del desempeño de los participantes en las interacciones intrasituacionales de los cuatro Grupos 1, 2, 3 y 4 del Estudio 1. MOR: Modalidad del objeto referente. P: Participante. 
El propósito de esta primera parte de la prueba fue que los participantes de los diferentes grupos se expusieran en un primer momento a una tarea de identificación, como criterio de medida inicial que permitiera caracterizar el desempeño de los estudiantes ante un requerimiento mínimo necesario en el aprendizaje de contenidos científicos (identificar un concepto o un descriptor correspondiente a un ámbito funcional de desempeño). El nivel funcional requerido en la tarea implicaba un nivel de desligamiento selector (Ribes y López, 1985) por lo cual, se ubicó funcionalmente en interacciones intrasituacionales.

La Figura 7 muestra los resultados individuales de los participantes en términos de los porcentajes de congruencia en la modalidad lingüística escribir y hablar en las preguntas en formato de respuesta abierta (interacciones extrasituacionales). En este nivel funcional el participante requería formular de forma congruente (semántica y sintácticamente) la referencia tanto en la modalidad de escribir como en la de hablar. En otras palabras, el estudiante tenía que elaborar una o varias oraciones congruentes, dándole sentido a la referencia escrita/hablada en función del contenido presentado en el material de Cambio Climático y Sequías en México. Los resultados muestran variaciones individuales importantes, los cuales se muestran a continuación. Con relación a los participantes de los Grupos 1 y 2 , el 1 y 6 presentaron $60 \%$ de congruencia, seguido por los participantes 2, 3, 5, 8 con 50\%, el participante 7 con $40 \%$ y el 4 con 30\% de congruencia. Los Grupos 3 y 4 , el participante 13 presentó el porcentaje más alto de congruencia con $50 \%$, seguido por los participantes 9 , 10 y 11 con $40 \%$. El participante 16 presentó $30 \%$ de congruencia, el participante $15,20 \%$ y finalmente, los participantes 12 y 14 con $10 \%$ de congruencia.

Estos resultados permiten de alguna manera enfatizar la necesidad de que en la implementación de las diferentes modalidades en el proceso de enseñanza-aprendizaje de contenidos científicos se evalúe considerando los tipos de tarea y niveles funcionales diferenciales, ya que cuando se observa el desempeño de los participantes ante dos criterios de tarea diferentes, los desempeños se muestran variables ante los criterios. Por ejemplo, el 
G1. Interacciones Extrasituacionales MOR: Textual

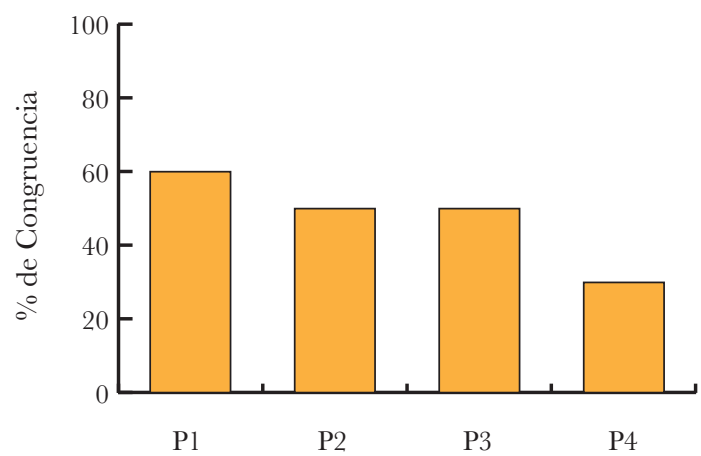

G3. Interacciones Extrasituacionales MOR: Auditiva

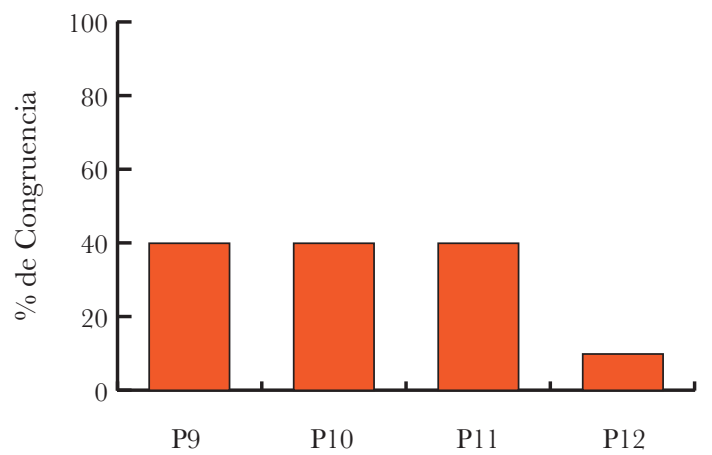

G2. Interacciones Extrasituacionales MOR: Textual

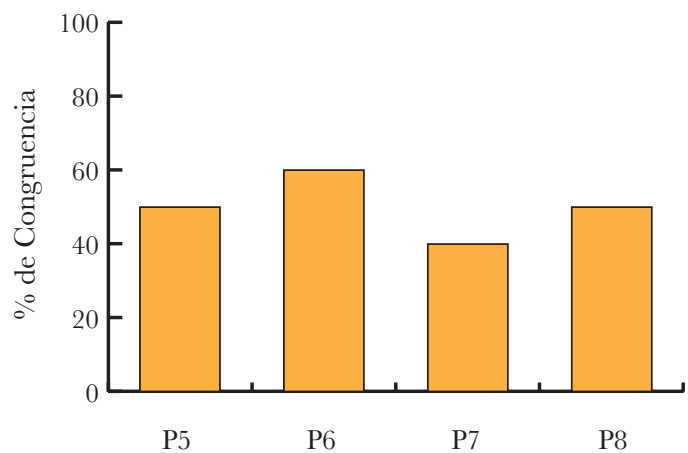

G4. Interacciones Extrasituacionales MOR: Auditiva

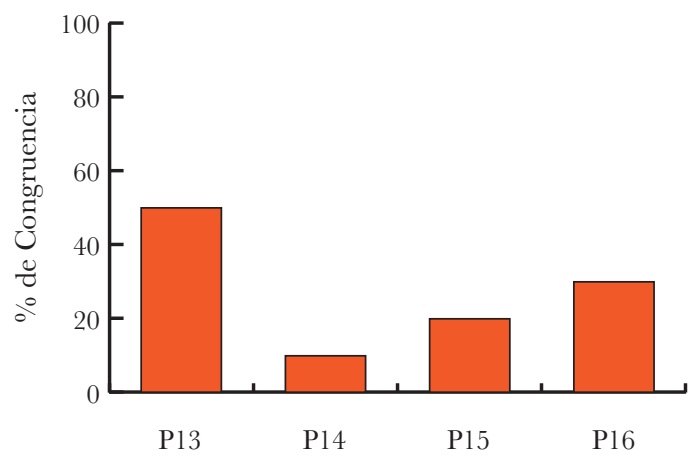

Figura 7. Presenta el porcentaje de congruencia del desempeño de los participantes en las interacciones extrasituacionales de los Grupos 1, 2, 3 y 4 del Estudio 1. MOR: Modalidad del objeto referente. P: Participante. 
participante 6 cuando se le pidió que seleccionara obtuvo $80 \%$ de aciertos pero cuando se le requirió que formulara de forma congruente, su desempeño bajo considerablemente $(60 \%)$, pero para el participante 1 ambas interacciones parecen ser prácticamente equivalentes (las primeras con $70 \%$ y las segundas con $60 \%$ ). Esto permite reflexionar sobre la importancia de los criterios de evaluación que cada profesor impone en su clase para evaluar el desempeño de sus estudiantes, así como la necesaria diversificación de distintos tipos de tarea y su nivel funcional, que le permitan explorar de forma suficiente la habilitación competencial de los estudiantes ante un objetivo instruccional en un momento curricular particular.

Otro comentario al respecto de estos resultados, es que las interacciones intrasituacionales y extrasituacionales se muestran diferenciales en función de la modalidad del objeto referente. En el caso de las primeras, estas no muestran variaciones significativas en las ejecuciones en función de la modalidad del objeto: textual o auditiva, pero en el caso del desempeño en las interacciones extrasituacionales se puede observar como los desempeños se modifican considerablemente entre los grupos que leyeron y escucharon. Si se suma el porcentaje de congruencia de los grupos que leyeron y de los que escucharon para las interacciones intrasituacionales el promedio fue para: G1 y G2: 68\% y para G3 y G4: $55 \%$, en el caso de las interacciones extrasituacionales el promedio fue de: G1 y G2: 48\% y para G3 y G4: 30\%. En el primer caso la diferencia fue de 13 puntos porcentuales y en el segundo fue de 18 .

Cuando se agrupa el desempeño de los participantes en términos de la secuencia de la modalidad lingüística implicada se observan las siguientes tendencias (ver Figura 8). En el análisis gráfico de los datos se distinguen diferencias en el caso de la modalidad lingǘstica escribir y hablar en dos de los cuatro grupos (G1 y G3), siempre con más alto porcentaje de congruencia el hablar que el escribir en aquellos grupos que primero escribieron y después hablaron. En los porcentajes grupales se muestra que el Grupo 1 presentó 45\% de congruencia para la modalidad lingǘstica escribir y $60 \%$ para la modalidad hablar, el Grupo 3 obtuvó 25\% de congruencia para la modalidad escribir y 60 para modalidad 
hablar, el Grupo 2 presentó 50\% de congruencia para la modalidad escribir y $45 \%$ para la modalidad hablar y finalmente, el Grupo 4 obtuvo 45\% de congruencia para la modalidad escribir y $40 \%$ para la modalidad hablar. Este resultado permite sugerir que posiblemente hay un efecto en la modalidad lingüística hablar cuando los participantes primero escriben, ya que esto no se observa en los participantes que primero hablan y después escriben. Lo cual parece indicar que la modalidad lingüística de escribir - por su nivel de complejidad-

Interacciones extra: por modalidad lingüística para todos los grupos

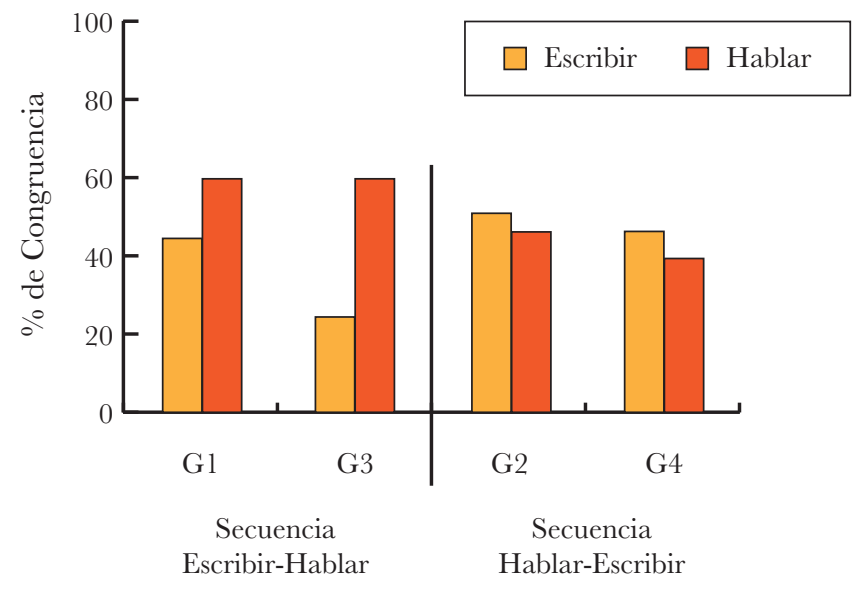

Figura 8. Presenta el porcentaje de congruencia del desempeño grupal obtenido en las interacciones extrasituacionales por modalidad lingǘstica del Estudio 1. G: Grupo.

posibilita funcionalmente mayor desligamiento en la modalidad hablar.

Cuando se desglosa el desempeño individual en términos de la modalidad lingüística involucrada, se encuentra que las ejecuciones son diferenciales en función de la secuencia al interior de los Grupos (ver Figura 9). En los grupos que fueron expuestos a la modalidad del objeto referente textual (G1 y G2), los participantes 1, 5, 6 y 7 presentan consistencia 
Gl. Interacciones Extrasituacionales por modalidad lingüística

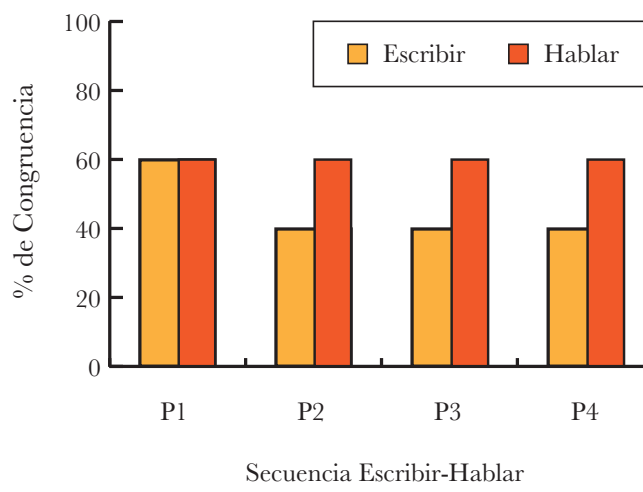

G3. Interacciones Extrasituacionales por modalidad lingüística

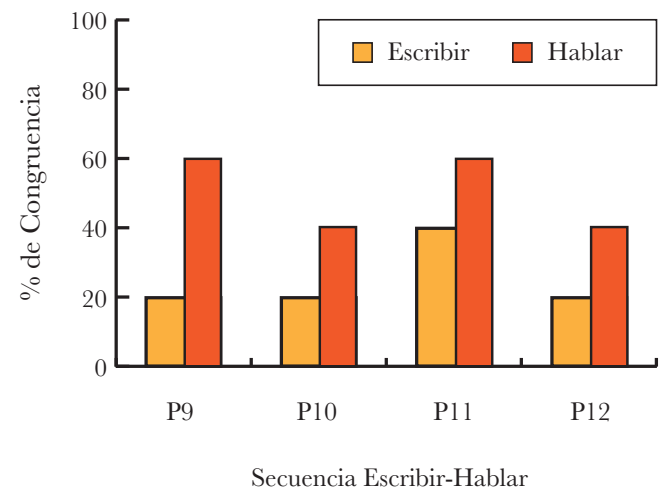

G2. Interacciones Extrasituacionales por modalidad lingüística

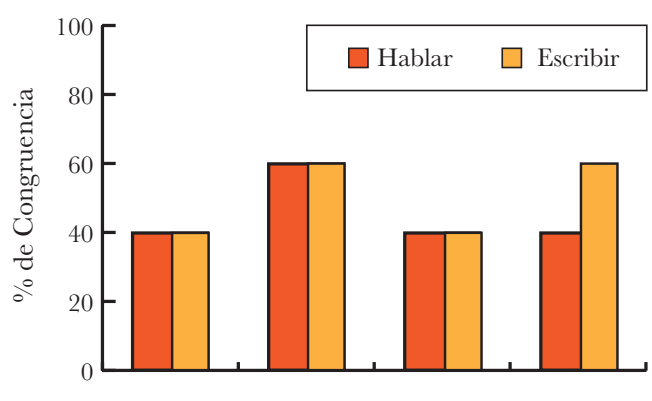

P5

P6

P7

P8

Secuencia Hablar-Escribir

G4. Interacciones Extrasituacionales por modalidad lingüística

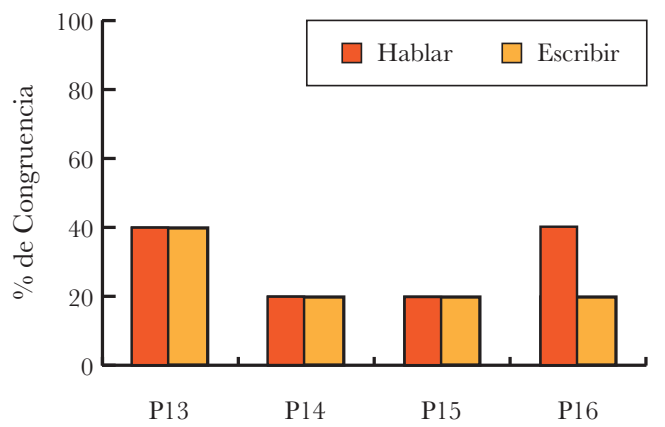

Secuencia Hablar-Escribir

Figura 9. Presenta el porcentaje de congruencia del desempeño individual obtenido en las interacciones extrasituacionales por modalidad lingüistica del Estudio 1. P: Participante. 
en el desempeño de ambas modalidades lingüísticas, 1 y 6 con una congruencia del 60\%, 5 y 7 con $40 \%$, en el caso del participante 8 presenta un porcentaje de congruencia del $60 \%$ para la modalidad lingüística escribir y $40 \%$ para la modalidad lingüística hablar, en los participantes 2, 3 y 4 la congruencia se invierte, fue mayor para la modalidad de hablar con un $60 \%$ y $40 \%$ para la modalidad escrita, es importante señalar que estos participantes primero escribieron y despúes hablaron. En los grupos cuya modalidad del objeto referente fue auditiva (G3 y G4), los participantes presentaron mayor consistencia en ambas modalidades lingüísticas, el participante 13 con $40 \%$ de congruencia, posteriormente el participante 16 con $40 \%$ de congruencia para la modalidad lingüística hablar no así para la modalidad escribir (20\%). En el caso del participante 9 presentó una congruencia del $60 \%$ en hablar y $20 \%$ en escribir, el participante 11 con $40 \%$ de congruencia en la modalidad lingüística escribir y $60 \%$ en la modalidad hablar, para los participantes 10 y 12 fue del $20 \%$ en la modalidad linguística escribir y $40 \%$ de congruencia en la modalidad hablar. Con los puntajes más bajos se encuentra a los participantes 14 y 15, con $20 \%$ de congruencia para ambas modalidades.

Algunas diferencias entre las modalidades del lenguaje oral y escrito es que este último requiere de altos niveles de abstracción. Cuando se habla se requiere obtener retroalimentación de los sonidos que se pronuncian del escucha o del propio hablante, aunque lo que se produce sea un producto evanescente (excepto si se graba) para el propio individuo, mientras que los productos en la modalidad escrita son más permanentes en la medida que generan vestigios gráficos, lo cual posibilita que el propio individuo y otros individuos puedan entrar en contacto con lo escrito en momentos posteriores a su elaboración y generan una función editora (Mares, 2008; Pacheco, 2010).

En la investigación que se realiza actualmente sobre la lecto-escritura, específicamente en nuestro país, se identifican las diferencias entre el desarrollo del lenguaje en la modalidad escribir y hablar, particularmente en términos de la ubicación espacio-temporal del escucha, la familiaridad con éste, la gramática y el estilo; así como la familiaridad y complejidad de los 
contenidos (Mares, Ribes y Rueda, 1993; Mares, Rueda y Luna, 1990).

Por su parte, Mares (2008) identificó que entre el lenguaje hablado y el lenguaje escrito hay diferencias en términos de las convenciones que constituyen sus respectivas gramáticas, estilos y esquemas de organización discursiva, específicamente la autora sostiene que las convenciones vinculadas con la modalidad escrita son más precisas (por lo menos así debería de ser idealmente particularmente en estudiantes universitarios). En palabras de la autora: "Existe una continuidad funcional entre las competencias involucradas en el dominio de la lengua hablada y escrita... las competencias de lectura y escritura que el niño requiere aprender, pueden ejercitarse en el modo hablado y transferirse al modo escrito, o facilitar su aprendizaje. La influencia también se da en el otro sentido, del modo escrito al hablado" (p. 181). Asimismo, la autora comenta que existen diferencias importantes entre los campos conductuales en el dominio de la lengua hablada y los implicados en el dominio de la lengua escrita. En términos de la relación escucha-hablante y la relación lector-escritor conllevan distancias temporales y espaciales distintas con respecto a la ubicación de los participantes. En el segundo caso, el lector y el escritor interactúan con alguien no presente ubicado en un contexto distinto, situación que obliga al desarrollo de competencias que le permitan ajustarse a lectores y escritores ausentes situados en otros contextos. Aun cuando mucho del trabajo realizado por la autora se llevó a cabo con niños de primaria, se considera que la relación lector-escritor posibilita al estudiante universitario interacciones más deligadas situacionalmente que permitan en un momento dado, transitar de interacciones intrasituacionales a extra y transituacionales, o de comportamiento mediado por otros (p.e. profesor) a poder mediar así mismo su interacción con los referentes disciplinares.

Los resultados del análisis en términos de interacciones transituacionales muestran que $81 \%$ de los participantes pudo elaborar un resumen y solamente el $56 \%$ una conclusión (ver Tabla 11). Los participantes de los grupos que fueron expuestos a la modalidad del objeto referente textual pudieron formular mayor número de resúmenes y conclusiones. En el caso de los participantes de los grupos que fueron expuestos a la modalidad del objeto referente auditiva elaboraron menor número de resúmenes, siendo esta tendencia más marcada para 
el caso de las conclusiones.

Un comentario con relación a las interacciones transituacionales es que el estudiante necesariamente requiere interactúar lingüísticamente con y en términos de los productos del comportamiento lingüístico de otros individuos o de él mismo, en este caso serían los escritores del artículo Sequías y cambio climático en México. El tipo de tarea implicaba que el estudiante formulara un discurso semántica y sintácticamente pertinente en donde describiera eventos y/o formulara relaciones entre dichos eventos, usando conectivos que le permitieran enlazar una oración con otra $(\mathrm{s})$.

Con base en estos resultados se puede señalar que la secuencia de la presentación de la modalidad lingüística no se muestra sensible para este nivel funcional de la tarea, por lo menos grupalmente hablando. Por ello, se considera importante enfatizar que los participantes que pudieron elaborar tanto el resumen como la conclusión de forma coherente, son los mismos que tienen porcentajes de coherencia mayores en las interacciones extrasituacionales (por ejemplo, P1, P6, P1 1 y P13). Asimismo aquellos que presentan mayor ocurrencia en el uso de conectivos, usan más conceptos técnicos de forma pertinente, es decir, presentan una habilitación competencial más pertinente en el uso funcional del lenguaje.

Esto se relaciona con la desligabilidad de la conducta lingüística, para Ribes (2000) ésta le permite al individuo interactuar con circunstancias no aparentes o no presentes en una situación determinada. La forma de mediación en el caso de las interacciones transituacionales le implica al estudiante fungir más como un mediador del producto lingüístico (resumen, conclusión). Según estos resultados pareciera que la posibilidad de desempeño efectivo depende más de la competencia lingüística de cada participante (historia de referencialidad), y no de una competencia que "idealmente hablando" debiera de exhibirse por los estudiantes de este nivel. Otros resultados que apoyan en esta dirección son los de Pacheco y Reséndiz (2010), las autoras en su estudio revisaron 26 reportes de investigación de alumnos de primero y sexto semestres de la carrera de Psicología, encontrando que la mayoría de los reportes de los alumnos de sexto semestre fueron más coherentes que los de 


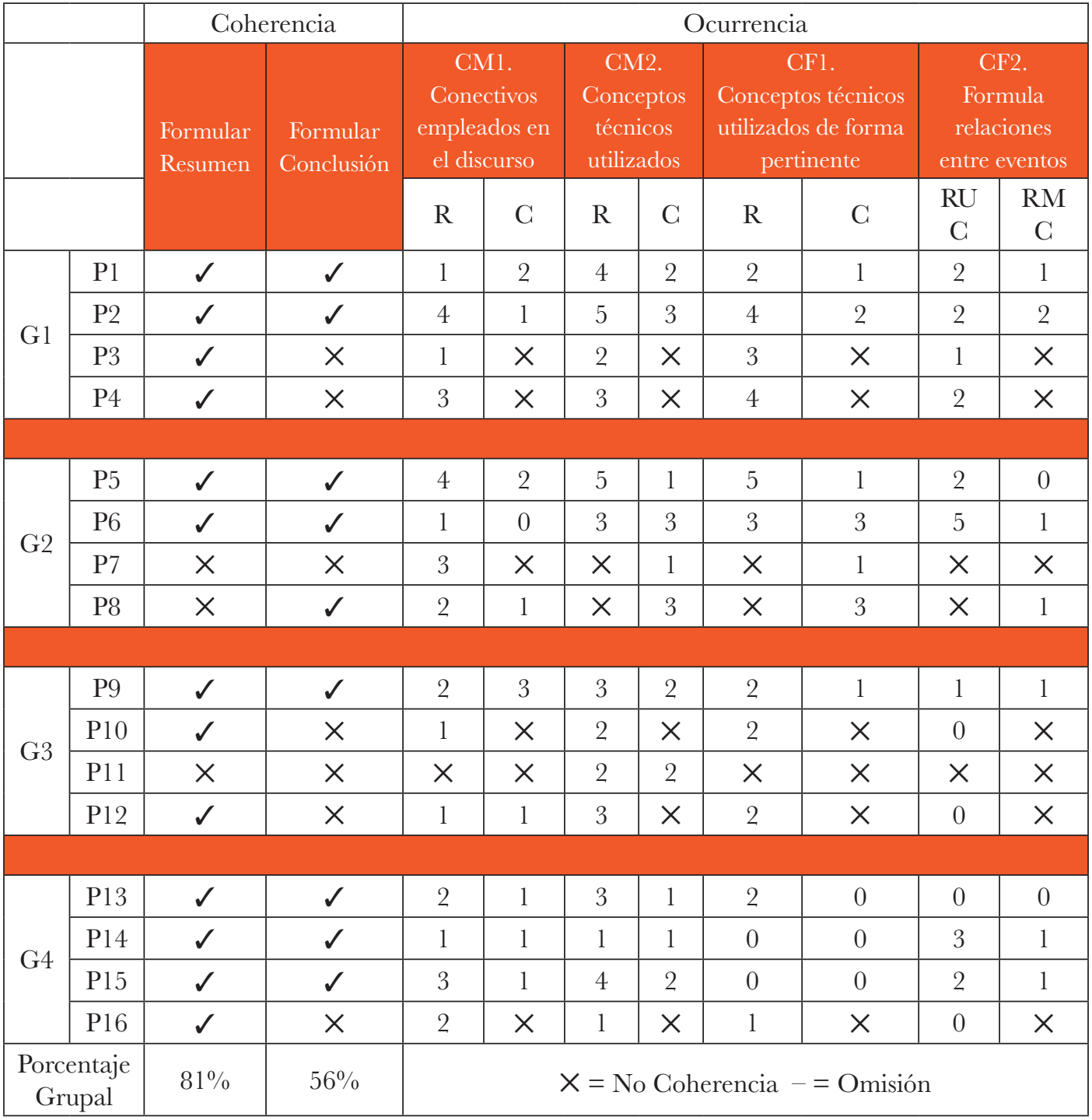

Tabla 11. Muestra la coherencia del desempeño de los participantes - del Estudio 1- en la tarea de elaboración de un resumen y una conclusión (interacciones transituacionales), asi como la ocurrencia en función de las categorías morfológicas y funcionales. CM: Categoría Morfológica, CF: Categoría Funcional, R: Resumen, C: Conclusión. RU: Relación Unicausal, RM: Relación Multicausal. 
primero, pero cuatro escritos de sexto obtuvieron puntajes bajos. Los resultados se discuten a la luz de si las habilidades se establecen azarosamente como resultado de la exposición a las diferentes tareas de los cursos curriculares y de las demandas específicas de los profesores, y no necesariamente por la habilitación competencial lingüística del estudiante.

En cuanto a la categoría morfológica uso de conectivos - CM1-, es importante señalar que los estudiantes universitarios utilizan en promedio dos conectivos en la elaboración del resumen y las conclusiones, usando solamente con mayor frecuencia el conectivo "y" en la mayoría de los casos. Desde una perspectiva lingüística, Prego (2006) ha estudiando el uso del conectivo "y" en el habla infantil, señalando que este conectivo se emplea a partir de los cinco años, el cual se utiliza para elaborar construcciones gramaticales compuestas y discurso interconectado, sin embargo, la autora también enfatiza que conforme se elevan los repertorios lingǘsticos se elevan las posibilidades de hacer variaciones en los modos de uso (p.e. el uso de los conectivos: además, incluso, por otra parte, también, en otro orden de ideas, de la misma manera, entre otras), lo cual al parecer no ocurre con los estudiantes participantes de este estudio.

Con respecto a los resultados en la categoría morfológica uso de conceptos técnicosCM2-(ver Tabla 11), los Grupos 1 y 2 presentaron mayor ocurrencia en el uso de conceptos técnicos. Los participantes que más conceptos técnicos utilizaron en la referencia fueron el 2 y el 5 con cinco ocurrencias, seguido de los participantes 1 y 15 con cuatro ocurrencias. Con tres ocurrencias se tiene a los participantes 4, 6, 9, 12 seguidos de los participantes 3, 10, 11 con dos ocurrencias. Finalmente, los participantes 14 y 16 con una ocurrencia. En estos resultados se encontró que los participantes que usaron de forma más frecuente conceptos técnicos, sólo lo hicieron de forma pertinente en un 50\% ( $\mathrm{CF} 1)$. El bajo promedio de ocurrencia del uso conectivos observado en los Grupos 3 y 4 sugiere que si bien se emplearon los términos, éstos fueron utilizados de manera desarticulada, sin conexión entre ellos (Irigoyen et al. 2011; Mares et al. 2004).

En relación a los resultados de la categoría funcional "formulación de relaciones 
entre eventos de forma unicausal" - CF2-, el Grupo 1 formuló el siguiente número de relaciones: los participantes 1, 2 y 4 con dos relaciones, y participante 3 con una relación. En el Grupo 2, el participante 6 presentó cinco relaciones, el participante 5 dos relaciones. En el Grupo 3 el participante 9 formuló dos relaciones, el participante 12 solamente una y los participantes 10 y 12 no formularon ninguna relación. Con respecto al desempeño del Grupo 4, el participante 14 presentó tres relaciones, el participante 15 dos relaciones y el 13 ninguna relación.

Los resultados de la categoría funcional "formulación de relaciones entre eventos o fenómenos de forma multicausal" -CF2- (ver Tabla 11). Los participantes del Grupo 1 formularon entre una y dos relaciones, el participante 2 dos relaciones, el participante 1 una relación, los participantes 2 y 4 no formularon ninguna relación. Los participantes del Grupo 2 presentaron en promedio una relación, el participante 6 presentó dos relaciones, el 8 una relación y los participantes 5 y 7 ninguna. En cuanto a los participantes del Grupo 3 se tiene que solamente el participante 9 formuló una relación, los demás participantes ninguna. Con respecto a los participantes del Grupo 4 solamente los participantes 14 y 15 presentaron una relación.

En función de los resultados obtenidos se replantean aspectos importantes en relación a la forma de evaluar la comprensión de contenidos científicos en los distintos momentos de formación. Desde el punto de vista planteado en el presente manuscrito, se requiere modificar la planeación, la instrumentación y la métrica utilizada para evaluarla, en donde no solamente se considere al estudiante y su conocimiento previo, sino también los tipos de tarea y los niveles funcionales acordes al objetivo instruccional. De tal manera que la evaluación de la comprensión recupere los distintos niveles competenciales del momento curricular, el o los objetivos instruccionales del espacio educativo, la modalidad del discurso didáctico, el tipo de objeto referente utilizado por el profesor, analizando el efecto disposicional que tiene cada uno de estos. 


\section{Estudio 2}

El objetivo del segundo estudio fue analizar si la explicitación del criterio, las variaciones en el tipo de tarea, su nivel funcional, y la modalidad lingüística involucrada, determinan ajustes diferenciales en la comprensión de un material (texto o audio) con contenido científico en estudiantes universitarios del área de Ciencias Sociales.

Los participantes de este estudio fueron 16 estudiantes universitarios que cursaban los primeros semestres del área de Ciencias Sociales de una universidad pública del norte del país. La selección de la muestra se llevó a cabo en los mismos términos que la del estudio anterior.

Se diseñó una situación de evaluación a partir de dos artículos con un contenido temático sobre ciencia y tecnología, el primero con una extensión en palabras de 3096 y 3178 para el segundo. El primer material fue el mismo que el utilizado en el Estudio 1 (material A), esto con el propósito de comparar los desempeños de los participantes con y sin criterio de ajuste explícito. El segundo fue el material B (La disminución en el nivel trófico de las capturas pesqueras en México). A partir de los materiales originales se elaboraron dos versiones, una en modalidad textual y otra en modalidad auditiva. Así, el instrumento de evaluación consistió de un texto y audio y una prueba cuyas preguntas implicaban variaciones en el tipo de tarea y su nivel funcional, así como la modalidad lingüística implicada. Los requerimientos que se prescribían como tipos de tarea, fueron: 1) seleccionar de entre una serie de opciones de respuesta el descriptor pertinente al enunciado (10 reactivos en formato de opción múltiple), este tipo de tarea se ubicó funcionalmente como interacciones intrasituacionales; 2) formular congruentemente de forma escrita y oral una o varias oraciones a partir de lo leído o escuchado en el material ( 5 reactivos en formato de respuesta abierta para la modalidad escrita y 5 para la modalidad lingüística hablar), este tipo de tarea se situó funcionalmente como interacciones extrasituacionales. Al igual que en el Estudio 1 también se les solicitó a los participantes que elaboraran un resumen y una conclusión (en modalidad escrita), esto 
con el propósito de caracterizar si el estudiante podía elaborar con sus propias palabras una descripción de los aspectos relevantes y las implicaciones propuestas en los materiales, este tipo de tarea se ubicó funcionalmente como interacciones transituacionales. De esta manera, los reactivos permitieron evaluar interacciones intrasituacionales, extrasituacionales y transituacionales.

Del mismo modo que en el Estudio 1, la evaluación se presentó de forma impresa en hojas de papel bond tamaño carta, atendiendo al orden al que había sido asignado previamente cada estudiante. Este orden consistió para los Grupos 1 y 2 en escribir y posteriormente hablar, o en su caso, para los Grupos 3 y 4 primero hablar para posteriormente escribir. Un cambio que se realizó con respecto al Estudio 1 fue la variable explicitación del criterio previo a lectura o escucha del material de estudio. El criterio se presentaba en la pantalla antes del texto y/o el audio, a partir de tres preguntas rectoras, las cuales implicaban un criterio de congruencia. Autores como Morales et al. (2005, 2010) y Morales et al. (2013) han enfatizado la explicitación del criterio de ajuste como un factor disposicional para el ajuste efectivo en tareas de ajuste lector.

Esta variación se sustenta en la siguiente evidencia. Morales et al. (2005) evaluaron los efectos de entrenar a estudiantes universitarios a identificar criterios de ajuste lector en la ejecución de tareas de identificación y elaboración en un primer experimento, y satisfacción de dichos criterios en un segundo experimento. Los investigadores se basaron en la premisa de que la carencia de habilidades para identificar el criterio de ajuste lector es una limitante para que la lectura sea un medio de instrucción y aprendizaje efectivo de nuevas habilidades y competencias.

Las evaluaciones se llevaron a cabo en cubículos exentos de ruidos. Para su aplicación se utilizaron cinco computadoras con audífonos (que permitieran la presentación tanto en la modalidad textual como en la auditiva), así como una grabadora para recabar los datos de la modalidad lingüística hablar. La duración de la sesión la estableció el desempeño del estudiante (aproximadamente 45 min.). Entre una fase y otra transcurrió una semana 
aproximadamente dependiendo de las posibilidades de cada estudiante para regresar al lugar de evaluación. Los desempeños tanto de la modalidad lingüística escribir como la de hablar fueron transcritos a una base de datos de Excel diseñada para su análisis.

Se empleó un diseño cuasiexperimental balanceado de materiales de evaluación equivalentes con cuatro grupos de comparación (Campbell y Stanley, 1982; Kerlinger y Lee, 2002). Los participantes fueron asignados aleatoriamente a los grupos en función de si el material de estudio se presentaba en modalidad textual o auditiva. El estudio constó de dos fases en función de la variación de la modalidad del objeto referente y la secuencia en la modalidad lingǘstica involucrada (escribir-hablar o hablar-escribir), en la primera fase los Grupos 1 y 2 fueron expuestos a la modalidad del objeto referente textual, lo que cambiaba para cada grupo fue la secuencia en la modalidad lingüística y los Grupos 3 y 4 a la modalidad del objeto referente auditiva, variando también la modalidad lingüística involucrada en cada caso. En la segunda fase aquellos grupos que habían leído en la primera, fueron expuestos a la modalidad auditiva y viceversa, modificándose la secuencia en la modalidad lingüística a la que habían sido expuestos en una primera fase, como se muestra en la Tabla 12.

De esta manera, los participantes se exponían a dos secuencias diferentes considerando las modalidades lingüísticas involucradas, una diferente para cada grupo, cada grupo quedó conformado por 4 estudiantes y dependiendo del grupo al que fueron asignados en la primer fase, automáticamente se asignaban al grupo correspondiente de la Fase II, como se muestra en el diseño (ver Tabla 12).

Las instrucciones se presentaron de forma oral por el investigador a los participantes, como se describe en el siguiente párrafo: "A continuación se te presentará un texto (o un audio) sobre un contenido temático que se vincula a la ciencia y a la tecnología, tu tarea consiste en leer un texto (o escuchar un audio para el caso de la modalidad auditiva) sobre el Cambio climático y sequías en México/La disminución en el nivel trófico de las capturas pesqueras en México, y contestar una serie de preguntas posteriores a que leas (o escuches) el material. Una vez iniciada la sesión de lectura (o audio) no podrás regresar al texto o al audio, contesta todas 
las preguntas que te sea posible". Cuando los participantes terminaban de leer o escuchar el material, se les proporcionó las hojas impresas con la prueba para resolver. Al finalizar la sesión, se agradecía la participación de los estudiantes por su colaboración.

Después de las instrucciones se introdujo la variable explicitación del criterio, el cual se presentaba en la pantalla del monitor, a partir de tres preguntas rectoras, el cual implicaba un nivel funcional extrasituacional.

Con respecto a los resultados de la Fase I, el desempeño de los participantes es analizado en términos de interacciones intrasituacionales (a partir de la correspondencia del desempeño del participante ante el tipo de tarea), extrasituacionales (a partir de la congruencia formulada por los participantes en las modalidades lingüísticas de escribir y hablar) y transituacionales (a partir de la coherencia en la elaboración de un resumen y una conclusión a partir de lo leído o escuchado). Adicionalmente, se llevó a cabo un análisis del desempeño de los participantes en la modalidad lingüística escribir en el resumen y la conclusión, a partir de dos tipos de categorías que denominamos: morfológicas o formales y funcionales (como se muestra en la Tabla 9, p. 131-132). El desempeño en las categorías

\begin{tabular}{|c|c|c|c|c|c|c|}
\hline Estudio 2 & \multicolumn{3}{|c|}{ FASE I } & \multicolumn{3}{|c|}{ FASE II } \\
\hline $\mathrm{N}=16$ & \multicolumn{6}{|c|}{ CON CRITERIO DE AJUSTE EXPLÍCITO } \\
\hline $\begin{array}{l}\text { Grupos } \\
(\mathrm{N}=4)\end{array}$ & $\begin{array}{c}\text { Modalidad } \\
\text { del objeto } \\
\text { referente }\end{array}$ & \multicolumn{2}{|c|}{$\begin{array}{l}\text { Secuencia de la } \\
\text { modalidad lingüística }\end{array}$} & $\begin{array}{c}\text { Modalidad } \\
\text { del objeto } \\
\text { referente }\end{array}$ & \multicolumn{2}{|c|}{$\begin{array}{l}\text { Secuencia de la } \\
\text { modalidad lingüística }\end{array}$} \\
\hline G1 & \multirow{2}{*}{$\begin{array}{c}\text { Material A. } \\
\text { Textual }\end{array}$} & Es & $\mathrm{Ha}$ & \multirow{2}{*}{$\begin{array}{c}\text { Material B. } \\
\text { Auditivo }\end{array}$} & $\mathrm{Ha}$ & Es \\
\hline G2 & & $\mathrm{Ha}$ & Es & & Es & $\mathrm{Ha}$ \\
\hline G3 & \multirow{2}{*}{$\begin{array}{c}\text { Material A. } \\
\text { Auditivo }\end{array}$} & Es & $\mathrm{Ha}$ & \multirow{2}{*}{$\begin{array}{c}\text { Material B. } \\
\text { Textual }\end{array}$} & $\mathrm{Ha}$ & Es \\
\hline G4 & & $\mathrm{Ha}$ & Es & & Es & $\mathrm{Ha}$ \\
\hline
\end{tabular}

Tabla 12. Muestra la asignación y la secuencia a la que fueron expuestos los participantes del Estudio 2. G: Grupo, Es: escribir, Ha: Hablar. 
morfológicas fue analizado en términos de: a) el número de conceptos técnicos utilizados para elaborar la referencia escrita, b) el número de conectivos usados para elaborar la referencia, c) el número de palabras que utiliza para elaborar la referencia; para el caso de las categorías funcionales: a) la ocurrencia del número de conceptos técnicos utilizados de forma pertinente, b) el número de relaciones que establece entre eventos de forma unicausal, y c) el número de relaciones entre eventos como relaciones multicausales.

La Figura 10 muestra el desempeño por participante en las interacciones intrasituacionales de la Fase I del Estudio 2. Si se analizan los desempeños de forma grupal, las ejecuciones muestran $76 \%$ de aciertos promedio para los grupos que se les presentó la modalidad del objeto referente textual y 59\% de aciertos para los grupos que se les presentó la modalidad auditiva. Si se comparan estos resultados con los del Estudio 1, en el caso de los grupos expuestos a la modalidad textual aumentó 8\% y en los grupos que fueron expuestos a la modalidad auditiva aumentó 4\%, sin olvidar que en el estudio anterior no se explicitó el criterio de ajuste.

En términos del porcentaje promedio para cada uno de los participantes por grupo fue: con mayor porcentaje de aciertos los participantes del Grupo 1 (P4, 80\%, P2, 70\%, P1 y P3, 60\%), el Grupo 2 obtuvo (P6, 90\%, P5 y P8, 80\% y P7, 60\%) seguidos por los participantes del Grupo 3 (P9 y P12, 70\%, P10 y P11, 60\%) y finalmente, los del Grupo 4 (P14, $70 \%, \mathrm{P} 13$ y $\mathrm{P} 16,60 \%$ y $\mathrm{P} 15,50 \%)$.

La Figura 11 muestra los resultados individuales de los participantes en relación a las interacciones extrasituacionales. En general, los participantes presentaron mayor porcentaje de congruencia que en el Estudio 1, particularmente en el caso de los grupos que leyeron el desempeño se incrementó considerablemente, a continuación se muestra detalladamente. Para los Grupos 1 y 2 los participantes 4 y 8 presentaron 70\% de congruencia, seguidos de los participantes 1, 3, 5, 6 y 7 con $60 \%$, y solamente el participante 2 con $50 \%$. Con respecto a los Grupos 3 y 4, los participantes 9, 11, 14, 15 con 60\% de congruencia, el 10, 12 y 13 con $50 \%$ y solamente el participante 16 con $40 \%$. 
G1. Interacciones Intrasituacionales MOR: Textual

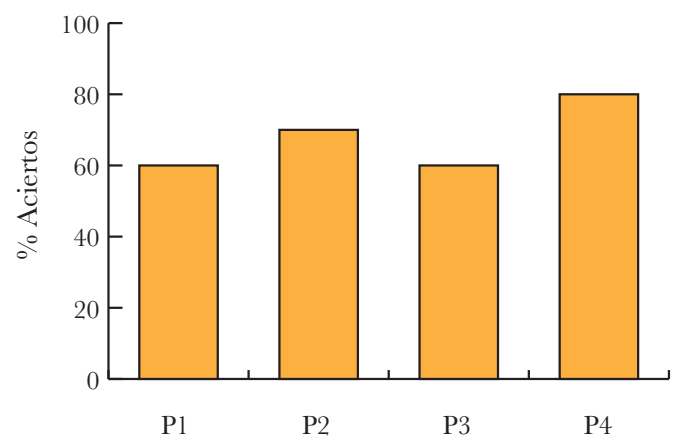

G3. Interacciones Intrasituacionales MOR: Auditiva

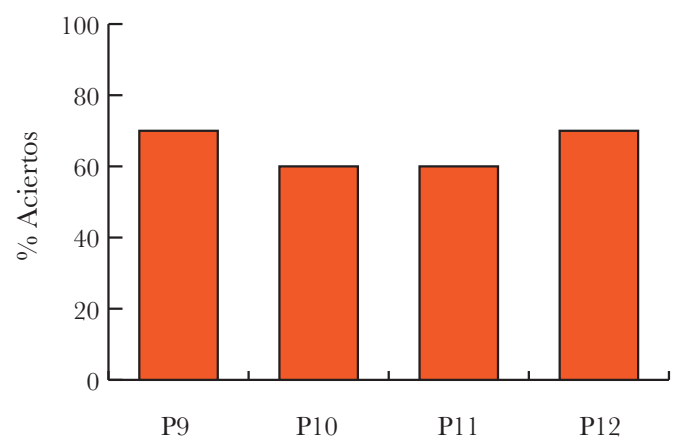

G2. Interacciones Intrasituacionales MOR: Textual

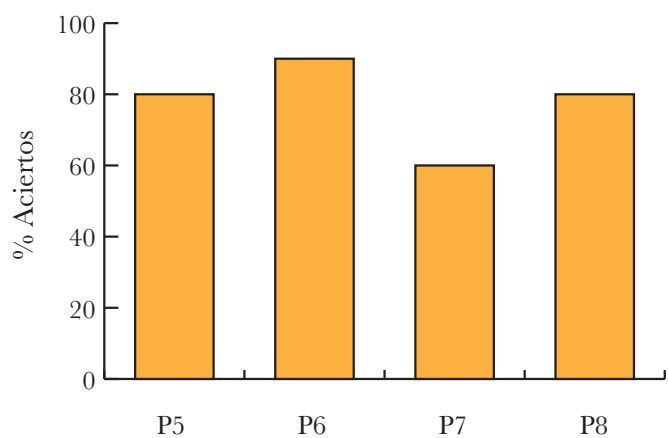

G4. Interacciones Intrasituacionales MOR: Auditiva

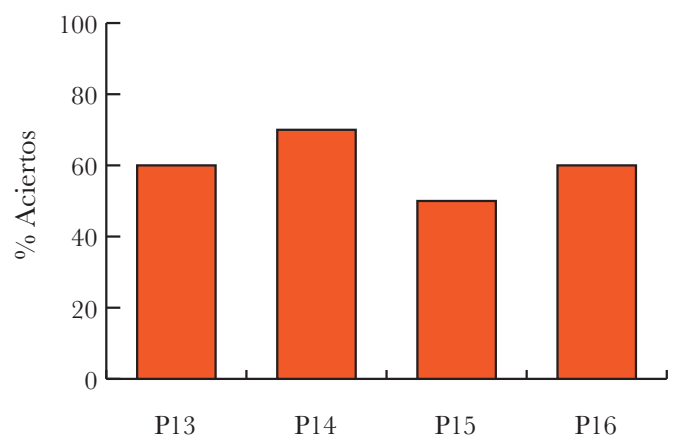

Figura 10. Presenta el porcentaje de aciertos del desempeño de los participantes en las interacciones intrasituacionales de los Grupos 1, 2, 3 y 4 en la Fase I del Estudio 2. MOR: Modalidad del objeto referente. P: Participante. 
G1. Interacciones Extrasituacionales MOR: Textual

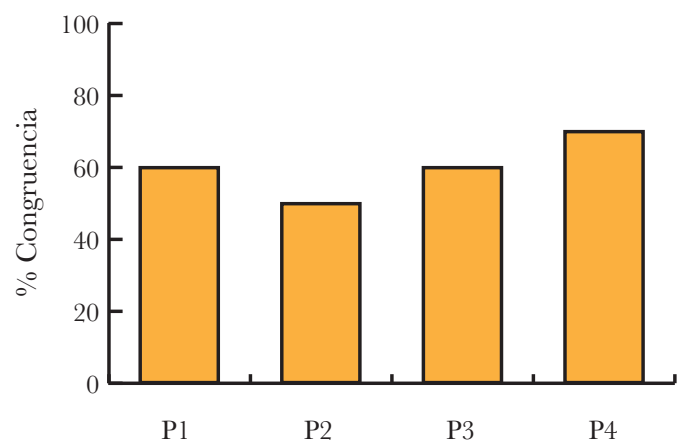

G3. Interacciones Extrasituacionales MOR: Auditiva

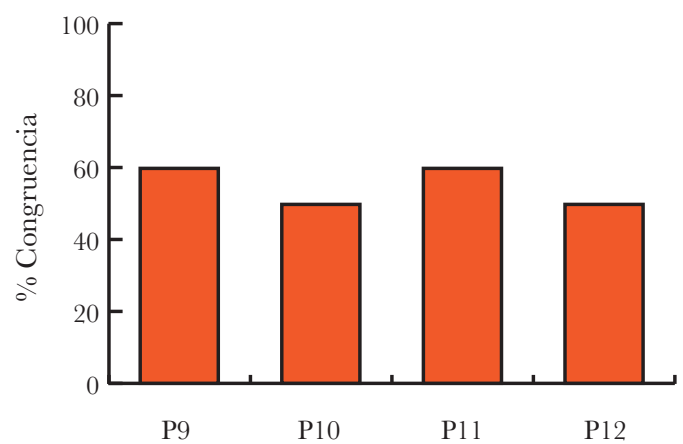

G2. Interacciones Extrasituacionales MOR: Textual

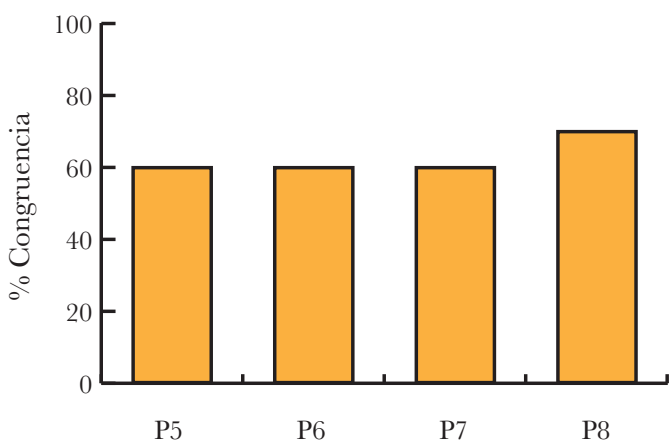

G4. Interacciones Extrasituacionales MOR: Auditiva

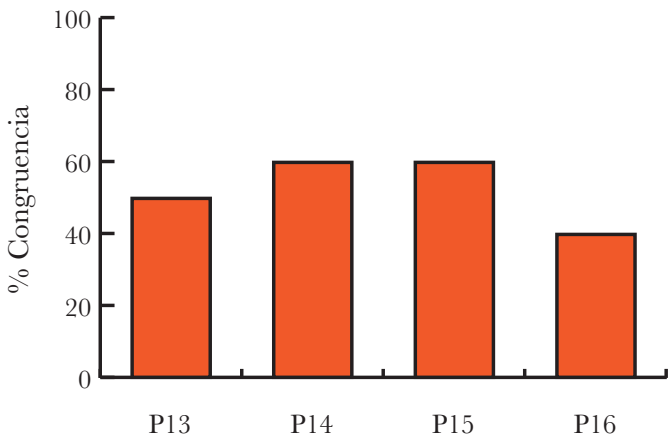

Figura 11. Presenta el porcentaje de congruencia del desempeño de los participantes en las interacciones extrasituacionales de los Grupos 1, 2, 3 y 4 en la Fase I del Estudio 2. MOR: Modalidad del objeto referente. P: Participante. 
Cuando se presenta el desempeño de los participantes tanto grupalmente como individualmente en términos de la secuencia de la modalidad lingüística implicada se observan tendencias importantes (ver Figura 12 y 13). Gráficamente podemos observar que la modalidad lingüística hablar es ligeramente mayor para todos los grupos al margen de la secuencia, excepto en el Grupo 4. No obstante, en los grupos que primero escribieron y después hablaron se observan tendencias con mayor porcentaje de congruencia con más de un 20\%, esta tendencia es similar a la del Estudio 1 (aunque con porcentajes de congruencia más bajos). En cuanto a los porcentajes grupales se tiene que el Grupo 1 presentó 55\% de congruencia para la modalidad lingǘstica escribir y 70\% de congruencia en hablar, el Grupo 3 obtuvó 50\% para la modalidad escribir y 70\% en hablar, el Grupo 2 presentó $50 \%$ en la modalidad lingüística escribir y $55 \%$ de congruencia en hablar y finalmente, el Grupo 4 presentó 50\% de congruencia en ambas modalidades linguísticas (ver Figura 12).

En relación a los porcentajes individuales estos se presentan en la Figura 13. Los participantes de los Grupos 1 y 2 que mostraron desempeños consistentes en ambas modalidades fueron el 1 y 6 con 60\% de congruencia, los participantes 2, 3, 4 y 8 presentaron mayor porcentaje de congruencia en la modalidad lingüística hablar que en escribir, siendo importante enfatizar que la mayoría de estos participantes primero escribieron y después hablaron, esta tendencia no se muestra en los participantes de los grupos que primero hablaron y después escribieron. Esta tendencia no se observó en el participante 7, el cual presentó $60 \%$ de congruencia en la modalidad escribir y $40 \%$ en hablar, el participante 5 presentó congruencia en ambas modalidades pero con un porcentaje bajo (40\%). Con respecto a los Grupos 3 y 4 los participantes que presentaron consistencia en ambas modalidades fue el participante 15 pero con una congruencia del 40\%, los participantes 9, 10, 11, 12 y 13 presentaron mayor congruencia en la modalidad lingüística hablar que en la de escribir, todos con $40 \%$ de congruencia en la modalidad escribir y $60 \%$ en hablar, solamente el participante 16 presentó una tendencia inversa con $60 \%$ en la modalidad escribir y $40 \%$ en hablar. Hasta aquí el análisis gráfico de los datos permite enfatizar que la modalidad lingüística hablar es 
mayor en congruencia en muchos más casos que la de escribir, sin tomar en cuenta tanto la modalidad del objeto referente (textual o auditiva), también nos permite sugerir que la secuencia de presentación de las modalidades lingüísticas tiene un efecto sobre la modalidad lingüística subsiguiente pero particularmente de escribir a hablar, dato consistente también en el primer estudio. Esto pareciera indicar que la modalidad lingǘstica escribir por sus características morfológicas y funcionales, le posibilita al participante interacciones más desligadas de la situación.

Como análisis complementario, se llevó a cabo una comparacion de medias para dos muestras independientes con datos apareados (prueba Wilcoxon), con el propósito de comparar estadísticamente el grado de significancia de las ejecuciones de los participantes del Estudio 1 con los del Estudio 2. A pesar de contar con una muestra tan pequeña el

Interacciones extra: por modalidad lingüística para todos los grupos

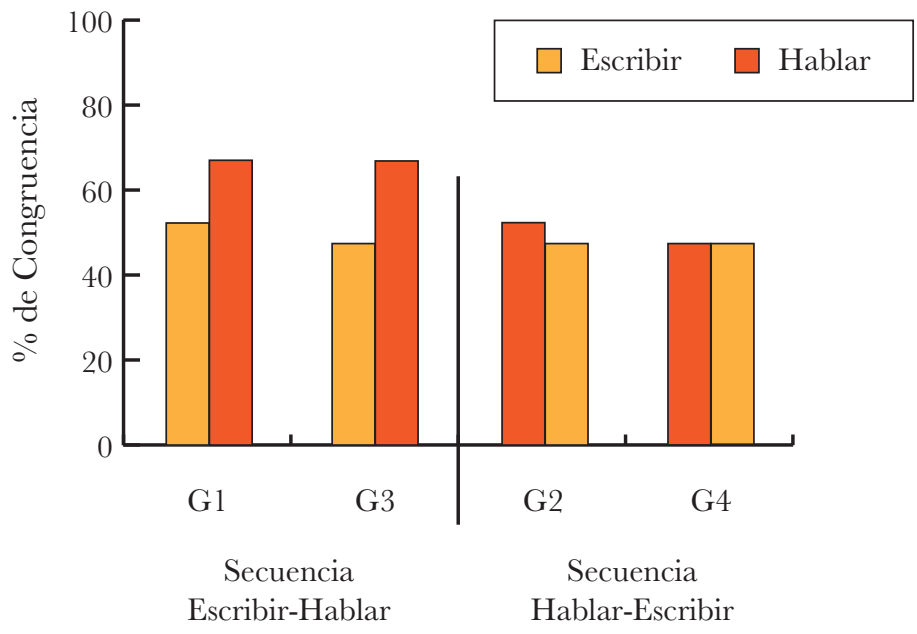

Figura 12. Presenta el porcentaje de congruencia del desempeño grupal en las interacciones extrasituacionales por modalidad linguística de los Grupos 1, 2, 3 y 4 en la Fase I del Estudio 2. G: Grupo. 
resultado mostró ser significativo tanto en las interacciones intrasituacionales (con una $\mathrm{p}$ de .03) como en las extrasituacionales (con una p de .003). En otras palabras los resultados muestran ser significativos entre los grupos del Estudio sin criterio (Estudio 1) y Estudio con criterio (Estudio 2) pero con mayor énfasis en las interacciones extrasituacionales (nivel en el que se explicitó el criterio de ajuste).

En este sentido, se puede señalar que las ejecuciones se muestran sensiblemente moduladas por la explicitación del criterio. Resultados que concuerdan con los presentados anteriormente son los de Mateos y Flores (2008), en su estudio los autores evaluaron la relación que guarda el grado de especificidad de los criterios de ajuste sobre el desempeño de estudiantes universitarios en tareas de identificación y elaboración. Los resultados destacan la importancia de la explicitación y/o especificación del criterio de ajuste para un desempeño variado y efectivo, además de la modalidad de las tareas de evaluación y su complejidad funcional.

En el caso de las interacciones extrasituacionales, el estudiante requería formular (semántica y sintácticamente) congruentemente los aspectos referidos (relacionados con un concepto y/o un referente teórico y su descriptor, o una descripción de las relaciones posibles que probabilizan la ocurrencia de un evento). En otras palabras, requería elaborar una o varias oraciones escritas u orales relacionadas con las preguntas planteadas, dándole sentido a la referencia escrita y/o hablada conforme a la descripción de eventos y/o relaciones referidos en los materiales. Pero ¿qué implica que el estudiante pueda o no elaborar una serie de oraciones dándole congruencia a las relaciones formuladas tanto para el caso de la modalidad escrita como en la oral? Este nivel funcional de interacción implica para autores como Ribes (2012) lo siguiente: "En el caso de la sustitución extrasituacional, el episodio sustitutivo consiste en que un hablante, gesticulador o escritor modifica mediante una intervención lingüística las relaciones de contingencias prevalentes en una situación. Aunque la transformación, modificación o reemplazo de las contingencias prevalentes tenga que ver con contingencias transferidas de otra situación, otro lugar, otro momento u otras 
G1. Interacciones Extrasituacionales por modalidad lingüística

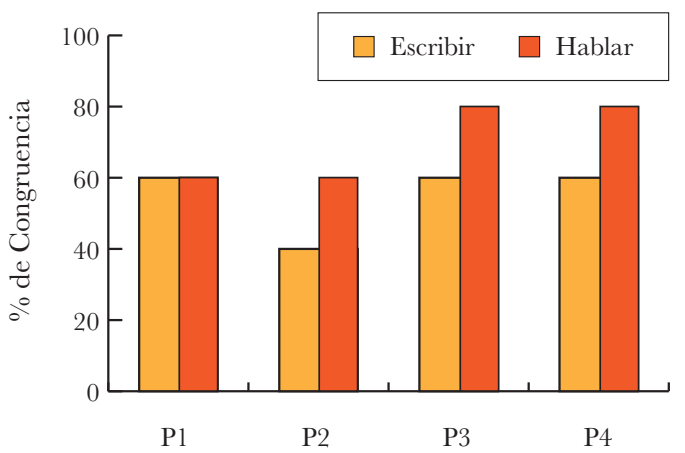

Secuencia Escribir-Hablar

G3. Interacciones Extrasituacionales por modalidad lingüistica

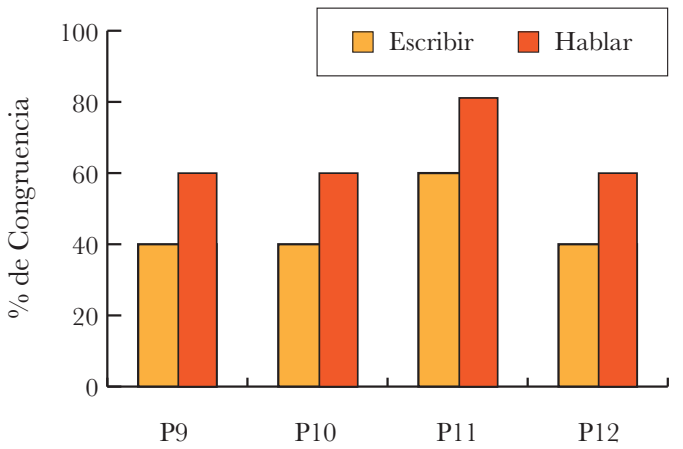

Secuencia Escribir-Hablar
G2. Interacciones Extrasituacionales por modalidad lingüística

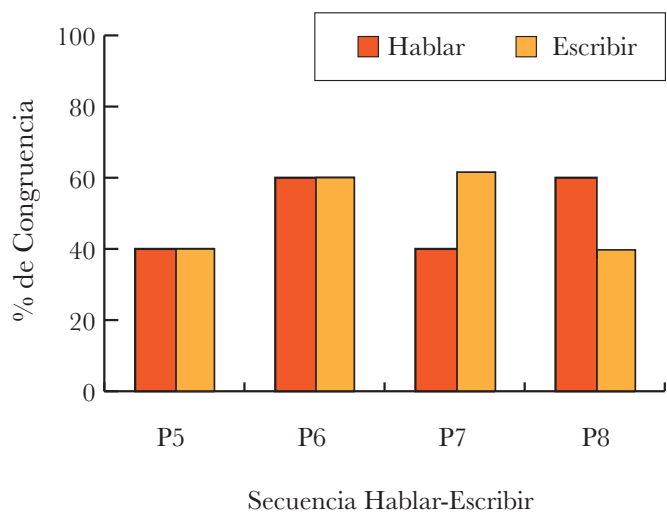

G4. Interacciones Extrasituacionales por modalidad lingüística

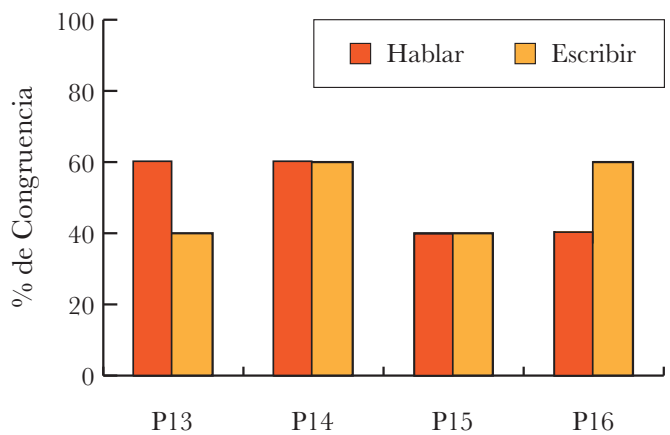

Secuencia Hablar-Escribir

Figura 13. Presenta el porcentaje de congruencia del desempeño individual obtenido en las interacciones extrasituacionales por modalidad lingüística de los Grupos 1, 2, 3 y 4 en la Fase I del Estudio 2. P: Participante. 
propiedades no aparentes en el instante, la sustitución extrasituacional siempre ocurre en el presente y en el lugar en que se produce el episodio" (p. 22). De tal manera, que en este tipo de interacciones se requiere cuando menos de un mediador que establezca contacto con los eventos como relaciones posibles dentro de un ámbito funcional de desempeño; que en algunos momentos de la formación puede ser el escritor de los artículos científicos o el profesor, a partir de las cuales el estudiante requiere responder con base en los cambios situacionales (sea en términos de instancias, modalidades y relaciones) propiciados por dichos mediadores. Si el mediado (en este caso el estudiante) no responde a los productos lingüísticos del escritor o profesor, no se completa el episodio, es decir, no se cumple el criterio funcional para poder hablar de una interacción extrasituacional.

Ríos-Checa (2011) ha presentado una propuesta para la enseñanza de la escritura tomando como referencia las interacciones de interdependencia entre el referidor (el que habla o escribe), referido (al que se le habla o escribe -que también puede ser el mismo referidor-) y referente (de lo que se habla o se escribe) bajo prácticas auspiciadas por los diferentes modos lingüísticos, en donde el estudiante pueda comportarse en correspondencia con la conducta del mediador (profesor o escritor) y con eventos y sus posibles relaciones, como situaciones referidas. Toda vez que cuando se habla de contenidos científicos los eventos referidos no siempre consisten de objetos y sus propiedades físicas, sino más bien en relaciones no aparentes descritas desde una teoría científica (p.e. conceptos como masa, fuerza, velocidad, gen, célula, fenotipo, etc.); poder ajustarse a criterios extrasituacionales requiere "haber experimentado" una serie de interacciones lingüísticas con dichos referentes científicos, es decir, una historia interactiva que involucre niveles de desligamiento intrasituacionales como aprender nominativos que hacen referencia a conceptos, procedimientos, lenguaje de datos y sus usos pertinentes para referir hechos, fenómenos, que le permitirá posteriormente convertirse en mediado (como hablante y escritor) y poder aplicar dichos principios o reglas a condiciones distintas en las que fueron enseñados. De ahí que posteriormente estos desempeños puedan correlacionarse con su desempeño efectivo como hablante y/o escritor, es decir, con un estudiante que comprende. 
Estudios llevados a cabo con estudiantes universitarios en esta misma área señalan que la escritura en un ámbito científico requiere una didáctica específica que incluya el dominio de las habilidades lingǘsticas de modo pasivo (p.e. como de lectura y/o escucha), en donde se diseñen situaciones orientadas a la práctica supervisada, el modelamiento y la evaluación-corrección de ejercicios que le permitan al estudiante identificar la semántica, sintaxis y estructura de los textos ajustados a los criterios disciplinares (Pacheco, 2010).

Con respecto a los resultados del análisis de las interacciones transituacionales éstas se muestran en la Tabla 13. En la Tabla se observa que el $87 \%$ de los participantes pudo elaborar un resumen y solamente el $43 \%$ una conclusión con coherencia. Los participantes $3,4,8,9,12$ y 14 elaboraron un resumen y una conclusión, pero los participantes $1,2,5$, 7, 10, 11, 15 y 16 solamente pudieron elaborar el resumen con coherencia. El participante 6 solamente elaboró una conclusión sin elaborar un resumen. Si se analiza el desempeño grupalmente no se observan diferencias funcionalmente hablando para este nivel de interacción en términos de las secuencias en las modalidades lingüísticas, aun cuando los participantes de los Grupos 1 y 2 muestran mayores desempeños de coherencia en las interacciones transituacionales que los Grupos 3 y 4 . Se puede observar también que estos resultados muestran desempeños ligeramente mayores que en el Estudio 1, esto podría ser atribuido a la variable de explicitación del criterio de ajuste.

Con respecto a los resultados de la categoría morfológica uso de conceptos técnicos -CM2- (ver Tabla 13), los Grupos 1 y 3 presentaron mayor porcentaje de ocurrencia en el uso de conceptos técnicos, con mayor número de ocurrencias el participante 11 (del Grupo 3) con seis ocurrencias, seguido por los participantes 9 y 12 con cinco ocurrencias, los participantes 1 y 2 (del Grupo 1) también con cinco ocurrencias. Con cuatro ocurrencias los participantes 7 y 8 (del Grupo 2), y el participante 10 (del Grupo 3) y 16 (del Grupo 4). Con tres ocurrencias los participantes 3 y 4 (del Grupo 1), el participante 5 (del Grupo 2) y los participantes 14 y 15 (del Grupo 4). 
Con respecto a esta misma categoría pero analizada desde un punto funcional, se encontró que en promedio solamente el $60 \%$ de estos conceptos técnicos son usados de forma pertinente por los estudiantes. Se considera que aunado al bajo promedio de ocurrencia de conectivos observado en los grupos se concluye que si bien se emplearon los términos, éstos fueron utilizados de manera desarticulada, y sin conexión entre ellos (Irigoyen et al. 2011; Mares et al. 2004).

Con relación a los resultados en términos de la categorías funcionales "formula relaciones entre eventos como relaciones unicausales y/o relaciones causales múltiples" CF2- (ver Tabla 13), se puede observar que el mayor número de relaciones para la categoría GF2, relaciones unicausales fue de cuatro ocurrencias, y el menor fue de dos, en el caso de la categoría CF2, relaciones multicausles el mayor número de relaciones fue de dos y el menor uno. Del Grupo 1 el participante 1 estableció cuatro relaciones y el 2 formuló tres relaciones unicausales en la CF2 en el resumen, los participantes 3 y 4 formularon dos relaciones unicausales y dos relaciones multicausales en la categoría CF2. Del Grupo 2 el participante 6 formuló dos relaciones unicausales y solamente una relación multicausal, de este mismo Grupo el participante 8 con tres relaciones unicausales, pero ninguna relación multicausal. Del Grupo 3 los participantes 9 y 12 formularon tres relaciones unicausales y dos relaciones multicausales. Del Grupo 4 solamente el participante 14 formuló tres relaciones unicausales, pero ninguna relación multicausal en esta categoría.

Con respecto a los resultados de la Fase II, la Figura 14 muestra el desempeño por participante en las interacciones intrasituacionales. Los desempeños analizados de forma grupal muestran ejecuciones del 68\% de aciertos promedio para los grupos que fueron expuestos a la modalidad del objeto referente textual y $53 \%$ de aciertos para los grupos que fueron expuestos a la modalidad auditiva. En términos del porcentaje promedio para cada uno de los participantes por grupo fue: con mayor porcentaje de aciertos los Grupos 3 y 4, el Grupo 3 presentó los siguientes porcentajes (P9 y P10, 80\%, P12, 70\% y P7, 60\%), seguido por el Grupo 4 (P13 y P16, 80\%, P14, 70\%, P15, 60\%). Con menor cantidad de aciertos los 
Aproximación metodológica al análisis de la comprensión de contenidos científicos

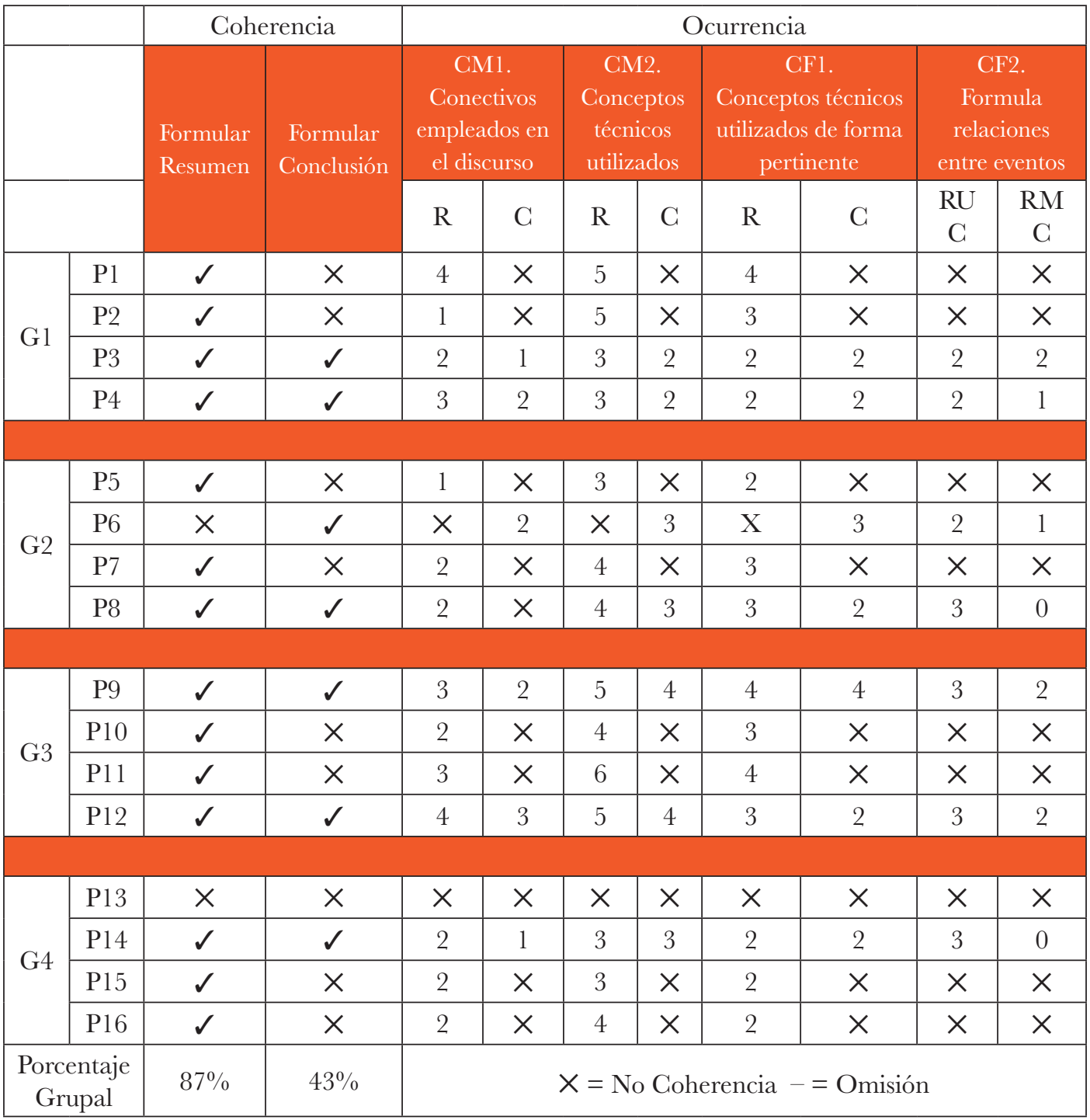

Tabla 13. Muestra la coherencia del desempeño de los participantes - de la Fase I, Estudio 2- en la tarea de elaboración de un resumen y una conclusión (interacciones transituacionales), asi como la ocurrencia en función de las categorías morfológicas y funcionales. CM: Categoría Morfológica, CF: Categoría Funcional, R: Resumen, C: Conclusión. RU: Relación Unicausal, RM: Relación Multicausal. 
G1. Interacciones Intrasituacionales MOR: Auditiva

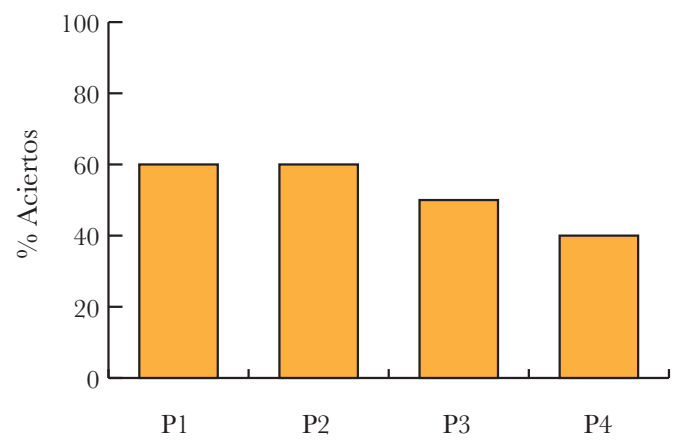

G3. Interacciones Intrasituacionales MOR: Textual

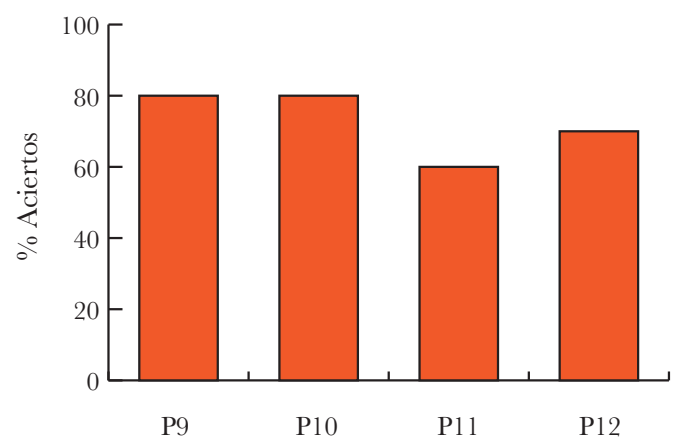

G2. Interacciones Intrasituacionales MOR: Auditiva

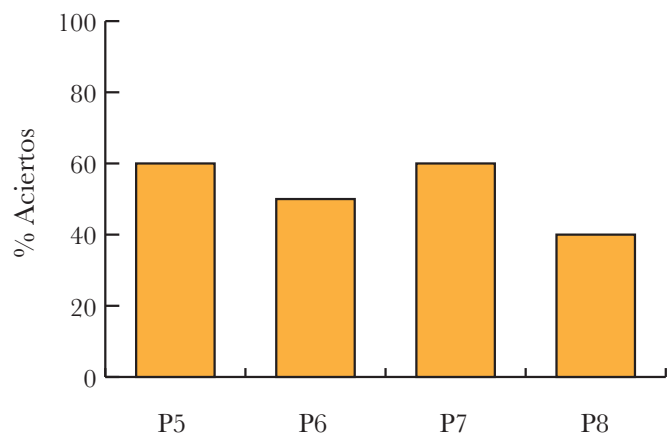

G4. Interacciones Intrasituacionales MOR: Textual

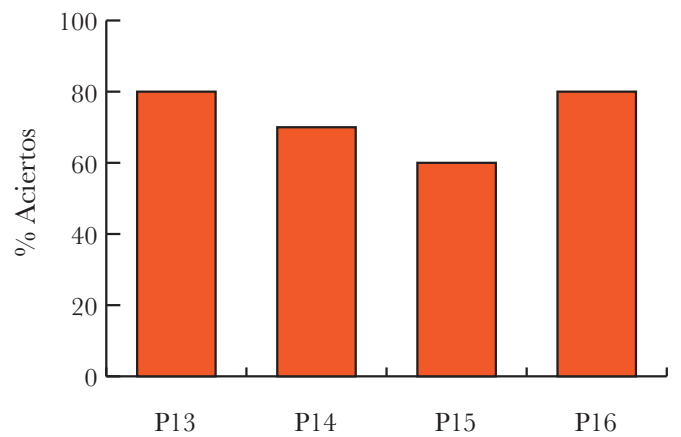

Figura 14. Presenta el porcentaje de aciertos del desempeño de los participantes en las interacciones intrasituacionales de los Grupos 1, 2, 3 y 4 en la Fase II del Estudio 2. MOR: Modalidad del objeto referente. P: Participante. 
Grupos 1 y 2, el Grupo 2 obtuvo entre 60 y 40\% de aciertos (P5 y P7, 60\%, P6, 50\%, P4, $40 \%$ ) y finalmente, los del Grupo 1 ( $\mathrm{P} 1$ y $\mathrm{P} 2,60 \%$, P3, 50\% y P4, 40\%).

Estos resultados se mantienen consistentes al compararlos con los de la Fase 1 en términos de tendencias grupales, toda vez que los participantes que fueron expuestos a la modalidad del objeto referente textual obtuvieron mejor porcentaje de aciertos en esta tarea. También en ésta fase se encontró el mismo efecto en relación con la explicitación del criterio, lo cual coincide con los resultados obtenidos por Morales et al. (2005).

La Figura 15 muestra los resultados individuales de los estudiantes en relación a las interacciones extrasituacionales. En general, los participantes presentaron una consistencia semejante en términos del porcentaje de congruencia de la Fase 1 de este mismo estudio, particularmente los grupos que fueron expuestos a la modalidad del objeto referente textual mantienen mayor porcentaje de aciertos. Recordemos que son los mismos participantes, sólo que ahora los que fueron expuestos a la modalidad del objeto referente textual fueron expuestos a la auditiva, y aquellos que primero fueron expuestos a la modalidad auditiva, posteriormente fueron expuestos a la textual. Para los Grupos 1 y 2, los porcentajes de congruencia fueron los siguientes: los participantes $1,3,6$ y 7 con $60 \%$ de congruencia, los participantes 4, 5 y 8 con $50 \%$ y finalmente el participante 14 con $40 \%$ de congruencia. Para los Grupos 3 y 4, el participante 14 obtuvo un porcentaje de congruencia del $80 \%$, seguido por los participantes 9,11 y 15 con $70 \%$, posteriormente los participantes 10,12 y 16 con $60 \%$ de congruencia y por último, el participante 15 con $40 \%$.

$\mathrm{Al}$ presentar los porcentajes obtenidos en las interacciones extrasituacionales en función de la modalidad lingüística involucrada (escribir y hablar) se encuentra que los porcentajes de congruencia varian en relación a la secuencia de cada grupo, manteniéndose al igual que en la Fase I un efecto ligeramente mayor en los desempeños dependiendo de si el participante primero escribía y después hablaba, en la modalidad lingüística hablar. A continuación en la Figuras 16 y 17 se presentan los resultados del porcentaje de congruencia grupal e individual por modalidad lingüística. 
G1. Interacciones Extrasituacionales MOR: Auditiva

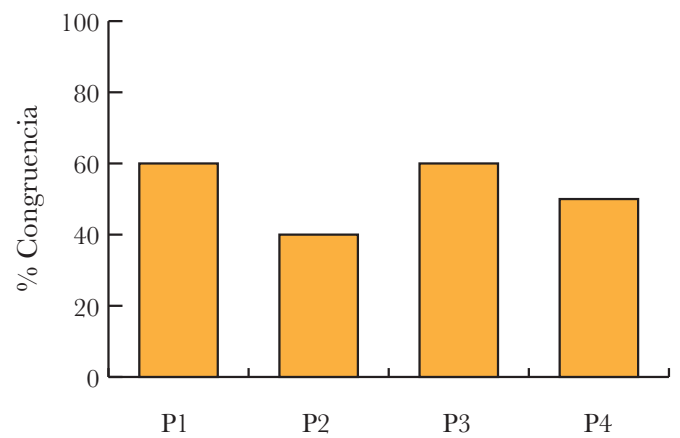

G3. Interacciones Extrasituacionales MOR: Textual

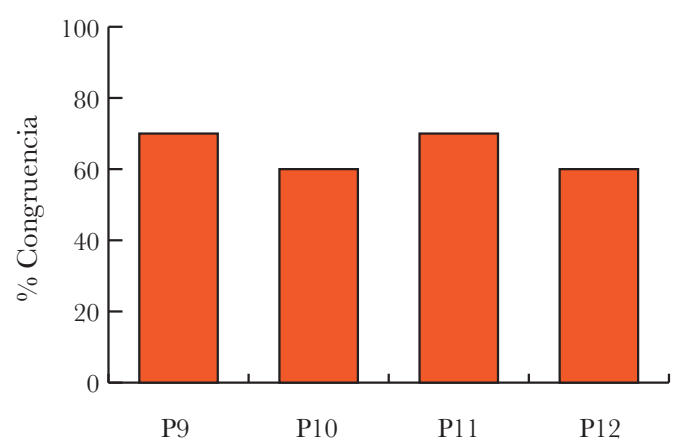

G2. Interacciones Extrasituacionales MOR: Auditiva

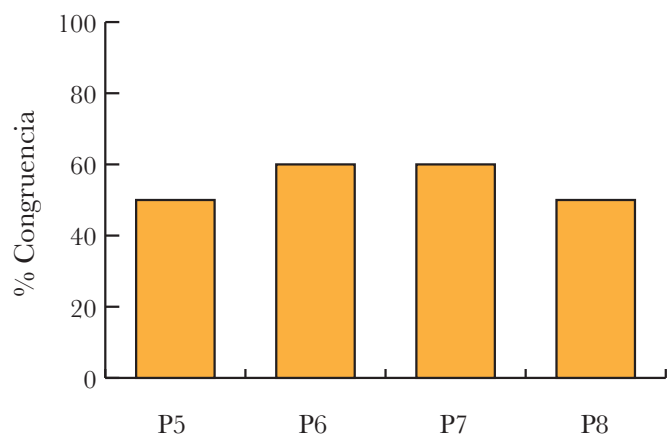

G4. Interacciones Extrasituacionales MOR: Textual

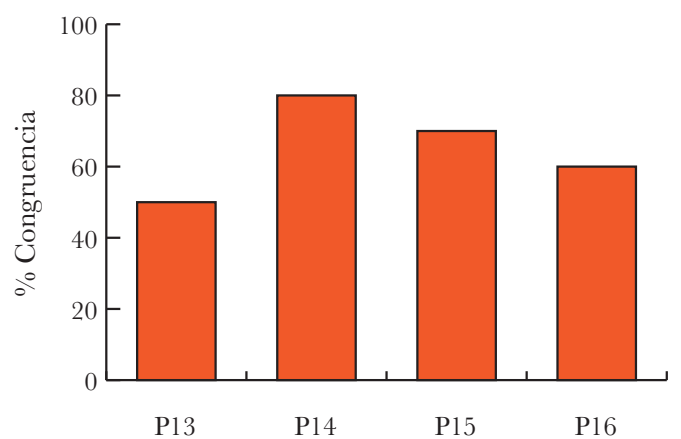

Figura 15. Presenta el porcentaje de congruencia del desempeño de los participantes en las interacciones extrasituacionales de los Grupos 1, 2, 3 y 4 en la Fase II del Estudio 2. MOR: Modalidad del objeto referente. P: Participante. 
En cuanto a los porcentajes grupales se muestra que el Grupo 1 presentó 50\% de congruencia para la modalidad lingǘstica escribir y 55\% de congruencia en hablar, el Grupo 3 obtuvo $65 \%$ para la modalidad escribir y $60 \%$ en hablar, el Grupo 2 presentó $40 \%$ en la modalidad lingüística escribir y $65 \%$ de congruencia en hablar y finalmente, el Grupo 4 presentó $50 \%$ de congruencia en la modalidad lingüística escribir y $65 \%$ en la modalidad hablar (ver Figura 16).

En relación a los resultados individuales los participantes de los Grupos 1 y 2 que presentaron desempeños consistentes en ambas modalidades lingüísticas fueron los participantes 1 y 3 con $60 \%$ y el participante 2 con $40 \%$ de congruencia. Los participantes 4, 5, 6 y 8 presentaron $40 \%$ en la modalidad lingüística escribir y $60 \%$ en la modalidad hablar, solamente el participante 7 presentó $40 \%$ en escribir y $80 \%$ en hablar. Con respecto a los Grupos 3 y 4 los participantes que presentaron consistencia en ambas modalidades fueron los participantes 11,12 y 15 con $60 \%$ y 9 con $80 \%$ de congruencia, los participantes 13 y 16 con $40 \%$ de congruencia en la modalidad lingǘstica escribir y $60 \%$ en la modalidad hablar, el participante 14 presentó $60 \%$ en la modalidad lingüística escribir y $80 \%$ en hablar, solamente el participante 10 mostró una congruencia mayor para la modalidad lingüística escribir $60 \%$ y $40 \%$ de congruencia en hablar. Hasta aquí el análisis gráfico de los datos sugiere que la secuencia de presentación de las modalidades lingüísticas tiene un efecto sobre la modalidad subsiguiente, pero más significativamente en la modalidad lingüística hablar cuando previamente el estudiante había escrito.

Con respecto a los resultados en las interacciones transituacionales estas se muestran en la Tabla 14. Se puede observar en la Tabla que el 75\% de los participantes pudo elaborar un resumen y solamente el 25\% una conclusión con coherencia. Solamente tres participantes (3, 8 y 12) pudieron formular un resumen y una conclusión con coherencia. Los participantes $1,2,4,5,6,9,13,14$ y 15 elaboraron un resumen pero no una conclusión, y los participantes 7 y 16 solamente pudieron formular una conclusión con coherencia pero no un resumen. Es importante mencionar que los participantes 9, 10 y 16 si elaboraron un "resumen" y 
una "conclusión", pero no fue tomada en el análisis de los datos como una formulación coherente, ya que elaboraron un listado de frases con sentido, pero sin conexión entre ellas, es decir, no se encontró una expresión relacional que vinculará los eventos, solamente se presentaron enunciados que iniciaban y terminaban -oraciones- pero sin ningún conectivo que les permitiera vincular una idea con otra.

$\mathrm{Al}$ analizar el desempeño grupalmente no se observan diferencias en las ejecuciones en términos de la secuencia en la modalidad lingüística, más bien se podrían atribuir a la habilitación competencial lingüística de cada estudiante (en este caso como escritor).

Interacciones extra: por modalidad lingüística para todos los grupos

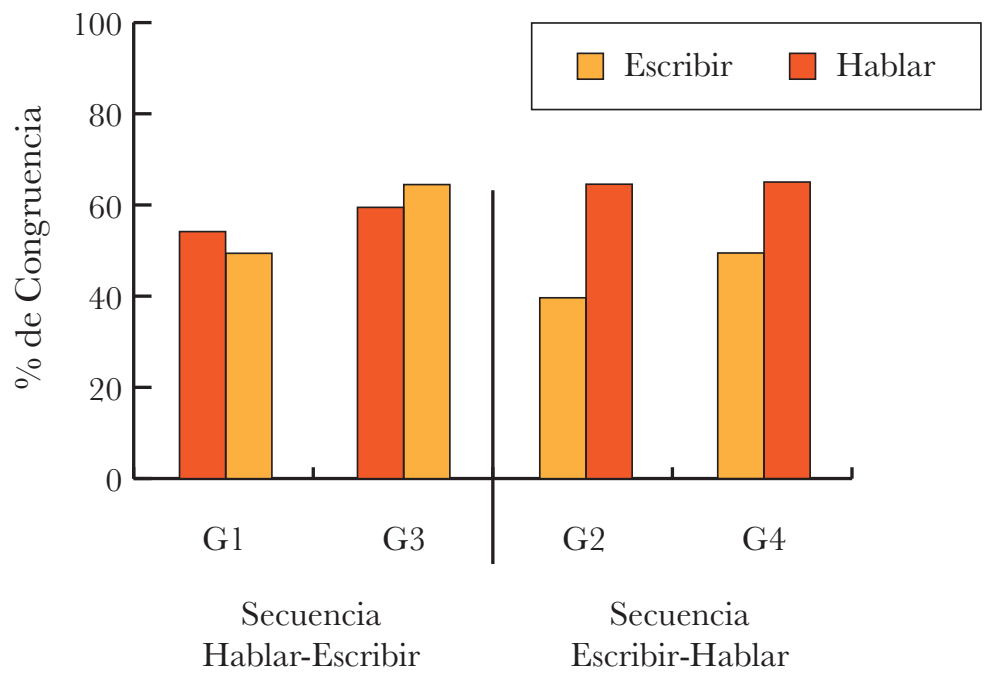

Figura 16. Presenta el porcentaje de congruencia del desempeño grupal en las interacciones extrasituacionales por modalidad lingǘrtica de los Grupos 1, 2, 3 y 4 en la Fase II del Estudio 2. G: Grupo. 
G1. Interacciones Extrasituacionales por modalidad lingüística

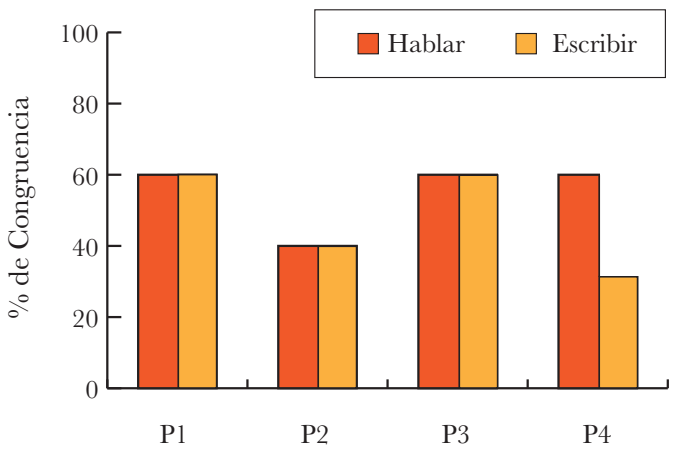

Secuencia Hablar-Escribir

G3. Interacciones Extrasituacionales por modalidad lingüística

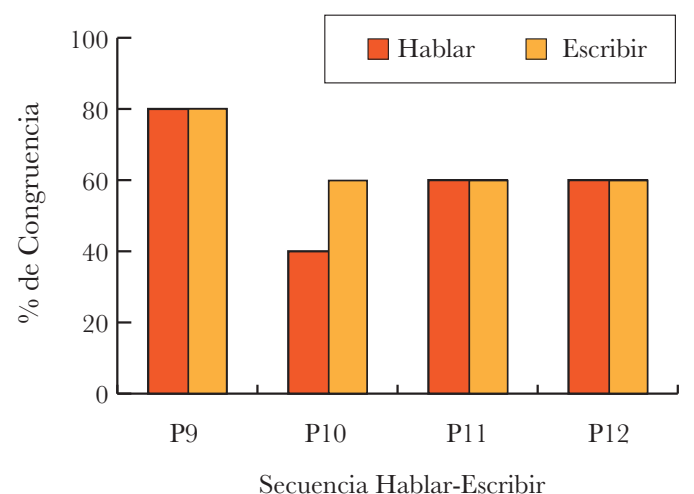

Secuencia Hablar-Escribir
G2. Interacciones Extrasituacionales por modalidad lingüística

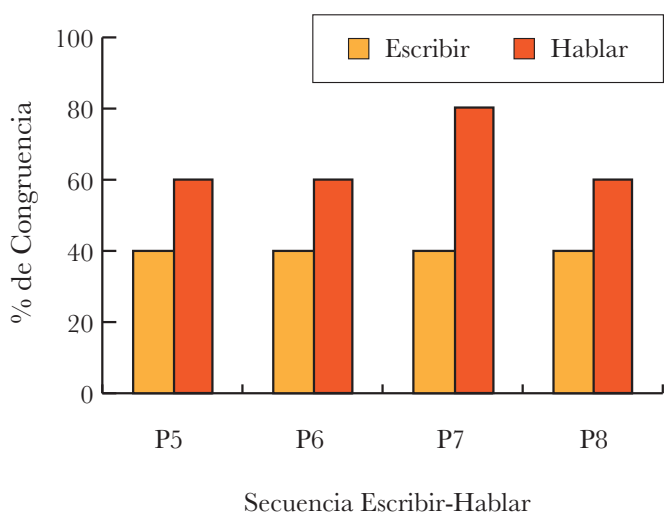

G4. Interacciones Extrasituacionales por modalidad lingüística

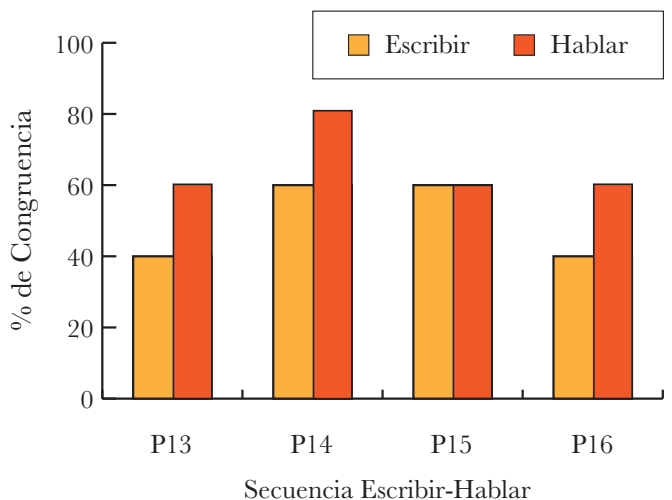

Figura 17. Presenta el porcentaje de congruencia del desempeño individual en las interacciones extrasituacionales por modalidad lingüística de los Grupos 1, 2, 3 y 4 en la Fase II del Estudio 2. P: Participante. 
Se sugiere que la competencia lingüística de cada estudiante tiene un efecto modulador (disposicional) que le posibilita escribir y hablar. Autores como Pacheco (2010) han mencionado como elementos importantes para el análisis de interacciones escritoras, la historia de contactos escritor-referente, la cual incluye: a) la colección de contactos indirectos constituidos por episodios en los que se ha hablado, leído o escrito acerca de los referentes - historia de referencialidad- y b) la colección de contactos directos constituida por los episodios en los que se ha interactuado sensorial - viendo, oliendo, tocando, oyendo, gustando- y manipulativamente con los referentes -historia situacional-.

Con respecto a los resultados de la categoría morfológica uso de conceptos técnicos -CM2- (ver Tabla 14). Los participantes del Grupo 1 presentaron el siguiente porcentaje de coherencia en el resumen: el participante 5 utilizó cinco conceptos técnicos, el participante 3 con tres conceptos, los participantes 1 y 2 con dos conceptos técnicos. Para el caso de las conclusiones solamente el participante 3 pudo formularla de forma coherente, en la cual utilizó 2 conectivos, 2 conceptos técnicos con pertinencia, y formuló una relación entre eventos de forma causal múltiple. Con respecto a los participantes del Grupo 2 estos presentaron menor porcentaje de ocurrencia en las categorías CM1, CM2, CF1 y CF2, a continuación se presenta de manera individual. El participante 6 utilizó dos conectivos, tres conceptos técnicos, pero solamente dos utilizados de forma pertinente, y formuló una relación causal entre eventos de forma aislada en el resumen. Los participantes 5 y 8 utilizaron dos y un conectivo respectivamente, dos y un concepto técnico, pero solamente uno lo utilizó de forma pertinente, estableciendo también solo una relación unicausal entre eventos en la formulación del resumen.

Con respecto al Grupo 3 solamente el participante 12 formuló un resumen y una conclusión utilizando un conectivo en el primero y dos en el segundo, dos conceptos técnicos en cada caso, y solamente una relación unicausal en el resumen. Del Grupo 4 los participantes 13, 14 y 15 elaboraron un resumen, utilizando dos conectivos (participantes 13 y 14) y un conectivo en la referencia (participante 15), tres (participante 13) y dos conceptos de forma 
pertinente (participantes 14 y 15), pero sin establecer relaciones entre eventos, requerimiento necesario en la comprensión de contenidos científicos.

Es importante resaltar ante los resultados obtenidos, que los materiales científicos le implican al estudiante establecer contacto con referentes abstractos, y que el sólo pasar del tiempo formativamente no lo auspiciará -leer, escribir y hablar-, si estos no son pertinentemente mediados en el desarrollo de su instrucción. En este sentido, autores como Carlino y Martínez (2009) comentan que se da por supuesto que los estudiantes deben "comprender" el contenido de los textos científicos, pero en parte, la adquisición de estas habilidades y competencias depende de la calidad de su preparación escolar previa (lo que en el presente trabajo se denomina historia de referencialidad), en donde pocas veces se les prescribe como criterio que establezcan relaciones a propiedades no aparentes o no presentes.

Con respecto a la categoría uso de conceptos técnicos pero desde un punto funcional - $\mathrm{CF} 1-$, se encontró que en promedio solamente el 60\% de estos conceptos técnicos son usados por los estudiantes de forma pertinente. Se considera que aunado al bajo promedio de ocurrencia de conectivos observado en los grupos, se concluye que si bien se emplearon los términos, éstos fueron utilizados de manera desarticulada y sin conexión entre ellos (Irigoyen et al. 2011; Mares et al. 2004).

Con relación a los resultados en las categorías funcionales "formula relaciones entre eventos como relaciones unicausales" y/o "formula relaciones causales múltiples" CF2- (ver Tabla 14). Se puede observar que el mayor número de relaciones unicausales para la categoría CF2 fue de cuatro ocurrencias, y el menor fue de dos, en esta misma categoría pero en función de las relaciones multicausales, el mayor número de relaciones fue de dos y el menor uno. Del Grupo 1 el participante 1 estableció cuatro relaciones y el participante 2 formuló tres relaciones unicausales en el resumen, los participantes 3 y 4 formularon dos relaciones unicausales y dos relaciones multicausales en esta misma categoría. Del Grupo 2 el participante 6 formuló dos relaciones unicausales, de este mismo Grupo el participante 8 con tres relaciones unicausales para la GF2, pero ninguna relación 


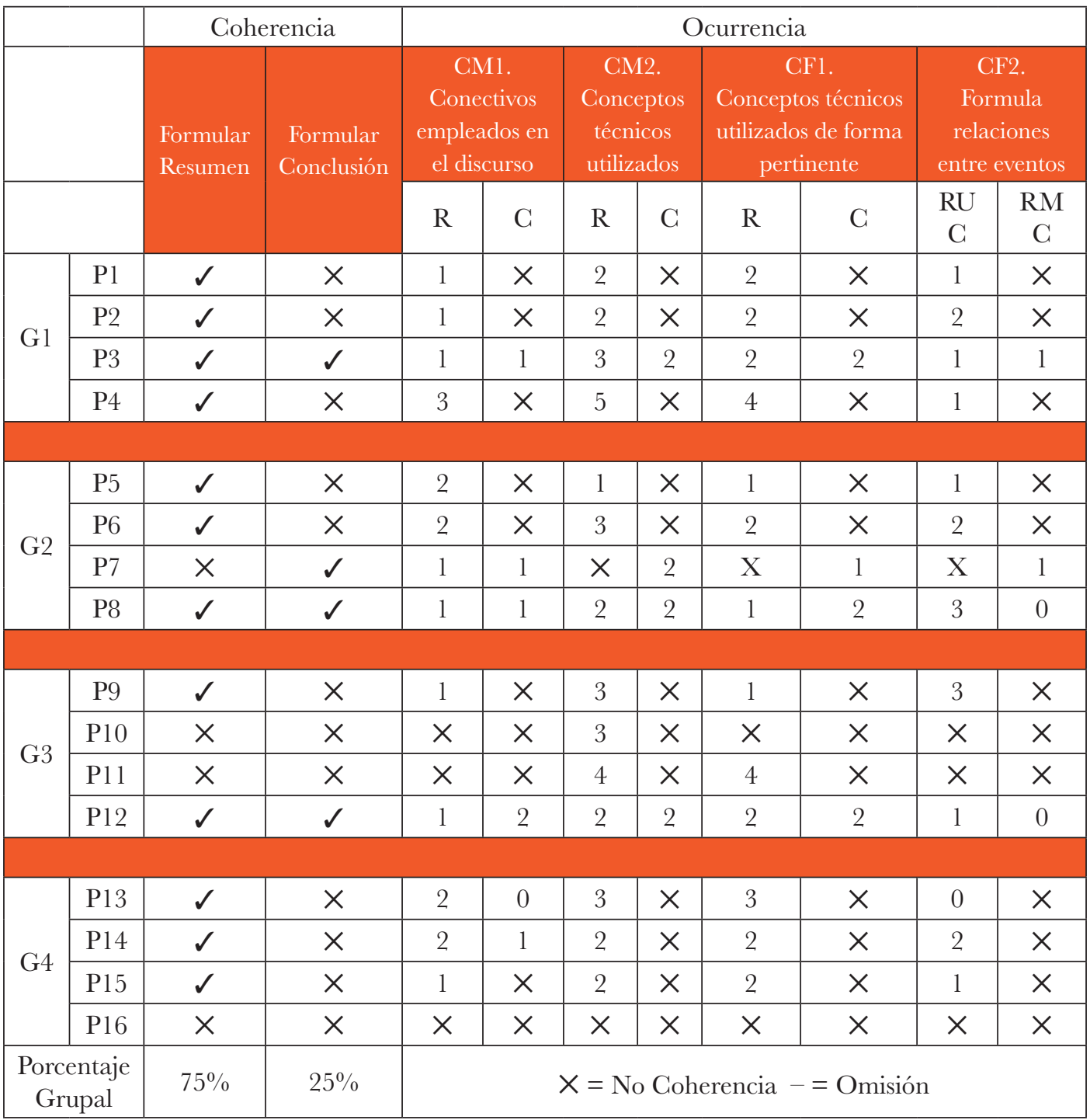

Tabla 14. Muestra la coherencia del desempeño de los participantes - en la Fase II del Estudio 2- en la tarea de elaboración de un resumen y una conclusión (interacciones transituacionales), asi como la ocurrencia en función de las categorías morfológicas y funcionales. CM: Categoría Morfológica, CF: Categoría Funcional, R: Resumen, C: Conclusión. RU: Relación Unicausal, RM: Relación Multicausal. 
multicausal. Del Grupo 3 los participantes 9 y 12 formularon tres relaciones unicausales. Del Grupo 4 solamente el participante 14 formuló dos relaciones unicausales y el participante 15 una relación unicausal pero ninguno de los dos presentó una relación multicausal. En función de estos resultados, vale la pena destacar que cuando se analizan los desempeños solamente en términos de aciertos y ocurrencias, sin enfatizar el tipo de tarea y su nivel funcional, se muestran ciertas tendencias en los desempeños que se obscurecen o simplemente no se observan, y que se considera que ambas formas de análisis del ajuste -efectivo- del estudiante a los diferentes objetos referentes y/o materiales de estudio (comprensión), debieran recuperarse como complementarias. Se ilustra el siguiente ejemplo: un profesor aplica una evaluación parcial a sus alumnos, en los cuales la mayoría obtuvieron obtuvieron excelentes porcentajes. Pero ¿qué criterios de tarea involucraba la evaluación? Tal vez la prueba involucraba identificar de entre una serie de opciones de respuesta el nominativo del concepto y lo evaluará en términos solamente de aciertos, pasaría algo diferente si este mismo profesor en una evaluación posterior, les solicitara a sus alumnos que elaboraran un ensayo en donde establecieran relaciones entre dos conceptos, o una justificación pertinente a partir de la elaboración de un procedimiento o representación gráfica, y se evaluara al estudiante en términos del tipo de relaciones que formula.

Bajo la lógica del análisis de los resultados, se considera que la evaluación de la comprensión deberá recuperar el tipo de competencia que en cierto espacio curricular se pretende auspiciar, el objetivo instruccional de ese momento curricular, la modalidad del discurso didáctico en función de la competencia, y el juego de lenguaje (conceptual, operacional y/o de medida), permitiendo que los estudiantes establezcan contacto con el referente en varias modalidades y niveles funcionales diferenciados. 


\section{Estudio 3}

El objetivo del tercer estudio fue analizar si la explicitación del criterio, las variaciones en el nivel funcional de la tarea y la modalidad lingüística involucrada, determina ajustes diferenciales en la comprensión de un material (texto o audio) con contenido científico en estudiantes universitarios de Ciencias de la Salud.

Los participantes de este estudio fueron 16 estudiantes universitarios que cursaban los primeros semestres del área de Ciencias de la Salud de una universidad pública del norte del país. La selección de la muestra se llevó a cabo en términos del promedio obtenido en el semestre inmediato anterior al inicio del estudio, el promedio de los estudiantes (de una población de 60 estudiantes) se dividió en triatiles tomando solamente los estudiantes del triatil medio (60 y $75 \%)$.

Los materiales fueron los mismos que los utilizados en el estudio 2. Asimismo, en este estudio se replicaron las mismas condiciones que en el Estudio 2. El motivo de la replicación de este estudio atendió a la posibilidad de comparar los desempeños de dos muestras de estudiantes universitarios con dos áreas de formación diferente y de esta manera, tener una caracterización de las formas en como se ajustan a los criterios de tarea y su nivel funcional con materiales sobre ciencia y tecnología.

Se empleó un diseño cuasiexperimental balanceado de materiales de evaluación equivalentes con cuatro grupos de comparación (Campbell y Stanley, 1982; Kerlinger y Lee, 2002). Los participantes fueron asignados aleatoriamente a los grupos en función de si el material de estudio se presentaba en modalidad textual o modalidad auditiva. El estudio constó de dos fases en función de la variación de la modalidad del objeto referente, en la primera fase los Grupos 1 y 2 fueron expuestos a la modalidad textual del objeto referente, lo que cambió para cada grupo fue la secuencia en la modalidad lingüística involucrada (escribir-hablar o hablar-escribir); los Grupos 3 y 4 fueron expuestos a la modalidad auditiva, y a las dos secuencias en la modalidad lingüística (escribir-hablar o hablar-escribir). En la 
segunda fase los Grupos 1 y 2 fueron expuestos a la modalidad auditiva y los Grupos 3 y 4 a la modalidad textual, modificándose la secuencia en la modalidad lingüística a la que habían sido expuestos en una primera fase, como se muestra en la Tabla 15.

\begin{tabular}{|c|c|c|c|c|c|c|}
\hline Estudio 3 & \multicolumn{3}{|c|}{ FASE I } & \multicolumn{3}{|c|}{ FASE II } \\
\hline $\mathrm{N}=16$ & \multicolumn{6}{|c|}{ CON CRITERIO DE AJUSTE EXPLÍCITO } \\
\hline $\begin{array}{l}\text { Grupos } \\
(\mathrm{N}=4)\end{array}$ & $\begin{array}{c}\text { Modalidad } \\
\text { del objeto } \\
\text { referente }\end{array}$ & \multicolumn{2}{|c|}{$\begin{array}{c}\text { Secuencia de la } \\
\text { modalidad lingüística }\end{array}$} & $\begin{array}{c}\text { Modalidad } \\
\text { del objeto } \\
\text { referente }\end{array}$ & \multicolumn{2}{|c|}{$\begin{array}{l}\text { Secuencia de la } \\
\text { modalidad lingüística }\end{array}$} \\
\hline G1 & \multirow{2}{*}{$\begin{array}{c}\text { Material A. } \\
\text { Textual }\end{array}$} & Es & $\mathrm{Ha}$ & \multirow{2}{*}{$\begin{array}{c}\text { Material B. } \\
\text { Auditivo }\end{array}$} & $\mathrm{Ha}$ & Es \\
\hline G2 & & $\mathrm{Ha}$ & Es & & Es & $\mathrm{Ha}$ \\
\hline G3 & \multirow{2}{*}{$\begin{array}{l}\text { Material A. } \\
\text { Auditivo }\end{array}$} & Es & $\mathrm{Ha}$ & \multirow{2}{*}{$\begin{array}{c}\text { Material B. } \\
\text { Textual }\end{array}$} & $\mathrm{Ha}$ & Es \\
\hline G4 & & $\mathrm{Ha}$ & Es & & Es & $\mathrm{Ha}$ \\
\hline
\end{tabular}

Tabla 15. Muestra la asignación y la secuencia a la que fueron expuestos los participantes del Estudio 3. G: Grupo, Es: escribi, Ha: Hablar.

En cuanto a los resultados de la Fase I, el desempeño de los participantes es analizado en términos de interacciones intrasituacionales (a partir de la correspondencia del desempeño del participante ante el tipo de tarea), extrasituacionales (a partir de la congruencia formulada por los participantes en las modalidades lingüísticas de escribir y hablar) y transituacionales (a partir de la coherencia en la elaboración de un resumen y una conclusión a partir de lo leído o escuchado). Adicionalmente, se llevó a cabo un análisis del desempeño de los participantes en la modalidad lingüística escribir en el resumen y la conclusión, a partir de dos tipos de categorías que se denomina: morfológicas o formales y funcionales (como se muestra en la Tabla 9, p. 134). El desempeño en las categorías morfológicas fue analizado en términos de: a) el número de conceptos técnicos utilizados para elaborar la referencia escrita, 
b) el número de conectivos usados para elaborar la referencia, c) el número de palabras que utiliza para elaborar la referencia; para el caso de las categorías funcionales: a) la ocurrencia del número de conceptos técnicos utilizados de forma pertinente, b) el número de relaciones que establece entre eventos de forma unicausal, y c) el número de relaciones entre eventos como relaciones multicausales.

La Figura 18 muestra el desempeño por participante en las interacciones intrasituacionales en la Fase I del Estudio 3. Los desempeños analizados de forma grupal muestran ejecuciones del $67 \%$ de aciertos promedio para los grupos que leyeron y $60 \%$ de aciertos promedio para los grupos que escucharon. Si se comparan estos resultados con los de la Fase I del Estudio 2, en el caso de los grupos que fueron expuestos a la modalidad del objeto referente textual es menor en un $9 \%$, y para los grupos que fueron expuestos a la modalidad auditiva fue casi equivalente por una decima porcentual (59\% en la Estudio 1 y $60 \%$ en el Estudio 2). En términos del porcentaje promedio para cada uno de los participantes por grupo fue: con mayor porcentaje de aciertos el Grupo 2 obtuvo (P7, 80\%, P5, 70\% y P6 y P8, 60\%), seguido por los participantes del Grupo 1 (P1 y P2, 70\%, P3 y P4, 60\%), continuando en términos del porcentaje de aciertos, los Grupos 3 y 4 con $60 \%$ de promedio general (P10, 90\%, P13, 70\%, P9, P12, P14 y P15, 60\%, P1 1 y $\mathrm{P} 16,50 \%)$.

La Figura 19 muestra los resultados individuales de los participantes en relación a las interacciones extrasituacionales. En general los participantes presentaron la misma tendencia que el Estudio 2 en términos del porcentaje de congruencia. Para los Grupos 1 y 2 el porcentaje de aciertos presentados por los participantes fueron los siguientes: con mayor porcentaje de aciertos $\mathrm{P} 2$ y P8, 70\%, seguido de los participantes $\mathrm{P} 3, \mathrm{P} 4, \mathrm{P} 5$ y P7, 60\%, P1 y P6, 50\% de aciertos. Para los Grupos 3 y 4 el participante 10 presentó un $80 \%$ de porcentaje de aciertos, seguido del participante 9, 11, 13 y 14, 60\%, P12, 50\% y P15 y P16 con 40\%.

Cuando se analiza el desempeño de los participantes tanto grupalmente como individualmente en términos de la secuencia de la modalidad lingüística implicada se observan tendencias importantes (ver Figura 20 y 21). Se puede observar que la modalidad 
G1. Interacciones Intrasituacionales MOR: Textual

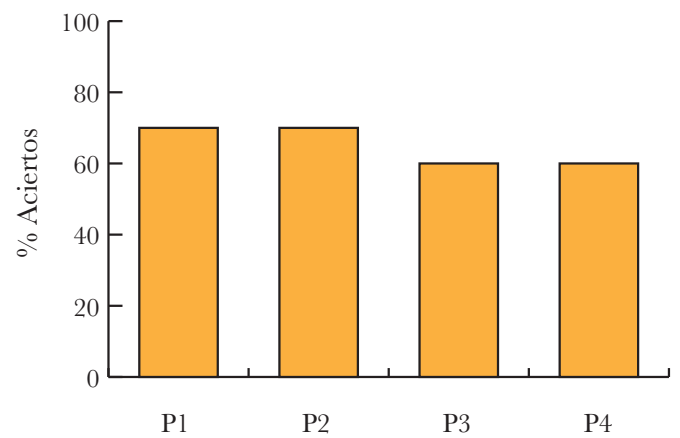

G3. Interacciones Intrasituacionales MOR: Auditiva

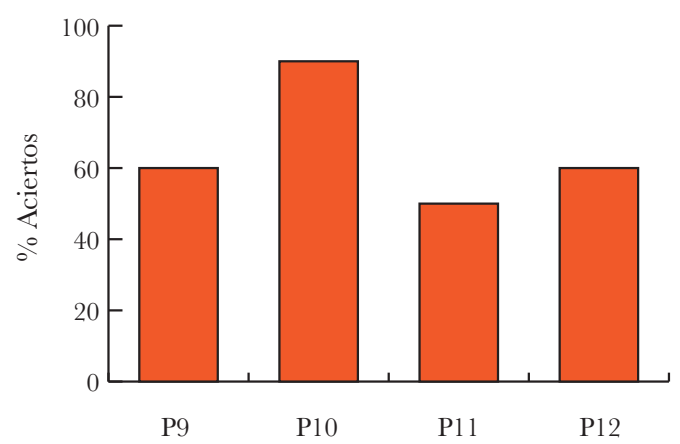

G2. Interacciones Intrasituacionales MOR: Textual

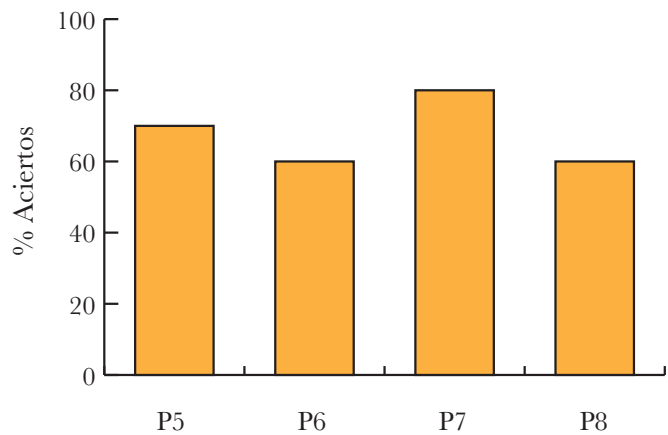

G4. Interacciones Intrasituacionales MOR: Auditiva

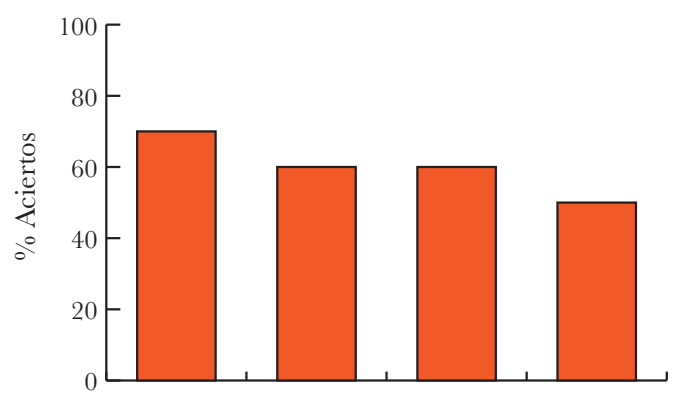

$\mathrm{P} 13$

P14

P15

P16

Figura 18. Presenta el porcentaje de aciertos del desempeño de los participantes en las interacciones intrasituacionales de los Grupos 1, 2, 3 y 4 en la Fase I del Estudio 3. MOR: Modalidad del objeto referente. P: Participante. 
lingüística hablar es mayor en los grupos que primero escribieron y después hablaron, con una diferencia en el porcentaje de congruencia del $20 \%$, esta tendencia es similar a la del Estudio 1 (aunque con porcentajes de congruencia más bajos). En cuanto a los porcentajes grupales se muestra que el Grupo 1 presentó 55\% de congruencia para la modalidad lingüística escribir y $65 \%$ de congruencia en modalidad lingüística hablar, el Grupo 3 obtuvó $55 \%$ para la modalidad escribir y $75 \%$ en hablar, el Grupo 2 presentó $60 \%$ en la modalidad lingüística escribir y $60 \%$ de congruencia en hablar y finalmente, el Grupo 4 presentó 50\% de congruencia en ambas modalidades lingüísticas (ver Figura 20).

Al presentar los porcentajes obtenidos en las interacciones extrasituacionales en función de la modalidad lingǘstica involucrada (escribir y hablar) se encuentra que los porcentajes de congruencia varian en relación a la modalidad lingüística, pero sobre todo en función de la secuencia de cada grupo, se observa un efecto ligeramente mayor en los desempeños cuando los participantes primero escriben y despúes hablan, esto no se observa en el sentido inverso (de hablar a escribir). En la Figura 21 se presentan los resultados individuales por modalidad lingüística, los participantes de los Grupos 1 y 2 que presentaron desempeños consistentes en ambas modalidades fueron el 3, 4, 5, 7 y 8 con $60 \%$ de congruencia, los participantes 2 y 8 presentaron $60 \%$ en la modalidad escribir y $80 \%$ en hablar, el participante 1 presentó $40 \%$ en la modalidad escribir y $60 \%$ de congruencia en la modalidad lingüística hablar. Con respecto a los Grupos 3 y 4 los participantes que presentaron consistencia en ambas modalidades fueron el 10, 14 y 15 (el primero con 80\% de congruencia y los segundos con $40 \%$ de congruencia), el participante 9 presentó $60 \%$ de congruencia para escribir y $80 \%$ para hablar, seguidos de los participantes 11,12 y 16 con $40 \%$ de congruencia en la modalidad escribir y $60 \%$ en la modalidad hablar, solamente el participante 13 presentó $60 \%$ de congruencia en la modalidad escribir y $40 \%$ en la modalidad hablar.

Con respecto a los resultados del análisis de las interacciones transituacionales, éstas se muestran en la Tabla 16. En la Tabla se observa que el 93\% de los participantes 
G1. Interacciones Extrasituacionales MOR: Textual

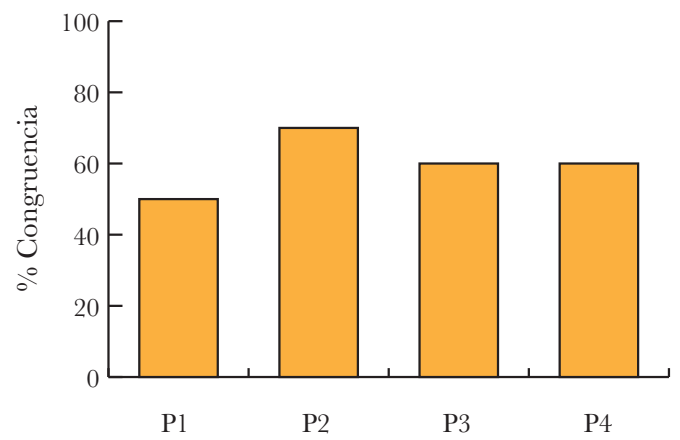

G3. Interacciones Extrasituacionales MOR: Auditiva

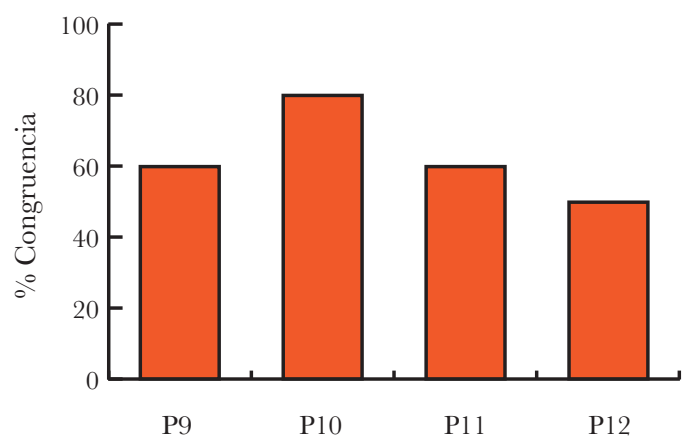

G2. Interacciones Extrasituacionales MOR: Textual

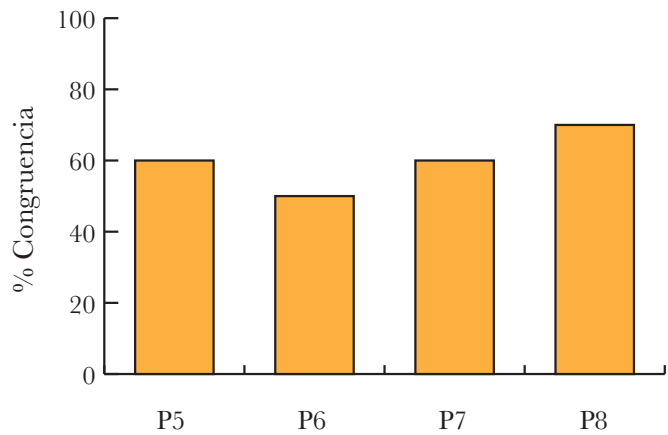

G4. Interacciones Extrasituacionales MOR: Auditiva

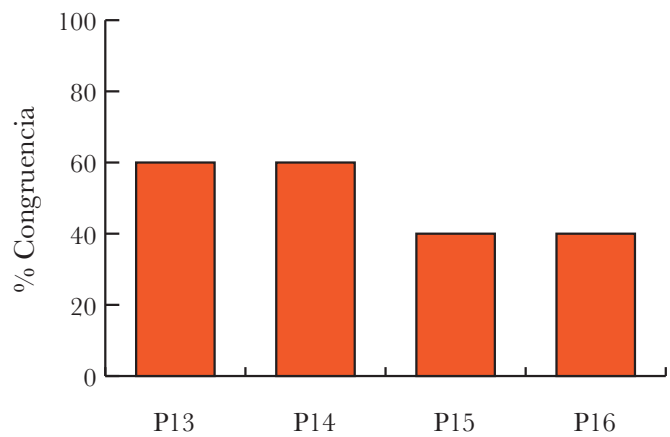

Figura 19. Presenta el porcentaje de congruencia del desempeño de los participantes en las interacciones extrasituacionales de los Grupos 1, 2, 3 y 4 en la Fase I del Estudio 3. MOR: Modalidad del objeto referente. P: Participante. 
Interacciones extra: por modalidad lingüística para todos los grupos

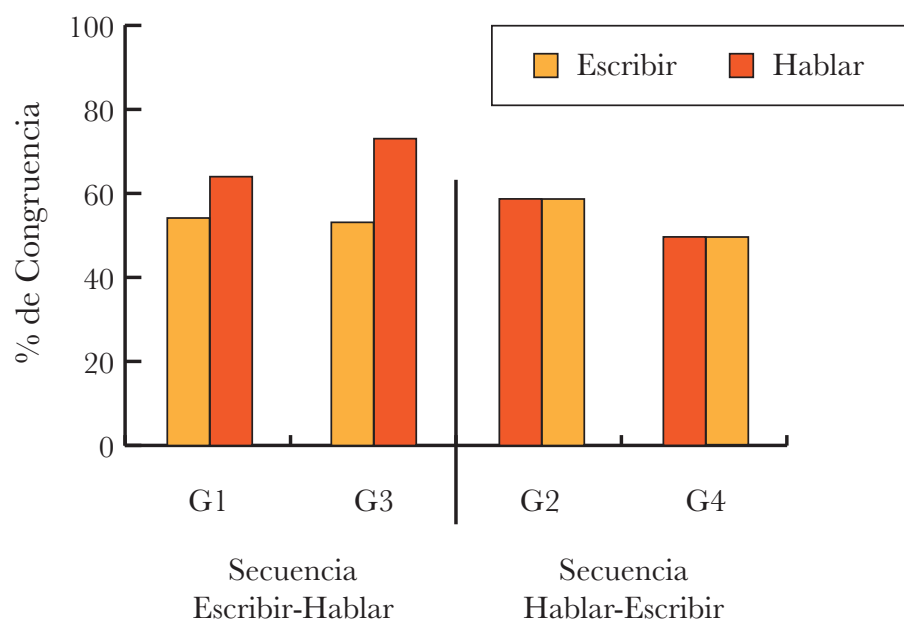

Figura 20. Presenta el porcentaje de congruencia del desempeño grupal en las interacciones extrasituacionales por modalidad lingüística de los Grupos 1, 2, 3 y 4 en la Fase I del Estudio 3. P. Participante.

pudo elaborar un resumen y el 68\% una conclusión con coherencia. Todos los participantes elaboraron un resumen, excepto el participante 3, en el caso de los participantes que elaboraron una conclusión coherente fueron el 3, 5, 6, 8, 9, 10, 11, 12, 13, 14 y 15. Si se analiza el desempeño grupalmente y lo comparamos con los del Estudio 2 (de esta misma fase) se observan diferencias para este nivel de interacción, $5 \%$ más en el caso de desempeño grupal en elaboración del resumen y 25\% más para el caso de la conclusión. Esto podría ser atribuido a las formas de entrenamiento a la que cada grupo de estudiantes es expuesto en sus respectivas áreas de conocimiento, por lo que sería necesario llevar a cabo otras situaciones de evaluación en donde se posibilite la identificación de las formas diferenciales en que cada área enseña los referentes disciplinares (como didáctica específica). 
G1. Interacciones Extrasituacionales por modalidad lingüística

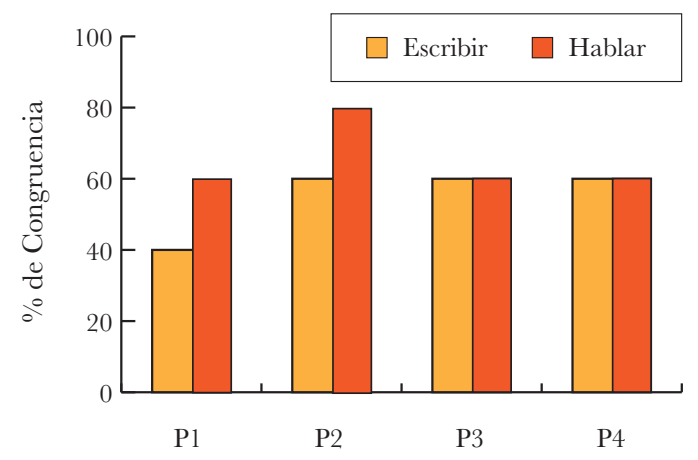

Secuencia Escribir-Hablar

G3. Interacciones Extrasituacionales por modalidad lingüística

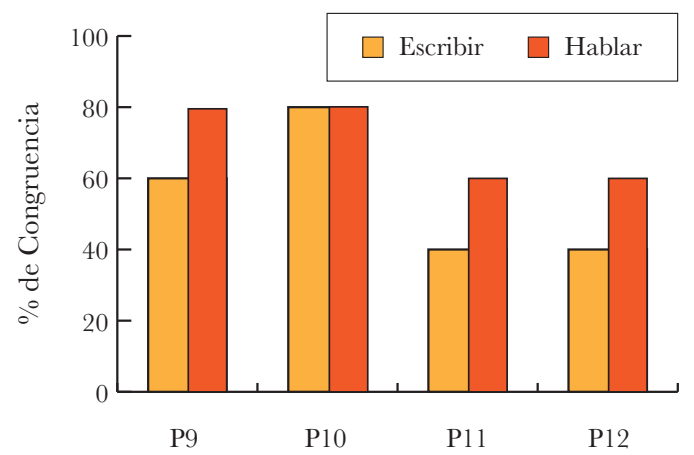

Secuencia Escribir-Hablar
G2. Interacciones Extrasituacionales por modalidad lingüística

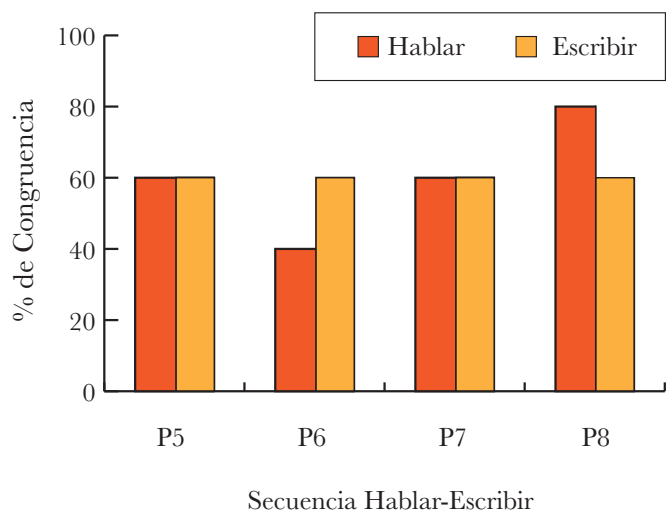

G4. Interacciones Extrasituacionales por modalidad lingüística

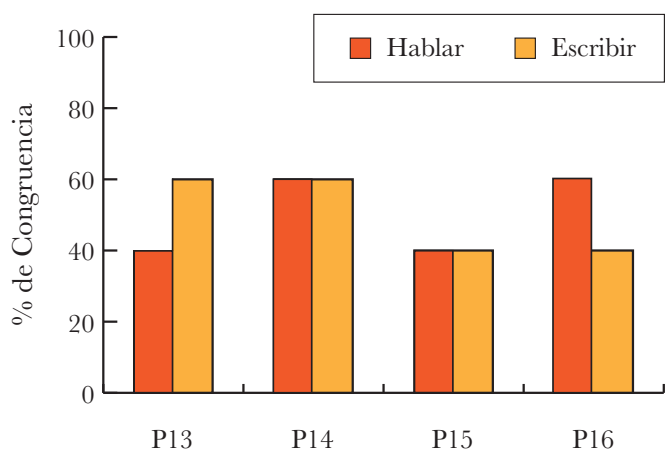

Secuencia Hablar-Escribir

Figura 21. Presenta el porcentaje de congruencia del desempeño individual en las interacciones extrasituacionales por modalidad lingüística de los Grupos 1, 2, 3 y 4 en la Fase I del Estudio 3. P: Participante. 
Con respecto a los resultados de la categoría morfológica uso de conceptos técnicos -CM2- (ver Tabla 16), los Grupos 3 y 4 presentaron mayor porcentaje de ocurrencia en el uso de conceptos técnicos utilizados en el resumen, con mayor número de ocurrencias los participantes 13 y 14 (del Grupo 4) y el participante 8 (del Grupo 2) con cuatro ocurrencias, seguido por el participante 2 (del Grupo 1), los participantes 9, 10, 12 (del Grupo 3), 15 y 16 (del Grupo 4) con tres ocurrencias. Los participantes 1 y 4 (del Grupo 1) y, participantes 5 y 6 (del Grupo 2) con dos ocurrencias.

Con respecto a esta misma categoría pero desde un punto de vista funcional, se encontró que en promedio el $70 \%$ de estos conceptos técnicos son usados de forma pertinente por los estudiantes. Con relación a los resultados en términos de la categorías funcionales "formula relaciones entre eventos como relaciones unicausales y relaciones causales múltiples" -CF2- (ver Tabla 16), podemos observar que el rango de ocurrencias para esta categoría fue de dos y una ocurrencia, tanto para relaciones unicausales como para las multicausales. Del Grupo 1 los participantes 1 y 2 establecieron una relación, el participante 4 formuló dos relaciones unicausales en el resumen. Del Grupo 2 los participantes 5 y 6 formularon una relación unicausal y el participante 8 no estableció ninguna relación. Del Grupo 3 los participantes 11 y 12 formularon dos relaciones unicausales y solamente el participante 11 una relación multicausal. Del Grupo 4 solamente el participante 14 formuló tres relaciones unicausales, pero ninguna relación multicausal en esta categoría.

Con respecto a los resultados de la Fase II, en la Figura 22 se muestra el desempeño por participante en las interacciones intrasituacionales. Los desempeños de forma grupal muestran ejecuciones del $57 \%$ de aciertos promedio para los grupos que fueron expuestos a la modalidad textual del objeto referente y $45 \%$ de aciertos promedio para los grupos que fueron expuestos a la modalidad auditiva. En términos del porcentaje promedio para cada uno de los participantes por grupo fue: con mayor porcentaje de aciertos encontramos al Grupo 3, el cual obtuvo 68\% de aciertos promedio (P9 y P10, 70\%, P11 y P12, 60\%), seguido por los participantes del Grupo 4 con 65\% de aciertos (P14 y P16, 70\%, P13 y P15, 


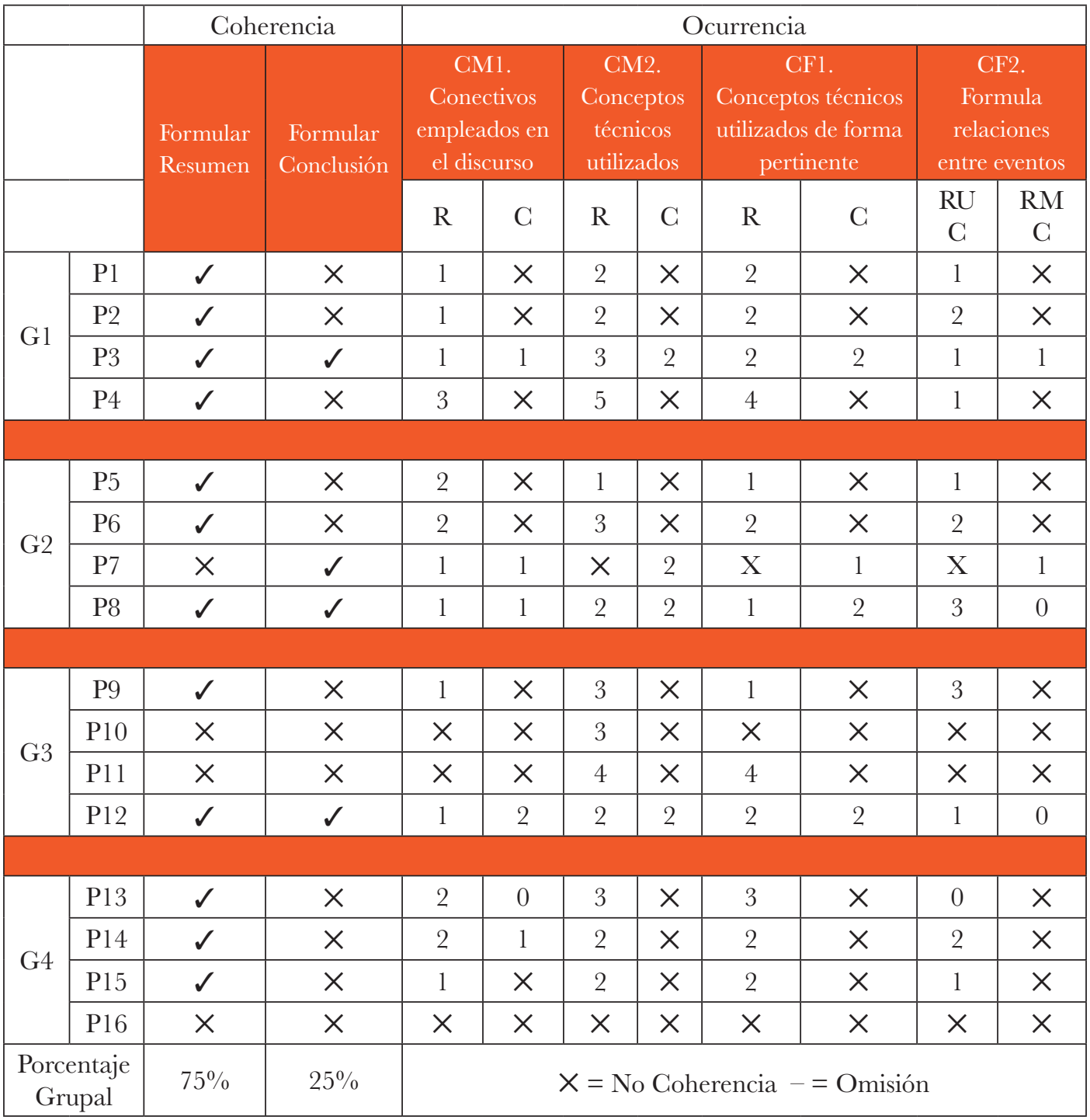

Tabla 16. Muestra la coherencia del desempeño de los participantes - de la Fase I, Estudio 3- en la tarea de elaboración de un resumen y una conclusión (interacciones transituacionales), asi como la ocurrencia en función de las categorías morfológicas y funcionales. CM: Categoría Morfológica, CF: Categoría Funcional, R: Resumen, C: Conclusión. RU: Relación Unicausal, RM: Relación Multicausal. 
G1. Interacciones Intrasituacionales MOR: Auditiva

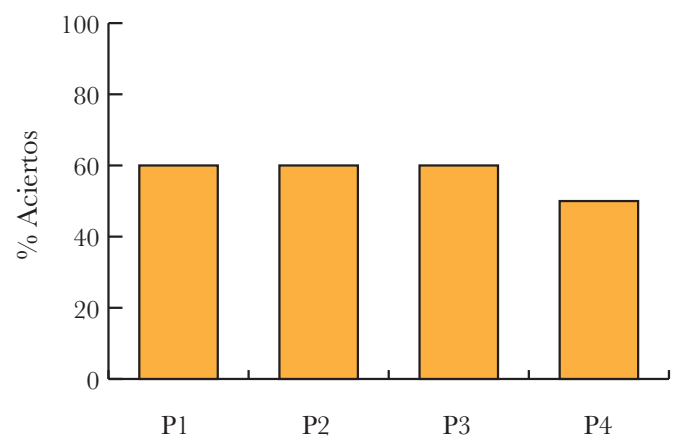

G3. Interacciones Intrasituacionales MOR: Textual

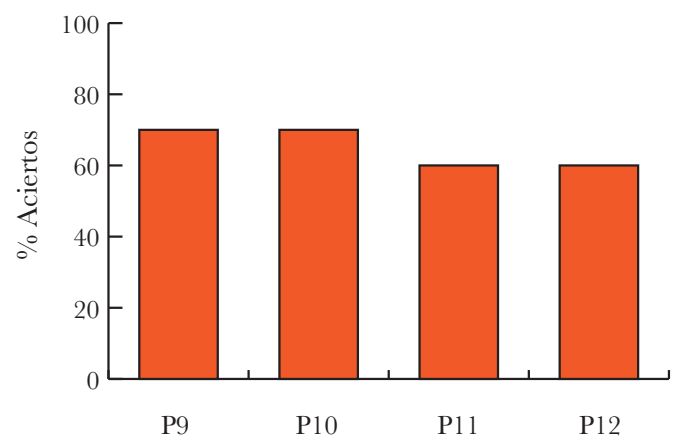

G2. Interacciones Intrasituacionales MOR: Auditiva

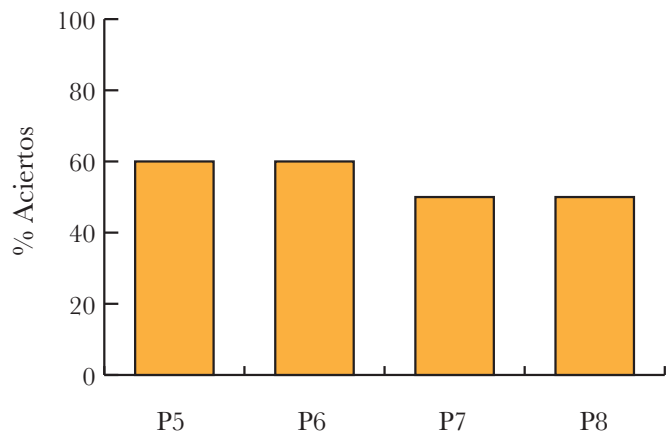

G4. Interacciones Intrasituacionales MOR: Textual

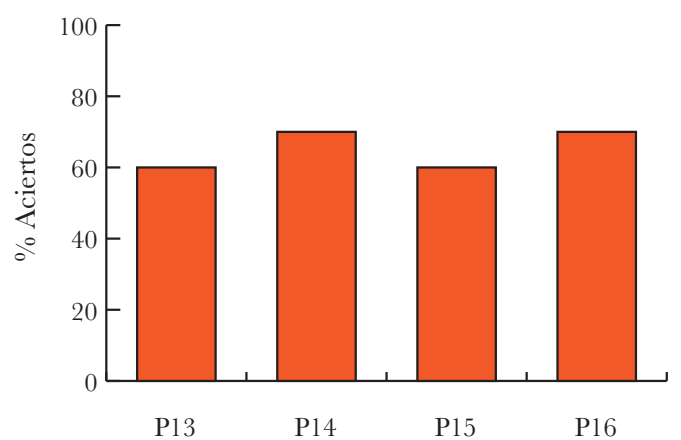

Figura 22. Presenta el porcentaje de aciertos del desempeño de los participantes en las interacciones intrasituacionales de los Grupos 1, 2, 3 y 4 en la Fase II del Estudio 3. MOR: Modalidad del objeto referente. P: Participante. 
$60 \%$ ) continuando en términos del porcentaje de aciertos, tenemos al Grupo 1 con 58\% de promedio general (P1, P2 y P3, 60\% y P4, 50\%), finalmente el Grupo 2 con 55\% de aciertos promedio (P5 y $\mathrm{P} 6,60 \%$; $\mathrm{P} 7$ y $\mathrm{P} 8,50 \%$ ).

La Figura 23 muestra los resultados individuales de los estudiantes en relación a las interacciones extrasituacionales. Los resultados no muestran diferencias significativas en función de si los participantes habían sido expuestos a la modalidad textual o auditiva del objeto referente. Para los Grupos 1 y 2 el porcentaje de aciertos presentados por los participantes fueron los siguientes. Con mayor porcentaje de aciertos el participante P3, $60 \%$, seguido de los participantes P1, P5, P7, 50\%, y los participantes P2, P6 y P8, 40\%. Para los Grupos 3 y 4 el participante 10 presentó un 80\% de porcentaje de aciertos, seguido de los participantes P9, P14 y P15, 60\%, los participantes P11 y $\mathrm{P} 12$, 50\% y los participantes $\mathrm{P} 13$ y $\mathrm{P} 16$ con $40 \%$.

$\mathrm{Al}$ presentar los porcentajes obtenidos en las interacciones extrasituacionales en función de la modalidad lingüística involucrada (escribir y hablar) se encuentra que los porcentajes de congruencia varian en relación a la secuencia de la modalidad lingüística implicada, manteniéndose éste dato consistente, tanto en la Fase 1 de este mismo estudio, como en la Fase 1 y 2 del estudio anterior. En la Figura 24 se presentan los resultados grupales por modalidad lingüística, el Grupo 1 presentó $50 \%$ de congruencia para la modalidad lingüística hablar y 45\% de congruencia en modalidad linguística escribir, el Grupo 3 presentó $60 \%$ de congruencia para la modalidad lingüística hablar y 55\% en escribir. El Grupo 2 obtuvó 40\% para la modalidad lingüística escribir y 55\% en hablar, el Grupo 4 presentó $45 \%$ de congruencia en la modalidad lingüística escribir y $60 \%$ en la modalidad lingüística hablar, lo cual nos indica la consistencia en el efecto de la secuencia en la modalidad lingüística involucrada, pero solamente en el caso de primero escribir y después hablar.

En cuanto al desempeño individual de los participantes de los Grupos 1 y 2 que presentaron desempeños consistentes en ambas modalidades lingüísticas fueron el 2 y 3 con $60 \%$ de congruencia, los participantes $\mathrm{P} 5$ y $\mathrm{P} 7$ presentaron $40 \%$ en escribir y $60 \%$ en 
G1. Interacciones Extrasituacionales MOR: Auditiva

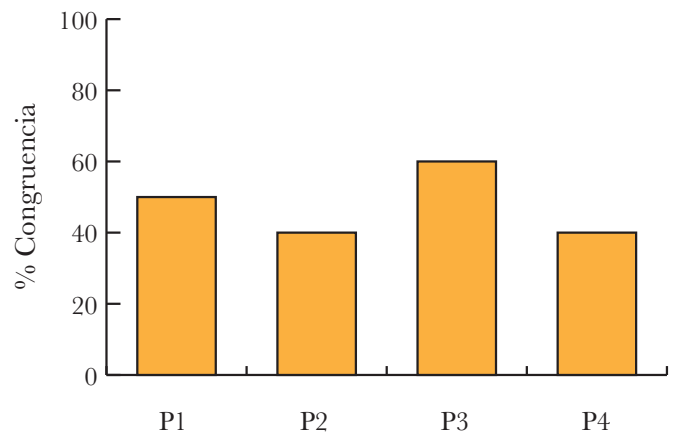

G3. Interacciones Extrasituacionales MOR: Textual

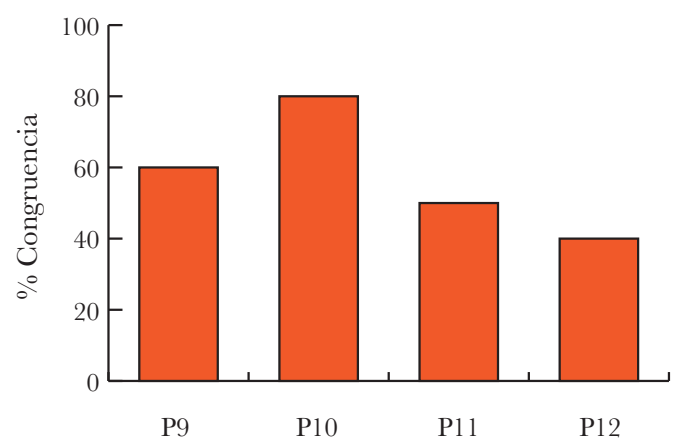

G2. Interacciones Extrasituacionales MOR: Auditiva

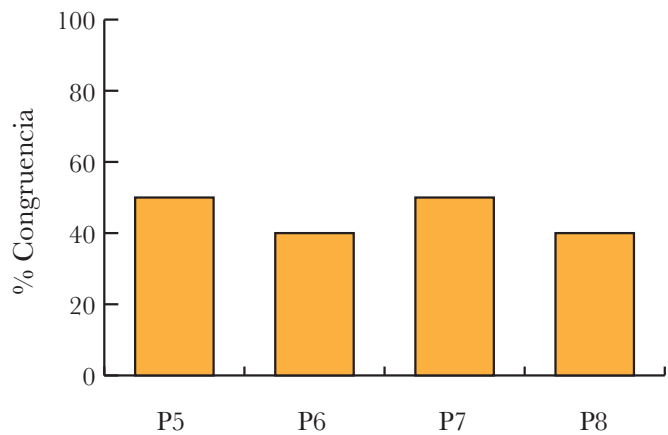

G4. Interacciones Extrasituacionales MOR: Textual

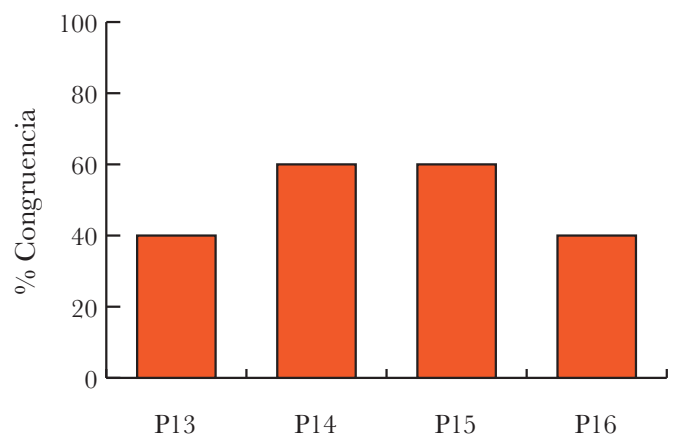

Figura 23. Presenta el porcentaje de congruencia del desempeño de los participantes en las interacciones extrasituacionales de los Grupos 1, 2, 3 y 4 de la Fase II del Estudio 3. MOR: Modalidad del objeto referente. P: Participante. 
Interacciones extra: por modalidad lingüística para todos los grupos

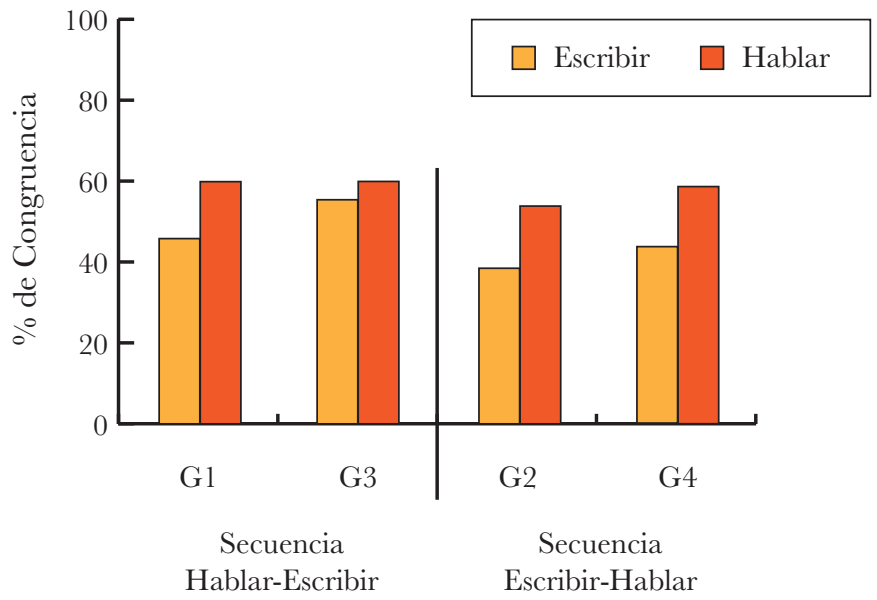

Figura 24. Presenta el porcentaje de congruencia del desempeño grupal en las interacciones extrasituacionales por modalidad lingüística de los Grupos 1, 2, 3 y 4 en la Fase II del Estudio 2. G: Grupo.

hablar, los participantes P1 y P8 presentaron 40\% de congruencia en ambas modalidades y el participante $\mathrm{P} 4$ presentó $40 \%$ en la modalidad escribir y $20 \%$ de congruencia en la modalidad hablar. Con respecto a los Grupos 3 y 4 los participantes que presentaron consistencia en ambas modalidades fueron el P10, P11 y P15 con 60\% de congruencia, el participante P9 presentó 60\% de congruencia en hablar y 40\% en escribir, seguido de los participantes P13, P14 y P16 con 40\% de congruencia en la modalidad lingǘstica escribir y $60 \%$ en hablar, solamente el participante P15 presentó 60\% de congruencia en ambas modalidades lingüísticas (ver Figura 25).

Con respecto a los resultados en las interacciones transituacionales de la Fase II estos se muestran en la Tabla 17. Se puede observar en la Tabla que el $75 \%$ de los participantes pudo elaborar un resumen y solamente el 68\% una conclusión con coherencia. Once participantes 
G1. Interacciones Extrasituacionales por modalidad lingüística

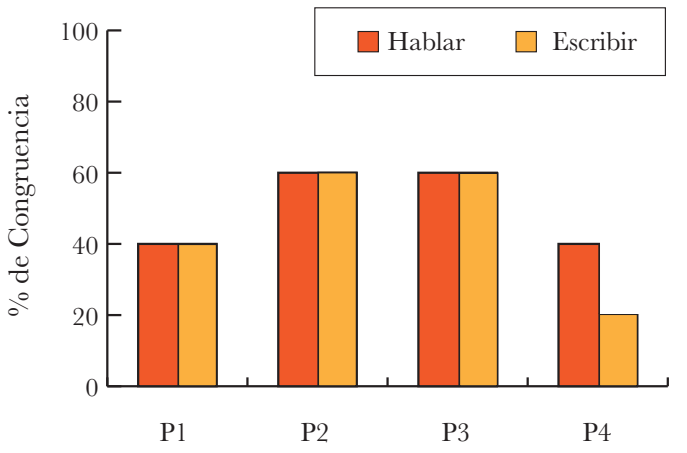

Secuencia Hablar-Escribir

G3. Interacciones Extrasituacionales por modalidad lingüística

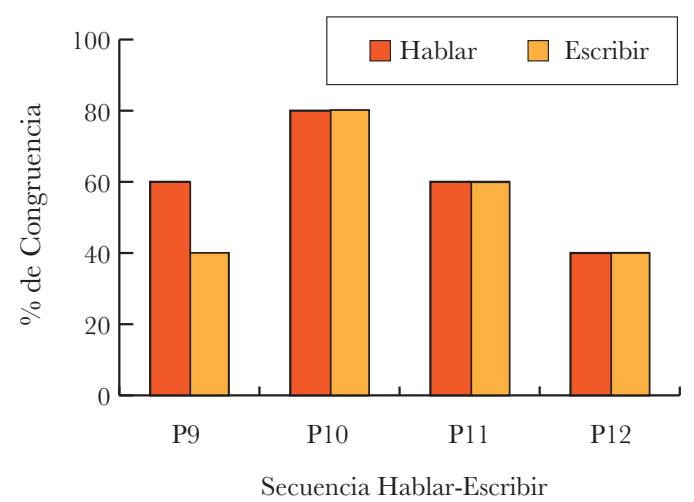

G2. Interacciones Extrasituacionales por modalidad lingüística

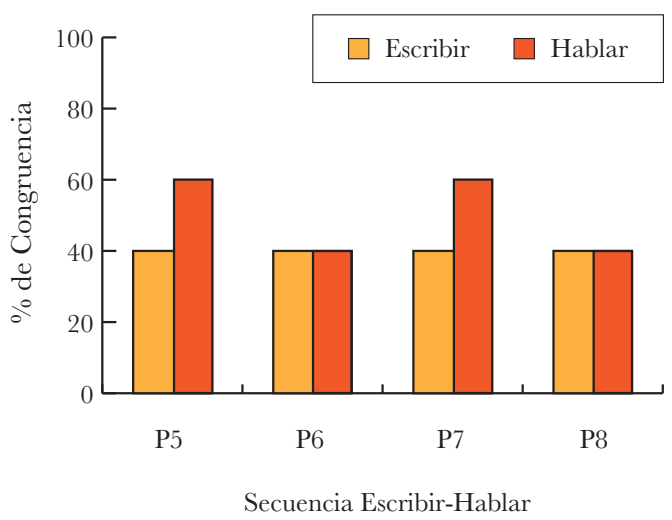

G4. Interacciones Extrasituacionales por modalidad lingüística

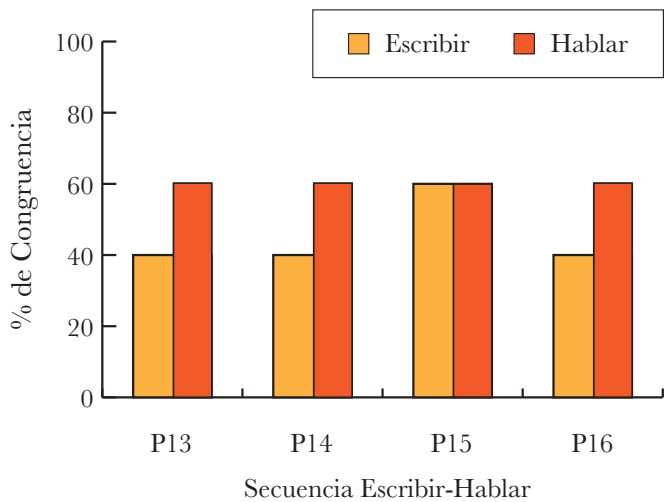

Figura 25. Presenta el porcentaje de congruencia del desempeño individual en las interacciones extrasituacionales por modalidad lingǘstica de los Grupos 1, 2, 3 y 4 en la Fase II del Estudio 3. P: Participante. 
pudieron formular tanto el resumen como la conclusión con coherencia. Los participantes 2, 3, 9 y 10 si elaboraron un "resumen" y una "conclusión", pero no fue recuperado para el análisis de los datos, toda vez que no fue considerado formulación coherente, ya que elaboraron un listado de frases con sentido, pero sin conexión entre ellas.

Con respecto a los resultados de la categoría morfológica uso de conceptos técnicos -CM2- (ver Tabla 17). Los participantes del Grupo 1 presentaron el siguiente porcentaje de coherencia en el resumen: el participante 4 utilizó tres conceptos técnicos y el participante 1 dos conceptos técnicos (los cuales fueron utilizados de forma pertinente en ambos casos -CF1-), en el caso de las conclusiones el participante 4 utilizó dos conceptos y el participante 1 solamente un concepto técnico. Con respecto a los participantes del Grupo 2, el participante 5 utilizó tres conceptos técnicos y los participantes 6, 7 y 8 dos conceptos. En relación a los participantes del Grupo 3, el participante 12 utilizó tres conceptos y el participante 11 dos conceptos técnicos en la formulación del resumen, y dos conceptos en la formulación de la conclusión. Con respecto al Grupo 4 solamente el participante 15 utilizó cinco conceptos técnicos, los participantes 14 y 16 cuatro conceptos y el participante 13 tres conceptos técnicos.

Con relación a los resultados en las categorías funcionales "formula relaciones entre eventos como relaciones unicausales" y "formula relaciones causales múltiples" -CF2- (ver Tabla 17), se puede observar que el mayor número de relaciones unicausales fue de dos, en esta misma categoría pero en función de las relaciones multicausales, el mayor número de relaciones fue de uno. Del Grupo 1 el participante 1 estableció dos relaciones unicausales y una relación muticausal, el participante 4 formuló solamente una relación también multicausal. Del Grupo 2 los participantes 5, 7 y 8 formularon una relación unicausales y una relación multicausal respectivamente. Del Grupo 3 los participantes 11 y 12 formularon una relación unicausal y solamente el participante 12 formuló una relación multicausal. Del Grupo 4 solamente el participante 12 formuló dos relaciones unicausales, los participantes 13, 14 y 16 una relación unicausal y solamente el participante 15 una relación multicausal. 


\begin{tabular}{|c|c|c|c|c|c|c|c|c|c|c|c|}
\hline & \multicolumn{2}{|c|}{ Coherencia } & \multicolumn{8}{|c|}{ Ocurrencia } \\
\hline & & \multirow[t]{2}{*}{$\begin{array}{l}\text { Formular } \\
\text { Resumen }\end{array}$} & \multirow[t]{2}{*}{$\begin{array}{c}\text { Formular } \\
\text { Conclusión }\end{array}$} & \multicolumn{2}{|c|}{$\begin{array}{c}\text { CM1. } \\
\text { Conectivos } \\
\text { empleados en } \\
\text { el discurso }\end{array}$} & \multicolumn{2}{|c|}{$\begin{array}{c}\text { CM2. } \\
\text { Conceptos } \\
\text { técnicos } \\
\text { utilizados }\end{array}$} & \multicolumn{2}{|c|}{$\begin{array}{l}\text { CF1. } \\
\text { Conceptos técnicos } \\
\text { utilizados de forma } \\
\text { pertinente }\end{array}$} & \multicolumn{2}{|c|}{$\begin{array}{c}\text { CF2. } \\
\text { Formula } \\
\text { relaciones } \\
\text { entre evento }\end{array}$} \\
\hline & & & & $\mathrm{R}$ & C & $\mathrm{R}$ & C & $\mathrm{R}$ & C & $\begin{array}{c}\mathrm{RU} \\
\mathrm{C}\end{array}$ & $\begin{array}{c}\mathrm{RM} \\
\mathrm{C}\end{array}$ \\
\hline \multirow{4}{*}{ G1 } & $\mathrm{P} 1$ & $\checkmark$ & $\checkmark$ & 1 & 3 & 2 & 1 & 2 & 1 & 2 & 1 \\
\hline & P2 & $x$ & $x$ & $x$ & $x$ & $x$ & $x$ & $x$ & $x$ & $x$ & $x$ \\
\hline & P3 & $x$ & $x$ & $x$ & $x$ & $x$ & $x$ & $x$ & $x$ & $x$ & $x$ \\
\hline & $\mathrm{P} 4$ & $\checkmark$ & $\checkmark$ & 0 & 1 & 3 & 2 & 3 & 2 & 0 & 1 \\
\hline & & & & & & & & & & & \\
\hline \multirow{4}{*}{ G2 } & P5 & $\checkmark$ & 1 & 2 & 0 & 3 & 1 & 2 & 1 & 1 & 1 \\
\hline & $\mathrm{P} 6$ & $\checkmark$ & $x$ & 2 & $x$ & 2 & $x$ & 2 & $x$ & $x$ & $x$ \\
\hline & $\mathrm{P} 7$ & $\checkmark$ & $\checkmark$ & 1 & 2 & 2 & 3 & 2 & 3 & 1 & 1 \\
\hline & P8 & $\checkmark$ & $\sqrt{ }$ & 2 & 2 & 2 & 2 & 1 & 2 & 1 & 1 \\
\hline & & & & & & & & & & & \\
\hline \multirow{4}{*}{ G3 } & $\mathrm{P} 9$ & $x$ & $x$ & $x$ & $x$ & $x$ & $x$ & $x$ & $x$ & $x$ & $x$ \\
\hline & $\mathrm{P} 10$ & $x$ & $x$ & $x$ & $x$ & $x$ & $x$ & $x$ & $x$ & $x$ & $x$ \\
\hline & $\mathrm{P} 11$ & $\checkmark$ & $\checkmark$ & 1 & 3 & 2 & 2 & 2 & 2 & 1 & 0 \\
\hline & $\mathrm{P} 12$ & $\checkmark$ & $\checkmark$ & 2 & 2 & 3 & 2 & 3 & 2 & 1 & 1 \\
\hline & & & & & & & & & & & \\
\hline \multirow{4}{*}{ G4 } & $\mathrm{P} 13$ & $\checkmark$ & $\checkmark$ & 4 & 3 & 3 & 2 & 3 & 2 & 1 & 0 \\
\hline & $\mathrm{P} 14$ & $\checkmark$ & $\checkmark$ & 2 & 0 & 4 & 3 & 3 & 1 & 1 & 0 \\
\hline & $\mathrm{P} 15$ & $\checkmark$ & $\checkmark$ & 3 & 2 & 5 & 3 & 4 & 1 & 2 & 1 \\
\hline & P16 & $\checkmark$ & $\checkmark$ & 3 & 2 & 4 & 3 & 3 & 2 & 1 & 0 \\
\hline \multicolumn{2}{|c|}{$\begin{array}{c}\text { Porcentaje } \\
\text { Grupal }\end{array}$} & $75 \%$ & $68 \%$ & & & $=$ & Gis & encia & Omi & & \\
\hline
\end{tabular}

Tabla 17. Muestra la coherencia del desempeño de los participantes -en la Fase II, Estudio 3- en la tarea de elaboración de un resumen y una conclusión (interacciones transituacionales), asi como la ocurrencia en función de las categorías morfológicas y funcionales. CM: Categoría Morfológica, CF: Categoría Funcional, R: Resumen, C: Conclusión. RU: Relación Unicausal, RM: Relación Multicausal. 
A manera de síntesis, los resultados de los estudios nos indican lo siguiente:

a) La explicitación del criterio tiene un efecto facilitador sobre la comprensión de contenidos científicos, particularmente si el nivel funcional del criterio se vincula con el nivel funcional en el que es solicitado el desempeño (interacciones extrasituacionales). Lo que significa que un mismo material puede auspiciar diferentes formas de entrar en contacto con el o, diferentes materiales pueden implicar un mismo desempeño, si el criterio no cambia o si la habilitación del estudiante es insuficiente con respecto al criterio. Este dato es semejante al de otros estudios (Morales, Cruz, León et al. 2010 y Morales, Pacheco, Canales et al. 2010).

b) El ajuste en el desempeño, esto es, la comprensión analizada en términos del tipo de tarea y su nivel funcional muestra desempeños diferenciales importantes, aquellas tareas que involucran menor grado de desligamiento son las que presentan mayor porcentaje de aciertos o de ocurrencia. Estos resultados coinciden con estudios sobre el análisis de los criterios de tarea (Irigoyen et al. 2006).

c) El nivel de ejecución en la comprensión (como desempeño efectivo) fue mayor (aproximadamente en un 20\% en los tres estudios) en la modalidad textual del objeto referente que en la auditiva. Esto puede deberse a que leer ocurre ante objetos de estímulos gráficos y el escuchar ocurre ante estímulos acústicos en la forma de vocalizaciones con permanencia temporal momentanéa (Martínez, Gómez y Zepeta, 2008).

d) La comprensión analizada en términos de la modalidad lingüística implicada muestra desempeños positivos señaladamente mayores para la modalidad lingüística hablar, no así para la de escribir. Autores como Camacho et al. (2007); Gómez, (2005); Irigoyen et al. (2006) han señalado que los modos lingüísticos presentan propiedades funcionales determinadas por su morfología, lo que permite explicar las diferencias en los desempeños de los participantes en las interacciones extrasituacionales de los Estudios 1, 2 y 3. 
e) Las variaciones en las secuencia de presentación de las modalidades lingüísticas muestran diferencias en términos de mayor porcentaje de congruencia si primero escriben y posteriormente hablan, que si primero hablan y después escriben. Esto se vincula con lo discutido por Camacho et al. (2006) en relación con la jeraquización -funcional- de los modos lingüísticos. Los autores plantean que cada modo lingüístico presenta, como propiedad funcional, grados diferenciales de desligamiento como factor disposicional, probabilizando que se adquieran y se transfieran repertorios competenciales en distintos niveles de organización del comportamiento -nivel de desligamiento bajo, medio, alto-. En el caso del modo hablar éste es ubicado en un nivel medio de deligamiento tanto para su adquisición como para su transferencia, en el caso del modo lingüístico escribir este se ubica en aquellos con mayor dificultad de adquisición, pero con mayor posibilidad de transferencia.

f) El desempeño de los participantes parece depender más del modo lingǘstico, del tipo de tarea y su nivel funcional que del contenido de los materiales de estudio. Este resultado es similar al encontrado por Morales et al. (2013). • 


\section{Capítulo 5}

Implicaciones para la planeación

de interacciones didácticas de contenidos científicos
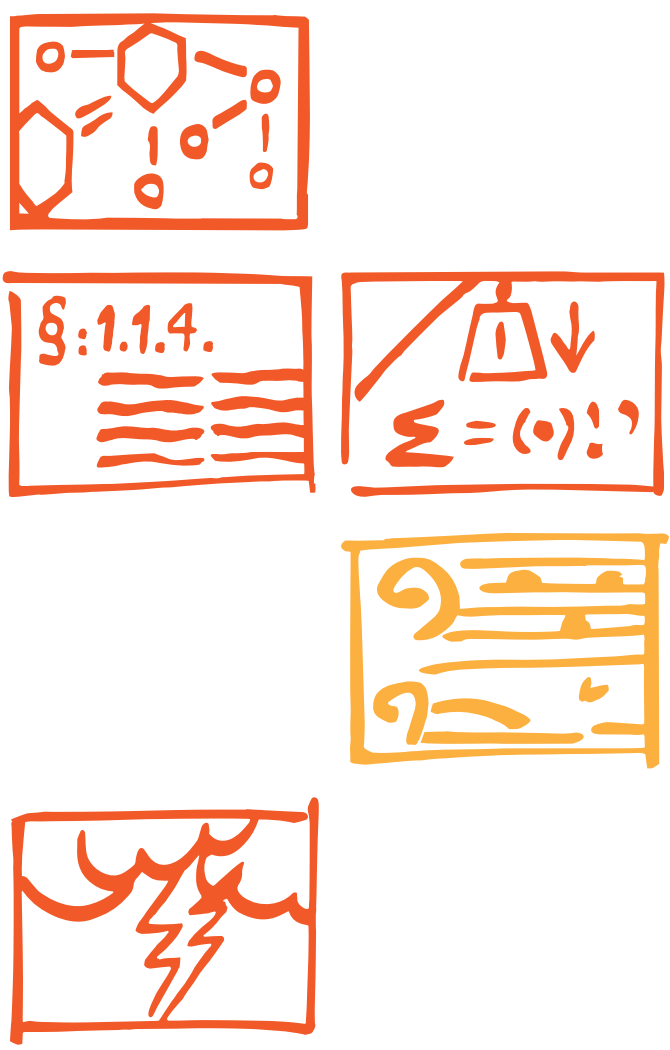
(Página en blanco) 


\section{Implicaciones para la planeación de interacciones didácticas de contenidos científicos}

Uno de los principales problemas que enfrenta la educación en México, es el nivel competencial que presentan los estudiantes en áreas como: comprensión lectora, expresión escrita y ciencias (INNE, 2009, 2012; OCDE, 2001; 2003; 2006; 2009). Los repertorios con los que cuentan los estudiantes mexicanos (de educación básica y nivel medio superior) evaluados en estos estudios (y con implicaciones para el presente manuscrito) son los que sintéticamente describimos en los siguientes tres puntos:

- En el área de comprensión lectora: una gran proporción de los estudiantes (60\%) no pueden evaluar críticamente un texto o establecer hipótesis; en algunos casos, sólo pueden reconocer las palabras o ubicar información directa en un texto.

- En el área de expresión escrita: un gran número de los estudiantes evaluados $(70 \%)$ no pueden escribir textos sin faltas de ortografía, no presentan puntuaciones correctas en sus redacciones y la segmentación de las palabras es inadecuada, también presentan dificultades para darle cohesión a la redacción de textos.

- En el área de ciencias: una proporción importante de los estudiantes mexicanos $(65 \%)$ no pueden identificar, explicar y aplicar de manera sistemática conocimientos científicos en situaciones complejas o vinculados con la vida cotidiana.

Estos resultados que si bien no son concluyentes, nos muestran una tendencia general en cuanto a los desempeños de estos estudiantes en las áreas evaluadas, y por lo tanto, un punto de referencia que permite visualizar también estrategias didácticas ineficaces por parte de los profesores (Peredo, 2011).

Esta situación no es exclusiva de los niveles básicos y medio superior, sino que se extiende al nivel superior. Utilizando la prueba de aptitud para la ciencia (PISA, 2000), Mares et al. (2009) e Irigoyen et al. (2009) realizaron una caracterización de estudiantes de 
primer ingreso a carreras universitarias. El primer estudio se llevó a cabo en la Facultad de Estudios Superiores-Iztacala de la UNAM, los resultados indicaron deficiencias con respecto a la lectura de gráficos, argumentación con base en información vertida en un texto, y la comunicación de ideas complejas. En el segundo estudio (llevado a cabo en la Universidad de Sonora) los resultados coinciden con los obtenidos en la FES-Iztacala, en términos de porcentajes muy similares en cuanto a una capacidad deficiente en la prueba de aptitud para la ciencia, y en competencia lectora específicamente en lo que concierne a la lectura de gráficos, la argumentación con base en la información de un texto y la comunicación de ideas complejas.

Con miras a una planeación que auspicie condiciones para una educación y que responda a las necesidades o problemáticas actuales "educación de calidad"; a nuestro juicio se deberá reflexionar sobre la caracterización del papel de los actores involucrados en el proceso educativo (administradores, gestores, profesores y alumnos), al formular en general las políticas educativas (Orozco et al. 2009).

De hecho, las distintas reformas educativas que se registran mundialmente en los últimos años, surgen en algunos casos de la inquietud sobre la falta de preparación académica de los estudiantes. De ahí que la planeación institucional de los espacios educativos de las carreras universitarias ha venido a constituir uno de los más importantes retos a los que se enfrentan los administradores, gestores y planeadores de la educación de este nivel. Sin embargo, encontramos que la planeación institucional de estos espacios es una tarea que en muchas instituciones de nuestro país se sigue realizando siempre de manera "provisional". La crítica entonces parece referirse a la falta de criterios de evaluación claros que permitan identificar aciertos y límites, resaltándose que más bien el trabajo en el ámbito de lo curricular solamente responde a dinámicas que la política educativa asume en cada ciclo presidencial (Díaz-Barriga, 2006).

Comentamos en renglones anteriores, que la mayoría de los indicadores que se recuperan para evaluar la calidad educativa de las instituciones de educación superior se 
centran en aspectos administrativos y de infraestructura dejando de lado otros indicadores que también son relevantes para el logro de profesionales competentes, como por ejemplo, los relacionados con el proceso de enseñanza-aprendizaje (Reyes, 1997). Desde nuestro punto de vista se debieran recuperar indicadores para evaluar el papel de todos y cada uno de los actores involucrados en el proceso educativo (administradores, gestores, profesores, alumnos, materiales), al formular las políticas educativas.

La evaluación del sistema educativo en su conjunto debiera ser el medio para diagnosticar, verificar y retroalimentar el estado de su funcionamiento. No obstante, las evaluaciones que se están realizando a nivel nacional son más a nivel básico y medio superior, prácticamente está ausente en el nivel superior; además estas evaluaciones están dirigidas al desempeño de los alumnos, al margen de la evaluación de profesores, planes de estudio y centros formadores. Una evaluación que permita retroalimentar el quehacer cotidiano en aula a nuestra consideración, deberá atender a las características individuales y grupales en las que están insertos los estudiantes, teniendo en cuenta criterios y categorías pertinentes para evaluar profesores, estudiantes y materiales educativos (objetos referentes), considerando formas de interacción didáctica efectivas y pertinentes en los distintos niveles de formación.

De ahí que se plantee como necesaria la reconsideración de los roles de los actores involucrados en el ámbito de la educación, particularmente aquellos que representan los elementos sustantivos del proceso de enseñanza-aprendizaje. Esta propuesta, sugiere la noción de interacción didáctica como el segmento analítico para las interacciones educativas (episodios instruccionales), noción que se define como el intercambio recíproco entre sujetos (docente y estudiante) y objetos referentes (materiales de estudio) en condiciones definidas por el ámbito funcional de desempeño (juegos de lenguaje) (Carpio e Irigoyen, 2005; Irigoyen et al. 2007, 2011).

La noción de interacción didáctica discutida en el presente manuscrito permite estudiar las relaciones que se establecen entre: docente-estudiante-objetos referentes, 
docente-objetos referentes, estudiante-objetos referentes, y estudiante-objetos referentesdocente. Dicha propuesta permite recuperar el sentido psicopedagógico del proceso de enseñanza-aprendizaje, y por lo tanto, analizar cuáles son las condiciones idóneas para la formación de profesionales que se desempeñen de manera efectiva y variada tanto en su ámbito disciplinar como en el ámbito profesional.

Específicamente en el presente libro, se analiza la interacción del estudiante con los objetos referentes. El estudiante en un episodio de interacción didáctica, establece contacto y se ajusta - efectivamente- en función de la modalidad del discurso didáctico (forma de mediación del profesor-objeto referente-estudiante) y del material de estudio. A esta interacción y al ajuste efectivo del estudiante ante el criterio explicitado en el material de estudio y/o del profesor se le ha denominado típicamente comprensión. Anteriormente se comentó que el concepto de comprensión se aplica - particularmente en el ámbito educativocuando se satisface un requerimiento el cual puede ser mediado por alguien (el profesor) o implícito en la misma interacción que se establece con el material de estudio.

En la propuesta que se presenta, la comprensión está referida a un concepto de tipo episódico de logro que describe más bien la pertinencia del actuar del alumno ante diferentes requerimientos, sean éstos mediados por el profesor o por los mismos objetos referentes (un video, una imagen, una conferencia y/o un texto). En el análisis de la comprensión se han recuperado frecuentemente solamente textos (De Vega, 1984; Johnston, 1989; León, 1996; Sánchez, 1974). No obstante, los requerimientos que se derivan del conjunto de prácticas delimitadas por un ámbito funcional de desempeño, y aunado a la inserción de las nuevas tecnologías de la información y la comunicación en el ámbito educativo, las modalidades de los objetos referentes que puede utilizar el profesor y el estudiante se potencializan. De ahí que se sugiera la ampliación en el análisis de la comprensión a las interacciones del estudiante con las diferentes modalidades de los objetos referentes.

Analizar la interacción estudiante-objetos referentes tomando en cuenta la modalidad lingüística implicada (escribir, hablar), el tipo de tarea y su nivel funcional, se 
considera posibilita una caracterización de cómo el estudiante va configurando lo que llamamos "aprender" contenidos científicos. Por lo cual, indagar sobre algunas de las variables relevantes a esta relación, permite clarificar las maneras en cómo adquiere el estudiante universitario una serie de habilidades y competencias correspondientes al área de conocimiento en la cual se está formando, que le permitirá exhibir repertorio pertinente a las demandas impuestas por el currículo académico, y posteriormente a su ejercicio profesional de manera eficiente y variada.

El concepto de ámbito funcional de desempeño hace referencia a un orden determinado de decires y haceres en un contexto disciplinar específico. Describir un ámbito funcional no es sino identificar conjuntos de prácticas. En el Modelo de la Práctica Científica Individual las prácticas que se dan en el ámbito científico son similares a las que ocurren con otras prácticas culturales, en donde la ciencia (como práctica cultural) es ejercitada, aprendida, transmitida y generada por individuos concretos en circunstancias definidas por criterios de organización y valoración específicos. Es en este sentido, que el análisis de los criterios de ajuste, tipos de tarea y las modalidades lingüísticas tienen una funcionalidad específica dentro de un ámbito disciplinar particular.

Diaz et al. (2005) plantean que las modalidades del discurso centradas en el desarrollo de competencias deben implicar situaciones variantes, pero en muchos casos la falta de preparación disciplinar y psicopedagógica del profesor lo llevan a proceder con la denominada "lección magistral", de tal manera señalan los autores, que ésta constituya la estrategia instruccional más empleada en toda la enseñanza universitaria (al margen de su pertinencia), a pesar de que existen estrategias más eficaces para lograr una habilitación competencial de los estudiantes en su proceso de aprendizaje.

Así, las variaciones en el discurso didáctico son condición necesaria para permitirle al profesor evaluar los desempeños del estudiante con criterios de tarea y modalidades linguísticas diferenciadas, generando una exploración competencial suficiente y modelándole al estudiante las competencias necesarias para el desempeño dentro de cierto ámbito 
disciplinar. La evaluación entonces no "ocurre" en un momento distinto del enseñar sino más bien es parte de los distintos momentos de formación del estudiante. De esta manera, la evaluación se realiza en términos de la forma en que se es mediado a través del discurso didáctico, de tal manera que el repertorio lingüístico exhibido por el estudiante sea analizado ante criterios diferenciados en forma (tipo de tarea: identificar, describir, nominar, relacionar, elaborar) y función (interacciones intrasituacionales, extrasituacionales y transituacionales), considerando siempre la modalidad lingüística (observar, escuchar, leer, señalar, hablar y escribir) y el objetivo instruccional planteado.

De esta manera, el profesor juega un papel sustancial como diseñador y auspiciador de las condiciones que permitan la ilustración y modelamiento de las prácticas pertinentes a los diferentes juegos de lenguaje (conceptual, procedimental, actitudinal) de un ámbito funcional de desempeño sea este disciplinar o profesional. Toda vez que es frecuente que los alumnos lleven a cabo trabajos en equipos, ya sea exposiciones frente a grupo o trabajos escritos solicitados por el profesor, pero sin que necesariamente se expliciten los criterios para la actividad, cuando expone oralmente a veces consiste más bien en opiniones, sin que el estudiante y en algunos casos el profesor tenga claro qué y cómo se evaluará el desempeño, es decir, se carece de criterios claros para la enseñanza y la evaluación, y por lo tanto, para generar el comportamiento lector o escritor como un desempeño variado y efectivo (Varela, 2010).

Por su parte, Irigoyen et al. (2011) y Varela (2013) proponen que evaluar el desempeño académico debe considerar las características del tipo de desempeño del estudiante dado el modo lingǘstico en que ocurre la interacción. Varela (2013) argumenta que a partir de la estrategia empleada en la enseñanza deberá derivarse la modalidad de evaluación, y discute en este sentido, las implicaciones que tiene para el estudiante que el profesor solamente presente información - exponga oralmente-, ya que la modalidad lingüística más pertinente para evaluar al estudiante sería simplemente como escucha. En líneas anteriores se han discutido las implicaciones de tomar como referencia solamente la modalidad expositiva del profesor en el aprendizaje de los contenidos científicos, en cuanto a sus posibilidades de 
transferencia del conocimiento adquirido, ya que en esta condición el estudiante fungiría solamente como escucha; modalidad lingüística insuficiente para el aprendizaje de los decires y haceres en un ámbito funcional de desempeño particular.

Enfatizando al respecto, sólo un profesor experto del área de conocimiento, podrá desempeñarse de manera competente, y por lo tanto, mediar los desempeños del estudiante partiendo de interacciones situacionales con los referentes a interacciones no aparentes y/o sustitutivas. Lo anterior supone la necesidad de que el profesor se prepare teórica, metodológica e instrumentalmente para una interacción didáctica variada y efectiva. Por su parte, el estudiante establece contacto y se ajusta en función de la modalidad del discurso didáctico y del material de estudio. A continuación y sin pretender ser exhaustivos, en la Tabla 18 describimos las posibles relaciones entre la modalidad del discurso didáctico, los materiales que pudiera utilizar el docente (objetos referentes), la modalidad lingüística implicada y los criterios de tarea sugeribles.

La propuesta presentada intenta recuperar de forma más integradora, cada una de las variables asociadas al análisis de la comprensión de contenidos científicos, dicha propuesta se sustenta en relaciones interdependientes que configuran un episodio - comprensivo-, a saber: los criterios de ajuste, los factores relacionados con el desempeño del estudiante, con los objetos referentes, y con las condiciones necesarias para la interacción, posibilitando así, caracterizar el peso específico que cada variable tiene en el desempeño -efectivo- del estudiante ante los objetos referentes y/o materiales de estudio.

A manera de síntesis, se discuten algunas de las implicaciones de los resultados de los estudios llevados a cabo, por variable analizada:

a) Con respecto al criterio de ajuste. La explicitación del criterio tienen un efecto facilitador sobre la comprensión de contenidos científicos, particularmente si el nivel funcional del criterio se vincula con el nivel funcional en el que es solicitado el desempeño (interacciones extrasituacionales), lo que significa que un mismo material puede auspiciar diferentes formas de entrar en contacto con el o, diferentes materiales 


\begin{tabular}{|c|c|c|c|c|c|}
\hline $\begin{array}{l}\text { Categorías } \\
\text { teóricas }\end{array}$ & $\begin{array}{l}\text { Modalidad } \\
\text { de discurso } \\
\text { didáctico }\end{array}$ & $\begin{array}{l}\text { Objeto referente } \\
\text { con el cual se } \\
\text { puede apoyar }\end{array}$ & $\begin{array}{l}\text { Modalidad lingüística } \\
\text { involucrada }\end{array}$ & \multicolumn{2}{|c|}{ Tipo de tarea } \\
\hline \multirow[t]{3}{*}{ Conceptuales } & \multirow{3}{*}{$\begin{array}{l}\text { Mediar el } \\
\text { contacto del } \\
\text { estudiante con } \\
\text { las maneras } \\
\text { pertinentes de } \\
\text { decir-hacer } \\
\text { que el alumno } \\
\text { deberá cumplir } \\
\text { en una situa- } \\
\text { ción problema } \\
\text { ilustración) }\end{array}$} & $\begin{array}{l}\text { Imagen fija } \\
\text { (fotografia, dibujo, } \\
\text { pintura) }\end{array}$ & \multirow{3}{*}{$\begin{array}{l}\text { - Escuchar-observar-leer } \\
\text { - Escuchar-leer-señalar } \\
\text { - Escuchar-leer-hablar } \\
\text { - Escuchar-leer-escribir } \\
\text { - Leer-escribir-hablar }\end{array}$} & \multirow{6}{*}{$\begin{array}{l}\text { Identificar } \\
\text { Enunciar } \\
\text { Relacionar }\end{array}$} & \multirow{6}{*}{$\begin{array}{l}\text { Referida a } \\
\text { instancia, } \\
\text { modali- } \\
\text { dad y/o } \\
\text { relación }\end{array}$} \\
\hline & & $\begin{array}{l}\text { Texto (libro, libro } \\
\text { electrónico, hiper- } \\
\text { texto) }\end{array}$ & & & \\
\hline & & $\begin{array}{l}\text { Texto con imagen } \\
\text { (Mapa, diagrama, } \\
\text { esquema, cartel, } \\
\text { fotografía con } \\
\text { texto) }\end{array}$ & & & \\
\hline \multirow[t]{2}{*}{$\begin{array}{l}\text { Procedimen- } \\
\text { tales }\end{array}$} & \multirow{2}{*}{$\begin{array}{l}\text { Moldea y } \\
\text { modela las } \\
\text { maneras de } \\
\text { hacer-decir } \\
\text { pertinentes al } \\
\text { objetivo instruc- } \\
\text { cional plantea- } \\
\text { do (práctica) }\end{array}$} & $\begin{array}{l}\text { Imagen en movi- } \\
\text { miento (animación, } \\
\text { video, documental, } \\
\text { película) }\end{array}$ & \multirow{2}{*}{$\begin{array}{ll}\text { - } & \text { Observar-señalar- } \\
\text { instrumentar } \\
\text { - Observar-hablar- } \\
\text { escribir } \\
\text { - Observar-hablar- } \\
\text { instrumentar } \\
\text { - Escuchar-señalar- } \\
\text { hablar } \\
\text { - Escuchar-señalar- } \\
\text { escribir } \\
\text { - Leer-escribir-hablar }\end{array}$} & & \\
\hline & & $\begin{array}{l}\text { Multimedia } \\
\text { (enciclopedia en } \\
\text { disco compacto o } \\
\text { en línea, sitios web, } \\
\text { simuladores) }\end{array}$ & & & \\
\hline $\begin{array}{l}\text { Representa- } \\
\text { cionales y de } \\
\text { medida }\end{array}$ & $\begin{array}{l}\text { *todas las } \\
\text { anteriores }\end{array}$ & $\begin{array}{l}\text { *todas las } \\
\text { anteriores }\end{array}$ & $\begin{array}{ll}\text { - } & \text { Escuchar-señalar } \\
\text { - } & \text { Escuchar-hablar- } \\
& \text { escribir } \\
\text { - } & \text { Escuchar-leer-escribir } \\
\text { - Observar-señalar- } \\
\text { instrumentar } \\
\text { - Observar-hablar- } \\
\text { escribir } \\
\text { - Observar-hablar- } \\
\text { instrumentar } \\
\text { - Leer-escribir-hablar }\end{array}$ & & \\
\hline
\end{tabular}

Tabla 18. Presenta las modalidades del discurso didáctico, asi como los objetos referentes a partir de los cuales se puede apoyar el docente para la enseñanza y evaluación de desempeños en un ámbito funcional de desempeño. 
pueden implicar un mismo desempeño, si el criterio no cambia o si la habilitación del estudiante es insuficiente con respecto al criterio.

Es importante señalar que la explicitación del criterio de ajuste depende del objetivo instruccional y del tipo de competencia que se requiere auspiciar, toda vez que si lo que se quiere es auspiciar comportamiento creativo, la explicitación del criterio no permitiría un desempeño variado con respecto a la situación. De tal manera, que la explicitación del criterio no puede presentarse al margen del objetivo instruccional en un espacio educativo específico.

b) En relación con el desempeño del estudiante. La adecuación del comportamiento del estudiante al criterio, es decir, la comprensión analizada en términos del tipo de tarea y su nivel funcional, muestra desempeños diferenciales. Esto en aquellas tareas que involucran menor grado de desligamiento, las cuales presentan mayor porcentaje de aciertos o de ocurrencia.

La comprensión analizada en términos de la modalidad lingüística implicada muestra desempeños positivos señaladamente mayores para la modalidad lingüística hablar, no así para la de escribir. Autores como Camacho et al. (2007); Gómez, (2005); Irigoyen et al. (2006) han señalado que los modos lingüísticos presentan propiedades funcionales determinadas por su morfología, lo que permite explicar las diferencias en los desempeños de los participantes en las interacciones extrasituacionales de los Estudios 1, 2 y 3.

Las variaciones en las secuencia de presentación de las modalidades lingüísticas muestran diferencias en términos de mayor porcentaje de congruencia si primero escriben y posteriormente hablan, que si primero hablan y después escriben. Esto se vincula con lo discutido por Camacho et al. (2006) en relación con la jeraquización -funcional- de los modos lingüísticos. Los autores plantean que cada modo lingüístico presenta, como propiedad funcional, grados diferenciales de desligamiento como factor disposicional, probabilizando que se adquieran y 
se transfieran repertorios competenciales en distintos niveles de organización del comportamiento - nivel de desligamiento bajo, medio, alto- ${ }^{-}$. En el caso del modo hablar éste es ubicado en un nivel medio de deligamiento tanto para su adquisición como para su transferencia, en el caso del modo lingüístico escribir este se ubica en aquellos con mayor dificultad de adquisición, pero con mayor posibilidad de transferencia (Quiroga, 2010).

c) Con respecto a la modalidad del objeto referente. El nivel de desempeño -efectivo- en la comprensión fue mayor en la modalidad textual del objeto referente que en la auditiva. Esto puede deberse a que leer ocurre ante objetos de estímulos gráficos y el escuchar ocurre ante estímulos acústicos en la forma de vocalizaciones con permanencia temporal momentánea (Martínez et al. 2008). El desempeño de los participantes en este estudio, parece depender más del modo lingüístico, del tipo de tarea y su nivel funcional que del contenido y modalidad de los materiales de estudio.

Otras implicaciones que se derivan de la propuesta presentada en el presente manuscrito son las que se describen a continuación:

- En cuanto a la planeación de los espacios educativos se ha supuesto que la diversidad ideológica, cultural y del conocimiento están bien representadas en un currículum universal y homogéneo de educación básica y superior, pero la pregunta sería ¿realmente esto es así? La planeación de los espacios educativos, deberá considerar que la enseñanza es grupal pero el aprendizaje es individual, y que por lo tanto, los haceres en las interacciones didácticas deberán partir de la consideración de individuos en el proceso educativo que responden diferencialmente en tiempo y modo a los referentes que se están pretendiendo establecer. Uno de los problemas fundamentales de nuestra concepción en educación es intentar homegenizar lo que por esencia es psicológicamente diferente. 
Recientemente Varela (2013), ha argumentado que lo único que ha cambiado en el ámbito de la educación, es el discurso de las autoridades, docentes y alumnos, pero que las prácticas educativas siguen siendo las que empleaban "tradicionalmente". El autor enfatiza que se requiere explicitar la dimensión psicológica de los procesos educativos; y contar con una teoría del desarrollo psicológico que permita una derivación tecnológica -congruente y coherente- hacia el análisis de los procesos educativos: requerimos claridad en qué se aprende, cómo se aprende, bajo qué condiciones y modalidades se aprende mejor (Carpio e Irigoyen, 2005; Irigoyen et al. 2007, 201 1; Varela, 2008, 2013). La elaboración de programas de estudio en las instituciones de educación superior por ejemplo, en muchos casos, se basa en contenidos que el profesor "sabe" - y no precisamente en la pertinencia disciplinar y curricular-, y en el tiempo de exposición por parte del mismo, pero no en el tiempo que el alumno necesita para aprender.

- En cuanto a la mediación del profesor en la interacción didáctica se quisiera resaltar que para que existan las condiciones apropiadas para el aprendizaje, el profesor deberá ser un experto de la disciplina que enseña, además ser capaz de mediar -en el sentido psicopedagógico- las habilidades y competencias que promueve el espacio educativo.

Varela $(2002,2013)$ señala con respecto a la forma de mediar al estudiante con los objetos referentes (discurso didáctico) los siguientes aspectos como relevantes:

a) solicitar a los estudiantes que identifiquen y describan los elementos y condiciones que son parte de la situación problema o son funcionales para su solución, b) auspiciar que el alumno refiera su propio comportamiento ante otros (enseñar a otros), lo que debiera constituir un caso de la función sustitutiva referencial (en donde el estudiante funja como referidor y referido ante una situación que le implica desligarse del aquí y el ahora). En este caso específico, se solicita al estudiante que describa lo que hace mediante los elementos y las condiciones presentes para poder satisfacer el criterio de logro que demanda la situación. El ejercicio variado de las 
habilidades anteriores, facilita que el alumno gradualmente sea capaz de identificar los componentes funcionales que son comunes a las circunstancias (en términos de relaciones, modalidades e instancias) presentadas durante el ejercicio variado, c) preguntar al estudiante la descripción de los elementos funcionales o implícitos, solicitándole identifique las semejanzas y diferencias (de eventos o relaciones relacionados con el área de conocimiento). Por lo tanto, la formulación de reglas y/o principios consiste en la elaboración de una descripción general que englobe las descripciones particulares que comparten una misma propiedad, y que facilita el manejo lógico de situaciones presentes y futuras (competencia transituacional). Este aspecto es posible mediante la retroalimentación que los alumnos pueden ir realizando a la par del profesor, enfatizando los pasos con los que se logró satisfacer los criterios de logro o ajuste de las diferentes situaciones problema.

En cuanto al desempeño del estudiante en la interacción didáctica, este establece contacto y se ajusta en función de la modalidad del discurso didáctico y del material de estudio. El concepto de comprensión según el análisis propuesto en el presente manuscrito refiere a la adecuación y/o ajuste funcionalmente pertinente del comportamiento a su circunstancia y las demandas que en ésta se establecen. En virtud de ello, es posible analizar tantas "comprensiones" como ajustes -señalar, hablar, escribir-, dejando a un lado supuestas acciones y/o procesos ocultos que preceden a la acción comprensiva. Los criterios a satisfacer por parte del estudiante se derivan del conjunto de prácticas colectivamente compartidas como cultura por el grupo social de referencia, esto es, de cada ámbito funcional de desempeño.

De esta manera, la comprensión dentro de un área de conocimiento siempre se da en relación con un objeto referente, ya sea mediado por el profesor o el propio estudiante en la interacción didáctica. Así, el objeto referente puede presentarse como lenguaje oral (como 
discurso), escrito (como texto), audiovisual (como grabación o videoconferencia). De tal manera que los desempeños en sus diferentes modos dependen de la forma de presentación del objeto referente. Por ejemplo, si se presenta mediante el discurso, el estudiante interactuará con el objeto referente escuchando o hablando acerca de él; si se presenta mediante un texto, lo leerá y hablará o escribirá acerca de él; si es una grabación con imagen, observará y escuchará para posteriormente escribir y hablar acerca de él. Valdría la pena señalar que idealmente debieran de llevarse a cabo combinaciones entre éstas, ya que con la inserción de las nuevas tecnologías dentro del aula es posible complementar las formas en como el estudiante pudiera establecer contacto con los materiales, las modalidades de evaluación y los criterios de tarea requeridos que auspicien condiciones de enseñanza acordes a las necesidades de cada área de formación disciplinar para el siglo XXI.

Se considera que la disponibilidad de las nuevas tecnologías en educación, no necesariamente ha modificado en el ámbito educativo los haceres ni del docente ni del estudiante, ni de la estructura misma de los materiales educativos. Por el contrario, las estrategias de enseñanza que se implementan cotidianamente en las clases de contenidos científicos, promueven la memorización y repetición de la información, soslayando las situaciones que favorezcan variaciones en modalidades lingüísticas, tipos de tarea y niveles de complejidad, que auspicien en los estudiantes de estas áreas repertorios efectivos, variados y en su caso novedosos.

La inserción de las nuevas tecnologías en la educación en general y en las situaciones de interacción didáctica en particular, ha puesto en la mesa de discusión la necesidad de reflexionar acerca de los fines y concepciones vigentes en relación a la enseñanza-aprendizaje, a lo que se enseña y a lo que se aprende (a la educación misma), pero también sobre la pertinencia de los modelos propuestos para su análisis y por lo tanto, de las funciones de los actores vinculados con el proceso de enseñanza-aprendizaje.

Esto es, por una parte el desarrollo tecnológico ha privilegiado la producción de materiales de apoyo (p.e. materiales multimedia, en formato impreso, digital, etc.) como 
auxiliares de los procesos de enseñanza-aprendizaje, pero descuidando sistemáticamente la vinculación con el conocimiento científico derivado de disciplinas como la lingüística, la psicología, la antropología, entre otras, que represente congruencia y coherencia teóricometodológica en su inserción a los procesos educativos.

Por otra parte, se hace inminente la habilitación del profesor en términos del uso pertinente de éstas en su quehacer cotidiano, y no nada más "formalmente". Se ha puesto de manifiesto que la formación, experiencia y habilidades del docente en el uso de las nuevas tecnologías resulta ser un elemento fundamental tanto en el uso técnico de la misma, como de sus formas y competencias exhibidas para la instrumentación y adaptación en las situaciones cotidianas del aula (Cabero, 2007). Se considera que la interacción entre los estudiantes y los objetos referentes con modalidades diferentes (texto, audio, multimedia) ha sido poco explorada, por ende, los estudios presentados en el presente manuscrito aportan elementos novedosos en el sentido de presentar situaciones variadas que permitan por una parte analizar lo que se dice y se hace a partir de lo que se lee y escucha, para de esta manera lograr interacciones más pertinentes en lo disciplinar y acordes a las demandas del siglo XXI.

Para que la inclusión de las nuevas tecnologías haga posible cumplir a cabalidad con la intencionalidad del proceso de enseñanza-aprendizaje, deberá plantear de forma clara los objetivos instruccionales, el perfil competencial requerido en cierto momento curricular, el nivel competencial que se requiere establecer, el tipo de material u objeto referente a presentar y los criterios de evaluación que serán requeridos.

En este sentido, los resultados de los estudios presentados en el presente manuscrito permiten reflexionar sobre si las modalidades de los objetos referentes presentadas por si mismas tienen un efecto particular en el desempeño de los alumnos o dependen de otras variables como el tipo de tarea y el modo lingüístico involucrado.

De ahí que se proponga que los estudios subsiguientes se dirijan hacia el análisis de la comprensión recuperando la modalidad del objeto referente y por lo tanto, la o las modalidades lingüísticas implicadas, y las formas en que son mediadas en relación a 
las categorías teóricas (taxonómicas, operacionales, de medida) de las distintas áreas de conocimiento, en donde se recupere el tipo y el nivel funcional requerido en la tarea, para que de esta manera se dote al profesor de una tecnología educativa que le permita la habilitación competencial del estudiante en función de un objetivo instruccional y momento curricular.

Recapitulando, se sugiere que uno de los grandes desafíos de la educación radica en modificar la concepción de la enseñanza-aprendizaje y pasar de ser un proceso de transmisión de información y de conocimiento al de establecimiento de los juegos de lenguaje propios de los diferentes áreas de conocimiento y por consiguiente, la concepción respecto a la comprensión -como desempeño efectivo- y sus condicionantes, en donde se promueva el establecimiento de competencias lingǘsticas extra y transituacionales, que auspicien el teorizar genuino una vez que se han desarrollado los desempeños de escucha, observador y lector.

Ribes (1990) enfatiza en este mismo sentido, que para determinar las condiciones indispensables para que el proceso educativo pueda ocurrir e incida directamente en las condiciones sociales que hacen factible educar e integrar a la educación en un proceso vivo, pertinente, funcional, cotidiano, de los individuos es necesario "Subrayar las destrezas y conocimientos sin indicir sobre los procesos psicológicos instrumentales para su adquisición, variación, transformación y empleo, representa la gran limitación del proceso de enseñanzaaprendizaje. La posibilidad de construir una tecnología educativa derivada del análisis experimental del comportamiento humano plantea la cuestión de añadir a la educación, como proceso que se materializa en última instancia a través del individuo, una dimensión relativa al aprendizaje como adquisición funcional de niveles diferenciales de desempeño conductual, niveles que no se establecen automáticamente mediante la instrucción de contenidos de destrezas particulares" (p. 137).

En este sentido, las instituciones de educación (en particular las de educación superior) se encuentran en la necesidad no sólo de producir conocimiento, sino también de considerar y replantear lo adecuado de sus objetivos formativos y métodos, como prácticas instruccionales pertinentes al objeto de conocimiento que enseñan, auspiciando ambientes 
de aprendizaje facilitadores de la generación del pensamiento crítico, que permita reflexionar y analizar las situaciones problema, así como adaptarse innovando, con referencia a los múltiples cambios y requerimientos que experimenta y requiere como respuesta la sociedad de los profesionales y científicos universitarios. • 


\section{Referencias}

Acuña, K., Irigoyen, J.J., \& Jiménez, M. (2009). Análisis de la percepción del desempeño docente en profesores de ciencias. En J. Varela, F. Cabrera y J.J. Irigoyen. Estudios sobre comportamiento y aplicaciones. Volumen I (pp. 89-118). Guadalajara: Universidad de Guadalajara.

Acuña, K., Irigoyen, J.J., \& Jiménez, M. (2010). Análisis de la comprensión en la formación de estudiantes en ciencias. Revista Mexicana de Psicología, 27 (2), 269-282.

Acuña, K., Irigoyen, J.J., \& Jiménez, M. (2011). Normativas de calidad y desempeños académicos. Algunas reflexiones sobre el proceso educativo. Revista de Educación y Desarrollo, 17 (abril-Junio), 23-31.

Acuña, K., Jiménez, M., \& Irigoyen, J.J. (2010). Consideraciones sobre la planeación de espacios educativos para la formación de estudiantes competentes. Revista de Educación y Desarrollo, 13, 5-16.

Alvarado, M. (2007). Concepciones de ciencia y la enseñanza de la ciencia. Ethos Educativo, $39,30-46$.

Alvarado, M., \& Flores, F. (2001). Concepciones de ciencia de los investigadores de la UNAM. Implicaciones para la enseñanza de la ciencia. Perfiles Educativos, XXIII (92), 32-53.

Alvarado, M., \& Flores, F. (2010). Percepciones y supuestos sobre la enseñanza de la ciencia. Las concepciones de los investigadores universitarios. Perfiles Educativos, XXXII (128), $10-26$.

Amaya, O. (2006). Las competencias académicas y laborales: ¿en orillas opuestas? Revista Internacional MAGISTERIO: Educación y Pedagogía, 22. Colombia. 
Arroyo, R. (2002). Análisis de la historia de referencialidad como factor modulador de la comprensión de textos. Tesis de Maestría Inédita. Facultad de Estudios Superiores Iztacala. Universidad Nacional Autónoma de México.

Arroyo, R., \& Mares, G. (2009). Efectos del tipo funcional de entrenamiento sobre el ajuste lector. Revista Mexicana de Análisis de la Conducta, 35 (1), 19-35.

Arroyo, R., Canales, G., Morales, G., Silva, H., \& Carpio, G. (2005). Programa de investigación para el análisis funcional del ajuste lector. Acta Colombiana de Psicología, $10(002), 31-39$.

Ausubel, D. (2002). Adquisición y retención del conocimiento. Barcelona: Editorial Paidós.

Barrón, C. (2005). Criterios para la evaluación de competencias en el aula. Una experiencia mexicana. Perspectiva Educacional, 45, 103-120.

Bazán, A., \& Mares, G. (2002). Influencia del nivel funcional de entrenamiento en la elaboración relacional en tareas de ejecución verbal. Revista Mexicana de Análisis de la Conducta, 28 (1), 19-40.

Benito, M. (2009). Debates en torno a la enseñanza de las ciencias. Perfiles Educativos, XXXI (123), 27-43.

Bernal, J. (1975). La libertad de la necesidad. Volumen I. Madrid: Editorial Lautaro.

Bunge, M. (1985). La Fillosofía de la Psicología. México: Siglo XXI Editores.

Cabero, J. (2007). Las nuevas tecnologías en la sociedad de la información. En J. Cabero. Nuevas tecnologías aplicadas a la educación. Madrid: McGraw-Hill. 
Calderón, D. (2009). Contra la pared. Estado de la educación en México 2009. México: Mexicanos Primero.

Calderón, D. (2011). Metas. Estado de la Educación en México 2011. México: Mexicanos Primero.

Camacho,J. (2006). Dos aspectos de la interacción educativa: la PC y los modos del lenguaje. Memorias del Primer Encuentro Virtual Internacional de Psicólogos Navegantes. Boletin Electrónico de Investigación de la Asociación Oaxaqueña de Psicología, 3, 104-108.

Camacho, J., \& Gómez, D. (2007). Variación de los modos de lenguaje en la adquisición y transferencia de conocimiento. En J.J. Irigoyen, M. Jiménez y K. Acuña. Enseñanza, aprendizaje y evaluación. Una aproximación a la Pedagogía de la Ciencias (pp. 105-135). Hermosillo: Universidad de Sonora.

Camacho, J., Irigoyen, J.J., Gómez, D., Jiménez, M., \& Acuña, K. (2007). Adquisición y transferencia de modos linguísticos en tareas de discriminación condicional sin retroalimentación reactiva. Enseñanza e Investigación en Psicología, 12 (1), 79-91.

Campanario, J. (2003). Contra algunas concepciones y prejuicios comunes de los profesores universitarios de ciencia sobre la didáctica de las ciencias. Enseñanza de las Ciencias, 21 (2), 319-328.

Campanario, J., \& Moya, A. (1999). ¿Cómo enseñar ciencias? Principales tendencias y propuestas. Enseñanza de las Ciencias, 17 (2), 179-192.

Campbell, D., \& Stanley,J. (1982). Experimental and quasi-experimental designs for research. Chicago: Rand McNally \& Company. 
Canales, G., Morales, G., Arroyo, R., Pichardo, A., \& Pacheco, V. (2005). Análisis funcional del ajuste lector en el ámbito educativo. En C. Carpio y J.J. Irigoyen. Psicología y Educación. Aportaciones desde la teoría de la conducta (pp. 69-85). México: Universidad Nacional Autónoma de México.

Carlino, P., \& Martínez, S. (2009). La lectura y la escritura: un asunto de todos/as. Neúquen. Editorial de la Universidad Nacional del Comahue.

Carnap, R. (1965). La superación de la metafísica mediante el análisis lógico del lenguaje. En A. Ayer (Ed.). El positivismo lógico (pp. 66-87). México: Fondo de Cultura Económica.

Carpio, C. (1994). Comportamiento animal y teoría de la conducta. En L. Hayes, E. Ribes y F. López. Psicología Interconductual. Contribuciones en honor a f. R. Kantor (pp. 45-68). Guadalajara: Universidad de Guadalajara.

Carpio, C., \& Irigoyen, J.J. (2005). Psicología y Educación. Aportaciones desde la Teoría de la Conducta. México: Universidad Nacional Autónoma de México.

Carpio, C., Pacheco, V., Canales,C., \& Flores, C. (2005). Aprendizaje de la Psicología: un análisis funcional. En C. Carpio \& J.J. Irigoyen. Psicología y Educación. Aportaciones desde la Teoría de la Conducta (pp.1-32). México: Universidad Nacional Autónoma de México.

Carpio, C. Pacheco, V., Flores, G., \& Canales, G. (2000). La naturaleza conductual de la comprensión. Revista Sonorense de Psicología, 14 (1 y 2), 25-34.

Carretero, M. (2000). Construir y enseñar las ciencias experimentales. Buenos Aires: Aique.

Carrillo, F. (1983). El comportamiento científico. México: Editorial Limusa. 
Cepeda, M.L., \& López, M. (2010). Hallazgos sobre la comprensión lectora en estudiantes universitarios. En M. L. Cepeda y M. López. Análisis estratégico de textos. Fundamentos Teórico-Metodológicos y Experiencias Instruccionales (pp. 1-16). México: Universidad Nacional Autónoma de México.

Chi, M. (1992). Conceptual change within and across ontological categories: Examples from Learning and Discovery in Science. En R. Giere (Ed). Cognitive Models of Science (pp. 129-186). Minneapolis: University of Minnesota Press.

Coll, C. (2007). Las competencias en la educación escolar: algo más que una moda y mucho menos que un remedio. Aula de Innovación Educativa, 161, 34-39.

Coll, C., Barbera, E., \& Onrubia, J. (2000). La atención de la diversidad en las prácticas de evaluación. Infancia y Aprendizaje, 90, 111-132.

Coll, G., Mauri, T., \& Onrubia, J. (2008). Análisis de los usos reales de las tic en contextos educativos formales: una aproximación sociocultural. Revista Electrónica de Investigación Educativa, 10 (1), 1-18.

De Vega, M. (1984). Introducción a la Psicología Cognitiva. Madrid: Editorial Alianza.

De Vega, M., Díaz, J., \& León, I. (1999). Procesamiento del discurso. En M. De Vega y F. Cuetos. Psicolinguística del español (pp. 13-52). Madrid: Trotta.

Díaz-Barriga, A. (2006). El enfoque de competencias en la educación. ¿Una alternativa o un disfraz de cambio? Perfiles Educativos, XXVIII (1 11), 7-36.

Díaz- Barriga, F. (2006). Enseñanza situada: vínculo entre la escuela y la vida. México: McGraw-Hill Interamericana. 
Díaz-Barriga, F., \& Rigo, M. (2000). Formación docente y educación basada en competencias. En M.A. Valle. Formación de competencias y certificación profesional (pp. 76-104). México: Universidad Nacional Autónoma de México.

Diéguez, A. (2005). Filosofía de la Ciencia. Málaga: Biblioteca Nueva.

Domínguez, S. (2007). El objeto de estudio de la investigación. Diversas aproximaciones. Revista de Desarrollo y Educación, 7, 41-50.

Domínguez, S. (2012). Significados de la ciencia en estudiantes universitarios. Aproximaciones a las representaciones sociales de la ciencia, del científico, y de la actividad científica. Guadalajara: Universidad de Guadalajara.

Fernández-Nistal, M., \& Peña, S. (2008). Concepciones de maestros de primaria sobre el planeta Tierra y gravedad. Implicaciones para la enseñanza de la ciencia. Revista Electrónica de Investigación Educativa, 10 (2). Recuperado de http://redie.uabc.mx/ vol10no2/contenido-fernandeznistal.html

Fernández-Nistal, M., Pérez, R., Peña, S., \& Mercado, S. (2011). Concepciones sobre la enseñanza del profesorado y sus actuaciones en clases de ciencias naturales de educación secundaria. Revista Mexicana de Investigación Educativa, 16 (49), 57 1-596.

Fernández, T., \& Midaglia, C. (2005). Uso de los informes generados por los sistemas de evaluación de aprendizaje en la educación primaria. Los casos de México y Uruguay. En S. Cueto (Ed.). Uso e Impacto de la Información Educativa en América Latina (pp. 111171). Santiago de Chile: PREAL. Recuperado de http://www.preal.org/Archivos/ Preal\%20Publicaciones\%5CLibros/useimpinfo.pdf.

Feyerabend, P. (1975). Tratado contra el Método. México: Editorial Rei. 
Fuentes, M.T. (2007). Análisis funcional de la comprensión lectora reconstructiva. En J.J. Irigoyen, M. Jiménez y K. Acuña. Enseñanza, Aprendizaje y Evaluación. Aproximación a la Pedagogía de la Ciencia (pp. 277-299). Hermosillo: Universidad de Sonora.

Fuentes, M.T., \& Ribes, E. (2001). Un análisis funcional de la comprensión lectora como interacción conductual. Revista Latina de Pensamiento y Lenguaje, 9 (2), 181-212.

Fuentes, N., \& Sánchez, R. (1989). Algunas condiciones para la investigación científica de la comunicación en México. Huella, cuadernos de divulgación académica, 17, Guadalajara: Instituto Tecnológico y de Estudios Superiores de Occidente.

Flores, F. (2000). La enseñanza de las ciencias. Su investigación y sus enfoques. Ethos Educativo, 24, 26-35.

Flores, F. (2004). El cambio conceptual: interpretaciones, transformaciones y perspectivas. Educación Química, 15 (3), 256-269.

Flores, F., Gallegos, L., \& Reyes, F. (2007). Perfiles y orígenes de las concepciones de ciencia de los profesores mexicanos de química. Perfiles Educativos, XXIX (116), 60-84.

Gallegos, L., \& Flores, F. (2003). Concepciones, cambio conceptual, modelos de representación e historia y filosofía en la enseñanza de la ciencia. En A. López. Saberes Científicos, Humanísticos y Tecnológicos: Procesos de Enseñanza y Aprendizaje. Tomo I (pp. 457-501). México: Consejo Mexicano de Investigación Educativa.

Gallegos, L., \& Flores, F. (2008). Las representaciones de la ciencia en niños y su función en el aprendizaje con los textos (pp. 111-139). En G. Mares (Coord.). Diseño psicopedagógico de textos. México: Universidad Nacional Autónoma de México. 
Galicia, X., Sánchez, A., Pavón, S., \& Mares, G. (2005). Análisis funcional del pensamiento lógico. En G. Carpio y J.J. Irigoyen. Psicología y Educación. Aportaciones desde la teoría de la conducta (pp. 263-306). México: Universidad Nacional Autónoma de México.

Gilbert, J., \& Boutler, C. (1998). Learning science through models and modelling. En B. Fraser \& K. Tobin (Eds.). International Handbook of Science Education (pp. 53-67). Dordrecht: Kluwer Academic Press.

Gómez, D. (2005). Transferencia entre modos del lenguaje y niveles de interacción: observar, escuchar, hablar, leer y escribir. Tesis Doctoral Inédita. Centro de Estudios e Investigaciones en Comportamiento. Universidad de Guadalajara.

Guevara, Y. (2008). Fracaso escolar. Investigación y propuestas de intervención. México: Universidad Nacional Autónoma de México.

Hammer, D. (2004). The variability of student reasoning: manifold cognitive resources. En E. Redish \& M. Vicentini (Eds.). Proceedings of Enrico Fermi Summer School in Physics, Course CLVI (pp. 279-340). Bologna: Italian Pshysical Society.

Hernández, G. (2004). Paradigmas en psicología de la educación. México: Paidós Educador.

Ibáñez, C. (2007). Un análisis crítico del modelo del triángulo pedagógico. Una propuesta alternativa. Revista Mexicana de Investigación Educativa, 12 (32), 435-456.

Ibáñez, C., \& Ribes, E. (2001). Un análisis Interconductual de los procesos educativos. Revista Mexicana de Psicología, 18 (3), 359-371. 
INEE (2005). Tercer Informe Anual. La Calidad de la Educación Básica en México 2005. México: Instituto Nacional para la Evaluación de la Educación. Recuperado de http:// www.inee.edu.mx/images/stories/Publicaciones/Informes_institucionales/2005/ Resumen_ejecutivo/Completo/re02_calidad_2005.pdf

INEE (2009). Panorama Educativo de México 2008: Indicadores del Sistema Educativo Nacional. México: Instituto Nacional para la Evaluación de la Educación.

INEE (2012). Panorama Educativo de México 2012. Indicadores del Sistema Educativo Nacional. Educación Básica y Media Superior. México: Instituto Nacional para la Evaluación de la Educación.

Irigoyen, J.J. (2006). Análisis de las interacciones didácticas en la enseñanza de las ciencias. Tesis de Doctorado en Educación. Facultad de Educación. Universidad Nacional de Educación a Distancia. Madrid, España.

Irigoyen, J.J., Acuña, K., \& Jiménez, M. (2006). Análisis de los criterios de tarea en el aprendizaje de la ciencia psicológica. Enseñanza e Investigación en psicología, 11 (2), 209226.

Irigoyen, JJ., Acuña, K., \& Jiménez, M. (2007). Evaluación de la comprensión lectora en el aprendizaje de la ciencia psicológica. En J.J. Irigoyen, M. Jiménez y K. Acuña. Enseñanza, aprendizaje y evaluación. Una aproximación a la pedagogía de las ciencias (pp. 213245). Hermosillo: Universidad de Sonora. 
Irigoyen, JJJ., Acuña, K., \& Jiménez, M. (2010). Análisis de competencias académicas en la formación de estudiantes en ciencias. En M.A. Fuentes, J.J. Irigoyen y G. Mares. Tendencias en Psicología y Educación. Revisiones Temáticas 1 (pp. 95-127). Red Mexicana de Investigación en Psicología Educativa. Sistema Mexicano de Investigación en Psicología.

Irigoyen, J.J., Acuña, K., \& Jiménez, M. (2011). Interacciones Didácticas en Educación Superior. Algunas consideraciones sobre la evaluación de desempeños. En J.J. Irigoyen, K. Acuña y M. Jiménez. Evaluación de desempeños académicos (pp. 73-95). Hermosillo: Universidad de Sonora.

Irigoyen,J.J., \& Jiménez, M. (2004).Análisis Funcional del Comportamiento y Educación. Hermosillo: Universidad de Sonora.

Irigoyen, J.J., Jiménez, M., \& Acuña, K. (2003). Nuevas tecnologías y Educación. Enseñanza e Investigación en Psicología, 8 (2), 203-216.

Irigoyen, J.J., Jiménez, M., \& Acuña, K. (2004). Evaluación del ejercicio instruccional en la enseñanza universitaria. Enseñanza e Investigación en Psicología, 9 (2), 293-302.

Irigoyen, J.J., Jiménez, M., \& Acuña, K. (2006). Evaluación de los modos lingüísticos en estudiantes. Enseñanza e Investigación en Psicología, 11 (1), 281-295.

Irigoyen, JJ., Jiménez, M., \& Acuña, K. (2007). Aproximación a la pedagogía de la ciencia. En J. J. Irigoyen, M. Jiménez y K. Acuña, K. Enseñanza, aprendizaje y evaluación. Una aproximación a la pedagogía de las ciencias (pp. 13-44). Hermosillo: Universidad de Sonora. 
Irigoyen, J.J., Mares, G., Jiménez, M., Rivas, O., Acuña, K., Rocha, H., Noriega,J., \& Rueda, E. (2009). Caracterización de estudiantes de nuevo ingreso a la Universidad de Sonora: un estudio comparativo. Revista Mexicana de Investigación en Psicología, 1 (1), 71 84. Recuperado de: http://www.revistamexicanadeinvestigacionenpsicologia.com/

Jiménez, M., Irigoyen, J.J., \& Acuña, K. (2011). Aprendizaje de contenidos científicos y su evaluación. En J.J. Irigoyen, K. Acuña y M.Jiménez. Evaluación de desempeños académicos (pp. 105-168). Hermosillo: Universidad de Sonora.

Johannes, H. (1978). Teoría del Conocimiento. México: Editores Mexicanos Unidos.

Johnston, P. (1989). La evaluación de la comprensión lectora. Un enfoque cognitivo. Madrid: Aprendizaje Visor.

Kantor, J.R. (1980). Psicología Interconductual. Un ejemplo de construcción científica sistemática. México: Editorial Trillas.

Kantor, J.R. (1990). La evolución científica de la psicología. México: Editorial Trillas.

Kantor, J.R., \& Smith, N.W. (1975). The Science of Psychology: An Interbehavioral Survey. Chicago: The Principia Press.

Kerlinger, F., \& Lee, H. (2002). Investigación del Comportamiento. Métodos de Investigación en Ciencias Sociales. México: McGraw-Hill.

Kuhn, T. (1977). La tensión esencial. México: Fondo de Cultura Económica.

Lakatos, I. (1983). La metodología de los programas de investigación científica. Madrid: Alianza Universidad. 
León, J. (1991). La mejora de la comprensión lectora: un análisis interactivo. Infancia y Aprendizaje, 5-6, 5-24.

León, J. (1996). La psicología cognitiva a través de la comprensión de textos. Revista de Psicología General y Aplicada, 49 (1), 13-25.

León, J. (2002). Mejorando la comprensión y el aprendizaje del discurso escrito: estrategias del lector y estilos de escritura. En I. Pozo y C. Monereo (Coord.). El aprendizaje estratégico (pp. 153-170). Madrid: Santillana. Aula XXI.

López, F. (1994). Cultura y convenciones: un análisis interconductual. En L. Hayes, E. Ribes y F. López. Psicología Interconductual. Contribuciones en honor a f. R. Kantor (pp. 127-142). Guadalajara: Universidad de Guadalajara.

López, R. (2001). Profesores universitarios y los valores del diálogo y la competitividad. Consideraciones finales. En R. López. Educación superior y valores (pp. 171-185). Culiacán: Universidad de Occidente.

López, R. (2007). Ética, conocimiento y educación superior. En R. López. Profesorado, conocimiento y enseñanza conservadora. Valores profesionales en la educación superior (pp. 29-49). México: Editorial Plaza y Valdés.

López, Á., Flores, F., \& Gallegos, L. (2000). La formación de docentes en física para el bachillerato. Reporte y reflexión sobre un caso. Revista Mexicana de Investigación Educativa, 5 (9), 113-135.

López, Á., Rodríguez, P., \& Bonilla, M. (2004). ¿Cambian los cursos de actualización las representaciones de la ciencia y la práctica docente? Revista Mexicana de Investigación Educativa, 9 (22), 699-719. 
López, G., \& Tinajero, G. (2009). Los docentes ante la reforma de bachillerato. Revista Mexicana de Investigación Educativa, 14 (43), 1191-1218.

Mares, G. (2008). Promoción de competencias a través de textos para la enseñanza de las ciencias naturales. En G. Mares. Diseño Psicopedagógico de textos. Diversos Enfoques (pp. 171-200). México: Universidad Nacional Autónoma de México.

Mares, G., Guevara, Y., \& Rueda, E. (1996). Modificación de las referencias orales y escritas a través de un entrenamiento en lectura. Revista Interamericana de Psicología, 30 (1), 189-207.

Mares, G., Guevara, Y., Rueda, E., Rivas, O., \& Rocha, H. (2004). Análisis de las interacciones maestra-alumnos durante la enseñanza de las ciencias naturales en primaria. Revista Mexicana de Investigación Educativa, 9 (22), 721-745.

Mares, G., Hickman, H., Cabrera, R., Caballero, L., \& Sánchez, E. (2009). Características de ingreso de los estudiantes de Psicología Iztacala. En H. Hickman. Psicología Iztacalay sus actores (pp. 1-40). México: Universidad Nacional Autónoma de México.

Mares, G., Ribes, E., \& Rueda, E. (1993). El nivel de la funcionalidad en lectura y su efecto sobre la transferencia de lo leído. Revista Sonorense de Psicología, 7 (1), 32-44.

Mares, G., Rivas, O., \& Bazán, A. (2002). Configuración en el modo escrito de competencias desarrolladas en forma oral como efecto del nivel funcional de ejercicio. Revista Mexicana de Análisis de la Conducta, 28 (2), 173-202. 
Mares, G., Rivas, O., Pacheco, V., Rocha, H., Dávila, P., Peñalosa, I., \& Rueda, E. (2006). Análisis de las lecciones de la enseñanza de la biología en primaria. Propuesta para analizar los libros de texto de ciencias naturales. Revista Mexicana de Análisis de la Conducta, 11 (30), 883-911.

Mares, G., \& Rueda, E. (1993). El habla analizada desde la perspectiva de Ribes y López: desarrollo horizontal. Acta Comportamentalia, 1 (1), 39-62.

Mares, G., Rueda, E., \& Luna, S. (1990). Transferencia de los estilos linguísticas en tareas referenciales. Revista Sonorense de Psicología, 4 (1), 84-97.

Mares, G., Rueda, E., Rivas, O., Rocha, H., Flores, E., Dávila, P., \& Peñalosa, I. (2009). Textos y la manera de trabajarlos. Su impacto en el aprendizaje de alumnos de segundo grado de primaria. Revista Mexicana de Análisis de la Conducta, 14 (40), 93-119.

Mateos, R., \& Flores, C. (2008). Efectos de variar el grado de explicitación del criterio de ajuste sobre el desempeño de estudiantes en tareas de identificación y elaboración. Acta Comportamentalia, 16 (1), 73-88.

Martín, E., \& Coll, C. (2003). Aprender contenidos científicos, desarrollar capacidades. Intenciones educativas y planificación en la enseñanza. Barcelona: Edebé.

Martínez, D., Gómez, D., \& Zepeta, E. (2008). Adquisición de los modos de leer y escuchar y su transferencia al modo escribir. En D. Gómez, G. Reyes, W. Salas y E. Zepeta. Investigación en Psicología Aplicada a la Educación (pp. 41-56). Xalapa: Universidad Veracruzana. 
Martínez, J.F. (2010). La construcción de indicadores y evaluación de la calidad en centros educativos. Seis experiencias en México. Revista Iberoamericana sobre Calidad, Eficacia y Cambio en Educación, o (5), 134-153.

Martínez, R., \& Moreno, R. (2002). Integración de teoría sustantiva, diseño de pruebas y modelos de análisis en la medición psicológica. En A. Bazán y A. Arce. Estrategias de evaluación y medición del comportamiento en Psicología (pp. 87-199). Ciudad Obregón: Instituto Tecnológico de Sonora.

Mejía, M., \& Camacho, J. (2007). Variación de aprendizaje al emplear distintos modos de lenguaje en una interacción académica. Enseñanza e Investigación en Psicología, 12 (2), 277-289.

Morales, G., Cruz, N., Hernández, M., Canales, G., Silva, H., Arroyo, R., \& Carpio, C. (2013). Contenido teórico del texto y formación de habilidades lectoras en estudiantes de psicología. Revista Mexicana de Investigación Educativa, 18 (56), 91-111.

Morales, G., Cruz, N., León, A., Arroyo, R., \& Carpio, C. (2010). Morfología y función en el análisis empírico del ajuste lector. Suma Psicológica, 17 (1), 35-45.

Morales, G., Pacheco, V., Canales, G., Silva, H., Arroyo, R., \& Carpio, C. (2010). Apuntes para la transformación de la enseñanza de la ciencia desde la perspectiva interconductual. En C. Carpio. Comportamiento creativo en estudiantes universitarios (pp. 79-109). México: Universidad Nacional Autónoma de México. 
Morales, G., Pichardo, A., Arroyo, R., Ganales, C., Silva, H., \& Carpio, G. (2005). Enseñanza de la Psicología a través de la lectura: un ejemplo del abordaje experimental en la comprensión de textos. En C. Carpio y JJ. Irigoyen. Psicología y Educación. Aportaciones desde la teoría de la conducta (pp. 127-173). México: Universidad Nacional Autónoma de México.

Morán, P. (2004). La docencia como recreación y construcción del conocimiento. Sentido pedagógico de la investigación en el aula. Perfiles Educativos, XXVI (105-106), 41-72.

Moreno, R. (1990). Análisis epistemológico de algunos aspectos sustantivos y metodológicos de la educación. Investigación en la Escuela, 12, 19-27.

Moreno, R. (1998). Causalidad en el modelo de campo psicológico. Aportaciones metodológicas. Acta Comportamentalia, 6 (monográfico), 59-72.

Moreno, D., Cepeda, M.L., Tena, O., Hickman, H., \& Plancarte, P. (2005). Conducta gobernada por reglas: implicaciones educativas. En C. Carpio y J.J. Irigoyen. Psicología y Educación: Aportaciones desde la teoría de la conducta (pp. 175-212). México: Universidad Nacional Autónoma de México.

Nagel, E. (1968). La estructura de la Ciencia. Buenos Aires: Editorial Paidós.

OCDE (2001). La medida de los conocimientos y destrezas de los alumnos: La evaluación de la lectura, las matemáticas y las ciencias en el proyecto PISA 2000. Madrid: Ministerio de Educación, Cultura y Deporte.

OCDE (2002). Definition and Selection of Competencies: Theoretical and Conceptual Fundatios (DeSeco). Recuperado de http://www.oecd.org/dataoecd/48/22/41529556.pdf 
OCDE (2003). Panorama Educativo: indicadores de la OCDE. Recuperado de http://www.oecd. org/dataoecd/31/11/29881539.pdf

OCDE (2006). Evaluación PISA 2006. Recuperado de http://www.pnte.cfnavarra.es/ publicaciones/pdf/pisa2006.pdf

OCDE (2009). Información sobre México en PISA. México: Instituto Nacional para la Evaluación de la Educación.

OCDE (2011). La medición del aprendizaje de los alumnos. Mejores prácticas para evaluar el agregado de las escuelas. OCED Publishing. Recuperado de http://www.oecd.org/edu/ school/47871357.pdf

Ogalde, I., \& González, M. (2008). Nuevas tecnologías y educación. Diseño, desarrollo, uso y evaluación de materiales didácticos. México: Editorial Trillas.

Orozco, J., Olaya, A., \& Villate, V. (2009). ¿Calidad de la educación o educación de calidad? Una preocupación más allá del mercado. Revista Iberoamericana de educación, 51, 161-181.

Pacheco, V. (2010). ¿iSe enseña a escribir a los universitarios? Análisis y propuestas desde la teoría de la conducta. México: Universidad Nacional Autónoma de México.

Pacheco, V., \& Reséndiz, N. (2010). Análisis funcional de textos escritos por estudiantes universitarios de Psicología Experimental. Enseñanza e Investigación en Psicología, 15 (1), 75-87.

Padilla, M.A. (2006). Entrenamiento de competencias de investigación en estudiantes de educación media y superior: Guadalajara: Universidad de Guadalajara. 
Padilla, M.A. (2008). ¿Pueden entrenarse competencias de investigación en Psicología al margen de las teorías psicológicas? Revista de Educación y Desarrollo, 9 (OctubreDiciembre), 45-53.

Padilla, M.A, Buenrostro, J., \& Loera, V. (2009). Análisis del entrenamiento de un nuevo científico. Implicaciones para la pedagogía de la ciencia. Guadalajara: Universidad de Guadalajara.

Peredo, M.A. (2011). Representaciones docentes del défici lector de los estudiantes. Revista Mexicana de Investigación Educativa, 16 (48), 221-242.

Pérez-Almonacid, R., \& Quiroga. L. (2010). Lenguaje: una perspectiva interconductual. Bogota: Corporación Universitaria Iberoamericana.

Perrenoud, P. (2004). Diez nuevas competencias para enseñar. Barcelona: Editorial Grao.

Pineda, M., Aguirre, N., Gómez, M., \& Mares, G. (2008). Efecto de dos tareas posteriores a la lectura sobre la transferencia de lo aprendido. Revista Psicología y Educación, 2 (3), pp. 1-14.

PISA (2000). Aptitudes para lectura, matemáticas y ciencias. OCDE, Aula XXI Santillana.

PISA (2003). Resultados de México en PISA 2000-2003. Recuperado de http://www.inee.edu. $\mathrm{mx} /$ images/stories/Publicaciones/Estudios_internacionales/PISA2000_2003/ Partes/informepisa06.pdf

PNUD (2009). Informe sobre Desarrollo Humano 2009. Superando barreras y desarrollo humanos. Recuperado de http://hdr.undp.org/en/media/HDR_2009_ES_ Complete.pdf 
Popper, K. (1975). La ciencia normal y sus peligros. En I. Lakatos y A. Musgrave (Ed.). La crítica y el desarrollo del conocimiento (pp.149-158). Barcelona: Editorial Grijalbo.

Postigo, Y., \& López-Manjón, A. (2012). Representaciones visuales del cuerpo humano. Análisis de los nuevos libros de primaria de ciencia naturales en la reforma educativa mexicana. Revista Mexicana de Investigación Educativa, 17 (53), 593-626.

Pozo, I. (2003). Adquisición de conocimiento. Madrid: Ediciones Morata.

Pozo, I., \& Flores, F. (2007). Cambio conceptualy representacional en la enseñanza de la ciencia. Madrid: Antonio Machado Libros.

Pozo, I., \& Rodrigo, M. (2001). Del cambio de contenido al cambio representacional en el conocimiento conceptual. Infancia y Aprendizaje, 24 (4), 407-423.

Prego, G. (2006). Evaluación de la cohesión en el habla infantil: los usos de "y" en edad temprana. En B. Gallardo, C. Hernández y V. Moreno (Eds.). Linguística clínica y neuropsicología cognitiva. Actas del Primer Congreso Nacional de Lingüística Clínica vol 2 (pp. 265-279). Valencia: Universitat.

Quiroga, L. (2010). Influencia del tipo de entrenamiento y del modo lingüístico sobre el ajuste a contigencias mediadas linguísticamente. Tesis de Maestría Inédita. Universidad Nacional de Colombia.

Reyes, A. (1997). Técnicas y modelos de calidad en el salón de clases. México: Editorial Trillas.

Ribes, E. (1990). Problemas conceptuales en el análisis del comportamiento humano. México: Editorial Trillas. 
Ribes, E. (1993). La práctica de la investigación científica y la noción de juego de lenguaje. Acta Comportamentalia, 1 (1), 63-82.

Ribes, E. (2000). Las psicologías y la definición de sus objetos de conocimiento. Revista Mexicana de Análisis de la Conducta, 26 (3), 365-382.

Ribes, E. (2004). La psicología cognoscitiva y el conocimiento de otras mentes. Acta Comportamentalia, 12 (3), 7-22.

Ribes, E. (2006). Competencias conductuales: su pertinencia en la formación y práctica profesional del psicólogo. Revista Mexicana de Psicología, 23 (1), 19-26.

Ribes, E. (2008). Educación básica, desarrollo psicológico y planeación de competencias. Revista Mexicana de Psicología, 25 (2), 193-207.

Ribes, E. (2009). La función de la investigación en la universidad pública mexicana. Ciencia, $6(2), 70-77$.

Ribes, E. (2010). Teoría de la Conducta 2. Avances y extensiones. México: Editorial Trillas.

Ribes, E. (2011). El concepto de competencia: su pertinencia en el desarrollo psicológico y la educación. Bordón. Revista de Pedagogía, 63 (1), 31-43.

Ribes, E. (2012). Las funciones sustitutivas de contingencias. En M.A. Padilla y R. PérezAlmonacid. La función sustitutiva referencial. Análisis histórico-crítico/avances y perspectivas (pp. 19-34). New Orleans: University Press of the South.

Ribes, E., \& López, F. (1985). Teoría de la Conducta: un análisis de campo y paramétrico. México: Editorial Trillas. 
Ribes, E., Moreno, R., \& Padilla, M.A. (1996). Un análisis funcional de la práctica científica: extensiones de un modelo psicológico. Acta Comportamentalia, 4 (2), 205-235.

Ribes, E., \& Sánchez, U. (1994). Conducta, juegos de lenguaje y criterios de validación del conocimiento. Acta Comportamentalia, 2 (1), 57-86.

Ríos-Checa, A. (2011). Escribir: tres teorías y una proposición para su enseñanza. En J.J. Irigoyen, K. Acuña y M. Jiménez. Evaluación de desempeños académicos (pp. 43-71). Hermosillo: Universidad de Sonora.

Rocha, T., \& Landa, P. (2012). La ejecución académica en estudiantes universitarios bajo condiciones presenciales y virtuales de aprendizaje. Revista Electrónica de Psicología Iztacala, 15 (1), 16-38.

Rodríguez, M.E. (2000). Efecto del entrenamiento de la correspondencia decir-hacer, decirdescribir y hacer-describir sobre la adquisición, generalidad y mantenimiento de una tarea de discriminación condicional en humanos. Acta Comportamentalia, 8 (1), $41-75$.

Rodríguez, M.E., Vera, F., García, D., \& Guitrón, O. (2012). La promoción de competencias sustitutivas en el contexto escolar. En M.A. Padilla y R. Perez-Almonacid. La función sustitutiva referencial. Análisis histórico-crítico/avances y perspectivas (pp. 203-228). New Orleans: University Press of the South.

Rodríguez-Moneo, M., \& Carretero, M. (2000). Adquisición de conocimiento y cambio conceptual. Implicaciones para la enseñanza de la ciencia. En M. Carretero. Construir y enseñar las ciencias experimentales (pp. 47-73). Buenos Aires: Aique. 
Ruiz, G. (2009). "El enfoque de la formación profesional en torno a la generación de competencia: ¿ejercicio impostergable o "lo que sucedió a un rey con los burladores que hicieron el paño?” Estudios pedagógicos, XXXV, 1, 287-299.

Ryle, G. (2005). El concepto de lo mental. Buenos Aires: Paidós.

Sánchez, B. (1974). Lectura, diagnóstico, enseñanzay recuperación. Buenos Aires: Editorial Kapelusz.

Sánchez, L. (2005). Concepciones de aprendizaje de profesores universitarios y profesionales no docentes: un estudio comparativo. Anales de Psicología, 21 (2), 231-243.

Schaff, A. (1974). Historia y Verdad. México: Editorial Grijalbo.

SEP (2007). Programa Sectorial de Educación, 2007-2012. México: Secretaría de Educación Pública.

SEP (2010). Estándares de Desempeño Docente en el Aula para la Educación Básica en México. México: Secretaría de Educación Pública. Recuperado de http://es.scribd. com/doc/57612696/Estandares-de-Desempeno-Docente-en-el-Aula-para-laEducacion-Basica-en-Mexico

Shulman, L. (1986). Those who understand: knowledge growth in teaching. Educational Reseacher, 15 (2), 4-14.

Silva, H., \& Morales, G. (2008). Ejercicio y didáctica científica, la relevancia de los grupos de investigación. En C. Carpio. Competencias profesionales y científicas del psicólogo. Investigación, experiencias y propuestas (pp. 119-134). México: Universidad Nacional Autónoma de México. 
Soto, J. (2009). Influencia de las creencias religiosas en los docentes de ciencia sobre la teoría de la evolución biológica y su didáctica. Revista Mexicana de Investigación Educativa, 14 (41), 515-538.

Tamayo, M. (2005). El proceso de la Investigación Científica. México: Editorial Limusa.

Tena, O., Hickman, H., Moreno, D., Cepeda, M., \& Larios, R. (2001). Estudios sobre comportamiento complejo. En G. Mares y Y. Guevara. Psicología Interconductual. Avances en la Investigación Básica (pp. 59-110). México: Universidad Nacional Autónoma de México.

UNESCO (1996). La educación encierra un tesoro. Informe a la UNESCO de la Comisión Internacional sobre la Educación para Siglo XXI. Recuperado de http://www.unesco.org/ education/pdf/DELORS_S.PDF

UNESCO (2007). Informe de seguimiento de la educación para todos en el mundo. Bases sólidas: atención y educación de la primera infancia. Recuperado de http:/ / unesdoc. unesco.org/images/0015/001505/150518S.pdf

Varela, J. (2002). Alumnos inteligentes: proposición formativa para la educación elemental y media básica. En G. Mares y Y. Guevara. Psicología Interconductual. Avances en la Investigación Tecnológica (pp. 113-144). México: Universidad Nacional Autónoma de México.

Varela, J. (2004). Consideraciones y estudio de la educación extracurricular basada en los modos lingüísticos. En J.J. Irigoyen y M. Jiménez. Análisis Funcional del Comportamiento y Educación (pp. 37-75). Hermosillo: Universidad de Sonora.

Varela, J. (2008). Textos para el aprendizaje de la geografía en la educación básica. En G. Mares. Diseño psicopedagógico de textos. Diversos enfoques (pp. 141-170). México: Universidad Nacional Autónoma de México. 
Varela, J. (2010). El maestro y el alumno ante la tecnología: ¿Efectos deseados? Revista Mexicana de Psicología, 27 (2), 197-204.

Varela, J. (2012). Como dar clase individual a un grupo de alumnos. Conductual, Revista Internacional de Interconductismo y Análisis de la Conducta. 1 (1), 103-140.

Varela, J., \& Quintana, C. (1995). Comportamiento inteligente y su transferencia. Revista Mexicana de Análisis de la Conducta, 21 (1), 47- 66.

Varela, J., \& Ribes, E. (2002). Aprendizaje, inteligencia y educación. En E. Ribes. Psicología del aprendizaje (pp. 191-204). México: Editorial El Manual Moderno.

Vosniadou, S. (2003). On the nature of naïve physics. In M. Limón \& L. Mason. (Eds.) Reconsidering Conceptual Change: issues in Theory and Practice (pp. 61-76). Dordrecht, Holanda: Kluwer Academic Publishers.

Wittgenstein, L. (1988). Investigaciones filosóficas. México: Universidad Nacional Autónoma de México.

Zabala, A., \& Arnau, L. (2007). La enseñanza de las competencias. Aula de Innovación Educativa, 161, 40-46.

Zarzosa, L., \& Luna, D. (2007). Propuesta para la comprensión de textos en estudiantes universitarios. En J.J. Irigoyen, M. Jiménez y K. Acuña. Enseñanza, aprendizaje y evaluación. Una aproximación a la pedagogía de las ciencias (pp. 169-212). Hermosillo: Universidad de Sonora. • 
$\mathbf{A}$

Acuña, K. 15, 17, 21, 22, 30, 31, 33, 52, 68, Campanario, J. 61

$71,76,87,121,122$

Campbell, D. 129, 134, 151, 174

Alvarado, M. 31, 61, 62, 63, 64

Canales, C. 40, 43, 47, 86, 91, 191

Amaya, O. 38

Carlino, P. 171

Aguirre, N. 106

Carnap, R. 48

Arnau, L. 20, 22, 25, 74

Arroyo, R. 24, 86, 91, 97, 110, 123

Carpio, C. 24, 43, 56, 57, 68, 86, 91, 111 ,

Ausubel, D. 21 197, 205

Carretero, M. 69, 95

Carrillo, F. 46, 48, 54, 115

B

Barbera, E. 20

Cepeda, M. L. 73, 74, 99

Barrón, C. 20

Chi, M. 63

Bazán, A. 106

Coll, C. 20, 21, 28, 30

Benito, M. 39

Bernal, J. 48

Cruz, N. 24, 118, 121, 123, 191

Bonilla, M. 31

\section{D}

Boutler, C. 63

Buenrostro, J. 42

Bunge, M. 115

De Vega, M. 81, 82, 198

Díaz, J. 82

Díaz-Barriga, A. 20, 196

Díaz-Barriga, F. 21

Diéguez, A. 49

G

Domínguez, S. 13, 115

Caballero, L. 39

Cabero, J. 208

F

Cabrera, R. 39

Fernández, T. 15

Calderón, D. 14

Fernández-Nistal, M. 32, 52, 71

Camacho, J. 21, 101, 102, 103, 121，191， Feyerabend, P. 49

192, 203

Flores, C. 24, 43, 86, 121, 158 
Flores, F. 31, 61, 62, 63, 64, 83, 84

Fuentes, M.T. 21, 98, 101, 123

G

Galicia, X. 40, 41

Gallegos, L. 61, 62, 63, 83, 84

García, D. 74

Gilbert, J. 63

Gómez, D. 21, 95, 101, 103, 191, 203

Gómez, M. 106

González, M. 99, 100

Guevara, Y. 31, 60, 106

Guitrón, O. 74, 75

$\mathbf{H}$

Hammer, D. 63

Hernández, G. 66

Hickman, H. 39, 73, 74

\section{I}

Ibáñez, C. 88, 93
Fuentes, N. 13

$\mathrm{J}$

Jiménez, M. 15, 21, 22, 30, 31, 33, 68, 76, 88, $111,121,122$

Johannes, H. 43

Johnston, P. 81, 82, 198

$\mathbf{K}$

Kantor, J.R. 44, 45, 89, 111,112

Kerlinger, F. 129, 134, 151, 174

Kuhn, T. 48, 49

L

Landa, P. 37

Larios, R. 73

Lakatos, I. 48, 49

Lee, H. 129, 134, 151, 174

León, A. 24, 118, 121, 123, 191

León, I. 82

León, J. 81, 82, 83, 84, 198

Loera, V. 42

López, Á. 31, 63

López, F. 27, 43, 46, 55, 69, 89, 90, 96, 107,

Irigoyen, J.J. 15, 17, 21, 22, 24, 30, 31, 33, 110, 111, 119, 138

39, 40, 47, 56, 57, 60, 66, 68, 70, 71, 76, 86, López, G. 29

87, 111, 116, 121, 122, 123, 147, 162, 171, López, M. 99

191, 195, 197, 200, 203, 205
López, R. 37, 93

López-Manjón, A. 63

Luna, D. 86 
Luna, S. 143

M

Mares, G. 39, 40, 60, 96, 103, 104, 106, 107, 109, 110, 123, 143, 144, 147, 162, 171, 195 Martín, E. 28

Martínez, D. 191, 204

Martínez, J.F. 14, 15, 18

Martínez, R. 115

Martínez, S. 171

Mauri, T. 30

Mateos, R. 24, 121, 158

Mercado, S. 32

Mejía, M. 121

Midaglia, C. 15

Morales, G. 24, 40, 47, 86, 91, 117, 118, 121, 123, 150, 165, 191, 192

Morán, P. 71

Moreno, D. 73, 74

Moreno, R. 41, 69, 111, 115, 116

Moya, A. 61

$\mathbf{N}$

Nagel, E.48

O

Ogalde, I. 99, 100

Olaya, A. 15
Onrubia, J. 20, 30

Orozco, J. 15, 196
$\mathbf{P}$

Pacheco, V. 40, 43, 47, 86, 121, 123, 143, 145, 161, 170, 191

Padilla, M.A. 21, 41, 42, 43, 44, 46, 47, 48, 49, 50, 51, 53, 57, 58, 60, 111,117

Pavón, S. 40

Peña, S. 32, 71

Peredo, M.A. 195

Perrenoud, P. 23

Pérez, R. 32

Pérez-Almonacid, R. 21

Pichardo, A. 86

Pineda, M. 106, 107

Plancarte, P. 74

Popper, K. 48

Postigo, Y. 63

Pozo, I. 61, 62

Prego, G. 147

Q

Quintana, C. 72, 91, 127

Quiroga, L. 21, 121, 204

$\mathbf{R}$

Reyes, A. 19, 197 
Reyes, F. 61

Reséndiz, N. 145

Ribes, E. 21, 24, 26, 27, 28, 29, 39, 41, 49 50, 51, 53, 55, 59, 69, 70, 72, 73, 85, 88, 89, 90, 94, 95, 96, 98, 101, 107, 110, 111, 119, 143, 145, 158, 209

Rigo, M. 20

Ríos-Checa, A. 160

Rivas, O. 60, 106

Rocha, H. 60

Rocha, T. 37

Rodrigo, M. 62

Rodríguez, M.E. 74, 75

Rodríguez, P. 31

Rodríguez-Moneo, M. 95

Rueda, E. 60, 96, 106, 143

Ruiz, G. 25

Ryle, G. 74, 88

S

Sánchez, A. 40

Sánchez, B. 81, 198

Sánchez, E. 39

Sánchez, L. 30, 71, 95

Sánchez, R. 13

Sánchez, U. 59

Schaff, A. 45

Shulman, L. 61
Silva, H. 40, 91

Smith, N.W. 111

Soto, J. 52, 71

Stanley, J. 129, 134, 151, 174

$\mathbf{T}$

Tamayo, M. 43

Tena, O. 73, 74

Tinajero, G. 29

V

Varela, J. 40, 72, 91, 94, 101, 105, 123, 127, 200, 205

Vera, F. 74

Villate, V. 15

Vosniadou, S. 63

W

Wittgenstein, L. 55

Z

Zabala, A. 20, 22, 25, 74

Zarzosa, L. 86

Zepeta, E. 191 • 


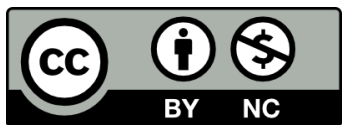

Esta obra está bajo una Licencia Creative Commons

Atribución-NoComercial 4.0 Internacional.

https://creativecommons.org/licenses/by-nc/4.0/deed.es

La comprensión de contenidos científicos en estudiantes universitarios

ISBN 978-607-96359-0-9

DOI 10.29410/QTP.13.01

Esta publicación digital se terminó en diciembre de 2013.

Su diseño y edición estuvieron a cargo de:

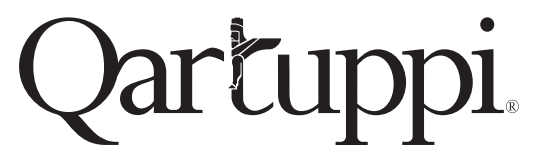

Qartuppi, S. de R.L. de G.V.

http://www.qartuppi.com 
(Página en blanco) 


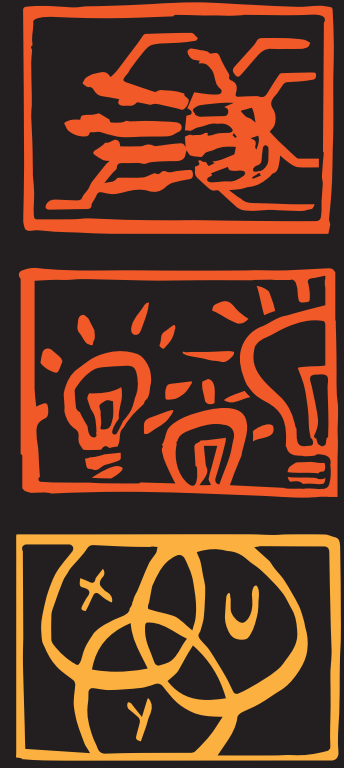




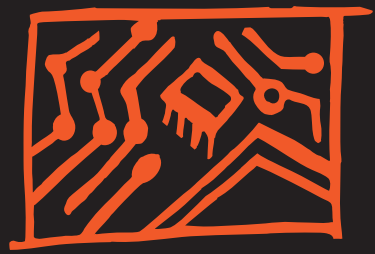

En el caso del aprendizaje de contenidos científicos se requiere que el estudiante sea capaz de mediar lingüísticamente (sea escribiendo o hablando) con los hechos, las operaciones y los criterios de medida pertinentes al ámbito funcional de desempeño que se enseña-aprende.
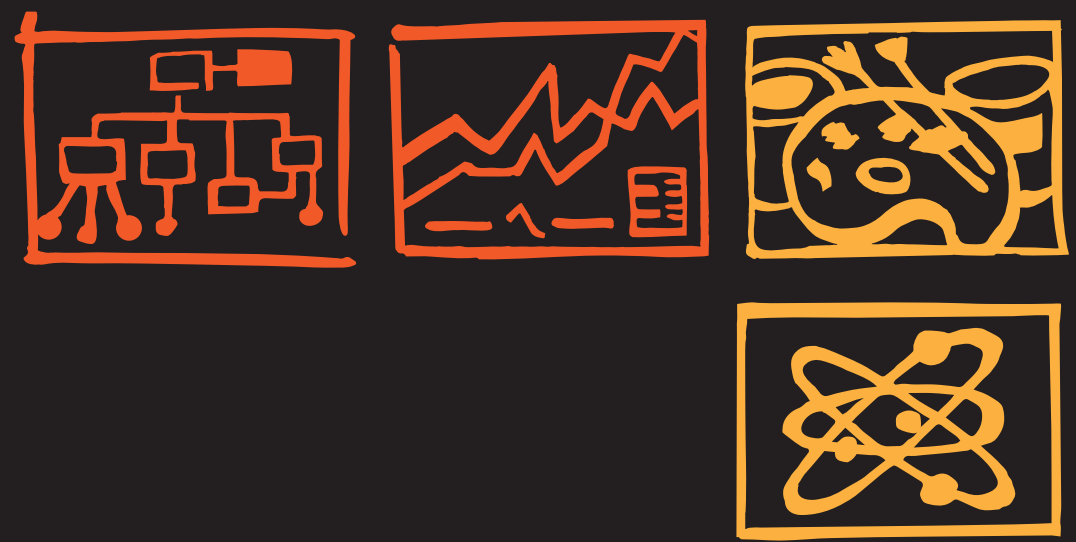

ISBN 978-607-96359-0-9
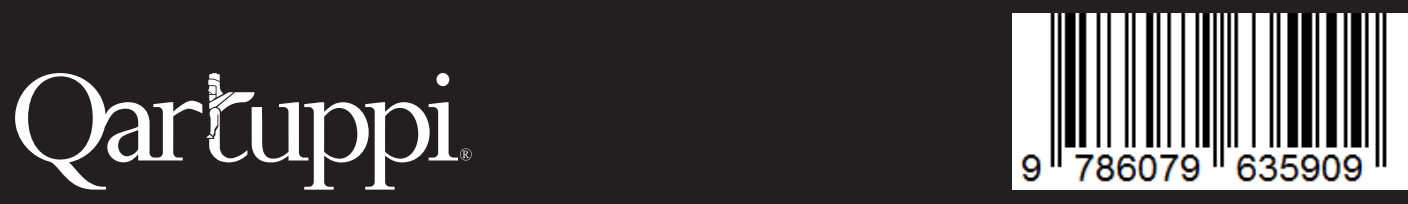